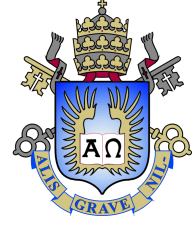

Letícia Caldas dos Santos

\title{
Abordagem Metaheurística para o Roteamento de Veículos Escolares em Zona Rural
}

Dissertação de Mestrado

Dissertação apresentada como requisito parcial para obtenção do grau de Mestre pelo Programa de Pós-graduação em Engenharia de Produção, do Departamento de Engenharia Industrial da PUCRio.

Orientador: Prof. Rafael Martinelli Pinto 


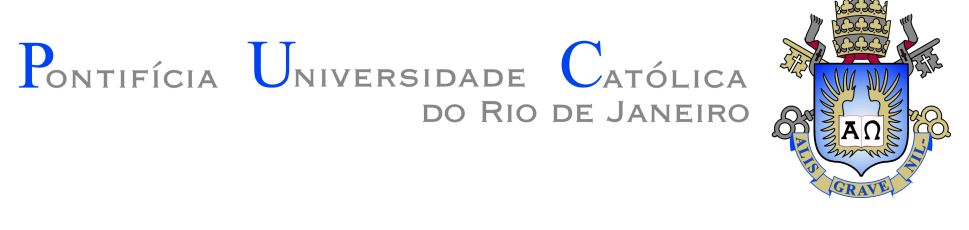

Letícia Caldas dos Santos

\section{Abordagem Metaheurística para o Roteamento de Veículos Escolares em Zona Rural}

Dissertação apresentada como requisito parcial para obtenção do grau de Mestre pelo Programa de Pós-graduação em Engenharia de Produção da PUC-Rio. Aprovada pela Comissão Examinadora abaixo:

Prof. Rafael Martinelli Pinto

Orientador

Departamento de Engenharia Industrial - PUC-Rio

Prof. Luciana de Souza Pessoa

Departamento de Engenharia Industrial - PUC-Rio

Prof. Teobaldo Leite Bulhões Júnior

UFPB

Rio de Janeiro, 29 de setembro de 2021 
Todos os direitos reservados. A reprodução, total ou parcial do trabalho, é proibida sem a autorização da universidade, do autor e do orientador.

\section{Letícia Caldas dos Santos}

Graduou-se em Engenharia de Produção pela Universidade Federal Fluminense em 2018. Atualmente desempenha a função de Coordenadora de Abastecimento em uma empresa nacional de varejo.

Ficha Catalográfica

Santos, Letícia Caldas dos

Abordagem Metaheurística para o Roteamento de Veículos Escolares em Zona Rural / Letícia Caldas dos Santos; orientador: Rafael Martinelli Pinto. - 2021.

161 f: il. color. ; $30 \mathrm{~cm}$

Dissertação (mestrado) - Pontifícia Universidade Católica do Rio de Janeiro, Departamento de Engenharia Industrial, 2021.

Inclui bibliografia

1. Engenharia Industrial - Teses.

2. Roteamento de Veículos Escolares. 3. Iterated Local Search. 4. Transporte Escolar Rural. 5. Metaheurística.

I. Pinto, Rafael Martinelli. II. Pontifícia Universidade Católica do Rio de Janeiro. Departamento de Engenharia Industrial. III. Título. 


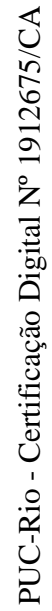

Dedico à minha família e amigos. 


\section{Agradecimentos}

Agradeço aos meus pais, Andréa e Luiz, e minha irmã, Natália, por todo apoio e incentivo para a concretização dos meus sonhos.

Agradeço ao Vinicius Ballona, por toda paciência, força e suporte nesse período.

Agradeço à minha família e amigos pela alegria dos momentos compartilhados e por me fazerem acreditar que seria possível executar este trabalho.

Agradeço ao orientador Rafael Martinelli, pela paciência, incentivo, suporte e todos os ensinamentos prestados durante todo o período do mestrado

Agradeço à equipe do transporte escolar da Secretaria de Estado de Educação do Rio de Janeiro, pelo suporte com os dados e todas as informações necessárias para entendermos o cenário.

A todos os professores e funcionários da PUC-Rio, pelos conhecimentos compartilhados e ajuda fornecida.

O presente trabalho foi realizado com apoio da Coordenação de Aperfeiçoamento de Pessoal de Nível Superior - Brasil (CAPES) - Código de Financiamento 001 


\section{Resumo}

Santos, Letícia Caldas dos; Pinto, Rafael Martinelli. Abordagem Metaheurística para o Roteamento de Veículos Escolares em Zona Rural. Rio de Janeiro, 2021. 161p. Dissertação de Mestrado - Departamento de Engenharia Industrial, Pontifícia Universidade Católica do Rio de Janeiro.

O transporte escolar é fundamental para garantir o acesso e permanência dos alunos nas escolas públicas, principalmente nas áreas rurais, onde os estudantes estão localizados em uma grande área com baixa densidade e as estradas encontram-se em situações precárias. O presente trabalho tem como objetivo aplicar a metaheurística Iterated Local Search para o roteamento de 13.664 alunos da zona rural do estado do Rio de Janeiro. Para isso, considerouse o problema de roteamento de veículo escolares, do inglês School Bus Routing Problem (SBRP), com frota heterogênea e escola única, com o objetivo de minimizar o custo total considerando as restrições de capacidade dos veículos e distância máxima de percurso. Para aplicação do método, foram considerados os dados fornecidos pela Secretaria de Estado de Educação do Rio de Janeiro (SEEDUC-RJ). Os resultados são apresentados em dois cenários, o primeiro considera os dados de 79 rotas utilizadas pela SEEDUC-RJ para comparação dos resultados obtidos com o ILS. O método mostrou uma redução de 40,5\% no custo médio das rotas e $46 \%$ na quilometragem média por aluno. O segundo cenário considera o roteamento da totalidade dos alunos, que foram divididos em 506 instâncias considerando escola e turno. A maior instância roteada possui 534 alunos. Os resultados consolidados por município são apresentados e mostram a concentração de municípios com maior custo médio por rota no noroeste fluminense. A implementação das rotas propostas pode trazer economia significativa com as despesas relacionadas ao transporte escolar rural, além de indicar um aumento no nível de serviço para os estudantes, com redução da quilometragem média por aluno.

\section{Palavras-chave}

Roteamento de Veículos Escolares; Iterated Local Search; Transporte Escolar Rural; Metaheurística;. 


\section{Abstract}

Santos, Letícia Caldas dos; Pinto, Rafael Martinelli (Advisor). Metaheuristic Approach to the School Bus Routing Problem in a rural area. Rio de Janeiro, 2021. 161p. Dissertação de Mestrado - Departamento de Engenharia Industrial, Pontifícia Universidade Católica do Rio de Janeiro.

School transport is essential to ensure access and permanence of students in public schools, especially in rural areas, where students are located in a large area with low density and roads are in precarious conditions. This work aims to apply the Iterated Local Search metaheuristic to route 13.664 rural students in the state of Rio de Janeiro. For this, we considered the School Bus Routing Problem (SBRP), with heterogeneous fleet and single school, in order to minimize the total cost considering the vehicles' capacity constraints and maximum travel distance. To apply the method, the data provided by Secretaria de Estado de Educação do Rio de Janeiro (SEEDUCRJ) were considered. The results are presented in two scenarios, the first considers data from 79 routes used by SEEDUC-RJ to compare the results obtained with the ILS. The method showed a reduction of $40.5 \%$ in the average cost of routes and $46 \%$ in the average mileage per student. The second scenario considers the routing of all students, who were divided into 506 instances considering school and shift. The largest routed instance has 534 students. The results consolidated by municipality are presented and show the concentration of municipalities with the highest average cost per route in northwestern Rio de Janeiro. The implementation of the proposed routes can bring significant savings with expenses related to rural school transport, in addition to indicating an increase in the level of service for students, with a reduction in the average mileage per student.

\section{Keywords}

School Bus Routing; Iterated Local Search; Rural School Transport; Metaheuristics;. 


\section{Sumário}

$\begin{array}{lll}1 & \text { Introdução } & 15\end{array}$

$\begin{array}{lll}1.1 & \text { Problema de Pesquisa e Justificativa } & 16\end{array}$

$\begin{array}{lll}1.2 & \text { Objetivos } & 17\end{array}$

$\begin{array}{lll}1.3 & \text { Relevância do trabalho } & 17\end{array}$

$\begin{array}{ll}1.4 & \text { Procedimentos metodológicos } \\ 1.4 .17\end{array}$

$\begin{array}{lll}1.4 .1 & \text { Classificação da pesquisa } & 18\end{array}$

$\begin{array}{lll}1.4 .2 & \text { Etapas da pesquisa } & 18\end{array}$

$\begin{array}{lll}\text { 1.4.3 Estrutura do documento } & 19\end{array}$

2 Referencial teórico $\quad 21$

2.1 O problema de roteamento de veículos escolares 21

$\begin{array}{lll}2.2 & \text { Formulação matemática } & 22\end{array}$

2.3 Revisão da literatura 24

2.4 Métodos de resolução 32

2.4.1 Iterated Local Search 32

3 Iterated Local Search aplicado ao Problema de Roteamento de Veículos Escolares

3.1 Representação da solução 35

3.2 Algoritmo Construtivo 36

3.2.1 Estruturas de Vizinhança e Busca Local 37

$\begin{array}{lll}3.2 .2 & \text { Perturbação } & 41\end{array}$

3.2.3 Critério de Aceitação 42

4 Aplicação $\quad 43$

4.1 Descrição do cenário $\quad 43$

4.1.1 Abrangência 43

4.1.2 Tratamento dos dados 44

4.1.3 Matriz de Distâncias $\quad 45$

4.1.4 Frota 45

4.1.5 Enquadramento do problema nas características do SBRP 46

$\begin{array}{lll}\text { 4.1.6 Resultados } & 46\end{array}$

4.1.6.1 Ambiente computacional e instâncias 47

4.1.6.2 Testes experimentais 48

$\begin{array}{lll}\text { 4.1.6.3 Aplicação } & 48\end{array}$

5 Conclusão $\quad 55$

A Número de alunos matriculados por turno em cada município 62

$\begin{array}{lll}\text { B Instâncias } & 71\end{array}$

$\begin{array}{llr}\text { C } & \text { Resultados } & 89\end{array}$

$\begin{array}{lll}\text { D Indicadores } & 94\end{array}$ 
E Resultados completos 


\section{Lista de figuras}

$\begin{array}{lll}\text { Figura 1.1 Etapas da pesquisa } & 19\end{array}$

Figura 2.1 Número de publicações por década 24

$\begin{array}{lll}\text { Figura 3.1 Representação de uma solução } & 35\end{array}$

$\begin{array}{lll}\text { Figura } 3.2 & \text { Ilustração de uma solução } & 38\end{array}$

Figura 3.3 Shift Intra-rotas 38

Figura 3.4 Swap Intra-rotas 39

Figura 3.5 Relocate Intra-rotas 39

Figura 3.6 Swap Inter-rotas 40

Figura 3.7 Relocate Inter-rotas 40

Figura 4.1 Escolas Estaduais 44

Figura 4.2 Distribuição das instâncias por número de alunos 47

Figura 4.3 Indicadores de desempenho $\quad 51$

Figura 4.4 Indicador de ocupação $\quad 51$

Figura 4.5 Mapa de calor com o custo médio por rota 52

Figura 4.6 Mapa de calor com a quilometragem média por aluno 53

Figura 4.7 Mapa de calor com a ocupação média das rotas $\quad 53$

Figura 4.8 Média de tempo computacional de acordo com o número de alunos na rota $\quad 54$ 


\section{Lista de tabelas}

$\begin{array}{lll}\text { Tabela 2.1 Classificações SBRP } & 26\end{array}$

Tabela 2.2 Revisão complementar da literatura e classificação nas $\begin{array}{ll}\text { características do SBRP } & 28\end{array}$

Tabela 4.1 Características dos Veículos 46

Tabela 4.2 Classificação do caso da SEEDUC-RJ de acordo com as características do SBRP 46

$\begin{array}{lll}\text { Tabela } 4.3 & \text { Testes experimentais } & 49\end{array}$

Tabela 4.4 Testes experimentais - perturbação 50

$\begin{array}{lll}\text { Tabela A.1 Escolas por município } & 70\end{array}$

$\begin{array}{lll}\text { Tabela B.1 Instâncias } & 71\end{array}$

$\begin{array}{lll}\text { Tabela C.1 Comparação de resultados } & 90\end{array}$

Tabela D.1 Indicadores rotas SEEDUC x ILS 96 


\section{Lista de Abreviaturas}

AAE - Associações de Apoio à Escola

ACO - Colônia de formigas

ALNS - Adaptative Large Neighborhood Search

BRG - Geração de rotas de ônibus

BRS - Programação de rotas de ônibus

BSS - Seleção de paradas de ônibus

C - Capacidade do veículo

CEPERJ - Centro Estadual de Estatísticas, Pesquisas e Formação de Servi-

dores Públicos do Rio de Janeiro

COO - Probabilidade de superlotação

COL - Probabilidade de atraso

EPT - Tempo de recolhimento mais cedo

GA - Algoritmo genético

HO - Frota Homogênea

HT - Frota Heterogênea

IBGE - Instituto Brasileiro de Geografia e Estatística

ILS - Iterated Local Search

ML - Escola Múltipla

MRL - Comprimento máximo da rota

MRT - Tempo máximo de percurso

MSR - Número máximo de paradas por rota

MSN - Número mínimo de estudantes para criar rota

MWT - Tempo ou distância máxima de caminhada

N - Número de veículos utilizados

NP - Carregamento Misto Não Permitido 
NS - Número de paradas

NT - Número de transferências

OVRP - Open Vehicle Routing Problem

P - Carregamento Misto Permitido

PNATE - Programa Nacional de Apoio ao Transporte Escolar

R - Localidade Rural

RTR - Record-to-record

RVND - Random Variable Neighborhood Descend

SA - Simulated Annealing

SBA - Ajuste do horário de entrada e saída escolar

SBRP - School Bus Routing Problem

SBS - Parada de ônibus compartilhada

SEEDUC-RJ - Secretaria de Estado de Educação do Rio de Janeiro

$\mathrm{SF}$ - Fator de segurança

STW - Janela de tempo de parada

SWD - Distância total percorrida a pé pelo aluno

TBD - Tempo ou distância total percorrida pelo veículo

TC - Custo total

TSD - Tempo ou distância total de deslocamento do aluno

TT - Tempo de transferência

TW - Janela de tempo da escola

U - Localidade Urbana

UC - Utilização da capacidade

UN - Escola Única

UR - Localidades Urbana e Rural

VND - Variable Neighborhood Descent

VRP - Vehicle Routing Problem 
Agradeço todas as dificuldades que enfrentei; não fosse por elas, eu não teria saído do lugar...As facilidades nos impedem de caminhar.

Chico Xavier, 


\section{Introdução}

O direito ao transporte escolar é assegurado aos alunos da escola pública pela Constituição Federal de 1988. Considerando a dimensão continental do Brasil e sua diversidade geográfica, cultural e social, a elaboração de políticas públicas na esfera nacional torna-se desafiadora. Buscando a elaboração de planos condizentes com a realidade de cada local, a obrigação de elaborar as políticas públicas é estendida aos estados e municípios buscando facilitar o acesso dos estudantes à educação (Brasil, 2012). Nesse sentido, em 2004 foi instituído o Programa Nacional de Apoio ao Transporte Escolar (PNATE), permitindo a transferência automática de recursos financeiros aos estados, Distrito Federal e municípios.

Em 2014, teve início no Brasil uma crise econômica que instaurou um período de recessão. Desde então, diversas políticas públicas foram adotadas pelos governos, buscando a recuperação do equilíbrio econômico. O atual governo tem optado por políticas de austeridade, contendo despesas públicas e realizando cortes orçamentários (Almeida e Sampaio, 2019). O Ministério da Educação e Cultura também se enquadra nesse contexto e, em 2019, anunciou o congelamento de mais de $\mathrm{R} \$ 7$ bilhões de investimentos. Na educação básica o valor chegou a $\mathrm{R} \$ 914$ milhões, atingindo também os recursos destinados ao transporte (Idoeta e Magenta, 2019).

Nesse sentido, a qualidade do gasto com educação deve ser prioridade e a aplicação de técnicas de otimização pode resultar em economias significativas, melhorando a eficiência com um alto nível de serviço. A otimização de percursos realizados por frotas de veículos é conhecida na literatura como Problema de Roteamento de Veículos, do Inglês Vehicle Routing Problem (VRP). O VRP é um problema de otimização combinatória que consiste na determinação de percursos de entrega ou coleta a partir de um ou mais depósitos, tendo como destinos pontos que representam clientes ou cidades, respeitando restrições estabelecidas (Laporte, 1992).

Uma importante ramificação do VRP é o problema de roteamento de veículos escolares, do inglês School Bus Routing Problem (SBRP). O SBRP é uma variante do VRP onde a escola é o ponto inicial ou final da rota e os estudantes são os clientes. Além disso, a garagem ou ponto inicial é diferente 
da escola e os deslocamentos da garagem até o primeiro aluno e da escola até a garagem não são considerados. O tempo que os alunos permanecem no veículo deve respeitar um limite máximo. Nesse sentido, deve-se buscar um equilíbrio entre o custo total do transporte, considerando distância percorrida, ocupação e número de veículos, e o tempo total de viagem (Rashidi et al., 2009).

O primeiro registro de publicação a tratar especificamente do SBRP é de Newton e Thomas (1969). Desde então, diversos estudos foram publicados sobre o assunto e suas diferentes configurações, especialmente na última década. Apesar disso, ainda não há um consenso sobre a melhor abordagem para os diferentes subproblemas e configurações (Ellegood et al., 2019).

\section{1}

\section{Problema de Pesquisa e Justificativa}

O transporte escolar é fundamental para garantir o acesso e permanência dos alunos nas escolas públicas, principalmente nas áreas rurais. Para a definição da rede de transporte é necessário estabelecer as rotas, selecionar os estudantes, selecionar veículos de acordo com o custo, segurança, capacidade e tempo de viagem. Essas diferentes variáveis exigem que um profissional qualificado gerencie a rede. Entretanto, na maioria das regiões rurais do Brasil, as atividades são realizadas com base na experiência e intuição do responsável, aumentando as despesas, tempo de viagem e número de veículos necessários (de Souza Lima, 2015). Além disso, no contexto rural a definição das rotas é ainda mais desafiadora, uma vez que os estudantes estão localizados em uma grande área com baixa densidade e as estradas encontram-se em situações precárias (Carvalho et al., 2010). Em muitos casos, a restrição do tempo máximo de viagem é atingida antes da capacidade do veículo (Ellegood et al., 2019).

A Secretaria de Estado de Educação do Rio de Janeiro (SEEDUC-RJ) possui 17.200 alunos cadastrados para utilização do transporte rural em 83 municípios do Estado e mais de 350 escolas, gerando em 2017 um investimento de $\mathrm{R} \$ 36$ milhões (Rosa, 2018b). Além do desafio relacionado ao tamanho da rede, atualmente as rotas do transporte escolar são feitas por servidores de maneira manual (Rosa, 2018b), o que pode resultar em roteiros que não representam a menor distância a ser percorrida e, consequentemente, levam ao uso ineficiente dos recursos.

Para a definição das rotas de cada escola, é necessário aplicar os conceitos de VRP, especificamente do SBRP. O SBRP pode ser resolvido através de métodos exatos, heurísticos ou metaheurísticos. Neste trabalho é proposta a 
utilização de metaheurística para o problema de transporte rural da SEEDUCRJ. O objetivo é verificar a aplicação do método em uma instância real, minimizando os custos da rede.

\section{2}

\section{Objetivos}

O objetivo principal do trabalho consiste em aplicar uma metaheurística para definir as rotas do transporte escolar rural no estado do Rio de Janeiro, minimizando o custo total e respeitando as restrições de capacidade e tempo de viagem.

Foram utilizados os dados de localização de 17.200 alunos cadastrados para uso do transporte rural na SEEDUC-RJ no ano de 2019.

A presente pesquisa também visa atingir alguns objetivos secundários, a saber:

- Entender as especificidades do transporte escolar no Rio de Janeiro

- Apresentar o comparativo com as rotas atuais, validando o método utilizado e os potenciais ganhos.

\section{3}

\section{Relevância do trabalho}

Embora a primeira publicação a tratar do SBRP seja de Newton e Thomas (1969) e exista uma grande quantidade de publicações sobre o tema, ainda há uma limitação no número de trabalhos que aplicam os métodos de resolução em instâncias reais, sobretudo considerando grandes instâncias. Além disso, não há um consenso sobre a melhor abordagem a ser utilizada frente aos diferentes subproblemas e configurações que podem ser explorados (Ellegood et al., 2019).

Por fim, além da aplicação em uma cenário real com 13.664 alunos, o presente trabalho também apresenta a comparação entre as rotas definidas pelo método e as rotas utilizadas atualmente no sistema, definidas de maneira manual pelos servidores.

\section{4}

\section{Procedimentos metodológicos}

Nesta Seção serão apresentados o enquadramento metodológico da pesquisa, o método utilizado e a estrutura do documento. 


\subsection{1 \\ Classificação da pesquisa}

A pesquisa de natureza aplicada caracteriza-se por uma abordagem quantitativa (do Nascimento e Sousa, 2017). O objetivo é descritivo, uma vez que busca descrever as características e configurações do problema de SBRP na área rural do estado do Rio de Janeiro a fim de esclarecer as abordagens que trazem menor custo e atendam às restrições de tempo e capacidade.

A estratégia de pesquisa é uma aplicação com dados reais, uma vez que será verificado o desempenho das abordagens propostas durante a pesquisa (do Nascimento e Sousa, 2017).

\section{4 .2}

\section{Etapas da pesquisa}

A pesquisa está sendo realizada em cinco etapas. Inicialmente, foi necessário compreender as características e restrições do transporte escolar. Paralelamente a essa etapa, foram coletados dados e informações que caracterizavam a localização das escolas, estudantes e veículos. Assim, foi realizada uma revisão da literatura, buscando entender o que já havia sido apresentado e quais abordagens poderiam ser exploradas. Foi definida a abordagem metaheurística a ser utilizada.

Os dados coletados foram tratados antes de iniciar as análises e aplicações. Assim, foi possível implementar a metaheurística considerando as características do problema. Por fim, a metaheurística foi aplicada e as análises e discussões apresentadas. A Figura 1.1 apresenta as atividades realizadas.

A compreensão das características do problema foi feita através de reuniões com a equipe de transporte escolar da SEEDUC-RJ. Além disso, o trabalho de Rosa (2018b) norteou o entendimento acerca do cenário atual de elaboração das rotas e investimentos no transporte escolar rural do Rio de Janeiro.

A coleta de dados também foi realizada com o apoio da equipe da SEEDUC-RJ, que forneceu os dados de localização, latitude e longitude, de cada aluno cadastrado para utilização do transporte rural em 2019; a escola em que estava matriculado, a localização da mesma e o turno. Também foram fornecidos os dados das rotas realizadas como: número da rota, escola que pertencia, alunos que faziam parte da rota, distância total, veículo utilizado e custo total. Os alunos eram identificados nas bases por meio de códigos, preservando suas identidades e não fornecendo dados pessoais.

A revisão da literatura foi realizada utilizando como base os trabalhos de Park e Kim (2010) e Ellegood et al. (2019), as duas últimas revisões publicadas 


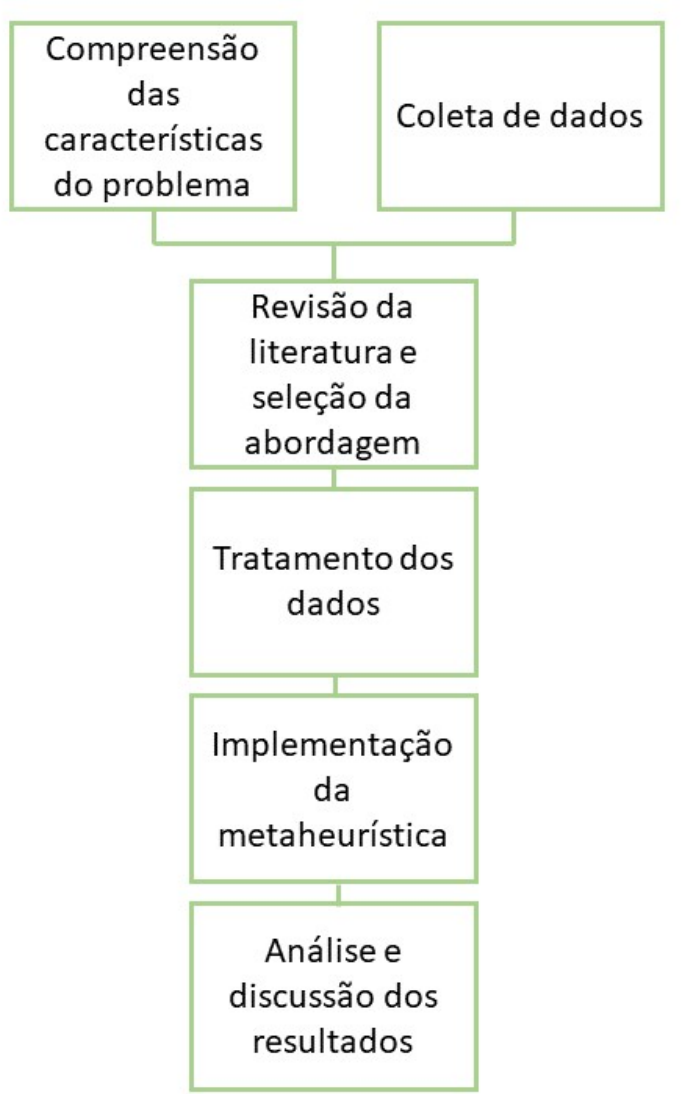

Figura 1.1: Etapas da pesquisa Fonte: Autora, 2021.

sobre o assunto. Com o objetivo de complementar e atualizar com as últimas publicações os trabalhos desses autores, foi feita uma pesquisa nas bases Scopus e Web of Science utilizando as palavras (metaheuristic* OR heuristic*) AND routing AND school.

O tratamento dos dados foi realizado para identificar possíveis erros na determinação da latitude e longitude dos alunos, uma vez que esta etapa foi feita de maneira manual pelos diretores das escolas.

Por fim, foi implementado o Iterated Local Search para resolução do problema, considerando as características levantadas. O programa principal foi escrito em Julia 1.6.1. O ambiente de desenvolvimento utilizado foi o Visual Studio Code. Os resultados obtidos foram analisados e apresentados.

\subsection{3}

\section{Estrutura do documento}

Este trabalho encontra-se dividido em cinco capítulos. O primeiro capítulo apresenta a contextualização do problema, objetivos, relevância, procedimentos metodológicos e estrutura do estudo.

O segundo capítulo dedica-se ao referencial teórico, definindo conceitos 
relacionados ao tema, apresentando os últimos trabalhos publicados e uma breve exposição sobre a metaheurística selecionada para solucionar o problema.

O terceiro capítulo descreve a representação da solução e a adaptação da metaheurística para aplicação no problema.

O quarto descreve os dados utilizados, as características consideradas, os resultados dos testes computacionais e a análise das soluções obtidas.

Por fim, o último capítulo traz as considerações finais e as proposições de trabalhos futuros. 


\section{2 \\ Referencial teórico}

Nesta Seção serão apresentadas as características e definição do problema, os trabalhos correlatos e o método de resolução que será utilizado.

\section{1}

\section{O problema de roteamento de veículos escolares}

O Problema de Roteamento de Veículos consiste na determinação de um conjunto otimizado de rotas que devem ser realizadas por uma frota de veículos para atender um grupo de clientes. De maneira geral, as rotas partem de um depósito, passam pelos clientes e terminam no depósito. As rotas devem atender às restrições de capacidade do veículo, tempo de viagem e minimizar o custo total. Para isso, pode-se definir como objetivo minimizar a distância total percorrida pela frota ou o número de veículos necessários, por exemplo (Toth e Vigo, 2002).

O VRP foi proposto inicialmente por Ramser et al. (1959) para a otimização de rotas de entrega de combustíveis para postos de gasolina. Passados mais de sessenta anos após a primeira publicação, os modelos de VRP estudados atualmente se tornaram muito mais complexos, uma vez que incorporaram uma série de características resultantes de aplicações reais, como por exemplo: janela de tempo para atendimento do cliente e demanda estocástica (Braekers et al., 2016).

Uma das variantes do VRP é o School Bus Routing Problem (SBRP), em português Problema de Roteamento de Veículos Escolares. O SBRP consiste no roteamento de uma frota de veículos escolares, onde os alunos precisam ser buscados em suas residências ou paradas de ônibus pré determinadas e levados até a escola (Bektaş e Elmastaş, 2007).

No SBRP, o depósito geralmente é diferente da escola, os veículos possuem uma capacidade máxima e há uma restrição para o tempo em que o aluno permanecerá no veículo (Park e Kim, 2010). Além disso, não são consideradas as distâncias do depósito até o primeiro aluno e da escola até o depósito. Dessa forma, o SBRP se assemelha ao VRP aberto, do inglês Open Vehicle Routing Problem (OVRP), capacitado e com restrição de distância, classificado como um problema NP-difícil (Park e Kim, 2010). De acordo com 
a teoria da complexidade computacional, não se conhecem algoritmos capazes de encontrar uma solução ótima em tempo polinomial para problemas da classe NP-difícil (Lenstra e Kan, 1981).

Nesse sentido, algoritmos exatos são eficientes apenas para pequenas instâncias. Para aplicações em instâncias reais, com grande escala e a necessidade de considerar características e restrições específicas do problema que está sendo tratado, heurísticas e metaheurísticas são mais adequadas uma vez que apresentam soluções próximas ao ótimo em um razoável intervalo de tempo (Žerovnik, 2015). Neste trabalho, utilizaremos a metaheurística Iterated Local Search (ILS). Segundo Lourenço et al. (2019), o ILS gera uma sequência de soluções a partir de um algoritmo construtivo e perturbações, concentrando a busca em um conjunto definido pelos ótimos locais. As estruturas que compõem a metaheurística serão detalhadas na Seção 3.

\section{2}

\section{Formulação matemática}

Podemos definir o SBRP de acordo com Hou et al. (2020b) sobre um grafo com um conjunto de nós e arcos $G=(V, E)$, onde $V=\{0,1,2,3 \ldots n, n+1\}$ é o conjunto de nós e $A=\{(i, j), i, j \in V \mid i \neq j\}$ é o conjunto de arcos. O nó 0 corresponde ao depósito e o nó $n+1$ corresponde a escola; o conjunto de nós $C=\{1,2,3, \ldots, n\}$ representa os pontos de paradas. Cada parada $i$ tem um número de estudantes $q_{i}$ a serem atendidos. Os nós que representam a escola e o depósito não possuem demanda associada. Cada arco $(i, j)$ possui uma distância associada $d_{i, j}$. Uma frota de veículos escolares heterogênea está localizada no depósito e o conjunto de tipos de veículos é representado por $M=\{1,2,3, \ldots, K\}$. Cada tipo de veículo $k$ possui uma capacidade $Q_{k}$, um custo fixo $f_{k}$ e um custo variável por unidade de distância percorrida $v_{k}$. O número de veículos do tipo $k$ é representado por $h_{k}$.

O objetivo do problema é determinar um conjunto de rotas com o mínimo custo total satisfazendo as seguintes restrições:

- Cada veículo deixa o depósito, visita uma série de pontos de paradas e finaliza a rota na escola.

- Cada ponto de parada deve ser visitado apenas uma vez.

- O número de estudantes atendidos por um veículo não pode exceder sua capacidade.

- O tempo total de viagem para os estudantes não pode exceder o tempo de viagem ou a distância máxima permitida $D$.

- O número de veículos do tipo $k$ utilizados não pode exceder $h_{k}$. 
A formulação matemática é baseada em três tipos de variáveis de decisão. A variável $x_{i j k}$ indica se um veículo do tipo $k$ se desloca do ponto $i$ ao ponto $j$, então $x_{i j k}=1$, caso contrário, $x_{i j k}=0$. A variável $y_{i k}$ indica o número cumulativo de estudantes em um veículo do tipo $k$. A variável $z_{i k}$ representa o tempo cumulativo de viagem de um veículo do tipo $k$ quando ele chega na parada $i$. Uma formulação de programação linear inteira é apresentada a seguir:

$$
\begin{gathered}
\min \sum_{j \in C} \sum_{k \in M} f_{k} x_{0 j k}+\sum_{i \in V\{n+1\}} \sum_{j \in V\{0,1\}} \sum_{k \in M} v_{k} d_{i j} x_{i j k} \\
\sum_{j \in V\{i, n+1\}} \sum_{k \in M} x_{i j k}=1, \forall i \in C \\
\sum_{i \in V\{n+1\}} x_{i p k}-\sum_{j \in V\{0,1\}} x_{p j k}=0, \forall p \in C, k \in M \\
y_{i k} \leq Q_{k}, \forall i \in V \backslash\{n+1\}, k \in M \\
y_{i k}+q_{j}-y_{j k} \leq M_{1}\left(1-x_{i j k}\right), \forall i \in V \backslash\{n+1\}, j \in V \backslash\{0, i\}, k \in M \\
z_{i k} \leq T, \forall i \in V \backslash\{0\}, k \in M \\
z_{j k}+t_{i j}+t_{i}-z_{i k} \leq M_{2}\left(1-x_{i j k}\right), \forall i \in V \backslash\{n+1\}, j \in V \backslash\{0, i\}, k \in M \\
\sum_{i \in V \backslash\{0\}} x_{0 i k} \leq h_{k}, \forall k \in M \\
z_{i k} \in \mathbb{Z}+, \forall i \in V, k \in M \\
y_{i k} \in \mathbb{Z}_{+}, \forall i \in V, k \in M \\
x_{i j k} \in\{0,1\}, \forall i \in V \backslash\{n+1\}, j \in V \backslash\{0, i\}, k \in M
\end{gathered}
$$

A função objetivo (2-1) minimiza a soma do custo fixo e variável. As restrições (2-2) asseguram que cada ponto de parada deve ser visitado apenas uma vez. As restrições (2-3) garantem que se um veículo do tipo $k$ visita um ponto de parada $p$, ele deve deixar o ponto de parada. As restrições (2-4) garantem que o número total de estudantes no veículo do tipo $k$ não excede sua capacidade. As equações (2-5) representam o acúmulo de estudantes no veículo. As restrições (2-6) garantem que o tempo de viagem de cada estudante no veículo não exceda o limite máximo $T$. As equações (2-7) representam o acúmulo do tempo de viagem do veículo. As restrições (2-8) limitam o número 
de veículos utilizados de cada tipo ao número máximo de veículos disponível. As restrições (2-9), (2-10) e (2-11) representam os domínios das variáveis de decisão.

\section{3}

\section{Revisão da literatura}

A primeira publicação sobre o SBRP foi feita por Newton e Thomas (1969). Os trinta anos seguintes à essa publicação tiveram uma média de menos de um artigo publicado por ano, explorando principalmente o contexto do problema na América do Norte (Ellegood et al., 2019).

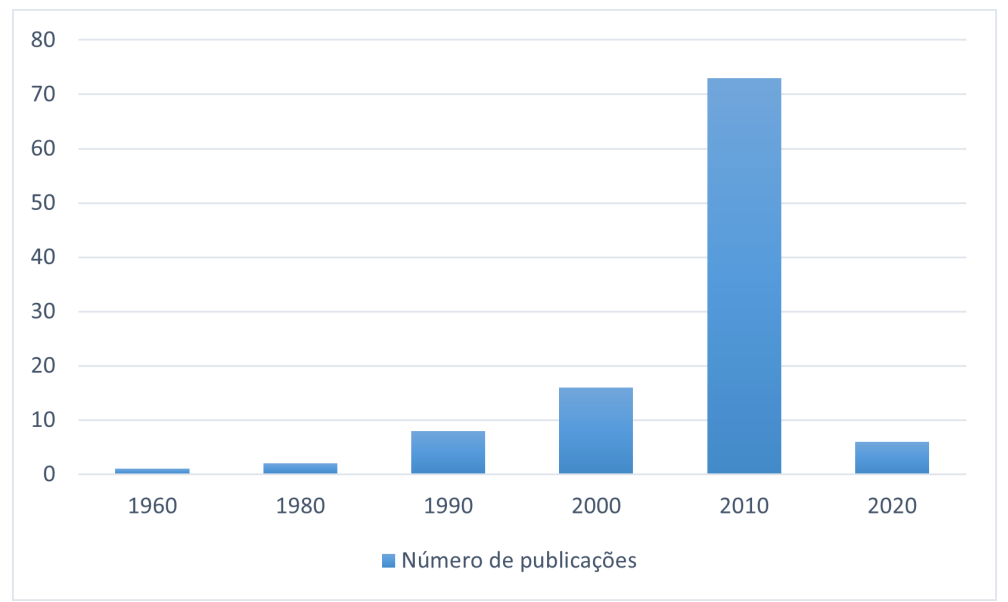

Figura 2.1: Número de publicações por década Fonte: Autora, 2021.

Park e Kim (2010) revisaram os vinte e nove trabalhos relacionadas ao SBRP publicados entre 1969 e 2009. Desses trabalhos, apenas cinco adotaram abordagens metaheuríticas. Ellegood et al. (2019) revisaram 64 trabalhos publicados na última década. Diferentemente do perfil apresentado nos primeiros quarenta anos de pesquisa, foi possível verificar aplicações na América do Norte, América do Sul, África, Ásia e Europa. Dos 64 trabalhos, 40 apresentaram abordagens metaheurísticas, adicionando complexidades de instâncias reais e aumentando a utilidade dos modelos.

Cabe destacar que passados 50 anos da primeira publicação sobre o tema, continuam a surgir na literatura novas abordagens e configurações a serem estudadas, dado o potencial de ganho que podem trazer para um ambiente real. Ellegood et al. (2019) também destacaram o grande gap que existe entre as práticas das escolas e os modelos acadêmicos. Os autores destacam a necessidade de mais estudos para quantificar na prática os benefícios da otimização, considerando potenciais ganhos econômicos e sociais. 
A Tabela 2.1 apresenta os diferentes critérios que podem ser utilizados para caracterizar os aspectos práticos do SBRP, de acordo com Ellegood et al. (2019). Os critérios serão detalhados na sequência.

Sub-problema: a seleção de paradas de ônibus (BSS) pode ser considerada na abordagem do problema. Nesse caso, o sub-problema identifica o ponto em que cada aluno deve encontrar o veículo escolar para iniciar a rota e onde devem ser deixados ao fim da rota. O problema admite o deslocamento a pé do aluno até a parada de ônibus (Ellegood et al., 2019). A geração das rotas (BRG) é o principal problema do SBRP e consiste na definição da rota a ser executada e os alunos alocados em cada veículo. A programação das rotas (BRS) e o ajuste do horário de entrada e saída escolar (SBA) são necessários para as configurações de múltiplas escolas. O horário das escolas e a programação das rotas precisam considerar o compartilhamento dos veículos.

Número de escolas: Para este trabalho, será considerada a definição apresentada por Ellegood et al. (2019) em que são classificados como escola única (UN) os trabalhos que abordam o problema para apenas uma escola e os trabalhos que, apesar de considerarem uma localidade com múltiplas escolas, utilizam metodologias para o roteamento de apenas uma escola por vez.

Localidade: A abordagem do problema em um contexto rural é impactada pela menor densidade populacional, maior distância percorrida por rota, menor número de estudantes por parada de ônibus, maior área de atendimento das escolas, entre outros (Chen et al., 2015). Essas características fazem com que, muitas vezes, a restrição do tempo de viagem seja atingida antes da capacidade máxima do veículo.

Carregamento Misto: O carregamento misto é uma característica que pode estar presente em problemas que abordam múltiplas escolas. Essa configuração permite que alunos de diferentes escolas sejam transportados no mesmo veículo ao mesmo tempo.

Frota: Pode-se considerar o uso de uma frota de veículos heterogênea (HT) ou homogênea (HO). Frotas heterogêneas apresentam veículos com diferentes características como: capacidade, tempo máximo de condução, custo fixo e custo variável. Para frotas homogêneas todos os veículos possuem as mesmas características.

Objetivos: A maior parte das publicações que têm como sub-problema a geração de rotas, busca minimizar o custo (Ellegood et al., 2019). Para isso, pode-se minimizar o custo fixo, representado pelo número de veículos utilizados $(\mathrm{N})$, o custo variável, equivalente ao tempo ou distância total percorrida (TBD) ou o custo total (TC), correspondente a soma das parcelas do custo total e variável. Podem ser considerados no custo variável o tempo total de 
Tabela 2.1: Classificações SBRP

\begin{tabular}{|c|c|}
\hline Critérios & Descrição \\
\hline \multirow{4}{*}{ Sub-problema } & Seleção de paradas de ônibus (BSS) \\
\hline & Geração de rotas de ônibus (BRG) \\
\hline & Programação de rotas de ônibus (BRS) \\
\hline & Ajuste do horário de entrada e saída escolar (SBA) \\
\hline \multirow{2}{*}{ Número de escolas } & Única (UN) \\
\hline & Múltipla (ML) \\
\hline \multirow{3}{*}{ Localidade } & Urbana (U) \\
\hline & Rural (R) \\
\hline & Urbana e Rural (UR) \\
\hline \multirow{2}{*}{ Carregamento Misto } & Permitido $(\mathrm{P})$ \\
\hline & Não Permitido (NP) \\
\hline \multirow{2}{*}{ Frota } & Homogênea (HO) \\
\hline & Heterogênea (HT) \\
\hline \multirow{11}{*}{ Objetivos } & Número de veículos utilizados (N) \\
\hline & Tempo ou distância total percorrida pelo veículo (TBD) \\
\hline & Tempo ou distância total de deslocamento do aluno (TSD) \\
\hline & Distância total percorrida a pé pelo aluno (SWD) \\
\hline & Comprimento máximo da rota (MRL) \\
\hline & Parada de ônibus compartilhada (SBS) \\
\hline & Utilização da capacidade (UC) \\
\hline & Custo total (TC) \\
\hline & Fator de segurança (SF) \\
\hline & Número de transferências (NT) \\
\hline & Número de paradas (NS) \\
\hline \multirow{11}{*}{ Restrições } & Capacidade do veículo (C) \\
\hline & Tempo máximo de percurso (MRT) \\
\hline & Janela de tempo da escola (TW) \\
\hline & Tempo ou distância máxima de caminhada (MWT) \\
\hline & Tempo de recolhimento mais cedo (EPT) \\
\hline & Número mínimo de estudantes para criar rota (MSN) \\
\hline & Tempo de transferência (TT) \\
\hline & Janela de tempo de parada (STW) \\
\hline & Número máximo de paradas por rota (MSR) \\
\hline & Probabilidade de superlotação (COO) \\
\hline & Probabilidade de atraso (COL) \\
\hline
\end{tabular}

Fonte: Adaptado de Rosa (2018b) 
deslocamento (TSD) ou a distância total percorrida a pé pelo aluno (SWD). Chalkia et al. (2016) consideraram um fator de segurança (SF) para cada rua e uma penalidade baseada nesse fator era adicionada ao tempo de viagem realizado na rua em questão. Alabas-Uslu (2008) consideraram em seu modelo multi-objetivo a minimização do comprimento máximo da rota (MRL). Essa abordagem busca equilibrar as distâncias das rotas. Minocha e Tripathi (2014) apresentaram um modelo que busca maximizar a utilização da capacidade dos veículos (UC), que corresponde ao número de estudantes transportados dividido pela capacidade do veículo. As publicações que consideraram o subproblema BSS, têm como objetivo minimizar a distância total percorrida a pé pelo aluno (SWD), o número de paradas (NS) ou as paradas de ônibus compartilhadas (SBS). Por fim, Bögl et al. (2015) consideraram na função objetivo uma penalidade por exceder o número máximo de transferências (NT).

Restrições: A capacidade do veŕculo $(\mathrm{C})$ está relacionada aos tipos de veículos considerados, no caso de frotas heterogêneas. Para frotas homogêneas, só é considerado um tipo de veículo e, portanto, a mesma capacidade para todos. A janela de tempo (TW) consiste no intervalo de tempo que os estudantes devem chegar na escola antes do início das aulas. O tempo máximo de percurso (MRT) apresenta grandes variações de acordo com a localidade considerada. Para áreas rurais, o MRT tende a assumir valores maiores que em áreas urbanas devido às condições das rodovias e as distâncias entre os estudantes e a escola. Essas três restrições são as mais comuns de serem encontradas nas abordagens do SBRP. O tempo de transferência (TT) apresentado no trabalho de Bögl et al. (2015), é utilizado para diminuir o tempo de espera em pontos de transbordo. A janela de tempo de parada (STW) admite que o tempo máximo de viagem de um estudante deve ser, no máximo, duas vezes o tempo que levaria o percurso direto da sua casa até a escola (López Santana e Romero Carvajal, 2015). Riera-Ledesma e Salazar-González (2013) utilizaram uma combinação de número máximo de paradas por rota (MSR), MRT e número mínimo de estudantes por rota (MSN), para balancear o carregamento entre as rotas. Caceres et al. (2017) consideraram demanda estocástica e, por isso, incluíram restrições que consideravam a probabilidade de superlotação (COO) e de atraso (COL). O tempo de recolhimento mais cedo (EPT) pode ser utilizado juntamente com TW para determinar MRT. Por fim, o tempo ou distância máxima de caminhada (MWT) é uma restrição definida pela política de transporte de cada distrito.

A Tabela 2.2 utiliza os critérios apresentados para classificar a revisão complementar aos trabalhos apresentados em Park e Kim (2010) e Ellegood et al. (2019). 


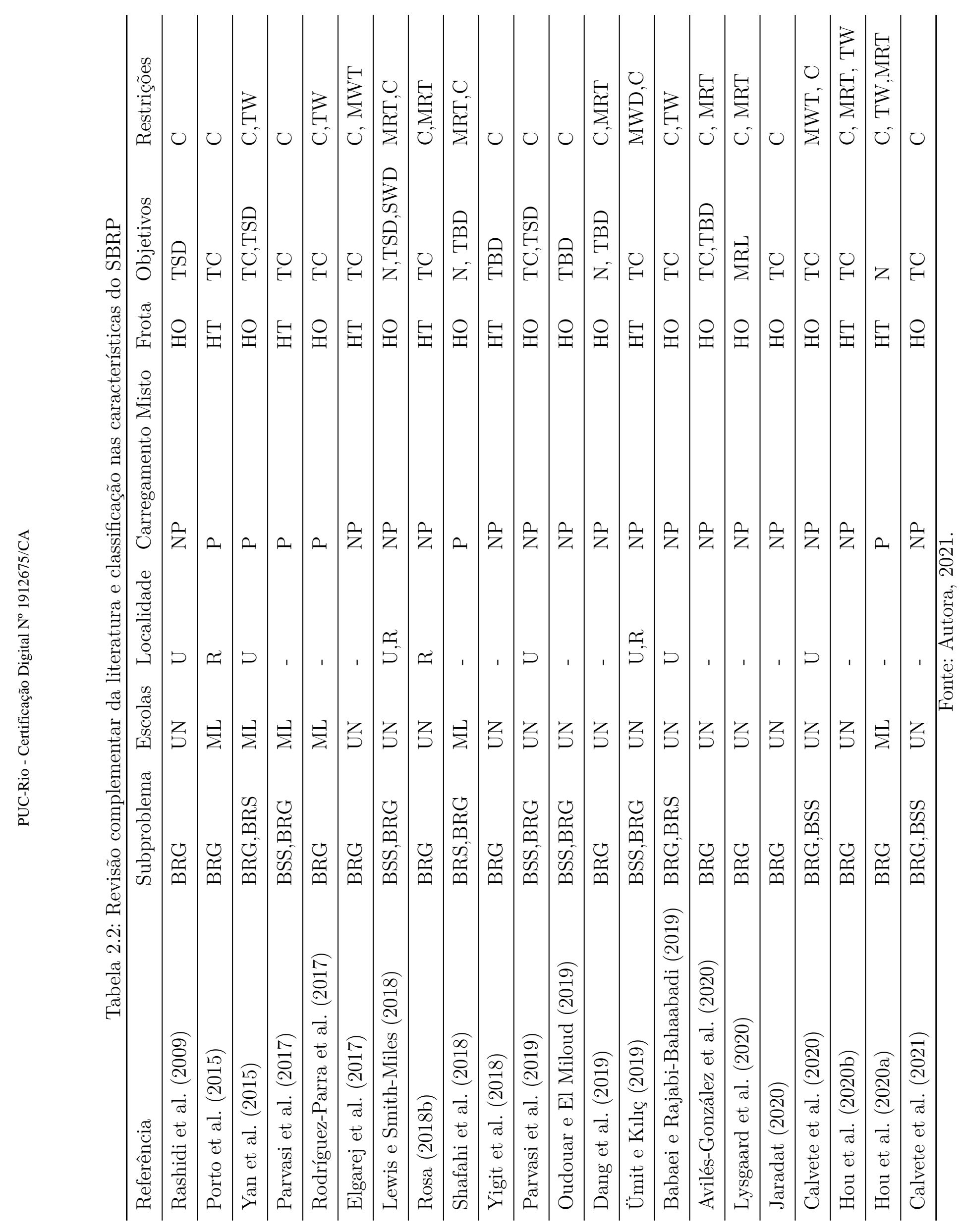


Rashidi et al. (2009) propuseram uma metodologia para resolução do SBRP em cenários reais. Os autores apresentaram uma combinação de algoritmos heurísticos de busca local e utilizaram a Busca Tabu para escapar de ótimos locais. O algoritmo foi aplicado em uma escola com 54 alunos na cidade de Tehran, no Irã, resultando em uma redução do tempo total de viagem dos estudantes em $19 \%$.

Porto et al. (2015) propuseram um método de roteamento para criar rotas melhores que atendessem estudantes de escolas rurais na cidade de Governador Valadares, no estado de Minas Gerais. Os autores consideraram o roteamento por escola, em que o melhor resultado foi obtido com uma heurística que combinava ILS e RVND (Random Variable Neighborhood Descend). Também foi considerado o roteamento para múltiplas escolas, onde o método com o melhor resultado foi o RTR (Record-to-record). Composto por duas fases, a primeira consiste na construção de uma solução inicial e a segunda na execução da busca local iterativamente. Lewis e Smith-Miles (2018) também utilizaram um método baseado no Iterated Local Search (ILS) para 10 instâncias reais do Reino Unido e Austrália. A maior instância considerada era composta por 757 estudantes e 1.817 paradas de ônibus.

Yan et al. (2015) consideraram um algoritmo heurístico baseado na decomposição de problemas e fixação de variáveis, com auxílio do CPLEX para resolução. Os autores consideraram a aplicação em instâncias de até 200 estudantes para o roteamento com carregamento misto e tempo de viagem estocástico. Babaei e Rajabi-Bahaabadi (2019) também consideraram tempo de viagem estocástico. Os autores utilizaram um algoritmo heurístico que combina colônia de formigas e decomposição de rotas, em um problema de roteamento e programação.

Parvasi et al. (2017) consideraram um problema com três etapas: localização das paradas de ônibus, alocação dos estudantes e roteamento. Três abordagens foram comparadas: EX-EX-EX, em que métodos exatos foram utilizados nas três etapas; GA-EX-TS, utilizando algoritmo genético para o problema de localização, método exato para alocação e Busca Tabu para o roteamento; SA-EX-TS, que diferentemente da segunda abordagem, utiliza Simulated Annealing na etapa de localização. As abordagens foram testadas em instâncias geradas aleatoriamente. A abordagem utilizando exclusivamente métodos exatos foi considerada para um grupo de pequenas 10 instâncias com até 19 estudantes e 10 potenciais pontos de parada. As demais abordagens apresentaram resultados similares na resolução de 50 instâncias de 93 estudantes e até 51 potenciais pontos de parada.

Rodríguez-Parra et al. (2017) geraram 51 instâncias aleatórias variando 
entre 4 e 20 estudantes para estudar estratégias que otimizassem o uso de ônibus no sistema de transporte escolar de Bogotá. As instâncias foram resolvidas primeiramente por algoritmos exatos e o ótimo foi encontrado em 21 instâncias, considerando um tempo limite de 4 horas. Dada a complexidade do problema, os autores também desenvolveram um método heurístico. O método proposto consiste na clusterização dos estudantes em cada veículo, em seguida a heurística de roteamento do vizinho mais próximo é aplicada. O gap médio entre as soluções encontradas pelo método e as soluções ótimas, ficou entre $7,3 \%$ e $7,8 \%$.

Elgarej et al. (2017) utilizaram uma abordagem baseada em uma estratégia de alocação, roteamento e localização. As paradas de ônibus são informações fornecidas pelo usuário do sistema, os estudantes são divididos em sub-clusters e, então, as rotas são geradas baseadas em um algoritmo de colônia de formigas artificiais. Calvete et al. (2021) aplicaram uma metaheurística de dois níveis que seleciona as paradas de ônibus, aloca os estudantes de acordo com suas preferências e constrói as rotas levando em consideração a capacidade do veículo. Os testes foram realizados em instâncias da literatura com até 800 estudantes.

Rosa (2018b) propôs uma metodologia para geocodificar o endereço de escolas e alunos, calcular a distância e o tempo de percurso e aplicar uma ferramenta para a obtenção das rotas. A ferramenta utiliza a metaheurística Adaptative Large Neighborhood Search (ALNS). O autor considerou o mesmo ambiente desta dissertação, os alunos cadastrados para transporte rural na SEEDUC-RJ. A primeira etapa da metodologia proposta, geocodificação das escolas e alunos, permitiu o desenvolvimento dos testes computacionais apresentados no capítulo 4 desta dissertação. A metodologia foi aplicada para um único município do estado, Nova Friburgo, com 150 alunos e 7 unidades escolares. Os resultados demonstraram uma redução de 41,62\% no custo das rotas.

Yigit et al. (2018) utilizaram as metaheurísticas algoritmo genético (GA) e colônia de formigas (ACO) em um caso real na província de Ankara, na Turquia. As instâncias consideradas possuíam até 18 paradas de ônibus. Os dois métodos utilizados foram capazes de promover melhorias nas rotas utilizadas em termos de distância e tempo, mas o GA retornou melhores resultados quando comparado com ACO. Ainda considerando os trabalho que utilizaram GA, Parvasi et al. (2019) utilizaram o método exato de enumeração explícita, capaz de resolver apenas pequenas instâncias em um tempo razoável. Assim, para resolver grandes instâncias, os autores propuseram uma estratégia que utiliza GA para localização das paradas de ônibus e Busca 
Tabu para o roteamento. Os resultados obtidos mostraram a alta eficiência do algoritmo híbrido, obtendo os mesmos resultados que o método exato com um menor tempo computacional para as pequenas instâncias. Ümit e Kılıç (2019) aplicaram GA para instâncias da literatura. Os testes foram realizados em duas instâncias, sendo a maior delas com 1.500 estudantes e 75 paradas.

Oudouar e El Miloud (2019) propuseram uma abordagem que consiste na geração das rotas para cada escola utilizando uma heurística básica, como Clarke and Wrigth ou varredura e em um algoritmo de clusterização para seleção das paradas de ônibus. O método foi aplicado em instâncias reais de até 108 estudantes.

Dang et al. (2019) utilizaram uma metaheurística híbrida que utiliza o ILS para gerar um conjunto de soluções e em seguida aplica um procedimento de particionamento (SP) para tentar encontrar a rota ótima. O modelo SP é resolvido pelo CPLEX e aplicado em instâncias da literatura. Quando comparado com outras heurísticas, o algoritmo proposto é competitivo e capaz de encontrar soluções de alta qualidade. Hou et al. (2020b) também utilizaram uma metaheurística híbrida do ILS com SP. O algoritmo proposto foi aplicado em uma instância real da cidade de Wuxi City na China, com até 790 estudantes.

Avilés-González et al. (2020) apresentaram a implementação do Simulated Annealing (SA) para resolução do SBRP. Os autores utilizaram uma técnica de design de experimentos para obter suporte estatístico na seleção dos parâmetros. O algoritmo foi aplicado em uma instância real com 41 estudantes e 21 possíveis pontos de parada.

Lysgaard et al. (2020) utilizam uma heurística multistart e em seguida um framework para programação linear inteira-mista. O algoritmo foi aplicado em instâncias reais da literatura de até 101 estudantes. Hou et al. (2020a) desenvolveram uma metaheurística que utiliza 3 estruturas de exploração da vizinhança para melhorar a solução de maneira iterativa.

Calvete et al. (2020) propuseram uma metaheuristica que faz uma alocação parcial dos estudantes e define as rotas que minimizam o custo total. Em seguida, é feito um refinamento para alocar os demais estudantes e obter uma solução viável. O algoritmo foi aplicado em instâncias da literatura com até 800 estudantes. Em 15,18\% das instâncias, o método obteve um resultado melhor que o apresentado na literatura e, em 66,07\% das instâncias, foi encontrado o mesmo resultado da literatura. 


\section{4}

\section{Métodos de resolução}

A revisão da literatura apresentada anteriormente mostrou a limitação dos métodos exatos para encontrar soluções, considerando grandes instâncias e restrições apresentadas em casos reais. Como alternativa, as heurísticas e metaheurísticas têm sido utilizadas e apresentado excelentes reultados. Heurísticas e metaheurísticas são de grande importância para problemas de otimização combinatória, uma vez que são capazes de encontrar soluções próximas ao ótimo em tempo polinomial (Gendreau e Potvin, 2005).

As metaheurísticas diferenciam-se das heurísticas por serem algoritmos genéricos, possibilitando a aplicação em uma vasta gama de problemas. Além disso, as metaheurísticas possuem ferramentas que permitem escapar de ótimos locais (Blum e Roli, 2003).

Com os métodos que buscam solução aproximada, a garantia de otimalidade da solução é sacrificada em troca da obtenção de boas soluções em um razoável intervalo de tempo. Segundo Blum e Roli (2003), os métodos podem ser classificados em métodos construtivos e métodos de busca local. Os algoritmos construtivos geram soluções adicionando elementos em uma estrutura até que uma solução esteja completa. Em favor da velocidade para obtenção de uma solução, geralmente retornam soluções de qualidade inferior quando comparado aos algoritmos de busca local. Algoritmos de busca local partem de uma solução inicial e, de maneira iterativa, buscam substituir a solução atual por uma solução melhor obtida através da exploração da vizinhança.

Neste trabalho, será utilizada a metaheurística Iterated Local Search. O ILS apresenta precisão, velocidade, flexibilidade, simplicidade e facilidade de implementação, características desejáveis em uma metaheurística (Lourenco et al., 2003). Além disso, os trabalhos descritos na Seção 2.3 que utilizaram o ILS apresentaram bons resultados, demonstrando o potencial do método para a resolução de grandes instâncias.

\subsection{1}

\section{Iterated Local Search}

O ILS utiliza a busca local para explorar os mínimos locais de uma função e, a cada iteração, gera uma perturbação na solução localmente ótima previamente visitada (Lourenco et al., 2003). A força da perturbação deve ser calibrada, de modo que não seja tão forte que o espaço solução seja explorado de maneira aleatória, e nem tão fraca que o algoritmo volte para a solução já visitada. O algoritmo é composto por quatro componentes: solução inicial, busca local, método de perturbação e critério de aceitação. O Algoritmo 1 
apresenta o pseudocódigo do ILS. O algoritmo parte de uma solução inicial $\mathrm{s}_{0}$ (linha 1), em seguida é aplicada uma busca local nessa solução (linha 2), obtendo um ótimo local s*. Entre as linhas 3 e 7 são demonstradas as etapas executadas em looping até que um determinado critério de parada seja atendido. Na linha 4, é aplicada uma perturbação na solução atual, seguida de uma nova busca local, obtendo-se s*' (linha 5). A solução s* é substituída pela solução s*' se estiver dentro do critério de aceitação adotado.

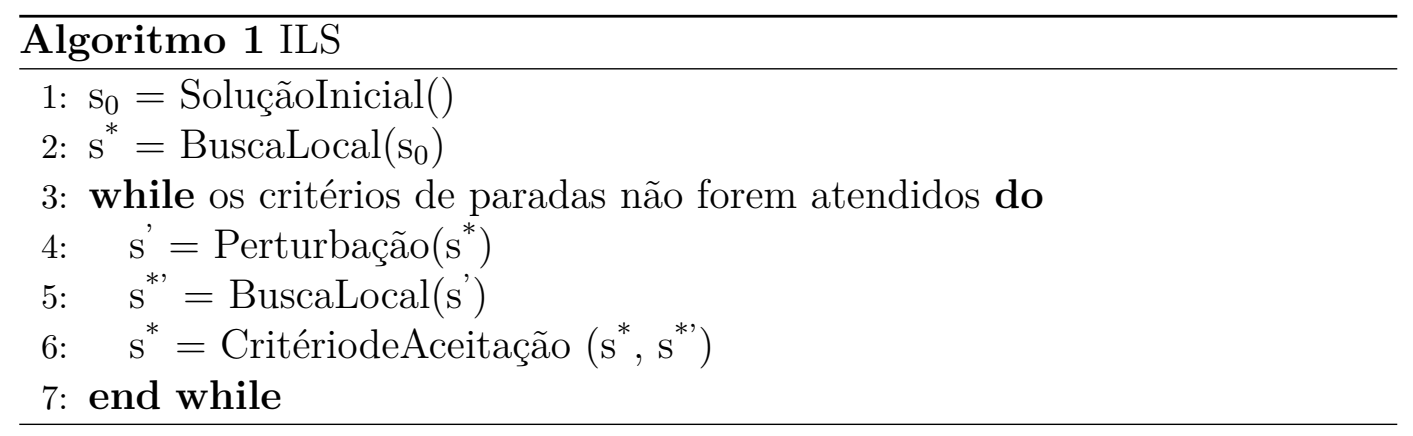

A Solução Inicial pode ser obtida através de um construtivo aleatório ou através de um algoritmo guloso. A utilização de algoritmos gulososos para a solução incial apresenta algumas vantagens. De maneira geral, as soluções obtidas após a busca local apresentam melhor qualidade e, além disso, a busca local necessita de menos passos, resultando em menor tempo de processamento (Lourenco et al., 2003).

A Busca Local parte da solução inicial e repetidamente substitui a solução atual por uma solução de melhor valor, através da busca em vizinhanças (Johnson et al., 1988). A estratégia de busca utilizada deve ser um balanço entre a velocidade e eficiência desejada.

Encontra-se na literatura trabalhos que utilizam na fase de Busca Local do ILS, o Variable Neighborhood Descent (VND). Proposto por Mladenović e Hansen (1997), o VND explora o espaço de solução a partir da troca sistemática entre as estruturas de vizinhança. O método só aceita soluções que apresentem resultados melhores que a solução atual e retorna a busca para a primeira vizinhança.

O algoritmo 2 apresenta o pseudocódigo do VND, utilizando as seguintes notações: $\mathrm{s}_{0}$ é a solução inicial, k é o conjunto com as estruturas de vizinhanças a serem exploradas $k=\left\{1,2,3 \ldots k_{\max }\right\}$ e $\mathrm{N}^{(\mathrm{k})}(\mathrm{s})$ é a vizinhança do tipo $\mathrm{k}$ da solução s. O algoritmo parte de uma solução inicial so (linha 1) e seleciona a primeira estrutura de vizinhança $\mathrm{k}=1$ (linha 2). Entre as linhas 3 e 11 há um loop para que todas as estruturas sejam exploradas. O melhor vizinho da solução inicial $\mathrm{s}_{0}$ na vizinhança $\mathrm{k}$ é encontrado (linha 4) e seu custo avaliado. Caso o custo do melhor vizinho seja menor que a solução inicial (linha 5), 
a solução inicial é substituída (linha 6) e a busca retorna para a primeira vizinhança (linha 7). Caso contrário, a busca passa para a vizinhança seguinte (linha 9).

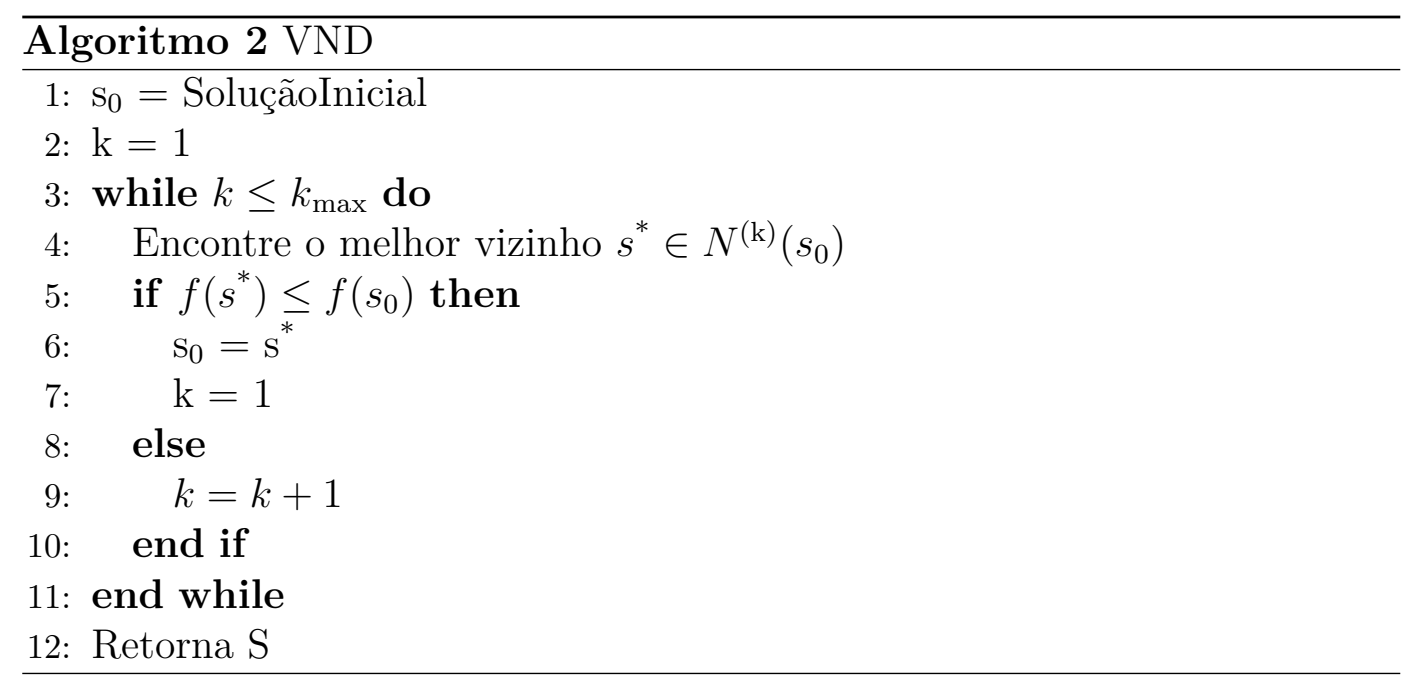

A Perturbação é utilizada para escapar do mínimo local resultante da busca local. A força da perturbação pode ser definida de acordo com o número de componentes da solução que são modificados. Caso a perturbação aplicada não tenha força suficiente, a busca local aplicada na sequência irá desfazer a perturbação e retornar para o ótimo local anterior, limitando a diversificação do espaço de busca. Caso a perturbação aplicada seja muito forte, o espaço de busca será explorado de maneira aleatória, resultando em uma baixa probabilidade de encontrar melhores soluções (Lourenço et al., 2019).

O Critério de Aceitação é utilizado para balancear a diversificação e intensificação da busca, uma vez que define a transição entre $s^{*}$ e $s^{*}$. Um critério que só aceite movimentos de melhora, favorece a intensificação, enquanto critérios que aceitam todas as soluções, favorecem a diversificação. Critérios intermediários podem ser utilizados, como o Simulated Annealing (SA), que utiliza a probabilidade para aceitar casos de piora da solução atual, evitando ótimos locais (Alvarez et al., 2018). 
3

\section{Iterated Local Search aplicado ao Problema de Roteamento de Veículos Escolares}

Este capítulo apresenta os algoritmos e estratégias utilizadas em cada etapa do ILS.

\section{1}

\section{Representação da solução}

Uma solução do problema é representada por um conjunto de vetores, onde cada vetor representa uma rota para um veículo. Também fazem parte da solução um vetor com a distância, o carregamento total, o custo e a capacidade do veículo de cada rota. A Figura 3.1 mostra uma solução composta por três rotas: R1, R2 e R3. As informações da rota Ri estão armazenadas na posição i dos vetores distância, carga, veículo e custo. Todas as rotas iniciam e terminam com o elemento 1 que representa a escola. Para o trajeto de ida, a distância até o primeiro aluno não é considerada no cálculo da distância e custo da rota. Para o retorno dos estudantes até suas casas, a distância do último aluno até o depósito (escola) também é desconsiderada. A rota R1 possui distância total de $25 \mathrm{~km}$, e possui 4 alunos alocados (6, 3, 8 e 2). Para essa rota foi alocado um veículo com capacidade igual a 8 que, de acordo com a frota disponível, equivale à uma Kombi. Por fim, a rota possui um custo total de $\mathrm{R} \$ 32,5$. A distância, carregamento, capacidade e custo totais da instância equivalem à soma das informações das rotas R1, R2 e R3.

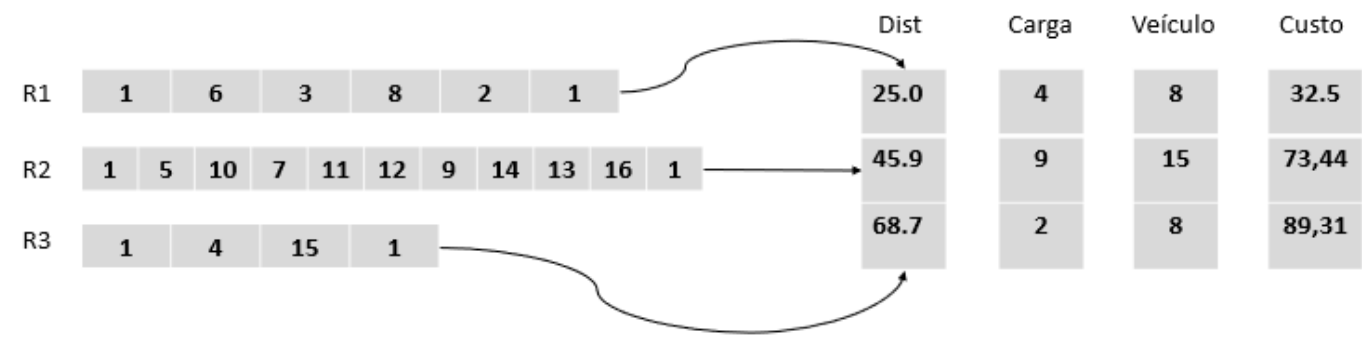

Figura 3.1: Representação de uma solução

Fonte: Autora, 2021. 


\section{2}

\section{Algoritmo Construtivo}

O algoritmo construtivo implementado constrói a solução a partir da escolha aleatória do primeiro aluno a ser incluído na rota. A partir desse primeiro aluno, o algoritmo utiliza a técnica do vizinho mais próximo, inserindo na rota o aluno ainda não visitado que apresenta a menor distância para o último elemento inserido na rota. Essa etapa é repetida até que a capacidade do veículo seja atingida ou a quilometragem máxima. O Algoritmo 3 apresenta o pseudocódigo do construtivo.

O conjunto com todos os alunos a serem visitados é representado por $N=\{1,2,3, \ldots n\}$, sendo $N=1$ a escola que está sendo roteada. O conjunto com todos os veículos disponíveis é representado por $V=$ $\{1,2,3, \ldots m\}$. Cada veículo possui uma capacidade máxima, representada pelo vetor $C=\{C[1], C[2], C[3] \ldots C[m]\}$ e um custo por quilômetro $K=$ $\{K[1], K[2], K[3] \ldots K[m]\}$. Além da capacidade máxima, a rota deve respeitar a distância ou tempo máximo de trajeto $\left(D_{\max }\right)$.

A linha 1 do Algoritmo 3 destaca as informações fornecidas para o construtivo como: característica da frota (número de veículos por tipo, capacidade e custo por $\mathrm{km}$ ), alunos a serem roteados, matriz de distância e a distância máxima permitida para a rota. O loop entre as linhas 2 e 20 é executado até que existam veículos disponíveis e alunos a serem roteados. A linha 3 inicia a montagem da rota com a seleção aleatória de um veículo da frota, seguido da também aleatória escolha do primeiro aluno a ser inserido (linha 4). Em seguida, a escola e o primeiro aluno selecionado são adicionados à rota (linha 5), soma-se 1 à carga, representando o primeiro aluno inserido (linha 6) e soma-se à distância total a distância da escola até o último aluno inserido (linha 7). No loop entre as linhas 8 e 12, o algoritmo deixa de ser aleatório e passa a ser baseado em um algoritmo guloso para inclusão dos demais elementos da rota. O aluno ainda não visitado que apresenta a menor distância para o último aluno inserido na rota é adicionado (linha 9) e, em seguida, a distância total da rota e a carga do veículo são atualizadas (linhas 10 e 11). Ao atingir a restrição de capacidade máxima do veículo ou a quilometragem máxima do percurso, a rota é encerrada adicionando a Escola ao final da mesma (linha 13) e atualizando a informação de distância (linha 14) e custo (linha 15). Por fim, os vetores que armazenam as informações de todas as rotas da instância são atualizados (linhas 16, 17, 18 e 19). A linha 21 apresenta as informações de saída do algoritmo.

As saídas do construtivo são cinco vetores:

- Rotas: vetor de vetores com todas as rotas da solução inicial, cada rota 


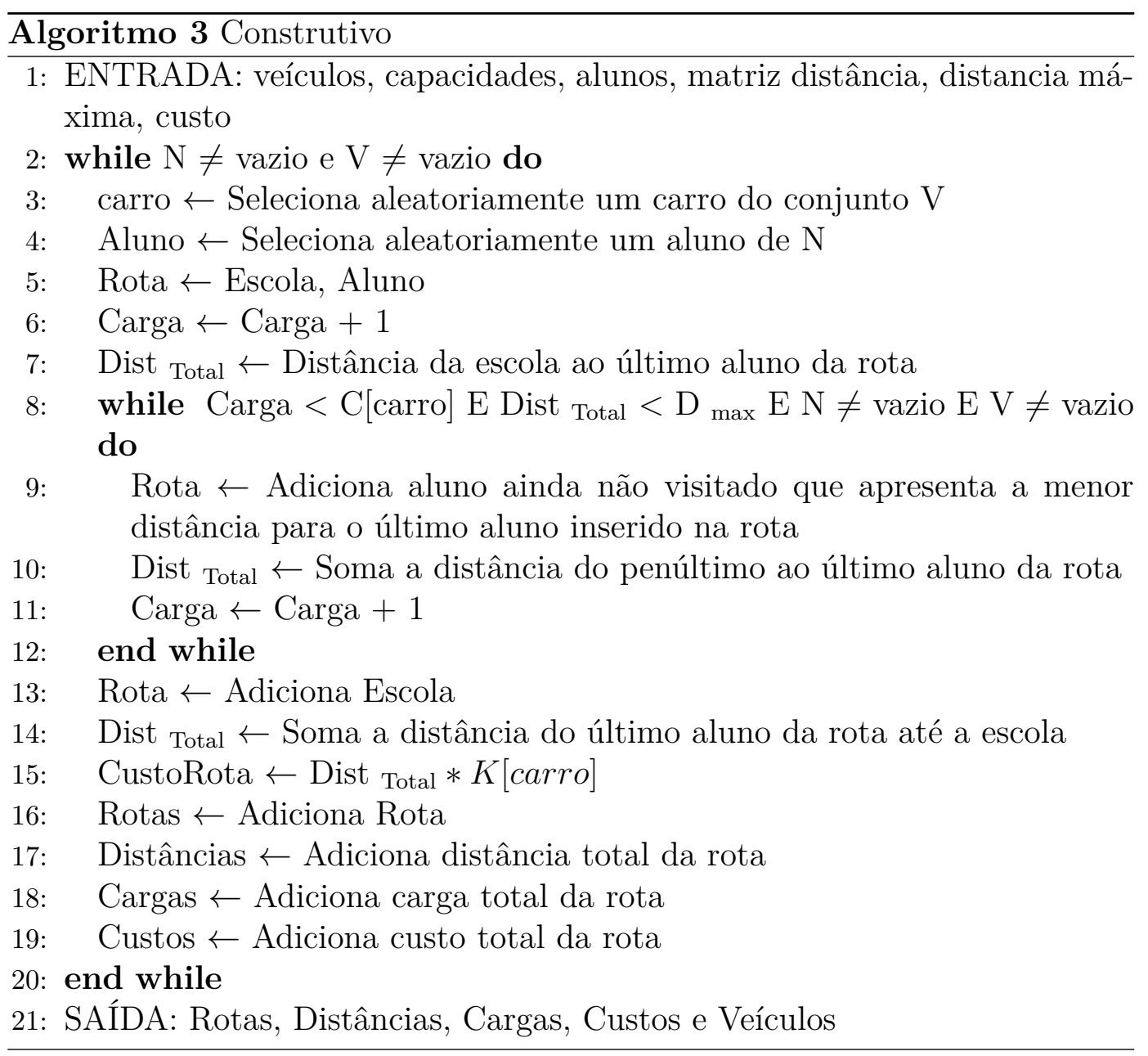

é um veículo e cada nó da rede (aluno) só pode estar em uma das rotas.

- Distância: vetor com a distância total de cada uma das rotas.

- Cargas: vetor com a carga final de cada veículo.

- Custos: vetor com o custo total de cada rota.

- Veículos: capacidade do veículo alocado em cada rota.

\subsection{1}

\section{Estruturas de Vizinhança e Busca Local}

A segunda etapa do ILS é a Busca Local. Para explorar o espaço de busca, foram utilizadas estruturas de vizinhança clássicas do VRP (Vidal et al., 2015) com movimentos intra-rotas e inter-rotas. Os movimentos intra-rotas são referentes às estruturas Shift, Swap e Relocate. Os movimentos inter-rotas implementados foram Swap e Relocate. A Fig. 3.2 apresenta uma ilustração de uma solução constituída por doze nós, divididos em três rotas, onde cada rota inicia e termina no depósito, representado pelo ponto azul. A seguir, cada um dos movimentos implementados será exemplificado a partir da solução da Fig. 3.2 . 


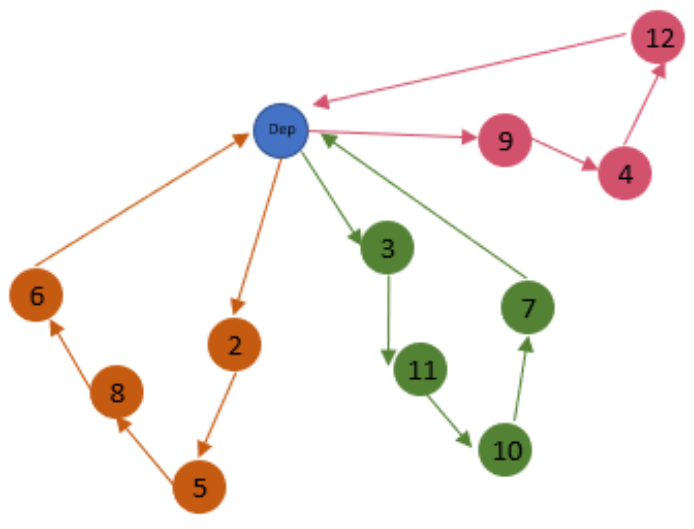

Figura 3.2: Ilustração de uma solução

Fonte: Autora, 2021.

\section{Estruturas Intra-rotas}

- Shift: Inversão da posição dos elementos i e i+1 (elementos consecutivos) da rota $\mathrm{r}_{\mathrm{a}}$. Na Fig. 3.3 é possível observar, destacados em amarelo, os dois elementos que foram invertidos (nós 5 e 8).

- Swap: Inversão da posição dos elementos i e j (não consecutivos) da rota $r_{a}$. Na Fig. 3.4 é possível observar, destacados em amarelo, os dois elementos que foram invertidos (nós 3 e 10).

- Relocate: exclusão de um elemento da rota $\mathrm{r}_{\mathrm{a}}$ com reinserção em outra posição. Na Fig. 3.5 está destacado em amarelo o elemento que foi reinserido em uma nova posição (nó 9).

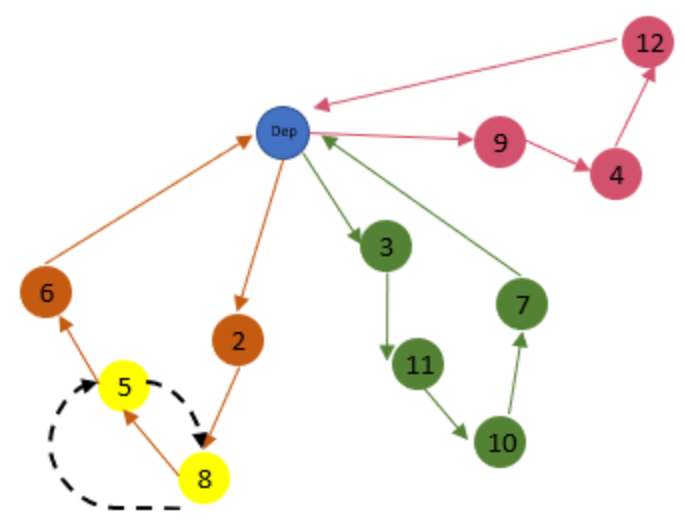

Figura 3.3: Shift Intra-rotas

Fonte: Autora, 2021.

\section{Estruturas Inter-rotas}

- Swap: permutação entre o elemento i da rota $\mathrm{r}_{\mathrm{a}}$ com o elemento j da rota $\mathrm{r}_{\mathrm{b}}$. Na Fig. 3.6 o movimento foi realizado com os nós 10 e 5. 


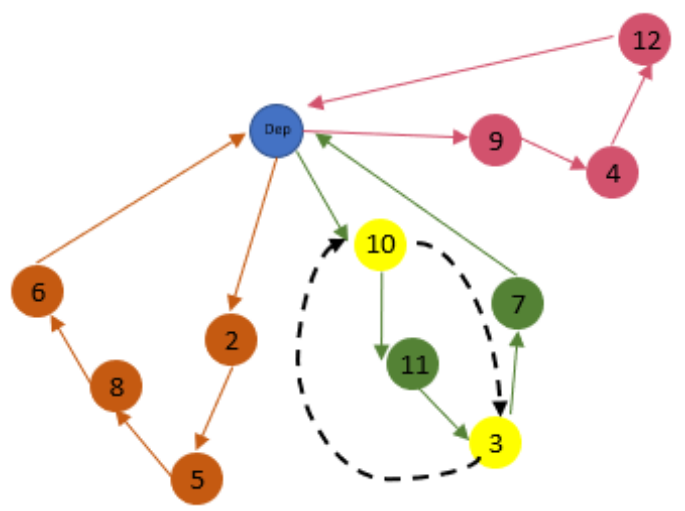

Figura 3.4: Swap Intra-rotas Fonte: Autora, 2021.

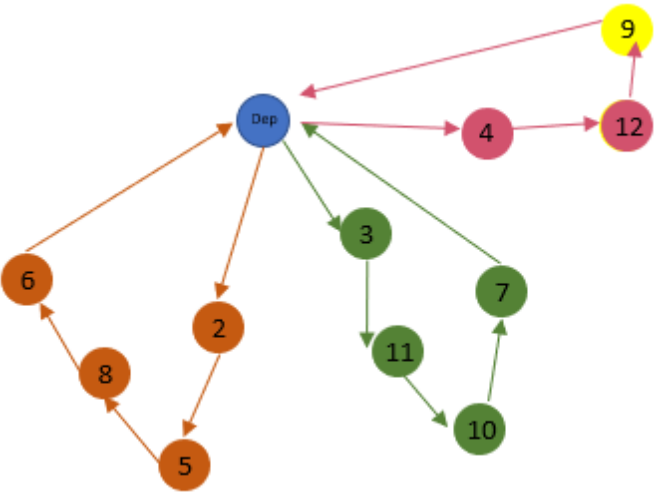

Figura 3.5: Relocate Intra-rotas Fonte: Autora, 2021.

- Relocate: exclusão de um elemento da rota $\mathrm{r}_{\mathrm{a}}$ com reinserção na rota $\mathrm{r}_{\mathrm{b}}$. Na Fig. 3.7 está destacado em amarelo o elemento que foi inserido em uma nova rota (nó 5).

\section{Ajuste da Frota}

Além desses movimentos, foi incluído na busca local a troca do veículo da rota. Como o veículo é escolhido de maneira aleatória no construtivo, a inclusão dessa estrutura permite o ajuste do veículo utilizado em cada rota de acordo com o número de alunos alocados.

Buscando explorar as vizinhanças de maneira sistemática, foi utilizado o método VND apresentado na Seção 2.4.1. Como a avaliação de toda a vizinhança em busca do melhor vizinho pode ser dispendiosa, a estratégia de First Improvement foi utilizada em vez da Best Improvement. Isso significa que ao encontrar o primeiro vizinho de melhora, a solução atual é substituída.

Na Busca Local, para cada um desses movimentos foi criada uma função que consiste em um bloco de avaliação e um bloco de execução. A função avaliação busca calcular o custo caso o movimento seja executado. Se o 


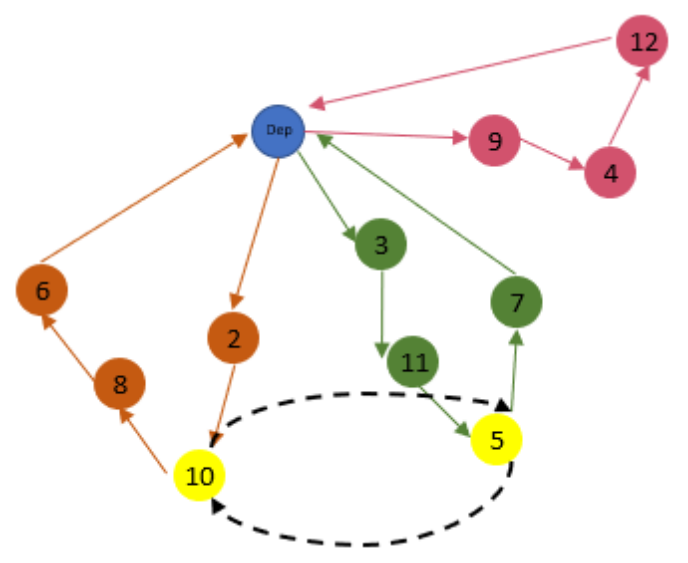

Figura 3.6: Swap Inter-rotas Fonte: Autora, 2021.

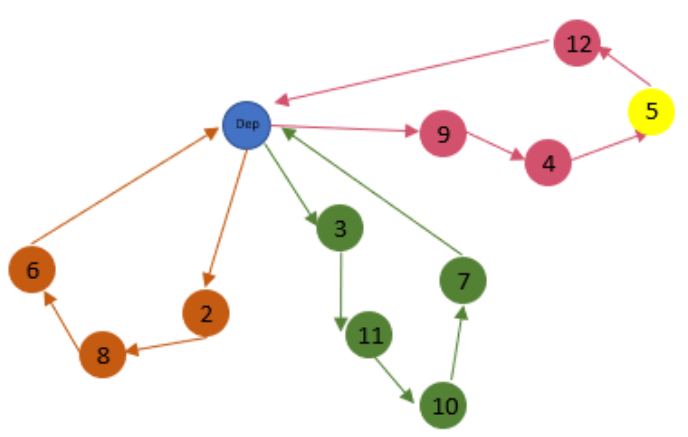

Figura 3.7: Relocate Inter-rotas Fonte: Autora, 2021.

custo resultante da avaliação for negativo, ou seja, a realização do movimento representará uma redução do custo total das rotas, o bloco execução é chamado e as rotas são modificadas. Em alguns casos, a realização dos movimentos pode resultar em cargas que violem a capacidade do veículo. Nesse caso, poderia ser incluído na função de avaliação uma restrição para só considerar movimentos que respeitassem a capacidade do veículo; ou permitir a violação, aplicando uma penalidade.

Para o problema estudado, optou-se por permitir a violação da capacidade. Essa escolha foi feita porque, apesar de obter apenas soluções viáveis com a restrição, o espaço de busca poderia ser limitado. Para os casos em que a carga do veículo supera sua capacidade, o excesso de carga é multiplicado por uma penalidade e esse valor somado ao custo total da solução. Assim, uma solução inviável para o problema, será entendida como ruim em termos de custos pelo algoritmo. O Algoritmo 4 apresenta o pseudocódigo geral para as vizinhanças da Busca Local. Cabe destacar que para os casos em que rota for igual a rota 2 (linhas 2 e 3 do Algoritmo 4), serão avaliadas as vizinhanças intra-rotas; caso contrário, serão avaliadas as vizinhanças inter-rotas. 
O algoritmo inicia verificando o número de rotas da instância (linha 1). Em seguida são selecionadas duas rotas da instância (linhas 2 e 3). Para essas duas rotas selecionadas, o loop entre as linhas 4 e 11 é executado enquanto forem obtidas melhorias. O algoritmo é composto por um bloco de avaliação (linha 6) e execução (linha 8). Para cada par de elementos pertencentes às duas rotas selecionadas, a troca é avaliada e, caso seja obtido um ganho no custo, o movimento é executado.

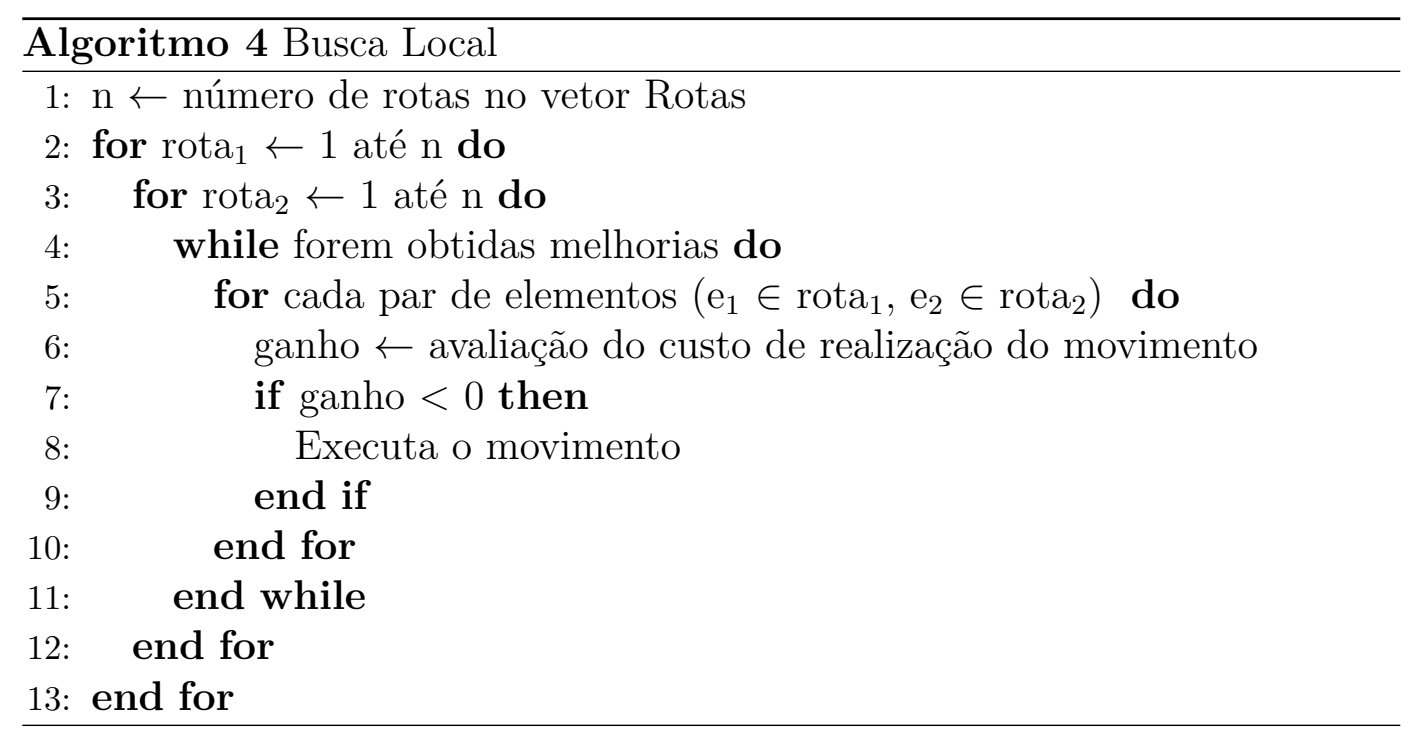

\subsection{2}

\section{Perturbação}

O terceiro elemento do ILS é a perturbação. Neste trabalho, a perturbação consiste em aplicar um número limitado de movimentos aleatórios do tipo intra-rotas e inter-rotas explorados na busca local. O Algoritmo 5 apresenta o pseudocódigo da perturbação.

Na linha 1 do algoritmo há a inicialização do laço de repetição. O código entre as linhas 1 e 7 é executado até que o número de movimentos definidos seja atingido. São sorteadas duas rotas da solução (linha 2) e uma posição de cada rota (linhas 3 e 4). Em seguida, um dos movimentos realizados na busca local é selecionado (linha 5) e, por fim, a troca é realizada (linha 6).

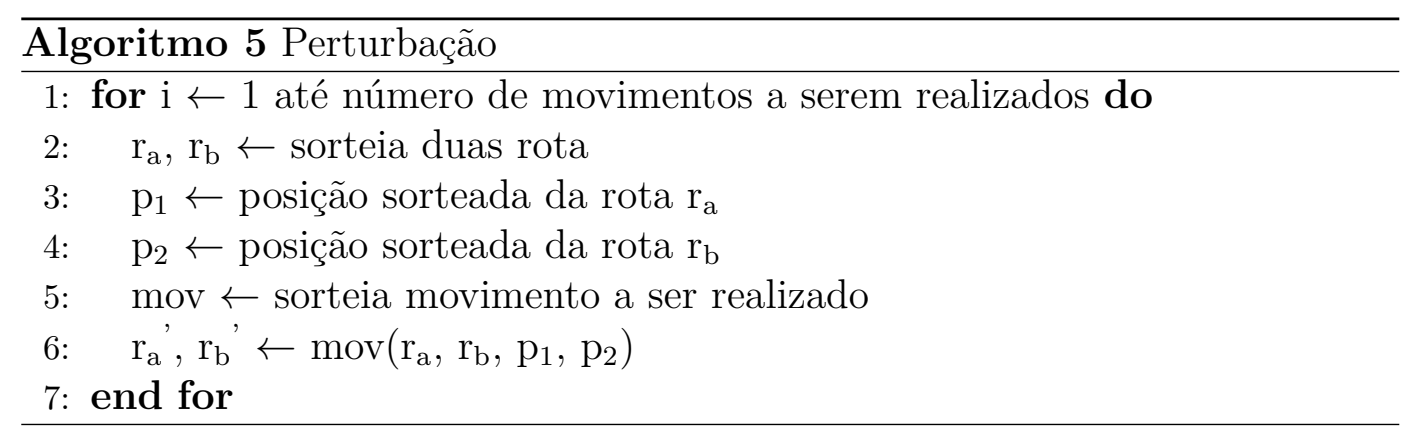




\subsection{3}

\section{Critério de Aceitação}

Como critério de aceitação utilizou-se o simulated annealing, onde a solução atual $s^{*}$ é substituída pela solução candidata $s^{*^{\prime}}$ dada a probabilidade $e^{-\left(f\left(s^{*^{\prime}}\right)-f\left(s^{*}\right)\right) / T}$, onde $T>0$ é a temperatura (Kirkpatrick et al., 1987). A temperatura inicia com um valor inicial $\mathrm{T}_{\mathrm{i}}$ e decresce a cada iteração seguindo a expressão $T=T r$, onde $0<r<1$ é a taxa de resfriamento. Neste trabalho, para definição da temperatura inicial e final, utilizou-se o método proposto por Pisinger e Ropke (2007), sendo $T_{\mathrm{i}}=\left(p_{\mathrm{i}} c\right) /-\log \left(p_{\mathrm{i}}\right)$ e $T_{\mathrm{f}}=\left(p_{\mathrm{f}} c\right) /-\log \left(p_{\mathrm{f}}\right)$, onde c é o custo da solução inicial. A temperatura inicial e final são então ajustadas de modo que aceitem $\mathrm{p}_{\mathrm{i}} \%$ das soluções que apresentem até $\mathrm{p}_{\mathrm{i}} \%$ de piora e finalizam aceitando $\mathrm{p}_{\mathrm{f}} \%$ das soluções com até $\mathrm{p}_{\mathrm{f}} \%$ de piora. A taxa de resfriamento (r) é definida levando em consideração o número de iterações a serem executadas $(\mathrm{n}), r=\left(T_{\mathrm{f}} / T_{\mathrm{i}}\right)^{(1 / \mathrm{n})}$. 


\section{4 \\ Aplicação}

Este capítulo tem como objetivo verificar a aplicabilidade da metaheurística apresentada na Seção 3 no problema de roteamento de transporte escolar rural do estado do Rio de Janeiro. Os resultados alcançados serão apresentados e comparados com o cenário atual das rotas. Os dados utilizados foram disponibilizados pela Secretaria de Estado de Educação do Rio de Janeiro (SEEDUC-RJ) por meio de arquivos eletrônicos.

\section{1}

\section{Descrição do cenário}

O direito ao transporte escolar é assegurado ao aluno pela Constituição Federal de 1988 e a Lei n 9.394/96. O Programa Nacional de Apoio ao Transporte Escolar, instituído pela Lei $n^{\circ} 10.880 / 2004$, busca garantir o acesso e permanência dos alunos da área rural nas unidades escolares por meio de assistência financeira aos estados e municípios. No contexto rural, a garantia do acesso ao transporte é fator determinante para a redução da evasão escolar, dada as grandes distâncias a serem percorridas em estradas precárias.

No estado do Rio de Janeiro, o transporte escolar rural é responsabilidade da SEEDUC-RJ. Cada escola deve contratar e gerenciar o transporte de seus alunos por meio dos recursos transferidos pela SEEDUC às Associações de Apoio à Escola - AAE, de acordo com a Resolução nº 5.506 (2017). Segundo Rosa (2018b), é responsabilidade do diretor da escola determinar as rotas e a frota de veículos que será utilizada. O custo da rota é calculado pela quilometragem total ou por dia de utilização, de acordo com o tipo de veículo.

\subsection{1}

\section{Abrangência}

O estado do Rio de Janeiro é composto por 92 municípios e, segundo dados do IBGE (2020), possui uma população estimada de 17.366.189 pessoas em uma área territorial de $43.750 .426 \mathrm{~km}^{2}$. Segundo a última série histórica divulgada pelo Centro Estadual de Estatísticas, Pesquisas e Formação de Servidores Públicos do Rio de Janeiro (CEPERJ), a população rural correspondia a 3,4\% da população do estado no censo demográfico de 2010 (CEPERJ, 2019). 
A SEEDUC-RJ possui mais de 700.000 alunos matriculados em 1.230 escolas em todo o estado. A Figura 4.1 mostra a distribuição das escolas em todo o estado Rosa (2018a). A imagem é um dos resultados do trabalho de Rosa (2018b), com a geolocalização dos estudantes e escolas da rede. As diferentes cores representam as divisões regionais utilizadas pela SEEDUC-RJ.

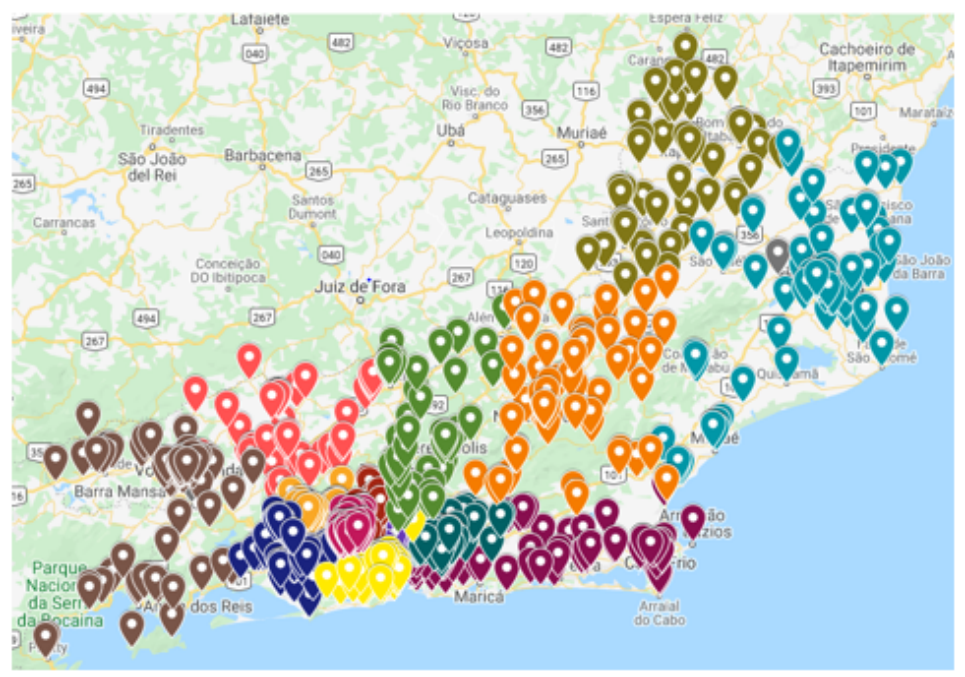

Figura 4.1: Escolas Estaduais Fonte: Rosa (2018a)
Escolas Estaduais

? metropolitana III

9 metropolitana iv

? metropolitana vil

METRopolitanaI

? baixadas litoraneas

Norte Fluminense

( metropolitana II

? medio paraiba

( metropolitana v

- serranall

O metropolitana VI

- serranai

- noroeste fluminense

- centrosul

- especial de unidades socioeducat.

Em 2019, a SEEDUC-RJ possuía 17.200 alunos cadastrados para uso do transporte escolar rural distribuídos em 357 escolas e 83 municípios. Também foram disponibilizados o turno em que o aluno está matriculado, podendo ser: manhã, tarde, noite ou integral. Todos os alunos são buscados e deixados diariamente nas suas residências ou locais próximos, quando não é possível o acesso. A localização dos pontos de embarque e das escolas foi disponibilizada pela Secretaria, através da latitude e longitude de cada um deles.

\subsection{2}

\section{Tratamento dos dados}

As latitudes e longitudes foram identificadas pelos diretores de cada escola de maneira manual, de acordo com a metodologia proposta por Rosa (2018b). Antes da aplicação do algoritmo, os dados passaram por uma etapa de tratamento para identificar inconsistências.

- Foram excluídos todos os registros de alunos em que a latitude e/ou longitude eram iguais a zero ou estavam fora do formato padrão. Essa etapa resultou na exclusão de 2.072 registros. 
- Foram excluídos os registros de alunos em que a latitude e longitude forneciam uma localização fora do estado do Rio de Janeiro. 586 registros foram desconsiderados.

- Foram excluídos todos os alunos dos turnos em que mais de $70 \%$ dos alunos possuíam a mesma localização. Para esses casos, foi assumido que o cadastro não foi realizado de maneira correta. Nessa etapa 878 registros foram excluídos.

Após o tratamento dos dados, restaram 13.664 alunos na base. O Apêndice A apresenta a distribuição do número de alunos por município e turno.

\subsection{3}

\section{Matriz de Distâncias}

Para determinar a distância entre cada ponto de embarque e destes para as respectivas escolas, foi utilizada a API do Open Street Maps via um script em Python. O uso da API foi necessário para a obtenção das distâncias reais. Segundo Rosa (2018b), a distância real apresentou valores até $78 \%$ maiores que as distâncias euclidiana e geodésica. Além disso, neste trabalho considerou-se a matriz distância assimétrica, levando em conta a diferença entre as distâncias do caminho de ida e volta.

Considerar a matriz assimétrica é relevante no contexto rural uma vez que o caminho entre a residência dos alunos e a escola, muitas vezes envolve estradas e rodovias. Embora não haja uma lei que defina o tempo ou distância máxima do percurso realizado pelos estudantes, a SEEDUC-RJ estabelece um tempo máximo de 2 horas ou $120 \mathrm{~km}$, considerando uma velocidade média de $60 \mathrm{~km} / \mathrm{h}$.

\subsection{4}

\section{Frota}

Os dados disponibilizados pela SEEDUC-RJ mostraram que as escolas utilizavam até quatro tipos de veículos: kombi, van, micro-ônibus e ônibus. A Tabela 4.1 apresenta a capacidade e o custo por quilômetro de cada veículo. No regime de contratação da Secretaria, não são considerados custos fixos, apenas custos variáveis. Por esse motivo, o cálculo do custo das rotas será feito multiplicando apenas o custo por $\mathrm{km}$ do veículo utilizado e a quilometragem total da rota.

Para determinação da frota disponível para cada instância, considerou-se que cada tipo de veículo possuiria um número suficiente para atender todos os alunos. Para uma instância com 80 alunos, a frota de veículos disponíveis era 
Tabela 4.1: Características dos Veículos

\begin{tabular}{lcc}
\hline Veículo & Capacidade & Custo por $\mathbf{~ K m}$ \\
\hline Kombi & 8 & 1.3 \\
\hline Van & 15 & 1.6 \\
\hline Micro-ônibus & 22 & 1.8 \\
\hline Ônibus & 45 & 2.5 \\
\hline
\end{tabular}

Fonte: Autora, 2021.

Tabela 4.2: Classificação do caso da SEEDUC-RJ de acordo com as características do SBRP

\begin{tabular}{ll}
\hline Critério & Classificação \\
\hline Sub-problema & Geração de rotas de ônibus (BRG) \\
\hline Número de escolas & Única (UN) \\
\hline Localidade & Rural (R) \\
\hline Carregamento Misto & Não Permitido (NP) \\
\hline Frota & Heterogênea (HT) \\
\hline Objetivos & Custo Total (TC) \\
\hline Restrições & Capacidade do veículo (C) \\
\hline & Tempo ou distância máxima de percurso (MRT) \\
\hline
\end{tabular}

constituída por 10 kombis - teto da divisão de 80 alunos pela capacidade de uma kombi, 8 alunos - 6 vans, 4 micro-ônibus e 2 ônibus.

\subsection{5}

\section{Enquadramento do problema nas características do SBRP}

Apresentado o cenário considerado para aplicação e suas características, a Tabela 4.2 demonstra o resultado da classificação do problema, de acordo com as características apresentadas na Seção 2.3.

\subsection{6}

\section{Resultados}

Nesta Seção serão apresentados os testes realizados para determinação dos parâmetros do modelo e os resultados das instâncias. 


\subsubsection{1}

\section{Ambiente computacional e instâncias}

O código principal foi escrito em Julia 1.6.1, executado em uma máquina com processador Intel ${ }^{\circledR}$ Core $^{\mathrm{TM}}$ i7-8700K CPU @ 3.70GHz, 64GB de memória RAM, utilizando apenas uma thread, e sistema operacional Ubuntu 20.04 LTS. O ambiente de desenvolvimento utilizado é o Visual Studio Code 1.59.

O algoritmo proposto foi utilizado para a resolução das instâncias apresentadas no apêndice B, onde a coluna Escola apresenta o código de identificação da instituição, o município em que está localizada e o número de alunos por turno. No apêndice B, a tabela está dividida em dois blocos, sendo o primeiro considerando o turno integral de maneira independente, ou seja, os alunos desse turno não poderiam ser levados para a escola ou para suas casas com alunos dos demais turnos. O segundo bloco consolida os alunos do turno integral, de modo que seriam levados para a escola juntamente com os alunos do turno da manhã e, no fim do dia, retornariam para suas casas com os alunos do turno da tarde. Considerando todos os cenários, totalizam-se 1.012 instâncias.

A Figura 4.2 apresenta a distribuição das instâncias nas categorias de tamanho (número de alunos). No eixo horizontal pode-se observar os intervalos de número de alunos considerados para cada categoria. No eixo vertical é indicado o número de instâncias de cada categoria.

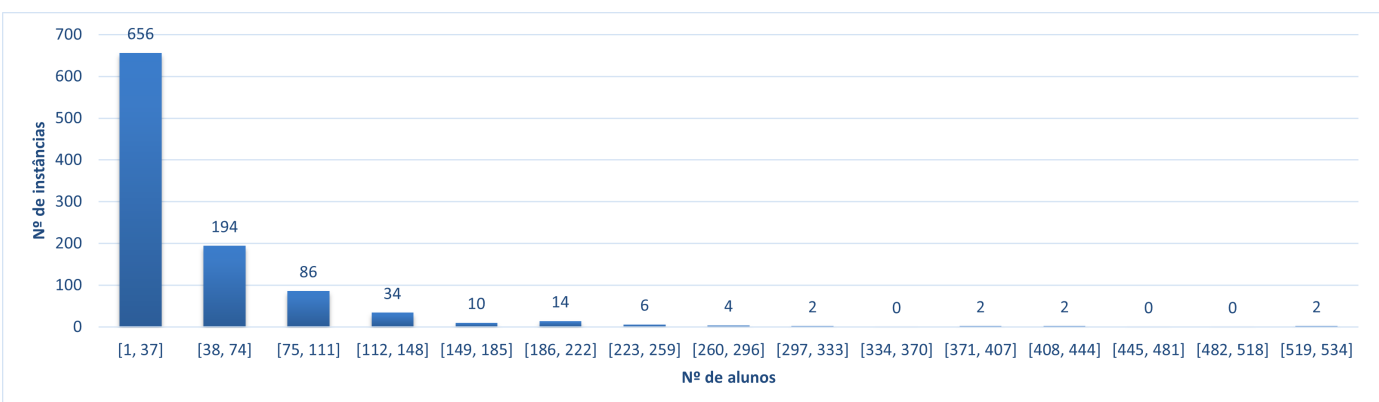

Figura 4.2: Distribuição das instâncias por número de alunos Fonte: Autora, 2021.

Considerando o primeiro bloco, a maior instância é da escola E199 do município de Itaperuna, no turno da manhã. Nessa instância foram roteirizados 389 alunos. No segundo bloco, a escola E199 também representa a maior instância, porém, ao consolidar o turno da manhã com os alunos do turno integral, foram roteirizados 534 alunos. 


\subsubsection{2 Testes experimentais}

A primeira rodada do ILS com os dados da SEEDUC foi realizada com todas as instâncias disponibilizadas para calibrar os parâmetros a serem utilizados. Foram utilizadas 10 sementes para cada instância. A Tabela 4.3 apresenta os parâmetros utilizados nos testes e os resultados obtidos. A coluna SA apresenta os percentuais utilizados no critério de aceitação, onde 0,5 - 0,01 significa que o algoritmo inicia com $50 \%$ de chances de aceitar uma solução de até $50 \%$ de piora e essa probabilidade vai decrescendo a cada rodada até que a probabilidade de aceitação seja de 1\%. Foram considerados os intervalos de probabilidade $50 \%-1 \%, 50 \%-5 \%, 50 \%-10 \%, 35 \%-1 \%, 35 \%-5 \%$, $35 \%-10 \%, 20 \%-1 \%, 20 \%-5 \%, 20 \%-10 \%$. A coluna $N$ corresponde ao número de iterações do ILS, que também é utilizada no cálculo da taxa de resfriamento do Simulated Annealing, variando entre 50, 75 e 100. Por fim, a coluna $\mathrm{P}$ apresenta o número de movimentos considerados na perturbação, que foi fixado em 5 .

Em seguida, são apresentados na tabela o menor custo total obtido entre todas as instâncias consideradas, o maior custo total e a média dos custos. Os experimentos mostraram que os melhores resultados foram obtidos com 100 iterações e as seguintes probabilidades de aceitação: $50 \%-1 \%, 20 \%-1 \%$ e $20 \%-5 \%$.

Uma nova rodada foi realizada pera verificar o impacto da variação do número de movimentos da perturbação nos resultados, sendo considerados 1 , 3, 5, 7 e 9 movimentos. Como os resultados obtidos foram iguais em 3 cenários considerados, foi escolhido executar a nova rodada considerando a variação da probabilidade de aceitação entre $50 \%$ e 1\%. A escolha desta configuração foi feita buscando obter maior diversificação nas primeiras rodadas do algoritmo. A Tabela 4.4 mostra que a melhor solução considerando a média dos resultados foi obtida com 5 movimentos.

\subsubsection{3}

\section{Aplicação}

Para comparação dos resultados, foram selecionadas 79 rotas que tiveram os dados disponibilizados pela SEEDUC. Para esses casos, foram obtidas as informações de estudantes alocados em cada rota, escola, turno, veículo utilizado, quilometragem total e custo da rota. As rotas foram agrupadas em combinações de escola e turno, com o objetivo de comparar o número de rotas utilizadas pela SEEDUC e o número proposto pelo ILS. O apêndice $\mathrm{C}$ mostra os valores das rotas utilizadas pela SEEDUC e os valores obtidos 
Tabela 4.3: Testes experimentais

\begin{tabular}{|c|c|c|c|c|c|c|}
\hline$\#$ & SA & $\mathbf{N}$ & $\mathbf{P}$ & Min & $\operatorname{Max}$ & Mean \\
\hline 1 & $0.5-0.01$ & 50 & 5 & 201.1200 & 244.9550 & 218.4595 \\
\hline 2 & $0.5-0.01$ & 75 & 5 & 200.6237 & 242.5026 & 216.9872 \\
\hline 3 & $0.5-0.01$ & 100 & 5 & 200.3087 & 240.8798 & 216.0157 \\
\hline 4 & $0.5-0.05$ & 50 & 5 & 201.1294 & 245.0993 & 218.5094 \\
\hline 5 & $0.5-0.05$ & 75 & 5 & 200.6237 & 242.5026 & 216.9872 \\
\hline 6 & $0.5-0.05$ & 100 & 5 & 200.3195 & 240.9210 & 216.0548 \\
\hline 7 & $0.5-0.1$ & 50 & 5 & 201.1178 & 245.0261 & 218.4878 \\
\hline 8 & $0.5-0.1$ & 75 & 5 & 200.6237 & 242.5026 & 216.9872 \\
\hline 9 & $0.5-0.1$ & 100 & 5 & 200.3195 & 240.9210 & 216.0548 \\
\hline 10 & $0.35-0.01$ & 50 & 5 & 201.1078 & 245.0238 & 218.4706 \\
\hline 11 & $0.35-0.01$ & 75 & 5 & 200.6237 & 242.5026 & 216.9872 \\
\hline 12 & $0.35-0.01$ & 100 & 5 & 200.3195 & 240.9210 & 216.0548 \\
\hline 13 & $0.35-0.05$ & 50 & 5 & 201.1294 & 245.0993 & 218.5094 \\
\hline 14 & $0.35-0.05$ & 75 & 5 & 200.6237 & 242.5026 & 216.9872 \\
\hline 15 & $0.35-0.05$ & 100 & 5 & 200.3195 & 240.9210 & 216.0548 \\
\hline 16 & $0.35-0.10$ & 50 & 5 & 201.1076 & 244.9542 & 218.4509 \\
\hline 17 & $0.35-0.10$ & 75 & 5 & 200.6237 & 242.5026 & 216.9872 \\
\hline 18 & $0.35-0.10$ & 100 & 5 & 200.3195 & 240.9210 & 216.0548 \\
\hline 19 & $0.20-0.01$ & 50 & 5 & 201.1076 & 244.9542 & 218.4488 \\
\hline 20 & $0.20-0.01$ & 75 & 5 & 200.6237 & 242.5026 & 216.9872 \\
\hline 21 & $0.20-0.01$ & 100 & 5 & 200.3087 & 240.8798 & 216.0157 \\
\hline 22 & $0.20-0.05$ & 50 & 5 & 201.1291 & 245.0771 & 218.4984 \\
\hline 23 & $0.20-0.05$ & 75 & 5 & 200.6345 & 242.5105 & 216.9953 \\
\hline 24 & $0.20-0.05$ & 100 & 5 & 200.3087 & 240.8798 & 216.0157 \\
\hline 25 & $0.20-0.10$ & 50 & 5 & 201.1076 & 244.9542 & 218.4509 \\
\hline 26 & $0.20-0.10$ & 75 & 5 & 200.6237 & 242.5026 & 216.9872 \\
\hline 27 & $0.20-0.10$ & 100 & 5 & 200.3195 & 240.921 & 216.0548 \\
\hline
\end{tabular}


Tabela 4.4: Testes experimentais - perturbação

\begin{tabular}{ccccccc}
\hline$\#$ & SA & $\mathbf{N}$ & $\mathbf{P}$ & Min & Max & Mean \\
\hline $\mathbf{1}$ & $0.5-0.01$ & 100 & 1 & 200.299 & 250.374 & 219.616 \\
\hline $\mathbf{2}$ & $0.5-0.01$ & 100 & 3 & 199.624 & 242.913 & 216.468 \\
\hline $\mathbf{3}$ & $\mathbf{0 . 5 - 0 . 0 1}$ & $\mathbf{1 0 0}$ & $\mathbf{5}$ & $\mathbf{2 0 0 . 3 0 9}$ & $\mathbf{2 4 0 . 8 8 0}$ & $\mathbf{2 1 6 . 0 1 6}$ \\
\hline $\mathbf{4}$ & $0.5-0.01$ & 100 & 7 & 200.993 & 240.784 & 216.717 \\
\hline $\mathbf{5}$ & $0.5-0.01$ & 100 & 9 & 201.594 & 240.207 & 216.924 \\
\hline \multicolumn{6}{c}{ Fonte: Autora, 2021. }
\end{tabular}

com a metaheurística. A coluna $\mathrm{N}^{\mathrm{or}}$ indica o número de rotas presentes na escola/turno. A coluna $\mathrm{Km}^{\mathrm{t}}$, apresenta a quilometragem total das rotas. Em seguida são apresentados o número de alunos alocados nas rotas. A coluna Capac $^{\mathrm{t}}$, mostra o total da capacidade dos veículos utilizados nas rotas e, por fim, a coluna $\mathrm{C}^{\mathrm{t}}$, indica o custo total das rotas.

Para os resultados do ILS, foi considerado o custo total médio das soluções e, a partir do custo, procurou-se a solução mais próxima desse valor para obter a informação de capacidade total dos veículos, número de alunos, rotas e quilometragem total. No apêndice C, foi colocado em negrito os custos das soluções em que o ILS obteve menores resultados.

O apêndice D apresenta para cada instância a quilometragem média por aluno e o percentual de ocupação dos veículos considerando as rotas utilizadas pela SEEDUC e os resultados do ILS. As Figuras 4.3 e 4.4 apresentam a comparação entre o número de rotas, quilometragem média, custo médio, quilometragem média por aluno e percentual de ocupação dos veículos. O ILS obteve custos mais baixos em $84 \%$ dos casos e, considerando todos os cenários, o custo médio das rotas passa de $\mathrm{R} \$ 136,91$ para $\mathrm{R} \$ 81,33$, uma redução de 40,5\%. O número de rotas e, portanto, o número de veículos necessários, diminuiu 8,8\%, passando de 79 para 72 rotas. A quilometragem média das rotas diminuiu $44 \%$ e a quilometragem média por aluno reduziu em $46 \%$. Por fim, o percentual de ocupação dos veículos aumentou de $68 \%$ para $73 \%$, indicando uma melhor utilização da frota.

Para os casos em que o ILS não retornou um custo menor que o valor original, a maior diferença foi observada na instância E164_M com um aumento de $10 \%$ na quilometragem total, aproximadamente $16 \mathrm{~km}$. Em relação ao custo total, o aumento foi de $5 \%$.

A comparação entre os resultados apresentados pelo ILS e as rotas originais da SEEDUC, mostram o potencial do método utilizado, cumprindo o objetivo de fornecer redução de custo considerando restrições importantes para 


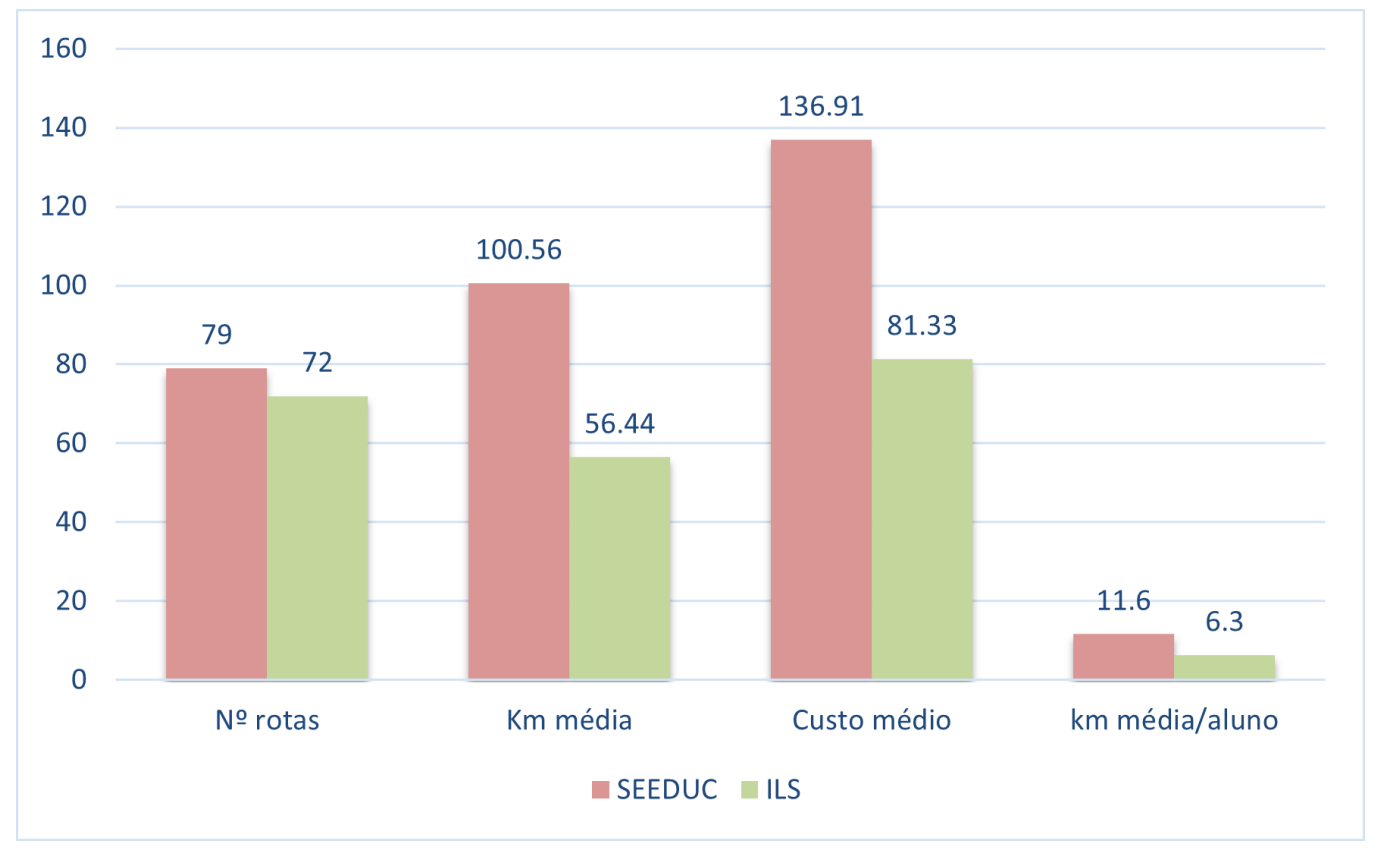

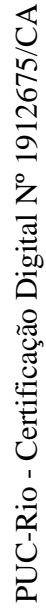

Figura 4.3: Indicadores de desempenho Fonte: Autora, 2021.

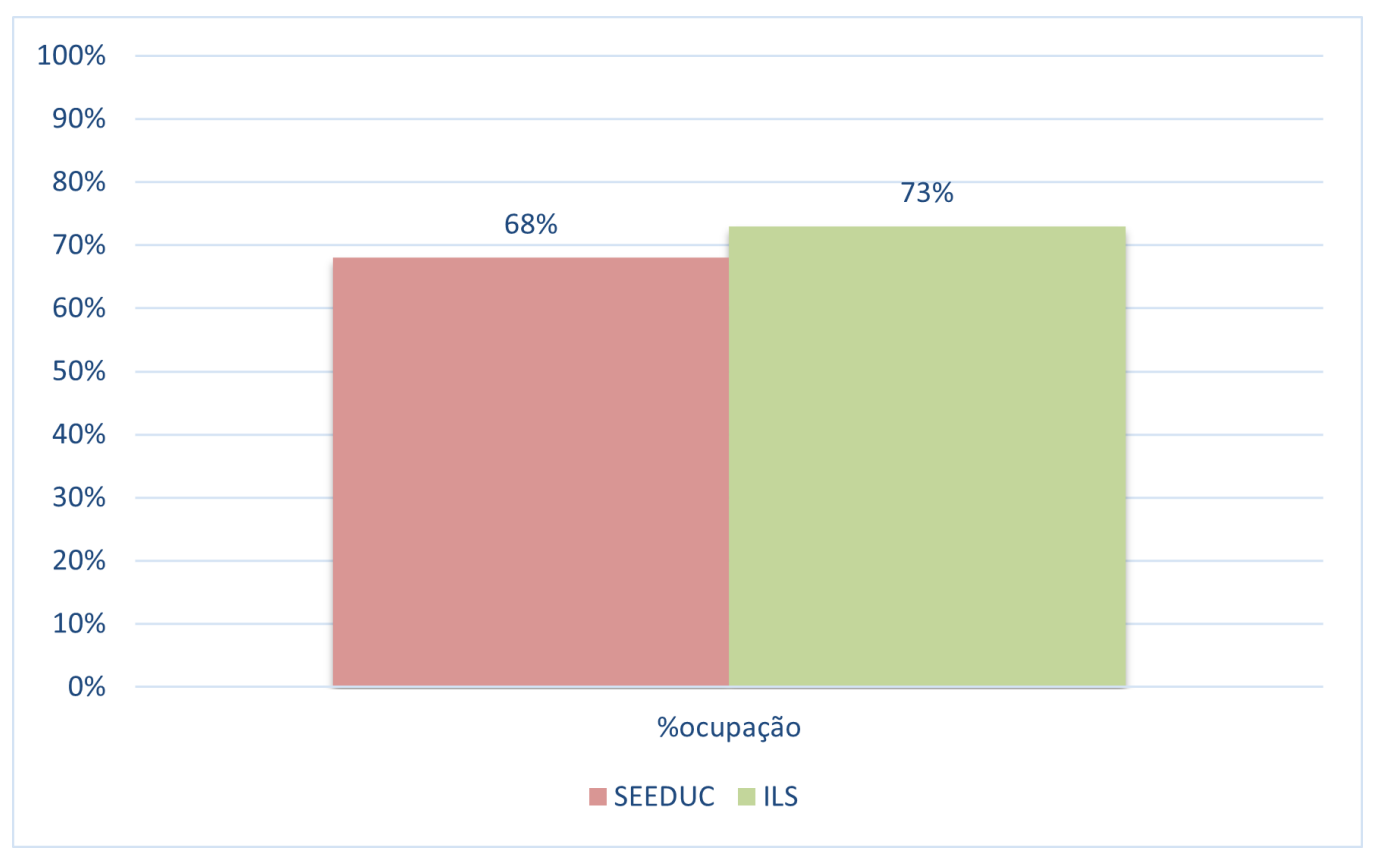

Figura 4.4: Indicador de ocupação

Fonte: Autora, 2021. 
garantir o conforto e segurança dos alunos, como: redução da quilometragem média por aluno e a não utilização de veículos acima de $100 \%$ da ocupação.

Com a validação dos resultados, o método foi aplicado para todas as instâncias. O apêndice E apresenta os resultados obtidos nas 1.012 instâncias. A primeira coluna apresenta a descrição da instância, composta pelo número da escola, turno e direção da rota. A coluna Custo Melhor apresenta o melhor custo obtido entre as 10 sementes utilizadas para cada instância. Em seguida é apresentado o custo médio, considerando as soluções obtidas em todas as 10 sementes e, na quarta coluna, o desvio do custo que é a diferença percentual entre o melhor custo e o custo médio. A coluna 5 traz a informação de número de rotas necessárias, seguida pelo número de alunos alocados nas rotas, a capacidade total dos veículos utilizados e o percentual de ocupação dos veículos. Assim como o custo, são apresentadas a melhor distância, distância média e o desvio. Por fim, para cada instância há o tempo médio para obtenção da solução em segundos.

A Figura 4.5 traz a representação do custo médio por município através de um mapa de calor. O município com menor custo médio foi São Gonçalo, com $\mathrm{R} \$ 3,92$ e o município com maior custo foi Varre-Sai com $\mathrm{R} \$ 1.272,63$. Pelo mapa, nota-se uma concentração dos municípios com maior custo médio no noroeste fluminense.

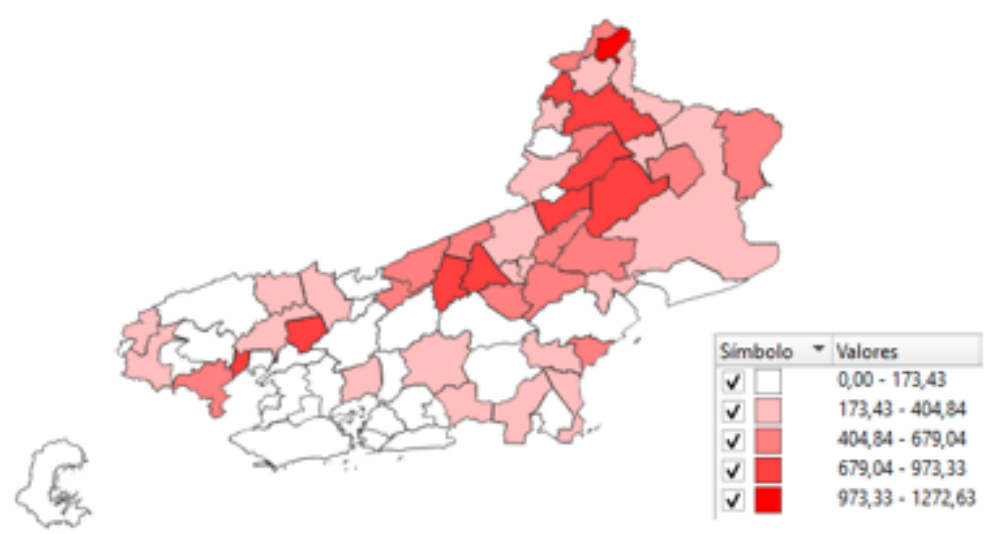

Figura 4.5: Mapa de calor com o custo médio por rota Fonte: Autora, 2021.

A Figura 4.6 traz a representação da quilometragem média por aluno em cada município. O município com menor indicador foi Três Rios, com 0,78 $\mathrm{km} /$ aluno e o município com o maior indicador foi Barra Mansa com 133,8 km/aluno. A ocupação média é representada na Figura 4.7. Os municípios com menor ocupação estão concentrados na região metropolitana, como Rio de Janeiro, Duque de Caxias e Nova Iguaçu, com 12,5\% de ocupação. Nota-se 
uma maior concentração de municípios com percentual de ocupação acima de $72 \%$ nas regiões Noroeste Fluminense e Serrana.

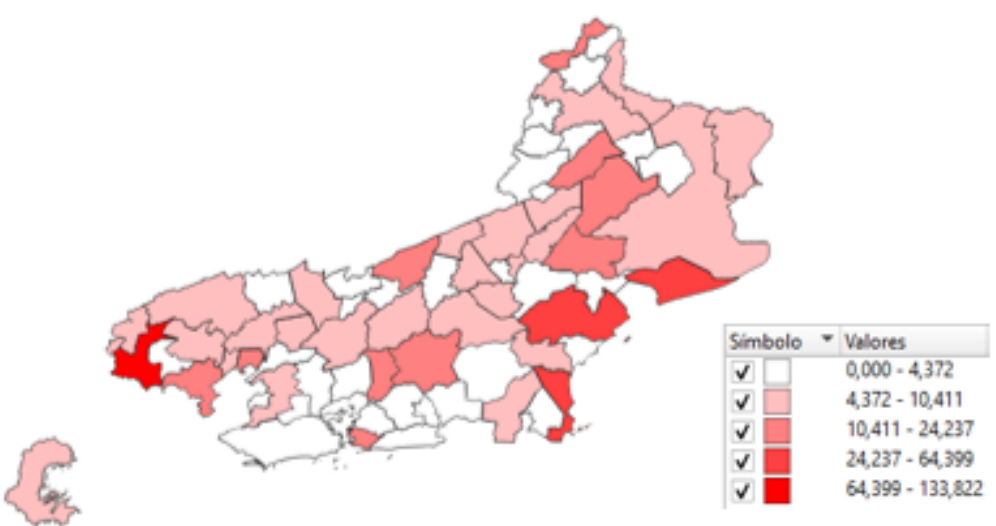

Figura 4.6: Mapa de calor com a quilometragem média por aluno Fonte: Autora, 2021.

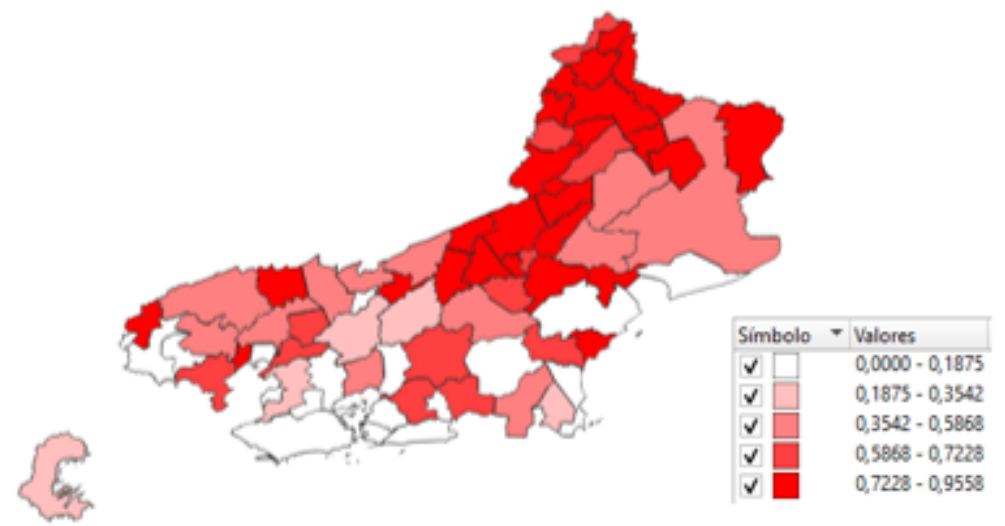

Figura 4.7: Mapa de calor com a ocupação média das rotas Fonte: Autora, 2021.

Analisando os tempos computacionais, a Figura 4.8 traz a curva do tempo médio computacional das instâncias de acordo com o número de alunos roteados. Observa-se que os resultados para instâncias com até 292 alunos foram obtidos em até 52 segundos, em média. A partir da instância com 292 alunos, o gráfico mostra um aumento exponencial no tempo computacional. Ainda assim, para a maior instância, com 534 alunos, os resultados foram obtidos em até 207 segundos (3,45 minutos). Nota-se então que, para o contexto de planejamento e definição das rotas, os resultados foram obtidos em baixo tempo computacional, não inviabilizando a aplicação do método.

Concluídas as etapas do método proposto, o estudo cumpriu seu objetivo de minimizar o custo total das rotas utilizadas no transporte escolar rural do estado do Rio de Janeiro. As restrições do cenário de aplicação foram 


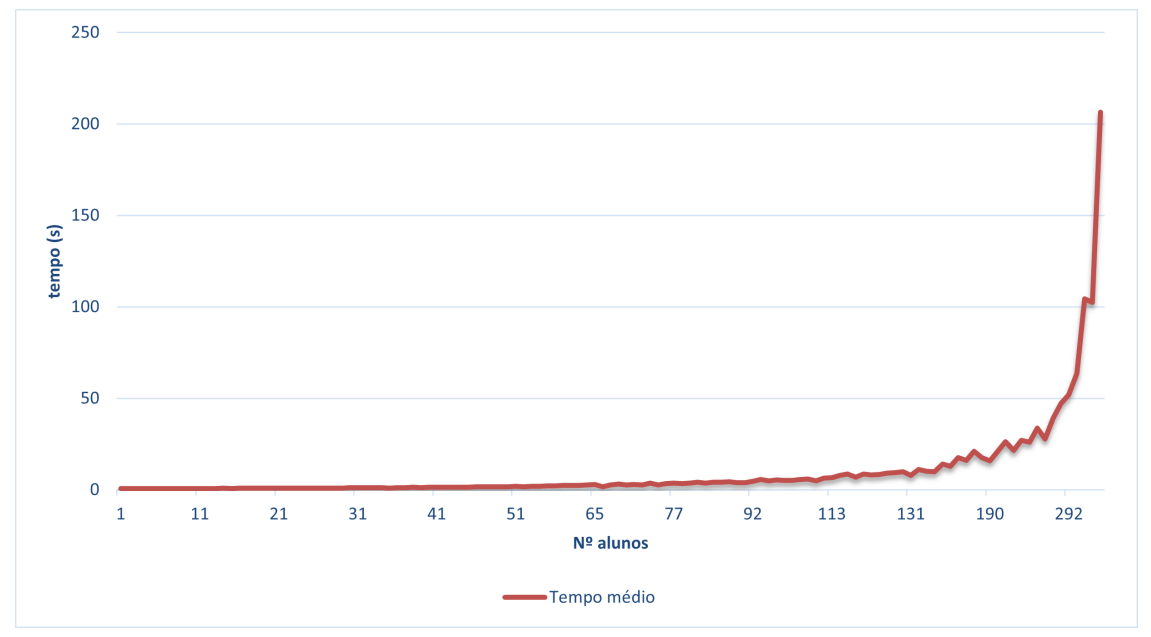

Figura 4.8: Média de tempo computacional de acordo com o número de alunos na rota

Fonte: Autora, 2021.

respeitadas e os resultados indicaram uma melhora no nível de serviço para os estudantes com a redução da quilometragem média por rota e por aluno. 


\section{5 \\ Conclusão}

Esta dissertação teve como objetivo principal aplicar o Iterated Local Search para definir as rotas do transporte escolar rural no estado do Rio de Janeiro. Para isso, analisou-se os dados de localização dos alunos e escolas fornecidos pela SEEDUC-RJ e, após tratamento dos dados, o método foi aplicado para o roteamento de 13.664 alunos.

O SBRP se assemelha a um OVRP, com restrição de capacidade, frota heterogênea e demanda determinística. Considerando os critérios de classificação do SBRP, o caso de aplicação tem como sub-problema a geração de rotas, com escola única, uma vez que o roteamento é feito por escola, não permitindo carregamento misto. Além disso, os dados utilizados são de áreas rurais, que possuem como característica a baixa densidade populacional, resultando em maiores distâncias entre as residências e as unidades escolares. Dessa forma, além da capacidade do veículo, também foi utilizada como restrição do problema a distância máxima a ser percorrida.

Os dados de 79 rotas reais foram disponibilizados pela SEEDUC, permitindo a comparação com os resultados da aplicação do ILS. Os resultados apresentaram uma redução de 8,8\% no número de veículos necessários. A redução do custo médio das rotas foi de 40,5\% e a quilometragem média por aluno reduziu em 46\%. Com a validação do método, o algoritmo foi aplicado para a totalidade dos dados, considerando 1.012 instâncias. Observou-se uma concentração dos municípios com maior custo na região noroeste do estado. Com relação à quilometragem média por aluno, o município com maior indicador foi Barra Mansa com 133,8 km/aluno.

Conclui-se, portanto, que o algoritmo utilizado fornece, em baixo tempo computacional, resultados que podem ser avaliados pela SEEDUC-RJ como alternativas para reformulação das rotas do transporte escolar rural, trazendo ganhos financeiros e aumentando o nível de serviço para os alunos.

Sugere-se como trabalhos futuros a consideração de diferentes cenários de características do problema, como múltiplas escolas e carregamento misto. Caso as variações sejam realizadas utilizando o mesmo conjunto de dados deste estudo, há a possibilidade da apresentação de análises comparativas. Além disso, indica-se a variação dos parâmetros utilizados no ILS, incluindo: 
estratégias de busca local e perturbação. 


\section{Referências bibliográficas}

Alabas-Uslu, C. (2008). A self-tuning heuristic for a multi-objective vehicle routing problem. Journal of the Operational Research Society, 59(7):988-996.

Almeida, L. d. M. G. e Sampaio, J. A. L. (2019). Os direitos sociais sob o crivo da austeridade: Breves reflexões sobre as consequências das medidas de cortes na educação, saúde e previdência. Revista de Direitos Sociais, Seguridade e Previdência Social, 5(2):23-44.

Alvarez, A., Munari, P., e Morabito, R. (2018). Iterated local search and simulated annealing algorithms for the inventory routing problem. International Transactions in Operational Research, 25(6):1785-1809.

Avilés-González, J. F., Mora-Vargas, J., Smith, N. R., e Cedillo-Campos, M. G. (2020). Artificial intelligence and doe: an application to school bus routing problems. Wireless Networks, 26(7):4975-4983.

Babaei, M. e Rajabi-Bahaabadi, M. (2019). School bus routing and scheduling with stochastic time-dependent travel times considering on-time arrival reliability. Computers \& Industrial Engineering, 138:106125.

Bektaș, T. e Elmastaș, S. (2007). Solving school bus routing problems through integer programming. Journal of the Operational Research Society, 58(12):15991604.

Blum, C. e Roli, A. (2003). Metaheuristics in combinatorial optimization: Overview and conceptual comparison. ACM COMPUTING SURVEYS, pages 268-308.

Bögl, M., Doerner, K. F., e Parragh, S. N. (2015). The school bus routing and scheduling problem with transfers. Networks, 65(2):180-203.

Braekers, K., Ramaekers, K., e Van Nieuwenhuyse, I. (2016). The vehicle routing problem: State of the art classification and review. Computers \& Industrial Engineering, 99:300-313.

Brasil (2012). Guia do Transporte Escolar. Ministério da Educação.

Caceres, H., Batta, R., e He, Q. (2017). School bus routing with stochastic demand and duration constraints. Transportation science, 51(4):1349-1364. 
Calvete, H. I., Galé, C., Iranzo, J. A., e Toth, P. (2020). A partial allocation local search matheuristic for solving the school bus routing problem with bus stop selection. Mathematics, 8(8):1214.

Calvete, H. I., Galé, C., Iranzo, J. A., e Toth, P. (2021). The school bus routing problem with student choice: a bilevel approach and a simple and effective metaheuristic. International Transactions in Operational Research.

Carvalho, W. L., da Cruz, R. O. M., Câmara, M. T., e de Aragão, J. J. G. (2010). Rural school transportation in emerging countries: The brazilian case. Research in transportation economics, 29(1):401-409.

CEPERJ, F. (2019). População residente por situação do domicílio. estado do rio de janeiro e seus municípios - 1970 a 2010.

Chalkia, E., Salanova Grau, J. M., Bekiaris, E., Ayfandopoulou, G., Ferarini, C., e Mitsakis, E. (2016). Safety bus routing for the transportation of pupils to school. Traffic Safety, 4:283-299.

Chen, X., Kong, Y., Dang, L., Hou, Y., e Ye, X. (2015). Exact and metaheuristic approaches for a bi-objective school bus scheduling problem. PloS one, 10(7):e0132600.

Dang, L.-X., Hou, Y.-e., Liu, Q.-s., e Kong, Y.-f. (2019). A hybrid metaheuristic algorithm for the bi-objective school bus routing problem. IAENG International Journal of Computer Science, 46(3).

de Souza Lima, F. M. (2015). A mixed load rural school bus routing problem with heterogeneous fleet: a study for the brazilian problem.

do Nascimento, F. P. e Sousa, F. L. L. (2017). Metodologia da pesquisa científica: teoria e prática. INESP.

Elgarej, M., Mansouri, K., e Youssfi, M. (2017). Route optimization for school bus scheduling problem based on a distributed ant colony system algorithm. In 2017 Intelligent Systems and Computer Vision (ISCV), pages 1-8. IEEE.

Ellegood, W. A., Solomon, S., North, J., e Campbell, J. F. (2019). School bus routing problem: Contemporary trends and research directions. Omega, 95:102056.

Gendreau, M. e Potvin, J.-Y. (2005). Metaheuristics in combinatorial optimization. Annals of Operations Research, 140(1):189-213. 
Hou, Y.-E., Dang, L., Dong, W., e Kong, Y. (2020a). A metaheuristic algorithm for routing school buses with mixed load. IEEE Access, 8:158293-158305.

Hou, Y.-e., Dang, L., Kong, Y., Wang, Z., e Zhao, Q. (2020b). A hybrid metaheuristic algorithm for the heterogeneous school bus routing problem and a real case study. IAENG International Journal of Computer Science, 47(4).

IBGE (2020). Rio de janeiro.

Idoeta, P. A. e Magenta, M. (2019). Transporte escolar, livros didáticos e outros programas: o impacto do corte de gastos na educação básica. BBC News Brasil.

Jaradat, A. S. (2020). Solving school bus routing problem by intelligent water drops algorithm. International journal of trends in computer science, (2).

Johnson, D. S., Papadimitriou, C. H., e Yannakakis, M. (1988). How easy is local search? Journal of computer and system sciences, 37(1):79-100.

Kirkpatrick, S., Gelatt Jr, C. D., e Vecchi, M. P. (1987). Optimization by simulated annealing. In Readings in Computer Vision, pages 606-615. Elsevier.

Laporte, G. (1992). The vehicle routing problem: An overview of exact and approximate algorithms. European journal of operational research, 59(3):345358.

Lenstra, J. K. e Kan, A. R. (1981). Complexity of vehicle routing and scheduling problems. Networks, 11(2):221-227.

Lewis, R. e Smith-Miles, K. (2018). A heuristic algorithm for finding costeffective solutions to real-world school bus routing problems. Journal of Discrete Algorithms, 52:2-17.

López Santana, E. R. e Romero Carvajal, J. d. J. (2015). A hybrid column generation and clustering approach to the school bus routing problem with time windows. Ingeniería, 20(1):101-117.

Lourenco, H. R., Martin, O., e Stutzle, T. (2003). Iterated local search. handbook of metaheuristics. f. glover and $g$. kochenberger.

Lourenço, H. R., Martin, O. C., e Stützle, T. (2019). Iterated local search: Framework and applications. In Handbook of metaheuristics, pages 129-168. Springer.

Lysgaard, J., López-Sánchez, A. D., e Hernández-Díaz, A. G. (2020). A matheuristic for the minmax capacitated open vehicle routing problem. International Transactions in Operational Research, 27(1):394-417. 
Minocha, B. e Tripathi, S. (2014). Solving school bus routing problem using hybrid genetic algorithm: a case study. In Proceedings of the Second International Conference on Soft Computing for Problem Solving (SocProS 2012), December 28-30, 2012, pages 93-103. Springer.

Mladenović, N. e Hansen, P. (1997). Variable neighborhood search. Computers \& operations research, 24(11):1097-1100.

Newton, R. M. e Thomas, W. H. (1969). Design of school bus routes by computer. Socio-Economic Planning Sciences, 3(1):75-85.

Oudouar, F. e El Miloud, Z. (2019). A hybrid heuristic for vehicle routing problem. In Proceedings of the 4th International Conference on Big Data and Internet of Things, pages $1-5$.

Park, J. e Kim, B.-I. (2010). The school bus routing problem: A review. European Journal of operational research, 202(2):311-319.

Parvasi, S. P., Mahmoodjanloo, M., e Setak, M. (2017). A bi-level school bus routing problem with bus stops selection and possibility of demand outsourcing. Applied Soft Computing, 61:222-238.

Parvasi, S. P., Tavakkoli-Moghaddam, R., Taleizadeh, A. A., e Soveizy, M. (2019). A bi-level bi-objective mathematical model for stop location in a school bus routing problem. IFAC-PapersOnLine, 52(13):1120-1125.

Pisinger, D. e Ropke, S. (2007). A general heuristic for vehicle routing problems. Computers \& operations research, 34(8):2403-2435.

Porto, M. F., Sarubbi, J. F. M., Thiéry, S., da Silva, C. M., Nunes, N. T. R., e de Carvalho, I. R. V. (2015). Developing a gis for rural school transportation in minas gerais, brazil. In 6th International Multi-Conference on Complexity, Informatics and Cybernetics, IMCIC 2015 and 6th International Conference on Society and Information Technologies, ICSIT 2015-Proceedings, volume 1, pages 62-67. Citeseer.

Ramser, G. D. J. et al. (1959). The truck dispatching problem. Management Science, 6(1):80-91.

Rashidi, T. H., Zokaei-Aashtiani, H., e Mohammadian, A. (2009). School bus routing problem in large-scale networks: New approach utilizing tabu search on a case study in developing countries. Transportation research record, 2137(1):140147. 
Riera-Ledesma, J. e Salazar-González, J. J. (2013). A column generation approach for a school bus routing problem with resource constraints. Computers \& Operations Research, 40(2):566-583.

Rodríguez-Parra, G. R., Guerrero, W. J., e Sarmiento-Lepesqueur, A. (2017). Cooperation strategies featuring optimization in the school transportation system in bogota. Dyna, 84(202):164-174.

Rosa, B. A. B. (2018a). SEEDUC - Escolas Estaduais. encurtador.com.br/ciR48. Acessado em 15 jan. 2021.

Rosa, B. A. B. (2018b). Uma metodologia para roteamento de veículos escolares utilizando sistemas de informação geográfica. Dissertação (Mestrado em Engenharia Elétrica), PUC-Rio.

Shafahi, A., Aliari, S., e Haghani, A. (2018). Balanced scheduling of school bus trips using a perfect matching heuristic. Transportation Research Record, 2672(48):1-11.

Toth, P. e Vigo, D. (2002). The vehicle routing problem. SIAM.

Ümit, Ü. G. e Kılıç, F. (2019). A school bus routing problem using genetic algorithm by reducing the number of buses. In 2019 Innovations in Intelligent Systems and Applications Conference (ASYU), pages 1-6. IEEE.

Vidal, T., Battarra, M., Subramanian, A., e Erdoğan, G. (2015). Hybrid metaheuristics for the clustered vehicle routing problem. Computers \& Operations Research, 58:87-99.

Yan, S., Hsiao, F.-Y., e Chen, Y.-C. (2015). Inter-school bus scheduling under stochastic travel times. Networks and Spatial Economics, 15(4):1049-1074.

Yigit, T., Unsal, O., e Deperlioglu, O. (2018). Using the metaheuristic methods for real-time optimisation of dynamic school bus routing problem and an application. International Journal of Bio-Inspired Computation, 11(2):123-133.

Žerovnik, J. (2015). Heuristics for np-hard optimization problems: simpler is better!? Logistics \& Sustainable Transport, 6(1):1-10. 
A

Número de alunos matriculados por turno em cada município

\begin{tabular}{|c|c|c|}
\hline Municipio & Turno & No alunos \\
\hline \multirow{4}{*}{ APERIBÉ } & INTEGRAL & 23 \\
\hline & MANHÃ & 41 \\
\hline & NOITE & 19 \\
\hline & TARDE & 30 \\
\hline APERIBÉ Total & & 113 \\
\hline \multirow{3}{*}{ ARARUAMA } & INTEGRAL & 17 \\
\hline & MANHÃ & 120 \\
\hline & NOITE & 37 \\
\hline \multicolumn{2}{|l|}{ ARARUAMA Total } & 174 \\
\hline AREAL & NOITE & 1 \\
\hline \multicolumn{2}{|l|}{ AREAL Total } & 1 \\
\hline \multirow{3}{*}{ BARRA DO PIRAÍ } & MANHÃ & 24 \\
\hline & NOITE & 1 \\
\hline & TARDE & 15 \\
\hline \multicolumn{2}{|l|}{ BARRA DO PIRAÍ Total } & 40 \\
\hline BARRA MANSA & NOITE & 1 \\
\hline \multicolumn{2}{|l|}{ BARRA MANSA Total } & 1 \\
\hline BOM JARDIM & NOITE & 36 \\
\hline \multicolumn{2}{|l|}{ BOM JARDIM Total } & 36 \\
\hline \multirow{4}{*}{ BOM JESUS DO ITABAPOANA } & INTEGRAL & 34 \\
\hline & MANHÃ & 185 \\
\hline & NOITE & 112 \\
\hline & TARDE & 104 \\
\hline \multicolumn{2}{|c|}{ BOM JESUS DO ITABAPOANA Total } & 435 \\
\hline
\end{tabular}




\begin{tabular}{|c|c|c|}
\hline & TARDE & 1 \\
\hline CABO FRIO Total & & 3 \\
\hline \multirow{4}{*}{ CACHOEIRAS DE MACACU } & INTEGRAL & 24 \\
\hline & MANHÃ & 124 \\
\hline & NOITE & 12 \\
\hline & TARDE & 20 \\
\hline \multicolumn{2}{|c|}{ CACHOEIRAS DE MACACU Total } & 180 \\
\hline \multirow{4}{*}{ CAMBUCÍ } & INTEGRAL & 50 \\
\hline & MANHÃ & 71 \\
\hline & NOITE & 48 \\
\hline & TARDE & 59 \\
\hline \multicolumn{2}{|l|}{ CAMBUCÍ Total } & 228 \\
\hline \multirow{4}{*}{ CAMPOS DOS GOYTACAZES } & INTEGRAL & 20 \\
\hline & MANHÃ & 437 \\
\hline & NOITE & 143 \\
\hline & TARDE & 190 \\
\hline \multicolumn{2}{|c|}{ CAMPOS DOS GOYTACAZES Total } & 790 \\
\hline \multirow{4}{*}{ CANTAGALO } & INTEGRAL & 22 \\
\hline & MANHÃ & 80 \\
\hline & NOITE & 39 \\
\hline & TARDE & 61 \\
\hline \multicolumn{2}{|l|}{ CANTAGALO Total } & 202 \\
\hline \multirow{3}{*}{ CARDOSO MOREIRA } & INTEGRAL & 57 \\
\hline & MANHÃ & 223 \\
\hline & NOITE & 46 \\
\hline \multicolumn{2}{|l|}{ CARDOSO MOREIRA Total } & 326 \\
\hline \multirow{4}{*}{ CARMO } & INTEGRAL & 80 \\
\hline & MANHÃ & 208 \\
\hline & NOITE & 6 \\
\hline & TARDE & 2 \\
\hline \multicolumn{2}{|l|}{ CARMO Total } & 296 \\
\hline \multirow{3}{*}{ CASIMIRO DE ABREU } & INTEGRAL & 56 \\
\hline & MANHÃ & 143 \\
\hline & NOITE & 6 \\
\hline
\end{tabular}


Apêndice A. Número de alunos matriculados por turno em cada município 64

\begin{tabular}{|c|c|c|}
\hline \multicolumn{2}{|c|}{ CASIMIRO DE ABREU Total } & 205 \\
\hline \multirow{3}{*}{ CONCEIÇÃO DE MACABU } & INTEGRAL & 26 \\
\hline & MANHÃ & 124 \\
\hline & TARDE & 44 \\
\hline \multicolumn{2}{|c|}{ CONCEIÇÃO DE MACABU Total } & 194 \\
\hline \multirow{4}{*}{ CORDEIRO } & INTEGRAL & 60 \\
\hline & MANHÃ & 48 \\
\hline & NOITE & 8 \\
\hline & TARDE & 17 \\
\hline \multicolumn{2}{|l|}{ CORDEIRO Total } & 133 \\
\hline \multirow{4}{*}{ DUAS BARRAS } & INTEGRAL & 12 \\
\hline & MANHÃ & 104 \\
\hline & NOITE & 7 \\
\hline & TARDE & 105 \\
\hline \multicolumn{2}{|l|}{ DUAS BARRAS Total } & 228 \\
\hline DUQUE DE CAXIAS & MANHÃ & 1 \\
\hline \multicolumn{2}{|l|}{ DUQUE DE CAXIAS Total } & 1 \\
\hline ENGENHEIRO PAULO DE FRONTIN & TARDE & 1 \\
\hline \multicolumn{2}{|c|}{ ENGENHEIRO PAULO DE FRONTIN Total } & 1 \\
\hline GUAPIMIRIM & TARDE & 1 \\
\hline \multicolumn{2}{|l|}{ GUAPIMIRIM Total } & 1 \\
\hline \multirow{2}{*}{ ITABORAÍ } & MANHÃ & 16 \\
\hline & TARDE & 10 \\
\hline \multicolumn{2}{|l|}{ ITABORAÍ Total } & 26 \\
\hline \multirow{4}{*}{ ITALVA } & INTEGRAL & 18 \\
\hline & MANHÃ & 65 \\
\hline & NOITE & 16 \\
\hline & TARDE & 38 \\
\hline \multicolumn{2}{|l|}{ ITALVA Total } & 137 \\
\hline \multirow{4}{*}{ ITAOCARA } & INTEGRAL & 55 \\
\hline & MANHÃ & 335 \\
\hline & NOITE & 53 \\
\hline & TARDE & 101 \\
\hline
\end{tabular}




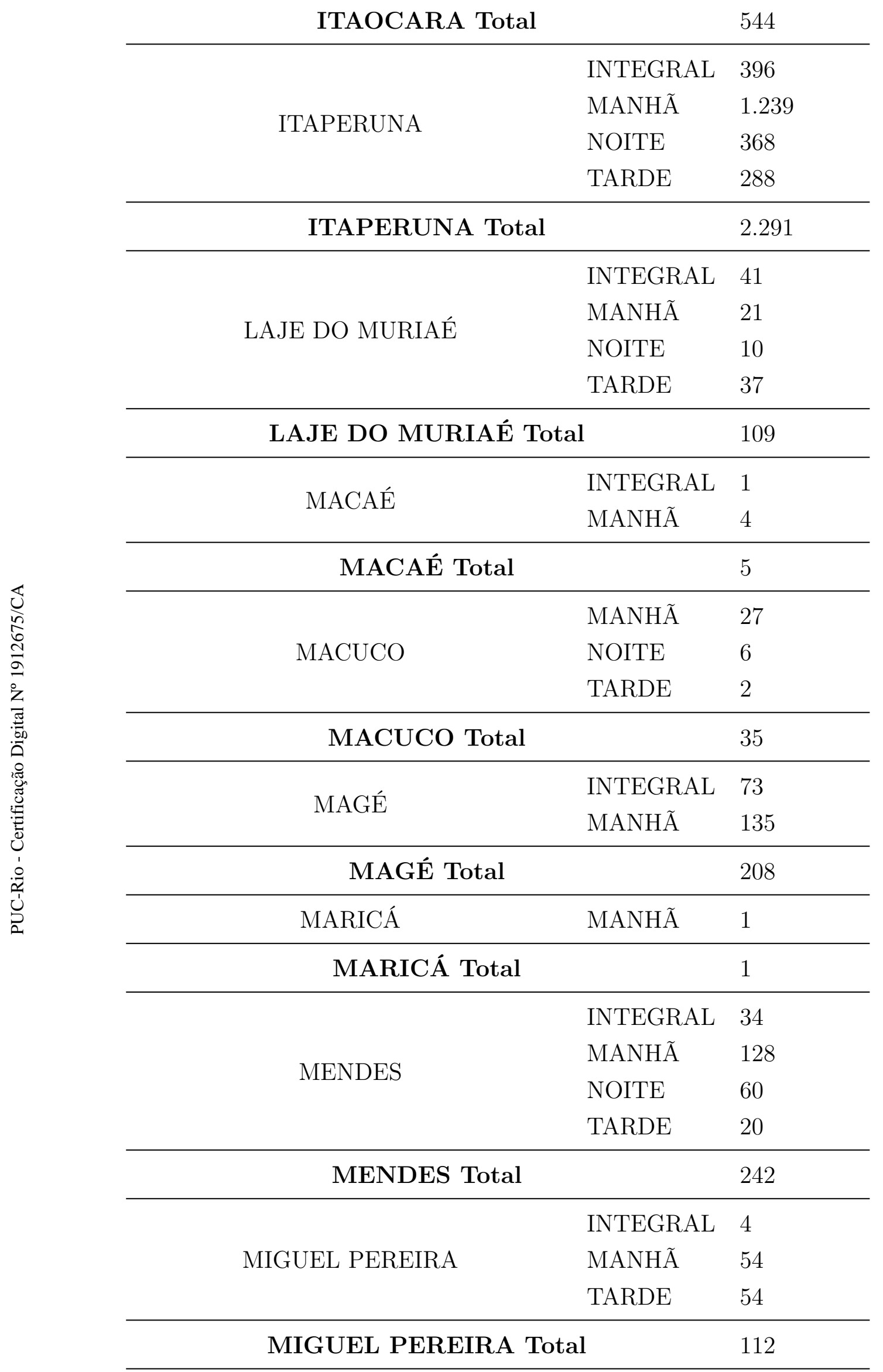

INTEGRAL 34 


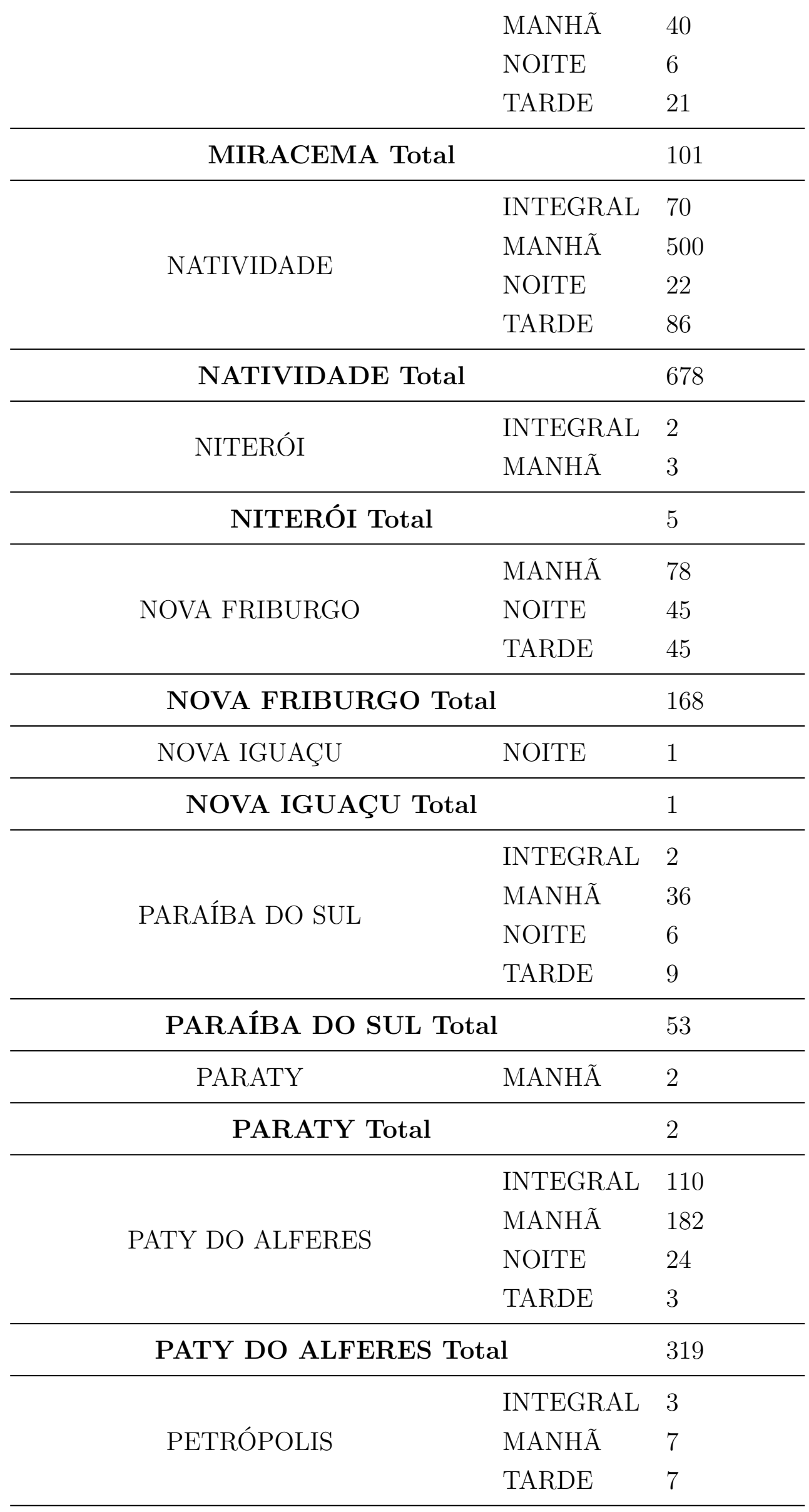




\begin{tabular}{|c|c|c|c|}
\hline & PETRÓPOLIS Total & & 17 \\
\hline & \multirow{4}{*}{ PIRAÍ } & INTEGRAL & 11 \\
\hline & & MANHÃ & 25 \\
\hline & & NOITE & 8 \\
\hline & & TARDE & 13 \\
\hline & \multicolumn{2}{|l|}{ PIRAÍ Total } & 57 \\
\hline & \multirow{4}{*}{ PORCIÚNCULA } & INTEGRAL & 16 \\
\hline & & MANHÃ & 144 \\
\hline & & NOITE & 92 \\
\hline & & TARDE & 24 \\
\hline & \multicolumn{2}{|l|}{ PORCIÚNCULA Total } & 276 \\
\hline & PORTO REAL & TARDE & 1 \\
\hline & \multicolumn{2}{|l|}{ PORTO REAL Total } & 1 \\
\hline & \multirow{3}{*}{ QUATIS } & MANHÃ & 29 \\
\hline & & NOITE & 15 \\
\hline 2 & & TARDE & 10 \\
\hline$z$ & \multicolumn{2}{|l|}{ QUATIS Total } & 54 \\
\hline & \multirow{2}{*}{ QUEIMADOS } & INTEGRAL & 1 \\
\hline 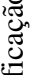 & & TARDE & 1 \\
\hline 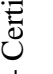 & \multicolumn{2}{|l|}{ QUEIMADOS Total } & 2 \\
\hline 0 & \multirow{2}{*}{ QUISSAMÃ } & MANHÃ & 1 \\
\hline & & NOITE & 1 \\
\hline & \multicolumn{2}{|l|}{ QUISSAMÃ Total } & 2 \\
\hline & \multirow{4}{*}{ RIO BONITO } & INTEGRAL & 27 \\
\hline & & MANHÃ & 163 \\
\hline & & NOITE & 72 \\
\hline & & TARDE & 77 \\
\hline & \multicolumn{2}{|l|}{ RIO BONITO Total } & 339 \\
\hline & \multirow{3}{*}{ RIO DAS FLORES } & INTEGRAL & 41 \\
\hline & & MANHÃ & 65 \\
\hline & & NOITE & 13 \\
\hline & \multicolumn{2}{|l|}{ RIO DAS FLORES Total } & 119 \\
\hline & RIO DAS OSTRAS & MANHÃ & 108 \\
\hline
\end{tabular}




\begin{tabular}{|c|c|c|}
\hline \multicolumn{2}{|l|}{ RIO DAS OSTRAS Total } & 108 \\
\hline \multirow{2}{*}{ RIO DE JANEIRO } & INTEGRAL & 1 \\
\hline & TARDE & 1 \\
\hline \multicolumn{2}{|l|}{ RIO DE JANEIRO Total } & 2 \\
\hline \multirow{2}{*}{ SANTA MARIA MADALENA } & INTEGRAL & 10 \\
\hline & NOITE & 7 \\
\hline \multicolumn{2}{|c|}{ SANTA MARIA MADALENA Total } & 17 \\
\hline \multirow{3}{*}{ SANTO ANTÔNIO DE PÁDUA } & INTEGRAL & 114 \\
\hline & MANHÃ & 215 \\
\hline & NOITE & 29 \\
\hline \multicolumn{2}{|c|}{ SANTO ANTÔNIO DE PÁDUA Total } & 358 \\
\hline \multirow{4}{*}{ SÃO FIDÉLIS } & INTEGRAL & 102 \\
\hline & MANHÃ & 91 \\
\hline & NOITE & 47 \\
\hline & TARDE & 4 \\
\hline \multicolumn{2}{|l|}{ SÃO FIDÉLIS Total } & 244 \\
\hline \multirow{4}{*}{ SÃO FRANCISCO DE ITABAPOANA } & INTEGRAL & 169 \\
\hline & MANHÃ & 216 \\
\hline & NOITE & 185 \\
\hline & TARDE & 15 \\
\hline \multicolumn{2}{|c|}{ SÃO FRANCISCO DE ITABAPOANA Total } & 585 \\
\hline SÃO GONÇALO & MANHÃ & 2 \\
\hline \multicolumn{2}{|l|}{ SÃO GONÇALO Total } & 2 \\
\hline \multirow{4}{*}{ SÃO JOSÉ DE UBÁ } & INTEGRAL & 23 \\
\hline & MANHÃ & 78 \\
\hline & NOITE & 50 \\
\hline & TARDE & 108 \\
\hline \multicolumn{2}{|l|}{ SÃO JOSÉ DE UBÁ Total } & 259 \\
\hline \multirow{3}{*}{ SÃO JOSÉ DO VALE DO RIO PRETO } & MANHÃ & 190 \\
\hline & NOITE & 81 \\
\hline & TARDE & 206 \\
\hline \multicolumn{2}{|c|}{ SÃO JOSÉ DO VALE DO RIO PRETO Total } & 477 \\
\hline SÃO PEDRO DA ALDEIA & NOITE & 2 \\
\hline
\end{tabular}




\begin{tabular}{|c|c|c|}
\hline \multicolumn{2}{|c|}{ SÃO PEDRO DA ALDEIA Total } & 2 \\
\hline \multirow{2}{*}{ SÃO SEBASTIÃO DO ALTO } & INTEGRAL & 9 \\
\hline & MANHÃ & 114 \\
\hline \multicolumn{2}{|c|}{ SÃO SEBASTIÃO DO ALTO Total } & 123 \\
\hline \multirow{3}{*}{ SAPUCAIA } & MANHÃ & 84 \\
\hline & NOITE & 1 \\
\hline & TARDE & 70 \\
\hline \multicolumn{2}{|l|}{ SAPUCAIA Total } & 155 \\
\hline \multirow{4}{*}{ SUMIDOURO } & INTEGRAL & 79 \\
\hline & MANHÃ & 213 \\
\hline & NOITE & 75 \\
\hline & TARDE & 47 \\
\hline \multicolumn{2}{|l|}{ SUMIDOURO Total } & 414 \\
\hline \multirow{2}{*}{ TERESÓPOLIS } & MANHÃ & 7 \\
\hline & TARDE & 10 \\
\hline \multicolumn{2}{|l|}{ TERESÓPOLIS Total } & 17 \\
\hline \multirow{3}{*}{ TRAJANO DE MORAES } & INTEGRAL & 81 \\
\hline & MANHÃ & 205 \\
\hline & TARDE & 54 \\
\hline \multicolumn{2}{|c|}{ TRAJANO DE MORAES Total } & 340 \\
\hline \multirow{2}{*}{ TRÊS RIOS } & INTEGRAL & 1 \\
\hline & NOITE & 48 \\
\hline \multicolumn{2}{|l|}{ TRÊS RIOS Total } & 49 \\
\hline \multirow{4}{*}{ VALENÇA } & INTEGRAL & 1 \\
\hline & MANHÃ & 67 \\
\hline & NOITE & 33 \\
\hline & TARDE & 88 \\
\hline \multicolumn{2}{|l|}{ VALENÇA Total } & 189 \\
\hline \multirow{4}{*}{ VARRE-SAI } & INTEGRAL & 120 \\
\hline & MANHÃ & 288 \\
\hline & NOITE & 172 \\
\hline & TARDE & 128 \\
\hline VARRE-SAI Total & & 708 \\
\hline
\end{tabular}




\begin{tabular}{cll} 
& INTEGRAL & 16 \\
VASSOURAS & MANHÃ & 62 \\
& NOITE & 39 \\
& TARDE & 6 \\
\hline VASSOURAS Total & & 123 \\
\hline Total Geral & & 13.664 \\
\hline
\end{tabular}

Tabela A.1: Escolas por município 
B

\section{Instâncias}

Tabela B.1: Instâncias

\begin{tabular}{|c|c|c|c|}
\hline Escola & Município & Turno & № alunos \\
\hline E1 & BOM JESUS DO ITABAPOANA & Manhã & 9 \\
\hline E1 & BOM JESUS DO ITABAPOANA & Noite & 7 \\
\hline E2 & BOM JESUS DO ITABAPOANA & Manhã & 39 \\
\hline E2 & BOM JESUS DO ITABAPOANA & Noite & 7 \\
\hline E2 & BOM JESUS DO ITABAPOANA & Tarde & 13 \\
\hline E3 & BOM JESUS DO ITABAPOANA & Manhã & 52 \\
\hline $\mathrm{E} 4$ & BOM JESUS DO ITABAPOANA & Integral & 21 \\
\hline $\mathrm{E} 4$ & BOM JESUS DO ITABAPOANA & Manhã & 36 \\
\hline E4 & BOM JESUS DO ITABAPOANA & Tarde & 27 \\
\hline E5 & BOM JESUS DO ITABAPOANA & Integral & 13 \\
\hline E5 & BOM JESUS DO ITABAPOANA & Manhã & 18 \\
\hline E5 & BOM JESUS DO ITABAPOANA & Tarde & 1 \\
\hline E6 & BOM JESUS DO ITABAPOANA & Manhã & 12 \\
\hline E6 & BOM JESUS DO ITABAPOANA & Tarde & 40 \\
\hline E7 & BOM JESUS DO ITABAPOANA & Manhã & 19 \\
\hline E7 & BOM JESUS DO ITABAPOANA & Tarde & 23 \\
\hline E8 & ITALVA & Integral & 18 \\
\hline E8 & ITALVA & Manhã & 33 \\
\hline E8 & ITALVA & Tarde & 38 \\
\hline E9 & ITALVA & Manhã & 32 \\
\hline E9 & ITALVA & Noite & 16 \\
\hline
\end{tabular}




\begin{tabular}{|c|c|c|c|}
\hline E10 & ITAPERUNA & Manhã & 3 \\
\hline E10 & ITAPERUNA & Tarde & 34 \\
\hline E11 & ITAPERUNA & Integral & 81 \\
\hline E11 & ITAPERUNA & Manhã & 229 \\
\hline E11 & ITAPERUNA & Noite & 81 \\
\hline E11 & ITAPERUNA & Tarde & 103 \\
\hline E12 & ITAPERUNA & Manhã & 86 \\
\hline E12 & ITAPERUNA & Noite & 9 \\
\hline E12 & ITAPERUNA & Tarde & 78 \\
\hline E13 & ITAPERUNA & Manhã & 103 \\
\hline E13 & ITAPERUNA & Tarde & 47 \\
\hline E14 & ITAPERUNA & Manhã & 149 \\
\hline E15 & ITAPERUNA & Manhã & 71 \\
\hline E15 & ITAPERUNA & Noite & 39 \\
\hline E16 & ITAPERUNA & Integral & 63 \\
\hline E16 & ITAPERUNA & Manhã & 17 \\
\hline E16 & ITAPERUNA & Noite & 56 \\
\hline E17 & ITAPERUNA & Integral & 95 \\
\hline E17 & ITAPERUNA & Noite & 63 \\
\hline E18 & ITAPERUNA & Manhã & 53 \\
\hline E18 & ITAPERUNA & Noite & 23 \\
\hline E19 & ITAPERUNA & Integral & 12 \\
\hline E19 & ITAPERUNA & Manhã & 8 \\
\hline E19 & ITAPERUNA & Noite & 32 \\
\hline E19 & ITAPERUNA & Tarde & 17 \\
\hline E20 & ITAPERUNA & Manhã & 9 \\
\hline $\mathrm{E} 20$ & ITAPERUNA & Tarde & 9 \\
\hline $\mathrm{E} 21$ & ITAPERUNA & Manhã & 82 \\
\hline E21 & ITAPERUNA & Noite & 11 \\
\hline
\end{tabular}




\begin{tabular}{|c|c|c|c|}
\hline $\mathrm{E} 22$ & ITAPERUNA & Manhã & 40 \\
\hline E23 & NATIVIDADE & Integral & 27 \\
\hline E23 & NATIVIDADE & Manhã & 113 \\
\hline E24 & NATIVIDADE & Integral & 43 \\
\hline E24 & NATIVIDADE & Manhã & 188 \\
\hline $\mathrm{E} 25$ & NATIVIDADE & Manhã & 193 \\
\hline E25 & NATIVIDADE & Noite & 10 \\
\hline $\mathrm{E} 25$ & NATIVIDADE & Tarde & 86 \\
\hline E26 & PORCIÚNCULA & Integral & 3 \\
\hline E26 & PORCIÚNCULA & Manhã & 39 \\
\hline E26 & PORCIÚNCULA & Noite & 25 \\
\hline $\mathrm{E} 27$ & PORCIÚNCULA & Manhã & 10 \\
\hline $\mathrm{E} 27$ & PORCIÚNCULA & Tarde & 20 \\
\hline E28 & PORCIÚNCULA & Manhã & 86 \\
\hline E28 & PORCIÚNCULA & Noite & 67 \\
\hline E29 & VARRE-SAI & Integral & 120 \\
\hline E29 & VARRE-SAI & Manhã & 288 \\
\hline E29 & VARRE-SAI & Noite & 172 \\
\hline E29 & VARRE-SAI & Tarde & 128 \\
\hline E30 & APERIBÉ & Manhã & 14 \\
\hline E30 & APERIBÉ & Noite & 19 \\
\hline E30 & APERIBÉ & Tarde & 30 \\
\hline E31 & CAMBUCÍ & Integral & 29 \\
\hline E31 & CAMBUCÍ & Manhã & 16 \\
\hline E31 & CAMBUCÍ & Noite & 6 \\
\hline E32 & CAMBUCÍ & Integral & 16 \\
\hline E32 & CAMBUCÍ & Manhã & 42 \\
\hline E32 & CAMBUCÍ & Noite & 36 \\
\hline E32 & CAMBUCÍ & Tarde & 47 \\
\hline
\end{tabular}




\begin{tabular}{|c|c|c|c|}
\hline E33 & CAMBUCÍ & Integral & 5 \\
\hline E33 & CAMBUCÍ & Manhã & 13 \\
\hline E33 & CAMBUCÍ & Noite & 6 \\
\hline E33 & CAMBUCÍ & Tarde & 12 \\
\hline E34 & SÃO JOSÉ DE UBÁ & Integral & 23 \\
\hline E34 & SÃO JOSÉ DE UBÁ & Manhã & 78 \\
\hline E34 & SÃO JOSÉ DE UBÁ & Noite & 50 \\
\hline E34 & SÃO JOSÉ DE UBÁ & Tarde & 108 \\
\hline E35 & ITAOCARA & Integral & 38 \\
\hline E35 & ITAOCARA & Manhã & 84 \\
\hline E35 & ITAOCARA & Noite & 38 \\
\hline E35 & ITAOCARA & Tarde & 41 \\
\hline E36 & ITAOCARA & Manhã & 32 \\
\hline E36 & ITAOCARA & Tarde & 47 \\
\hline E37 & ITAOCARA & Manhã & 41 \\
\hline E38 & ITAOCARA & Manhã & 97 \\
\hline E38 & ITAOCARA & Noite & 4 \\
\hline E39 & MIRACEMA & Integral & 7 \\
\hline E39 & MIRACEMA & Manhã & 10 \\
\hline E40 & MIRACEMA & Integral & 23 \\
\hline E40 & MIRACEMA & Manhã & 25 \\
\hline E40 & MIRACEMA & Noite & 5 \\
\hline E41 & MIRACEMA & Integral & 4 \\
\hline E41 & MIRACEMA & Manhã & 5 \\
\hline E41 & MIRACEMA & Noite & 1 \\
\hline E41 & MIRACEMA & Tarde & 21 \\
\hline E42 & SANTO ANTÔNIO DE PÁDUA & Integral & 27 \\
\hline $\mathrm{E} 42$ & SANTO ANTÔNIO DE PÁDUA & Manhã & 38 \\
\hline E43 & SANTO ANTÔNIO DE PÁDUA & Integral & 87 \\
\hline
\end{tabular}




\begin{tabular}{|c|c|c|c|}
\hline E43 & SANTO ANTÔNIO DE PÁDUA & Noite & 17 \\
\hline E44 & SANTO ANTÔNIO DE PÁDUA & Manhã & 19 \\
\hline E44 & SANTO ANTÔNIO DE PÁDUA & Noite & 6 \\
\hline $\mathrm{E} 45$ & SANTO ANTÔNIO DE PÁDUA & Manhã & 33 \\
\hline E46 & CAMPOS DOS GOYTACAZES & Manhã & 1 \\
\hline E47 & CAMPOS DOS GOYTACAZES & Integral & 1 \\
\hline $\mathrm{E} 47$ & CAMPOS DOS GOYTACAZES & Manhã & 1 \\
\hline E47 & CAMPOS DOS GOYTACAZES & Tarde & 1 \\
\hline E48 & CAMPOS DOS GOYTACAZES & Manhã & 1 \\
\hline $\mathrm{E} 49$ & CAMPOS DOS GOYTACAZES & Tarde & 1 \\
\hline $\mathrm{E} 50$ & CAMPOS DOS GOYTACAZES & Noite & 3 \\
\hline $\mathrm{E} 51$ & CAMPOS DOS GOYTACAZES & Manhã & 44 \\
\hline $\mathrm{E} 51$ & CAMPOS DOS GOYTACAZES & Tarde & 74 \\
\hline $\mathrm{E} 52$ & CAMPOS DOS GOYTACAZES & Tarde & 20 \\
\hline E53 & CAMPOS DOS GOYTACAZES & Integral & 19 \\
\hline E53 & CAMPOS DOS GOYTACAZES & Manhã & 31 \\
\hline E53 & CAMPOS DOS GOYTACAZES & Noite & 39 \\
\hline E54 & CAMPOS DOS GOYTACAZES & Manhã & 30 \\
\hline E54 & CAMPOS DOS GOYTACAZES & Noite & 10 \\
\hline $\mathrm{E} 55$ & CAMPOS DOS GOYTACAZES & Manhã & 77 \\
\hline E55 & CAMPOS DOS GOYTACAZES & Noite & 54 \\
\hline $\mathrm{E} 55$ & CAMPOS DOS GOYTACAZES & Tarde & 21 \\
\hline E56 & CAMPOS DOS GOYTACAZES & Manhã & 3 \\
\hline E56 & CAMPOS DOS GOYTACAZES & Noite & 6 \\
\hline $\mathrm{E} 57$ & CAMPOS DOS GOYTACAZES & Manhã & 41 \\
\hline E57 & CAMPOS DOS GOYTACAZES & Noite & 17 \\
\hline E58 & CAMPOS DOS GOYTACAZES & Manhã & 87 \\
\hline E58 & CAMPOS DOS GOYTACAZES & Tarde & 72 \\
\hline E59 & CAMPOS DOS GOYTACAZES & Manhã & 92 \\
\hline
\end{tabular}




\begin{tabular}{|c|c|c|c|}
\hline E59 & CAMPOS DOS GOYTACAZES & Noite & 1 \\
\hline E59 & CAMPOS DOS GOYTACAZES & Tarde & 1 \\
\hline E60 & CAMPOS DOS GOYTACAZES & Manhã & 29 \\
\hline E60 & CAMPOS DOS GOYTACAZES & Noite & 13 \\
\hline E61 & CARDOSO MOREIRA & Integral & 57 \\
\hline E61 & CARDOSO MOREIRA & Manhã & 49 \\
\hline E61 & CARDOSO MOREIRA & Noite & 18 \\
\hline E62 & SÃO FIDÉLIS & Integral & 99 \\
\hline E62 & SÃO FIDÉLIS & Manhã & 75 \\
\hline E62 & SÃO FIDÉLIS & Noite & 42 \\
\hline E63 & SÃO FIDÉLIS & Manhã & 12 \\
\hline E63 & SÃO FIDÉLIS & Tarde & 4 \\
\hline E64 & SÃO FIDÉLIS & Integral & 3 \\
\hline E64 & SÃO FIDÉLIS & Manhã & 4 \\
\hline E64 & SÃO FIDÉLIS & Noite & 5 \\
\hline E65 & SÃO FRANCISCO DE ITABAPOANA & Integral & 123 \\
\hline E65 & SÃO FRANCISCO DE ITABAPOANA & Noite & 125 \\
\hline E65 & SÃO FRANCISCO DE ITABAPOANA & Tarde & 15 \\
\hline E66 & SÃO FRANCISCO DE ITABAPOANA & Manhã & 92 \\
\hline E66 & SÃO FRANCISCO DE ITABAPOANA & Noite & 17 \\
\hline E67 & SÃO FRANCISCO DE ITABAPOANA & Manhã & 16 \\
\hline E68 & SÃO FRANCISCO DE ITABAPOANA & Manhã & 44 \\
\hline E69 & SÃO FRANCISCO DE ITABAPOANA & Noite & 31 \\
\hline E70 & SÃO FRANCISCO DE ITABAPOANA & Manhã & 40 \\
\hline E70 & SÃO FRANCISCO DE ITABAPOANA & Noite & 12 \\
\hline E71 & CONCEIÇÃO DE MACABU & Integral & 26 \\
\hline E71 & CONCEIÇÃO DE MACABU & Manhã & 23 \\
\hline E72 & CONCEIÇÃO DE MACABU & Manhã & 70 \\
\hline E72 & CONCEIÇÃO DE MACABU & Tarde & 44 \\
\hline
\end{tabular}




\begin{tabular}{|c|c|c|c|}
\hline E73 & CONCEIÇÃO DE MACABU & Manhã & 31 \\
\hline E74 & MACAÉ & Integral & 1 \\
\hline E75 & MACAÉ & Manhã & 1 \\
\hline E76 & MACAÉ & Manhã & 1 \\
\hline E77 & MACAÉ & Manhã & 2 \\
\hline E78 & QUISSAMÃ & Manhã & 1 \\
\hline E78 & QUISSAMÃ & Noite & 1 \\
\hline E79 & AREAL & Noite & 1 \\
\hline $\mathrm{E} 80$ & PARAÍBA DO SUL & Integral & 2 \\
\hline E80 & PARAÍBA DO SUL & Manhã & 9 \\
\hline $\mathrm{E} 80$ & PARAÍBA DO SUL & Noite & 1 \\
\hline $\mathrm{E} 81$ & PARAÍBA DO SUL & Manhã & 2 \\
\hline $\mathrm{E} 81$ & PARAÍBA DO SUL & Noite & 1 \\
\hline $\mathrm{E} 82$ & PARAÍBA DO SUL & Manhã & 1 \\
\hline $\mathrm{E} 82$ & PARAÍBA DO SUL & Noite & 4 \\
\hline $\mathrm{E} 82$ & PARAÍBA DO SUL & Tarde & 2 \\
\hline $\mathrm{E} 83$ & PARAÍBA DO SUL & Manhã & 24 \\
\hline $\mathrm{E} 83$ & PARAÍBA DO SUL & Tarde & 7 \\
\hline E84 & SAPUCAIA & Manhã & 4 \\
\hline E84 & SAPUCAIA & Noite & 1 \\
\hline $\mathrm{E} 84$ & SAPUCAIA & Tarde & 2 \\
\hline E85 & SAPUCAIA & Manhã & 1 \\
\hline E86 & SAPUCAIA & Manhã & 14 \\
\hline E87 & SAPUCAIA & Manhã & 65 \\
\hline E87 & SAPUCAIA & Tarde & 68 \\
\hline E88 & TRÊES RIOS & Integral & 1 \\
\hline E89 & CANTAGALO & Manhã & 14 \\
\hline E89 & CANTAGALO & Noite & 39 \\
\hline E90 & CANTAGALO & Integral & 22 \\
\hline
\end{tabular}




\begin{tabular}{|c|c|c|c|}
\hline E90 & CANTAGALO & Manhã & 7 \\
\hline E91 & CANTAGALO & Manhã & 17 \\
\hline E91 & CANTAGALO & Tarde & 39 \\
\hline E92 & CANTAGALO & Manhã & 13 \\
\hline E93 & CANTAGALO & Manhã & 29 \\
\hline E93 & CANTAGALO & Tarde & 22 \\
\hline E94 & CARMO & Integral & 71 \\
\hline E94 & CARMO & Manhã & 137 \\
\hline E95 & CARMO & Integral & 9 \\
\hline E95 & CARMO & Manhã & 45 \\
\hline E96 & CARMO & Manhã & 26 \\
\hline E96 & CARMO & Noite & 6 \\
\hline E96 & CARMO & Tarde & 2 \\
\hline E97 & CORDEIRO & Manhã & 48 \\
\hline E97 & CORDEIRO & Noite & 8 \\
\hline E97 & CORDEIRO & Tarde & 17 \\
\hline E98 & CORDEIRO & Integral & 60 \\
\hline E99 & MACUCO & Manhã & 27 \\
\hline E99 & MACUCO & Noite & 6 \\
\hline E99 & MACUCO & Tarde & 2 \\
\hline E100 & BOM JARDIM & Noite & 12 \\
\hline E101 & BOM JARDIM & Noite & 24 \\
\hline E102 & DUAS BARRAS & Integral & 12 \\
\hline E102 & DUAS BARRAS & Manhã & 23 \\
\hline E102 & DUAS BARRAS & Noite & 7 \\
\hline E102 & DUAS BARRAS & Tarde & 24 \\
\hline E103 & DUAS BARRAS & Manhã & 81 \\
\hline E103 & DUAS BARRAS & Tarde & 81 \\
\hline E104 & NOVA FRIBURGO & Tarde & 1 \\
\hline
\end{tabular}




\begin{tabular}{|c|c|c|c|}
\hline E105 & NOVA FRIBURGO & Manhã & 1 \\
\hline E106 & NOVA FRIBURGO & Tarde & 31 \\
\hline E107 & NOVA FRIBURGO & Manhã & 2 \\
\hline E107 & NOVA FRIBURGO & Tarde & 1 \\
\hline E108 & NOVA FRIBURGO & Manhã & 20 \\
\hline E108 & NOVA FRIBURGO & Tarde & 1 \\
\hline E109 & NOVA FRIBURGO & Manhã & 47 \\
\hline E109 & NOVA FRIBURGO & Tarde & 11 \\
\hline E110 & NOVA FRIBURGO & Manhã & 8 \\
\hline E111 & SUMIDOURO & Integral & 79 \\
\hline E111 & SUMIDOURO & Manhã & 213 \\
\hline E111 & SUMIDOURO & Tarde & 47 \\
\hline E112 & SANTA MARIA MADALENA & Integral & 10 \\
\hline E112 & SANTA MARIA MADALENA & Noite & 7 \\
\hline E113 & SÃO SEBASTIÃO DO ALTO & Manhã & 66 \\
\hline E114 & TRAJANO DE MORAES & Manhã & 131 \\
\hline E114 & TRAJANO DE MORAES & Tarde & 41 \\
\hline E115 & TRAJANO DE MORAES & Manhã & 34 \\
\hline E115 & TRAJANO DE MORAES & Tarde & 13 \\
\hline E116 & CASIMIRO DE ABREU & Integral & 56 \\
\hline E116 & CASIMIRO DE ABREU & Manhã & 12 \\
\hline E116 & CASIMIRO DE ABREU & Noite & 5 \\
\hline E117 & CASIMIRO DE ABREU & Manhã & 2 \\
\hline E117 & CASIMIRO DE ABREU & Noite & 1 \\
\hline E118 & CASIMIRO DE ABREU & Manhã & 47 \\
\hline E119 & RIO DAS OSTRAS & Manhã & 108 \\
\hline E120 & ARARUAMA & Manhã & 1 \\
\hline E121 & ARARUAMA & Noite & 1 \\
\hline E122 & ARARUAMA & Manhã & 1 \\
\hline
\end{tabular}




\begin{tabular}{|c|c|c|c|}
\hline E123 & ARARUAMA & Manhã & 23 \\
\hline E123 & ARARUAMA & Noite & 29 \\
\hline E124 & ARARUAMA & Manhã & 16 \\
\hline E125 & ARARUAMA & Integral & 17 \\
\hline $\mathrm{E} 125$ & ARARUAMA & Manhã & 79 \\
\hline E125 & ARARUAMA & Noite & 7 \\
\hline E126 & CABO FRIO & Tarde & 1 \\
\hline E127 & CABO FRIO & Integral & 2 \\
\hline E128 & SÃO PEDRO DA ALDEIA & Noite & 2 \\
\hline E129 & BARRA MANSA & Noite & 1 \\
\hline E130 & PIRAÍ & Integral & 11 \\
\hline E130 & PIRAÍ & Manhã & 21 \\
\hline E130 & PIRAÍ & Tarde & 13 \\
\hline E131 & PIRAÍ & Manhã & 4 \\
\hline E131 & PIRAÍ & Noite & 8 \\
\hline E132 & QUATIS & Manhã & 29 \\
\hline E132 & QUATIS & Noite & 15 \\
\hline E132 & QUATIS & Tarde & 10 \\
\hline E133 & PORTO REAL & Tarde & 1 \\
\hline E134 & BARRA DO PIRAÍ & Manhã & 1 \\
\hline E135 & BARRA DO PIRAÍ & Manhã & 2 \\
\hline E135 & BARRA DO PIRAÍ & Noite & 1 \\
\hline E136 & BARRA DO PIRAÍ & Manhã & 21 \\
\hline E136 & BARRA DO PIRAÍ & Tarde & 14 \\
\hline E137 & RIO DAS FLORES & Integral & 41 \\
\hline E137 & RIO DAS FLORES & Manhã & 50 \\
\hline E137 & RIO DAS FLORES & Noite & 13 \\
\hline E138 & RIO DAS FLORES & Manhã & 15 \\
\hline E139 & VALENÇA & Integral & 1 \\
\hline
\end{tabular}




\begin{tabular}{|c|c|c|c|}
\hline E139 & VALENÇA & Manhã & 3 \\
\hline E140 & VALENÇA & Manhã & 4 \\
\hline E141 & VALENÇA & Manhã & 1 \\
\hline E141 & VALENÇA & Tarde & 1 \\
\hline E142 & VALENÇA & Manhã & 2 \\
\hline E143 & VALENÇA & Manhã & 4 \\
\hline E143 & VALENÇA & Tarde & 1 \\
\hline E144 & VALENÇA & Manhã & 14 \\
\hline E144 & VALENÇA & Noite & 9 \\
\hline E144 & VALENÇA & Tarde & 10 \\
\hline E145 & VALENÇA & Manhã & 39 \\
\hline E145 & VALENÇA & Tarde & 33 \\
\hline E146 & VALENÇA & Noite & 24 \\
\hline E146 & VALENÇA & Tarde & 43 \\
\hline E147 & PARATY & Manhã & 2 \\
\hline E148 & ENGENHEIRO PAULO DE FRONTIN & Tarde & 1 \\
\hline E149 & MENDES & Manhã & 65 \\
\hline E149 & MENDES & Noite & 15 \\
\hline E149 & MENDES & Tarde & 20 \\
\hline E150 & MENDES & Integral & 34 \\
\hline E150 & MENDES & Manhã & 63 \\
\hline E150 & MENDES & Noite & 45 \\
\hline E151 & MIGUEL PEREIRA & Integral & 4 \\
\hline E151 & MIGUEL PEREIRA & Manhã & 4 \\
\hline E151 & MIGUEL PEREIRA & Tarde & 2 \\
\hline E152 & MIGUEL PEREIRA & Manhã & 50 \\
\hline E152 & MIGUEL PEREIRA & Tarde & 52 \\
\hline E153 & PATY DO ALFERES & Integral & 96 \\
\hline E154 & PATY DO ALFERES & Manhã & 117 \\
\hline
\end{tabular}




\begin{tabular}{|c|c|c|c|}
\hline E154 & PATY DO ALFERES & Tarde & 1 \\
\hline E155 & VASSOURAS & Integral & 2 \\
\hline E155 & VASSOURAS & Manhã & 17 \\
\hline E155 & VASSOURAS & Noite & 39 \\
\hline E155 & VASSOURAS & Tarde & 2 \\
\hline E156 & VASSOURAS & Manhã & 1 \\
\hline E157 & PETRÓPOLIS & Integral & 1 \\
\hline E158 & PETRÓPOLIS & Manhã & 1 \\
\hline E159 & PETRÓPOLIS & Tarde & 1 \\
\hline E160 & PETRÓPOLIS & Manhã & 1 \\
\hline E161 & PETRÓPOLIS & Tarde & 1 \\
\hline E162 & PETRÓPOLIS & Tarde & 5 \\
\hline E163 & PETRÓPOLIS & Integral & 2 \\
\hline E163 & PETRÓPOLIS & Manhã & 5 \\
\hline E164 & SÃO JOSÉ DO VALE DO RIO PRETO & Manhã & 190 \\
\hline E164 & SÃO JOSÉ DO VALE DO RIO PRETO & Noite & 81 \\
\hline E164 & SÃO JOSÉ DO VALE DO RIO PRETO & Tarde & 206 \\
\hline E165 & TERESÓPOLIS & Manhã & 4 \\
\hline E165 & TERESÓPOLIS & Tarde & 3 \\
\hline E166 & TERESÓPOLIS & Manhã & 1 \\
\hline E166 & TERESÓPOLIS & Tarde & 2 \\
\hline E167 & TERESÓPOLIS & Manhã & 2 \\
\hline E167 & TERESÓPOLIS & Tarde & 5 \\
\hline E168 & CACHOEIRAS DE MACACU & Integral & 13 \\
\hline E168 & CACHOEIRAS DE MACACU & Manhã & 15 \\
\hline E169 & CACHOEIRAS DE MACACU & Manhã & 67 \\
\hline $\mathrm{E} 170$ & CACHOEIRAS DE MACACU & Integral & 4 \\
\hline E171 & CACHOEIRAS DE MACACU & Tarde & 20 \\
\hline E172 & CACHOEIRAS DE MACACU & Manhã & 9 \\
\hline
\end{tabular}




\begin{tabular}{|c|c|c|c|}
\hline E173 & CACHOEIRAS DE MACACU & Integral & 7 \\
\hline E173 & CACHOEIRAS DE MACACU & Manhã & 7 \\
\hline E173 & CACHOEIRAS DE MACACU & Noite & 1 \\
\hline E174 & CACHOEIRAS DE MACACU & Manhã & 26 \\
\hline E174 & CACHOEIRAS DE MACACU & Noite & 11 \\
\hline E175 & RIO BONITO & Manhã & 65 \\
\hline E176 & RIO BONITO & Integral & 11 \\
\hline E176 & RIO BONITO & Manhã & 45 \\
\hline E176 & RIO BONITO & Noite & 71 \\
\hline E176 & RIO BONITO & Tarde & 39 \\
\hline E177 & RIO BONITO & Integral & 1 \\
\hline E177 & RIO BONITO & Manhã & 18 \\
\hline E178 & RIO BONITO & Integral & 15 \\
\hline E178 & RIO BONITO & Manhã & 22 \\
\hline E178 & RIO BONITO & Tarde & 9 \\
\hline E179 & RIO BONITO & Tarde & 10 \\
\hline E180 & RIO BONITO & Manhã & 3 \\
\hline E180 & RIO BONITO & Tarde & 7 \\
\hline E181 & RIO BONITO & Manhã & 10 \\
\hline E181 & RIO BONITO & Noite & 1 \\
\hline E181 & RIO BONITO & Tarde & 12 \\
\hline E182 & GUAPIMIRIM & Tarde & 1 \\
\hline E183 & ITABORAÍ & Manhã & 16 \\
\hline E183 & ITABORAÍ & Tarde & 10 \\
\hline E184 & MAGÉ & Manhã & 1 \\
\hline E185 & MAGÉ & Integral & 73 \\
\hline E185 & MAGÉ & Manhã & 129 \\
\hline E186 & MAGÉ & Manhã & 1 \\
\hline E187 & MAGÉ & Manhã & 1 \\
\hline
\end{tabular}




\begin{tabular}{|c|c|c|c|}
\hline E188 & MAGÉ & Manhã & 3 \\
\hline E189 & NITERÓI & Manhã & 1 \\
\hline E190 & NITERÓI & Manhã & 1 \\
\hline E191 & NITERÓI & Manhã & 1 \\
\hline E192 & NOVA IGUAÇU & Noite & 1 \\
\hline E193 & QUEIMADOS & Tarde & 1 \\
\hline E194 & RIO DE JANEIRO & Integral & 1 \\
\hline E195 & SÃO GONÇALO & Manhã & 1 \\
\hline E196 & SÃO GONÇALO & Manhã & 1 \\
\hline E197 & LAJE DO MURIAÉ & Integral & 41 \\
\hline E197 & LAJE DO MURIAÉ & Manhã & 21 \\
\hline E197 & LAJE DO MURIAÉ & Noite & 10 \\
\hline E197 & LAJE DO MURIAÉ & Tarde & 37 \\
\hline E198 & VASSOURAS & Integral & 14 \\
\hline E198 & VASSOURAS & Manhã & 44 \\
\hline E198 & VASSOURAS & Tarde & 4 \\
\hline E199 & ITAPERUNA & Integral & 145 \\
\hline E199 & ITAPERUNA & Manhã & 389 \\
\hline E199 & ITAPERUNA & Noite & 54 \\
\hline E200 & SÃO SEBASTIÃO DO ALTO & Integral & 9 \\
\hline E200 & SÃO SEBASTIÃO DO ALTO & Manhã & 48 \\
\hline E201 & CASIMIRO DE ABREU & Manhã & 82 \\
\hline E202 & SÃO FRANCISCO DE ITABAPOANA & Integral & 46 \\
\hline E202 & SÃO FRANCISCO DE ITABAPOANA & Manhã & 24 \\
\hline E203 & APERIBÉ & Integral & 23 \\
\hline E203 & APERIBÉ & Manhã & 27 \\
\hline E204 & DUQUE DE CAXIAS & Manhã & 1 \\
\hline E205 & QUEIMADOS & Integral & 1 \\
\hline E206 & PORCIÚNCULA & Integral & 13 \\
\hline
\end{tabular}




\begin{tabular}{|c|c|c|c|}
\hline E206 & PORCIÚNCULA & Manhã & 9 \\
\hline E206 & PORCIÚNCULA & Tarde & 4 \\
\hline E207 & BARRA DO PIRAÍ & Tarde & 1 \\
\hline E208 & CARDOSO MOREIRA & Manhã & 174 \\
\hline E208 & CARDOSO MOREIRA & Noite & 28 \\
\hline E209 & ITAOCARA & Integral & 17 \\
\hline E209 & ITAOCARA & Manhã & 81 \\
\hline E209 & ITAOCARA & Noite & 11 \\
\hline E209 & ITAOCARA & Tarde & 13 \\
\hline E210 & TRAJANO DE MORAES & Integral & 81 \\
\hline E210 & TRAJANO DE MORAES & Manhã & 40 \\
\hline E211 & MARICÁ & Manhã & 1 \\
\hline $\mathrm{E} 212$ & PATY DO ALFERES & Integral & 14 \\
\hline E212 & PATY DO ALFERES & Manhã & 65 \\
\hline E212 & PATY DO ALFERES & Noite & 24 \\
\hline E212 & PATY DO ALFERES & Tarde & 2 \\
\hline E213 & RIO DE JANEIRO & Tarde & 1 \\
\hline E214 & NATIVIDADE & Manhã & 6 \\
\hline $\mathrm{E} 214$ & NATIVIDADE & Noite & 12 \\
\hline $\mathrm{E} 215$ & SANTO ANTÔNIO DE PÁDUA & Manhã & 123 \\
\hline E216 & SUMIDOURO & Noite & 75 \\
\hline $\mathrm{E} 217$ & NITERÓI & Integral & 2 \\
\hline E218 & NOVA FRIBURGO & Noite & 45 \\
\hline E219 & TRÊS RIOS & Noite & 48 \\
\hline E220 & SANTO ANTÔNIO DE PÁDUA & Manhã & 2 \\
\hline $\mathrm{E} 220$ & SANTO ANTÔNIO DE PÁDUA & Noite & 6 \\
\hline E221 & BOM JESUS DO ITABAPOANA & Noite & 98 \\
\hline $\mathrm{E} 4$ & BOM JESUS DO ITABAPOANA & Manhã e Integral & 57 \\
\hline $\mathrm{E} 4$ & BOM JESUS DO ITABAPOANA & Tarde e Integral & 48 \\
\hline
\end{tabular}




\begin{tabular}{|c|c|c|c|}
\hline E5 & BOM JESUS DO ITABAPOANA & Manhã e Integral & 31 \\
\hline E5 & BOM JESUS DO ITABAPOANA & Tarde e Integral & 14 \\
\hline $\mathrm{E} 8$ & ITALVA & Manhã e Integral & 51 \\
\hline E8 & ITALVA & Tarde e Integral & 56 \\
\hline E11 & ITAPERUNA & Manhã e Integral & 310 \\
\hline E11 & ITAPERUNA & Tarde e Integral & 184 \\
\hline E16 & ITAPERUNA & Manhã e Integral & 80 \\
\hline E19 & ITAPERUNA & Manhã e Integral & 20 \\
\hline E19 & ITAPERUNA & Tarde e Integral & 29 \\
\hline E23 & NATIVIDADE & Manhã e Integral & 140 \\
\hline $\mathrm{E} 24$ & NATIVIDADE & Manhã e Integral & 231 \\
\hline E26 & PORCIÚNCULA & Manhã e Integral & 42 \\
\hline E29 & VARRE-SAI & Manhã e Integral & 408 \\
\hline E29 & VARRE-SAI & Tarde e Integral & 248 \\
\hline E31 & CAMBUCÍ & Manhã e Integral & 45 \\
\hline E32 & CAMBUCÍ & Manhã e Integral & 58 \\
\hline E32 & CAMBUCÍ & Tarde e Integral & 63 \\
\hline E33 & CAMBUCÍ & Manhã e Integral & 18 \\
\hline E33 & CAMBUCÍ & Tarde e Integral & 17 \\
\hline E34 & SÃO JOSÉ DE UBÁ & Manhã e Integral & 101 \\
\hline E34 & SÃO JOSÉ DE UBÁ & Tarde e Integral & 131 \\
\hline E35 & ITAOCARA & Manhã e Integral & 122 \\
\hline E35 & ITAOCARA & Tarde e Integral & 79 \\
\hline E39 & MIRACEMA & Manhã e Integral & 17 \\
\hline E40 & MIRACEMA & Manhã e Integral & 48 \\
\hline E41 & MIRACEMA & Manhã e Integral & 9 \\
\hline E41 & MIRACEMA & Tarde e Integral & 25 \\
\hline E42 & SANTO ANTÔNIO DE PÁDUA & Manhã e Integral & 65 \\
\hline E47 & CAMPOS DOS GOYTACAZES & Manhã e Integral & 2 \\
\hline
\end{tabular}




\begin{tabular}{|c|c|c|c|}
\hline $\mathrm{E} 47$ & CAMPOS DOS GOYTACAZES & Tarde e Integral & 2 \\
\hline E53 & CAMPOS DOS GOYTACAZES & Manhã e Integral & 50 \\
\hline E61 & CARDOSO MOREIRA & Manhã e Integral & 106 \\
\hline E62 & SÃO FIDÉLIS & Manhã e Integral & 174 \\
\hline E64 & SÃO FIDÉLIS & Manhã e Integral & 7 \\
\hline E65 & SÃO FRANCISCO DE ITABAPOANA & Tarde e Integral & 138 \\
\hline E71 & CONCEIÇÃO DE MACABU & Manhã e Integral & 49 \\
\hline E80 & PARAÍBA DO SUL & Manhã e Integral & 11 \\
\hline E90 & CANTAGALO & Manhã e Integral & 29 \\
\hline E94 & CARMO & Manhã e Integral & 208 \\
\hline E95 & CARMO & Manhã e Integral & 54 \\
\hline E102 & DUAS BARRAS & Manhã e Integral & 35 \\
\hline E102 & DUAS BARRAS & Tarde e Integral & 36 \\
\hline E111 & SUMIDOURO & Manhã e Integral & 292 \\
\hline E111 & SUMIDOURO & Tarde e Integral & 126 \\
\hline E116 & CASIMIRO DE ABREU & Manhã e Integral & 68 \\
\hline E125 & ARARUAMA & Manhã e Integral & 96 \\
\hline E130 & PIRAÍ & Manhã e Integral & 32 \\
\hline E130 & PIRAÍ & Tarde e Integral & 24 \\
\hline E137 & RIO DAS FLORES & Manhã e Integral & 91 \\
\hline E139 & VALENÇA & Manhã e Integral & 4 \\
\hline E150 & MENDES & Manhã e Integral & 97 \\
\hline E151 & MIGUEL PEREIRA & Manhã e Integral & 8 \\
\hline E151 & MIGUEL PEREIRA & Tarde e Integral & 6 \\
\hline E155 & VASSOURAS & Manhã e Integral & 19 \\
\hline E155 & VASSOURAS & Tarde e Integral & 4 \\
\hline E163 & PETRÓPOLIS & Manhã e Integral & 7 \\
\hline E168 & CACHOEIRAS DE MACACU & Manhã e Integral & 28 \\
\hline E173 & CACHOEIRAS DE MACACU & Manhã e Integral & 14 \\
\hline
\end{tabular}




\begin{tabular}{|c|c|c|c|}
\hline E176 & RIO BONITO & Manhã e Integral & 56 \\
\hline E176 & RIO BONITO & Tarde e Integral & 50 \\
\hline E177 & RIO BONITO & Manhã e Integral & 19 \\
\hline E178 & RIO BONITO & Manhã e Integral & 37 \\
\hline E178 & RIO BONITO & Tarde e Integral & 24 \\
\hline E185 & MAGÉ & Manhã e Integral & 202 \\
\hline E197 & LAJE DO MURIAÉ & Manhã e Integral & 62 \\
\hline E197 & LAJE DO MURIAÉ & Tarde e Integral & 78 \\
\hline E198 & VASSOURAS & Manhã e Integral & 58 \\
\hline E198 & VASSOURAS & Tarde e Integral & 18 \\
\hline E199 & ITAPERUNA & Manhã e Integral & 534 \\
\hline E200 & SÃO SEBASTIÃO DO ALTO & Manhã e Integral & 57 \\
\hline E202 & SÃO FRANCISCO DE ITABAPOANA & Manhã e Integral & 70 \\
\hline E203 & APERIBÉ & Manhã e Integral & 50 \\
\hline E206 & PORCIÚNCULA & Manhã e Integral & 22 \\
\hline E206 & PORCIÚNCULA & Tarde e Integral & 17 \\
\hline E209 & ITAOCARA & Manhã e Integral & 98 \\
\hline E209 & ITAOCARA & Tarde e Integral & 30 \\
\hline E210 & TRAJANO DE MORAES & Manhã e Integral & 121 \\
\hline E212 & PATY DO ALFERES & Manhã e Integral & 79 \\
\hline E212 & PATY DO ALFERES & Tarde e Integral & 16 \\
\hline \multicolumn{3}{|c|}{ Total } & 6262 \\
\hline \multicolumn{3}{|c|}{ Total Geral } & 19926 \\
\hline
\end{tabular}


C

Resultados

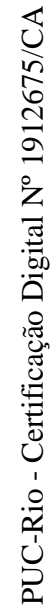




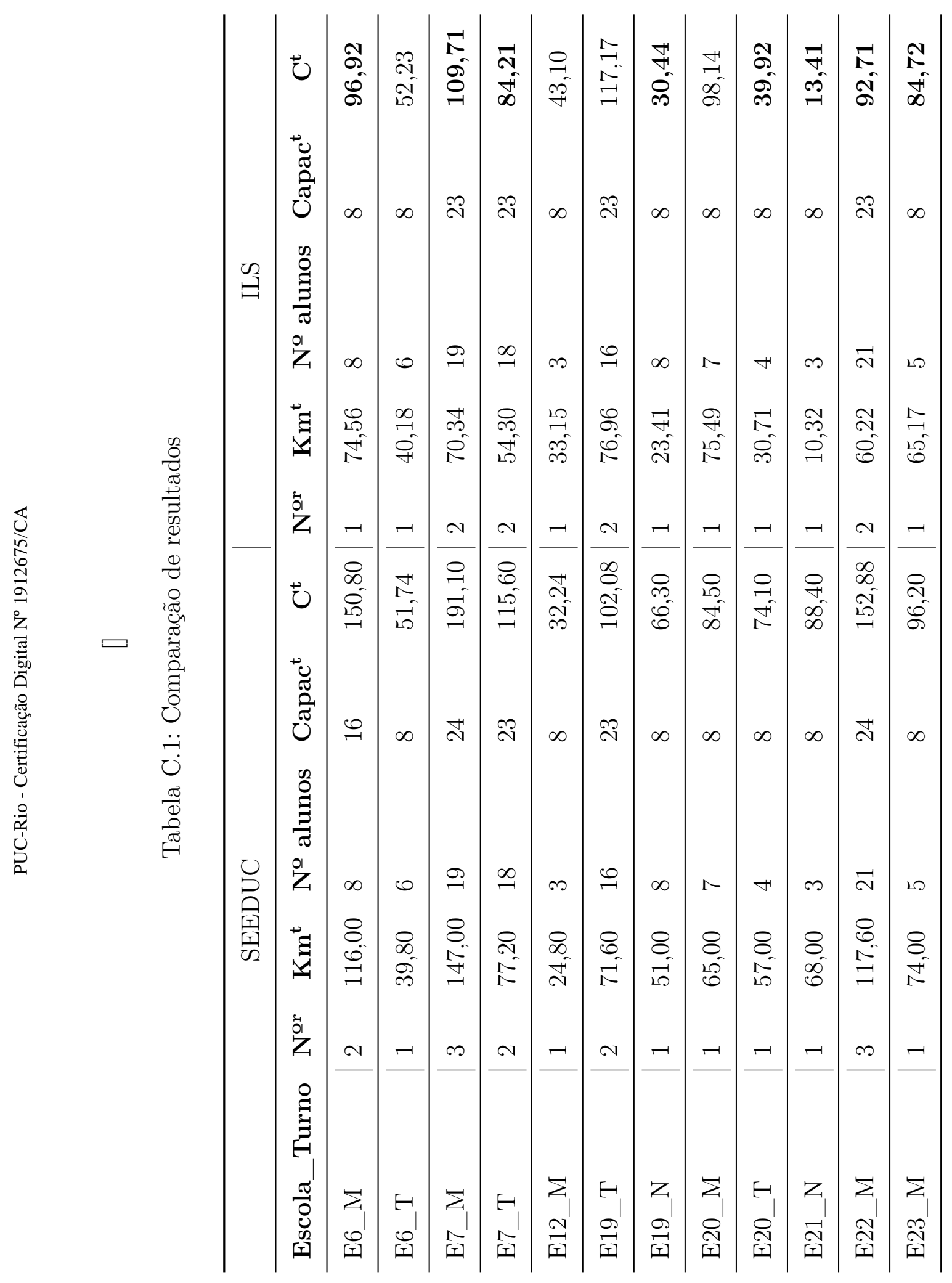




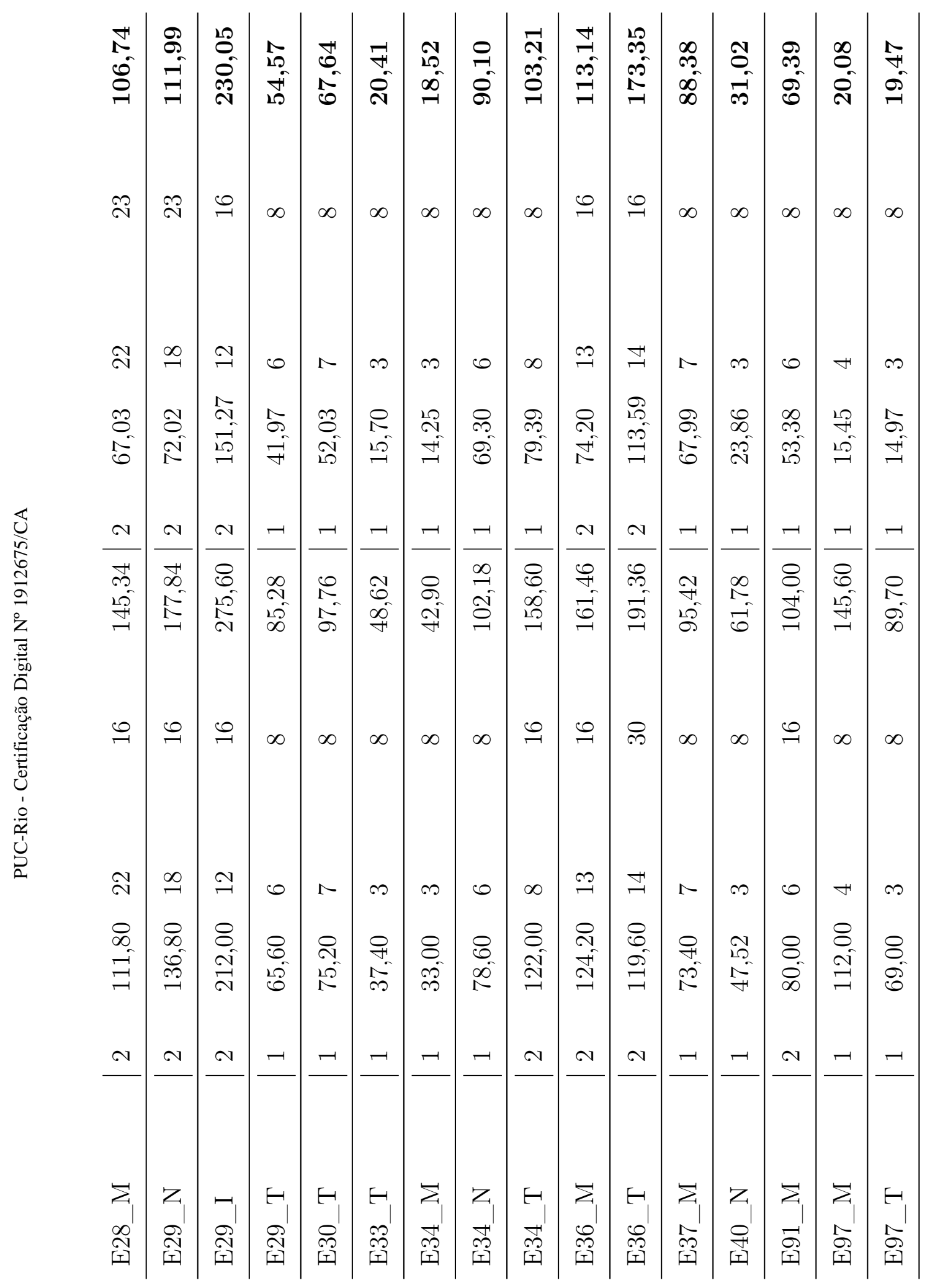




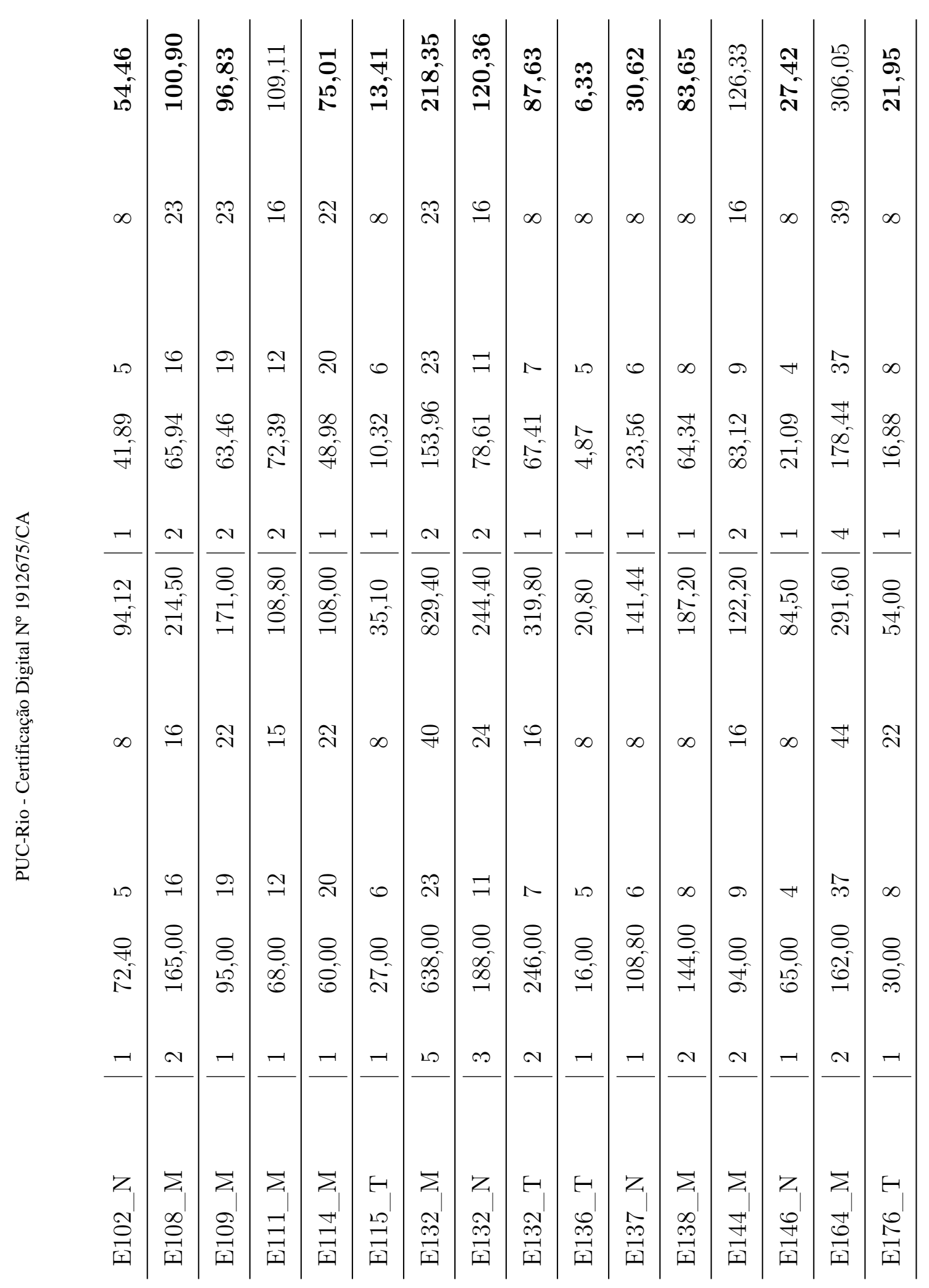




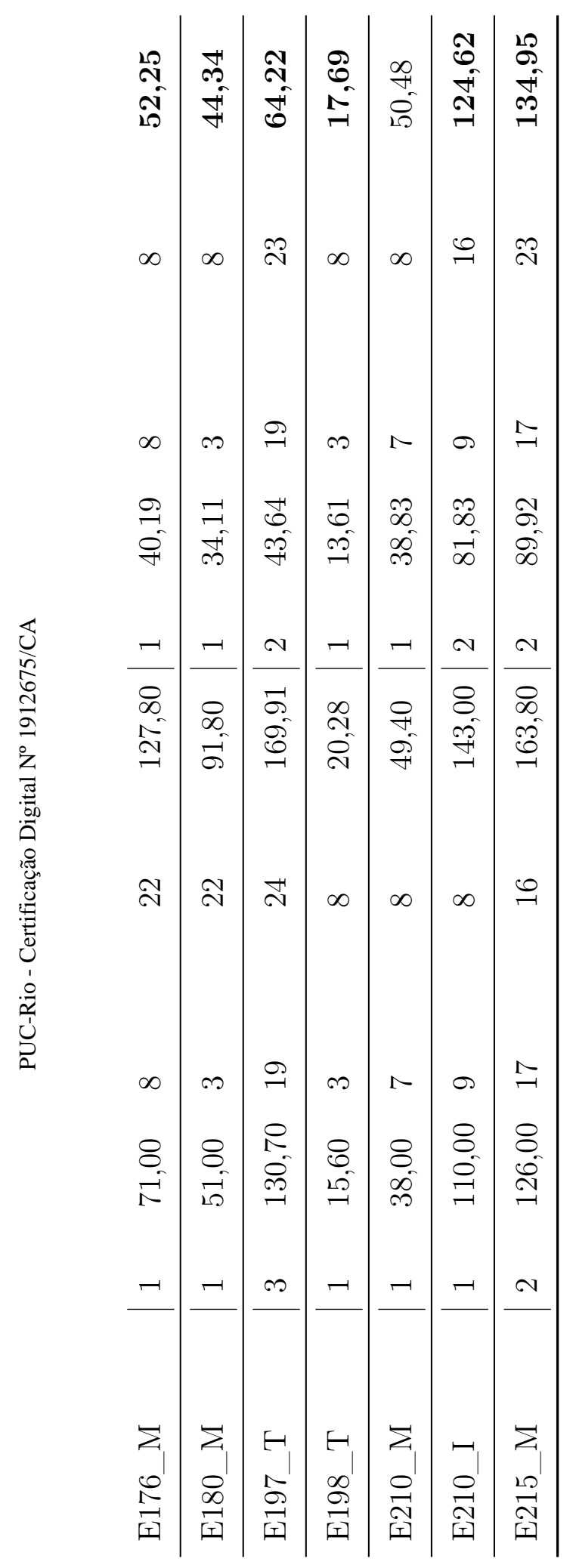


D

\section{Indicadores}

\begin{tabular}{|c|c|c|c|c|}
\hline & \multicolumn{2}{|c|}{ SEEDUC } & \multicolumn{2}{|l|}{ ILS } \\
\hline Escola_Turno & km média/aluno & \%ocupação & km média/aluno & \%ocupação \\
\hline E6_M & 14,5 & $50 \%$ & 9,32 & $100 \%$ \\
\hline E6_T & 6,63 & $75 \%$ & 6,7 & $75 \%$ \\
\hline E7_M & 7,74 & $79 \%$ & 3,7 & $83 \%$ \\
\hline E7_T & 4,29 & $78 \%$ & 3,02 & $78 \%$ \\
\hline E12_M & 8,27 & $38 \%$ & 11,05 & $38 \%$ \\
\hline E19_T & 4,48 & $70 \%$ & 4,81 & $70 \%$ \\
\hline E19_N & 6,38 & $100 \%$ & 2,93 & $100 \%$ \\
\hline E20_M & 9,29 & $88 \%$ & 10,78 & $88 \%$ \\
\hline $\mathrm{E} 20 \_\mathrm{T}$ & 14,25 & $50 \%$ & 7,68 & $50 \%$ \\
\hline $\mathrm{E} 21 \_\mathrm{N}$ & 22,67 & $38 \%$ & 3,44 & $38 \%$ \\
\hline E22_M & 5,6 & $88 \%$ & 2,87 & $91 \%$ \\
\hline E23_M & 14,8 & $63 \%$ & 13,03 & $63 \%$ \\
\hline E28_M & 5,08 & $138 \%$ & 3,05 & $96 \%$ \\
\hline $\mathrm{E} 29 \_\mathrm{N}$ & 7,6 & $113 \%$ & 4 & $78 \%$ \\
\hline E29_I & 17,67 & $75 \%$ & 12,61 & $75 \%$ \\
\hline $\mathrm{E} 29 \_\mathrm{T}$ & 10,93 & $75 \%$ & 7 & $75 \%$ \\
\hline $\mathrm{E} 30 \_\mathrm{T}$ & 10,74 & $88 \%$ & 7,43 & $88 \%$ \\
\hline E33_T & 12,47 & $38 \%$ & 5,23 & $38 \%$ \\
\hline E34_M & 11 & $38 \%$ & 4,75 & $38 \%$ \\
\hline E34_N & 13,1 & $75 \%$ & 11,55 & $75 \%$ \\
\hline E34_T & 15,25 & $50 \%$ & 9,92 & $100 \%$ \\
\hline
\end{tabular}




\begin{tabular}{|c|c|c|c|c|}
\hline E36_M & 9,55 & $81 \%$ & 5,71 & $81 \%$ \\
\hline E36_T & 8,54 & $47 \%$ & 8,11 & $88 \%$ \\
\hline E37_M & 10,49 & $88 \%$ & 9,71 & $88 \%$ \\
\hline $\mathrm{E} 40 \_\mathrm{N}$ & 15,84 & $38 \%$ & 7,95 & $38 \%$ \\
\hline E91_M & 13,33 & $38 \%$ & 8,9 & $75 \%$ \\
\hline E97_M & 28 & $50 \%$ & 3,86 & $50 \%$ \\
\hline $\mathrm{E} 97 \_\mathrm{T}$ & 23 & $38 \%$ & 4,99 & $38 \%$ \\
\hline $\mathrm{E} 102 \_\mathrm{N}$ & 14,48 & $63 \%$ & 8,38 & $63 \%$ \\
\hline E108_M & 10,31 & $100 \%$ & 4,12 & $70 \%$ \\
\hline E109_M & 5 & $86 \%$ & 3,34 & $83 \%$ \\
\hline E111_M & 5,67 & $80 \%$ & 6,03 & $75 \%$ \\
\hline E114_M & 3 & $91 \%$ & 2,45 & $91 \%$ \\
\hline $\mathrm{E} 115 \_\mathrm{T}$ & 4,5 & $75 \%$ & 1,72 & $75 \%$ \\
\hline E132_M & 27,74 & $58 \%$ & 6,69 & $100 \%$ \\
\hline $\mathrm{E} 132 \_\mathrm{N}$ & 17,09 & $46 \%$ & 7,15 & $69 \%$ \\
\hline $\mathrm{E} 132 \_\mathrm{T}$ & 35,14 & $44 \%$ & 9,63 & $88 \%$ \\
\hline E136_T & 3,2 & $63 \%$ & 0,97 & $63 \%$ \\
\hline $\mathrm{E} 137 \_\mathrm{N}$ & 18,13 & $75 \%$ & 3,93 & $75 \%$ \\
\hline E138_M & 18 & $100 \%$ & 8,04 & $100 \%$ \\
\hline $\mathrm{E} 144 \_\mathrm{M}$ & 10,44 & $56 \%$ & 9,24 & $56 \%$ \\
\hline E146_N & 16,25 & $50 \%$ & 5,27 & $50 \%$ \\
\hline E164_M & 4,38 & $84 \%$ & 4,82 & $95 \%$ \\
\hline $\mathrm{E} 176 \_\mathrm{T}$ & 3,75 & $36 \%$ & 2,11 & $100 \%$ \\
\hline E176_M & 8,88 & $36 \%$ & 5,02 & $100 \%$ \\
\hline E180_M & 17 & $14 \%$ & 11,37 & $38 \%$ \\
\hline $\mathrm{E} 197 \_\mathrm{T}$ & 6,88 & $79 \%$ & 2,3 & $83 \%$ \\
\hline E198_T & 5,2 & $38 \%$ & 4,54 & $38 \%$ \\
\hline $\mathrm{E} 210 \_\mathrm{M}$ & 5,43 & $88 \%$ & 5,55 & $88 \%$ \\
\hline E210_I & 12,22 & $113 \%$ & 9,09 & $56 \%$ \\
\hline
\end{tabular}




\begin{tabular}{|c|c|c|c|c|}
\hline E215_M & 7,41 & $106 \%$ & 5,29 & $74 \%$ \\
\hline
\end{tabular}

Tabela D.1: Indicadores rotas SEEDUC x ILS 
E

Resultados completos

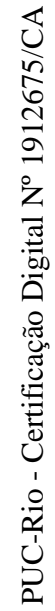




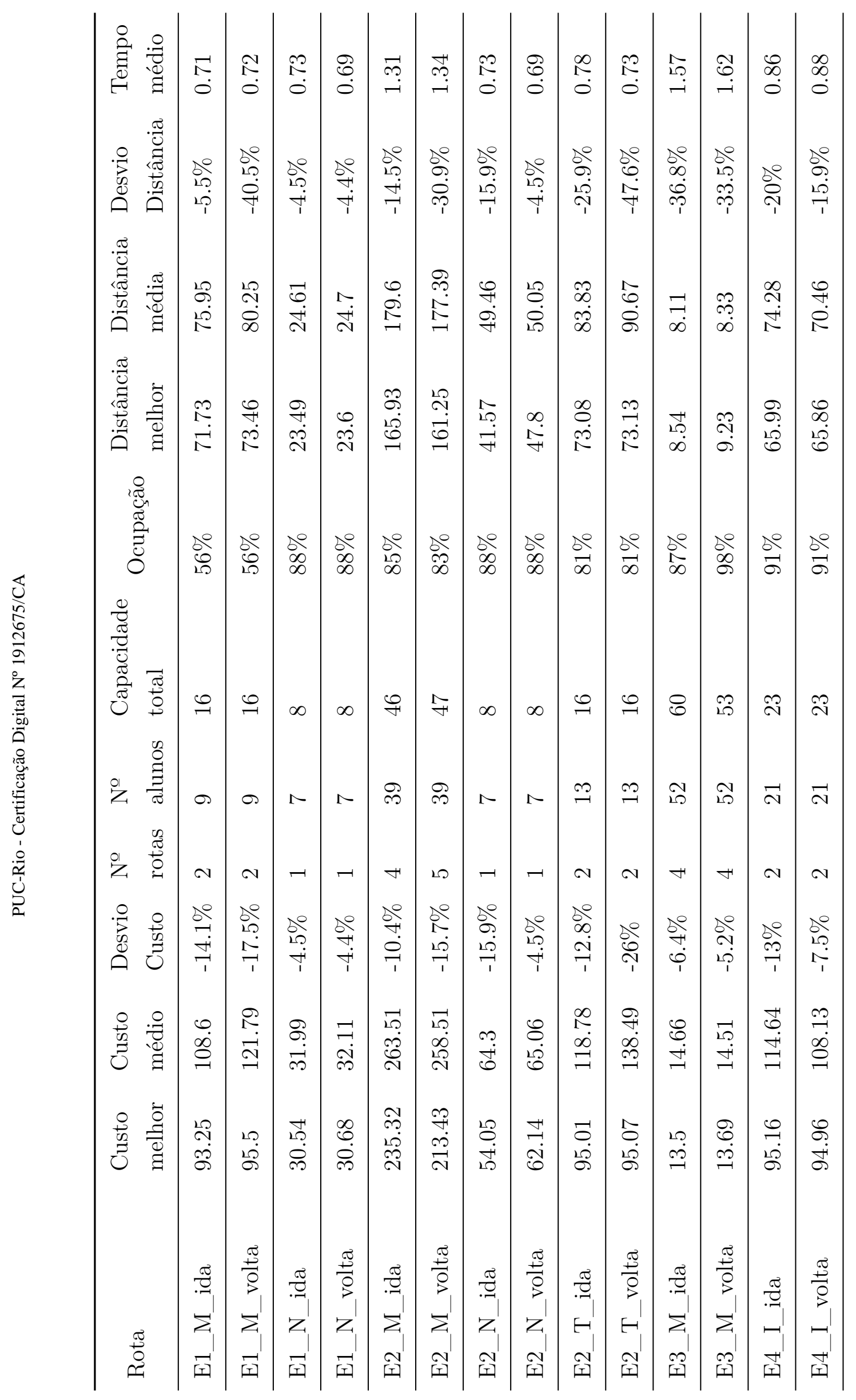




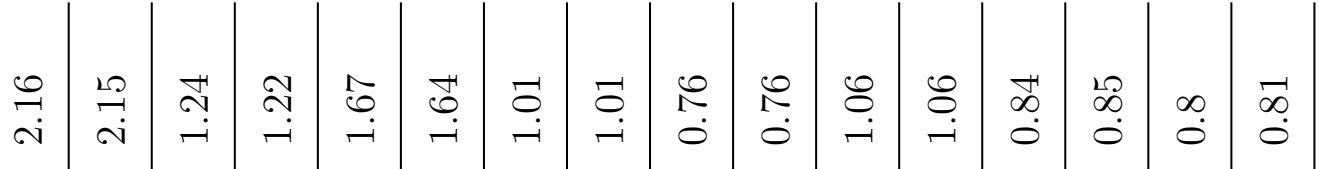

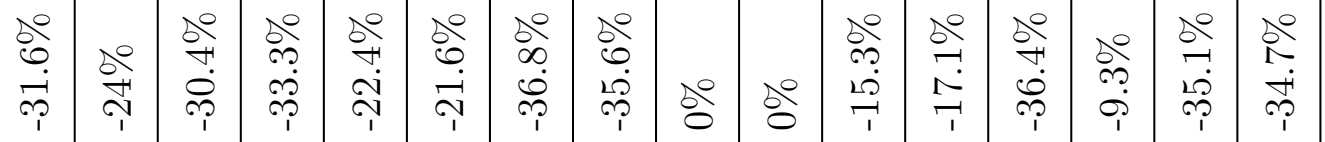

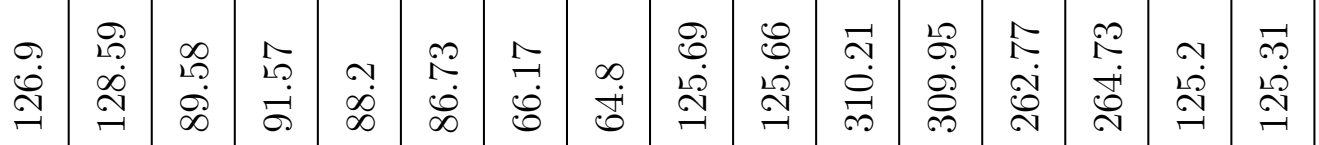

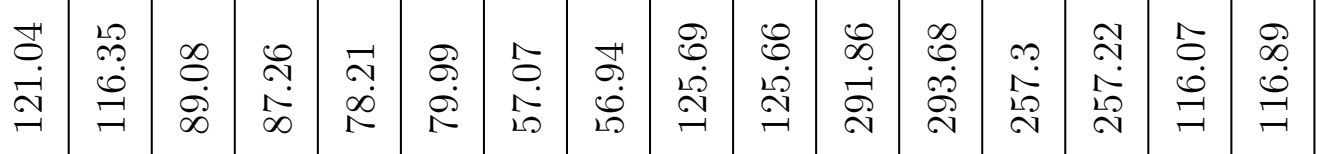

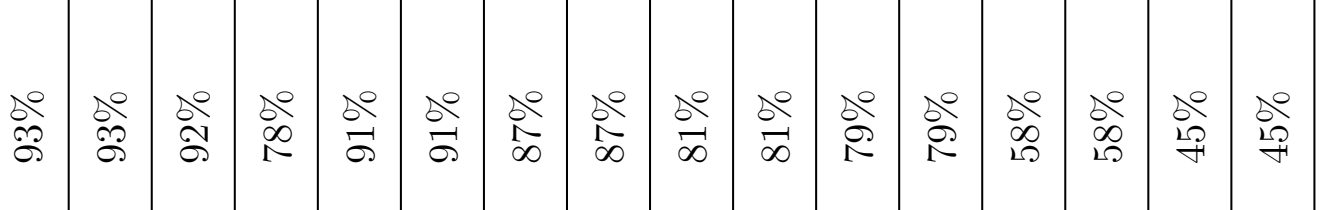

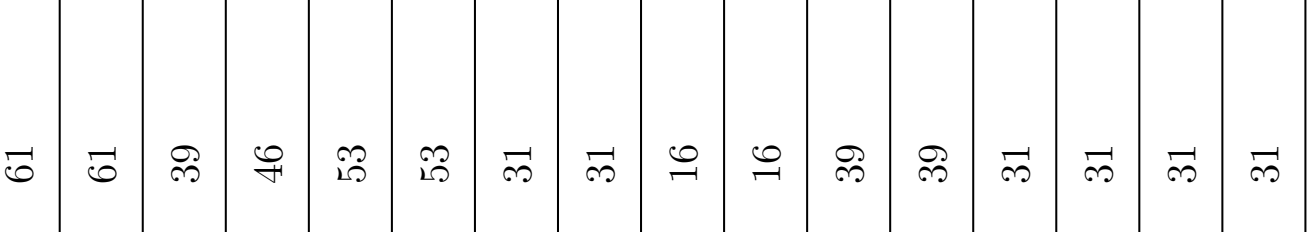

$$
\begin{aligned}
& \text { 占占 }
\end{aligned}
$$

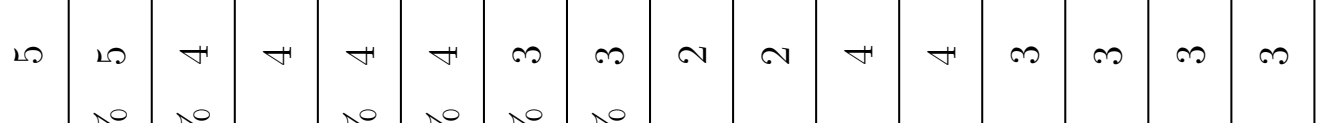

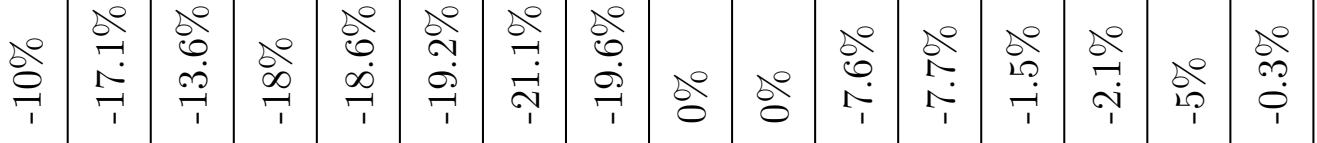

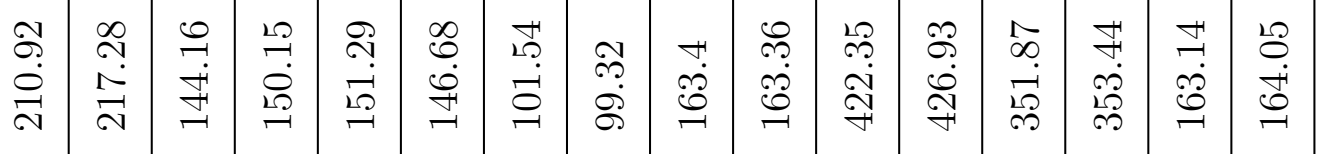

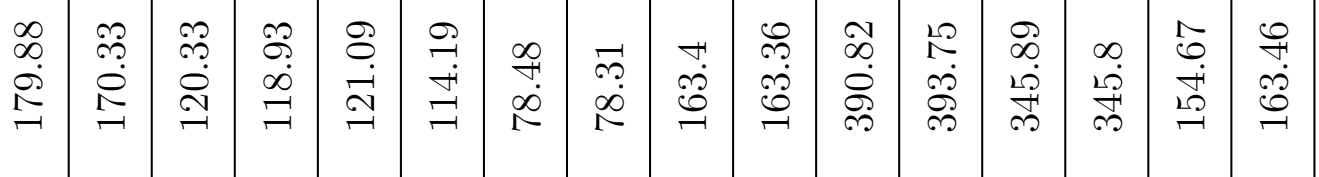

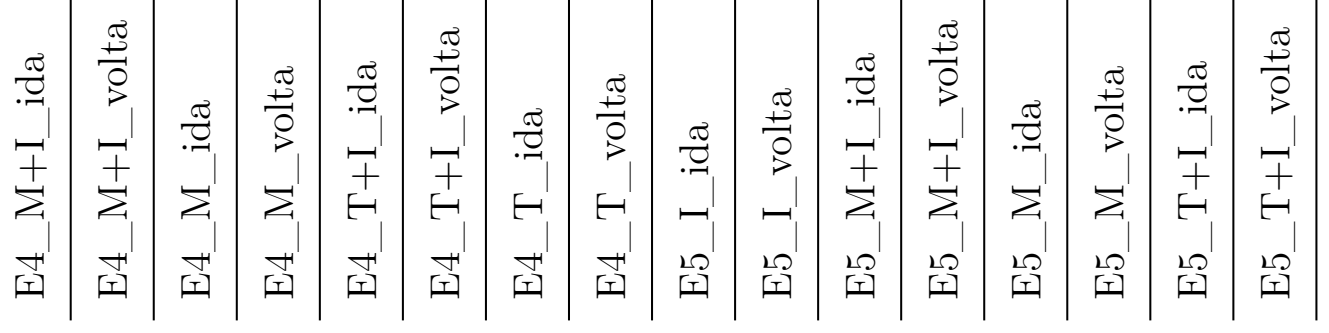

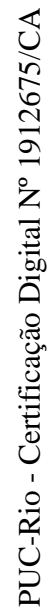




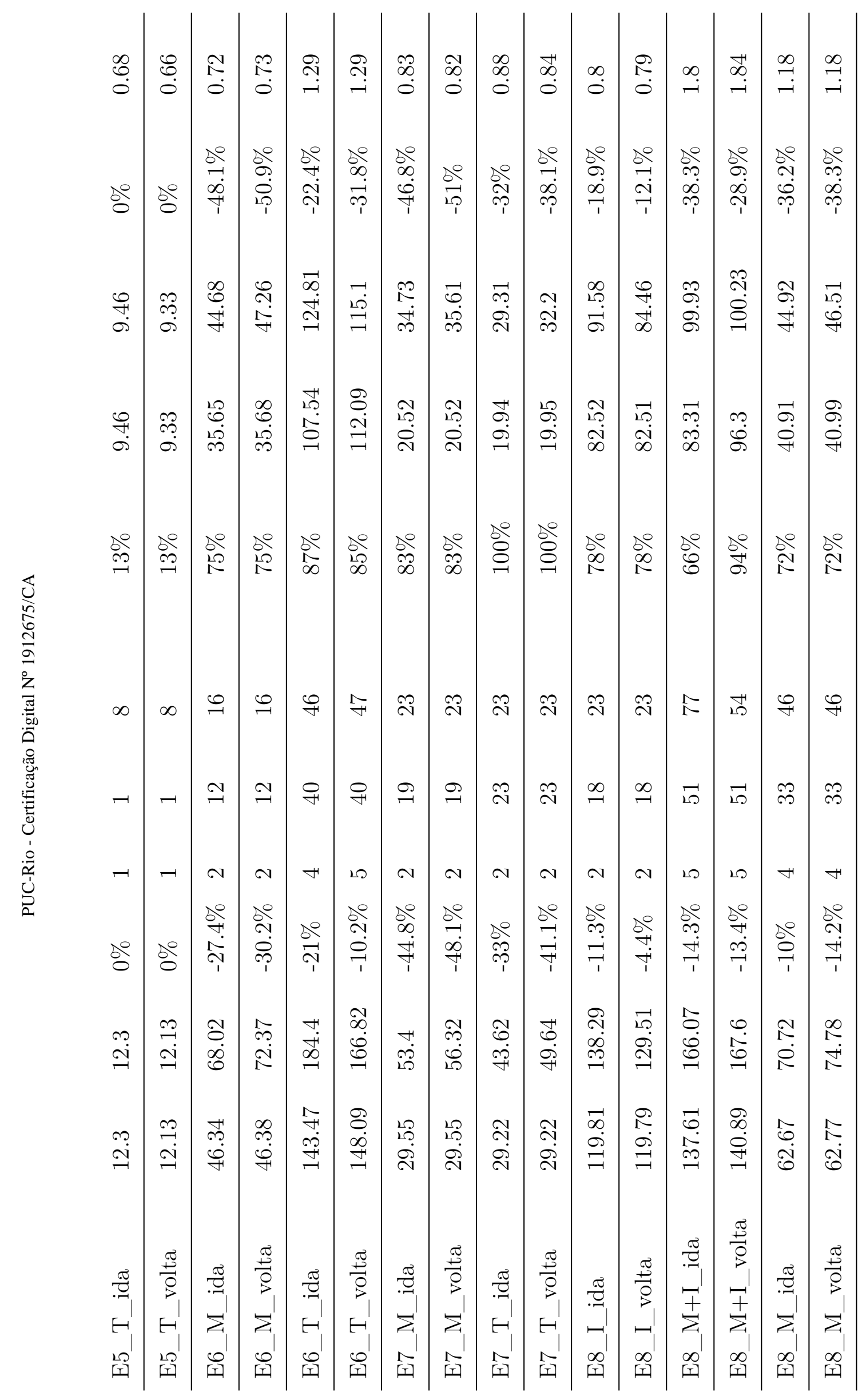




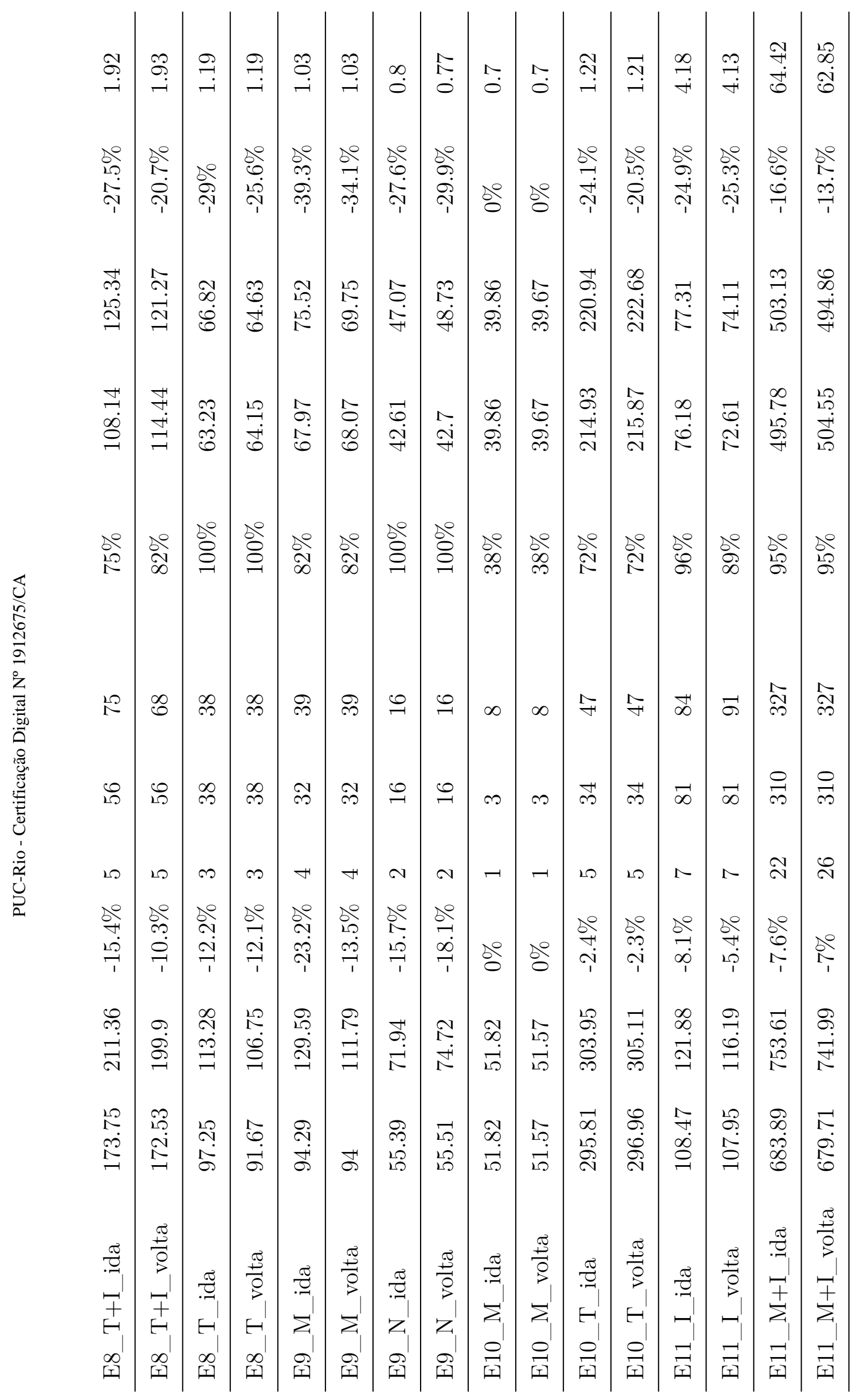




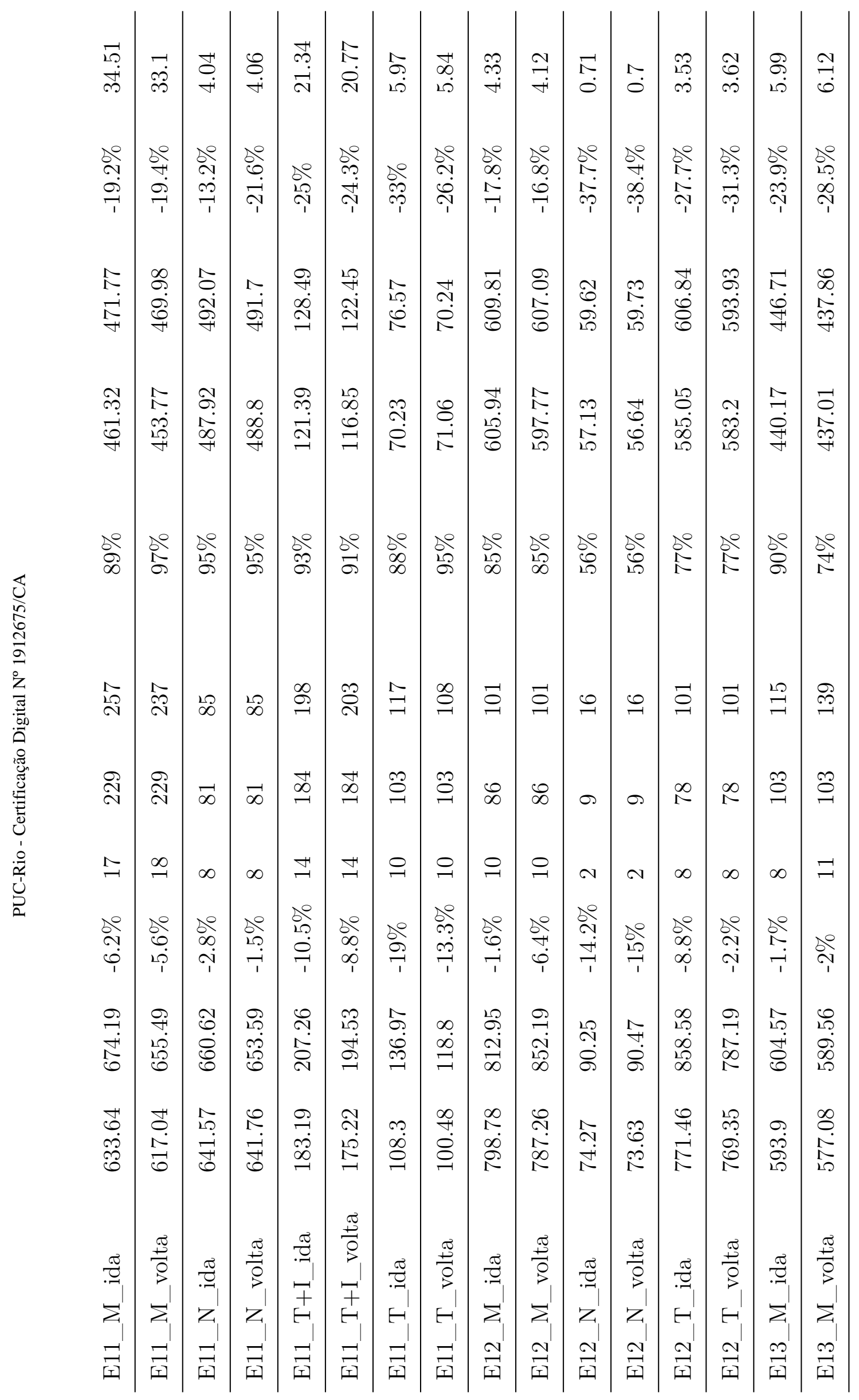




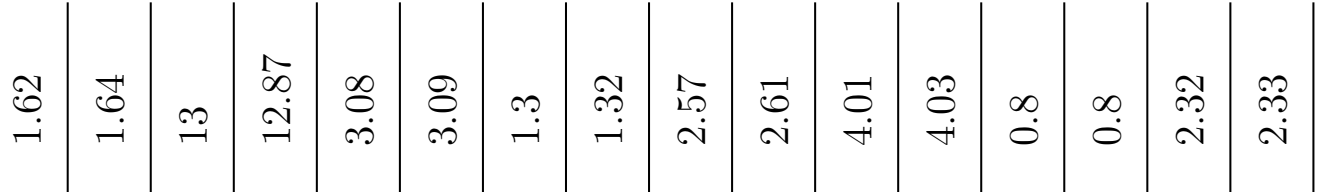

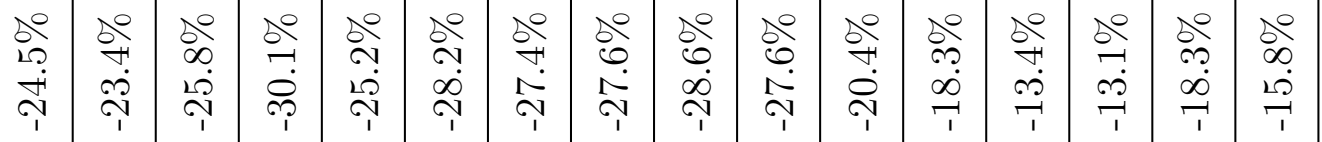

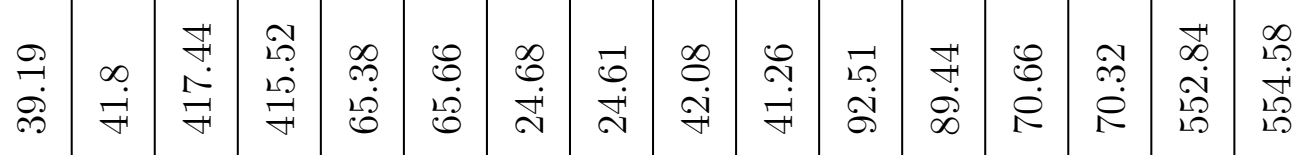

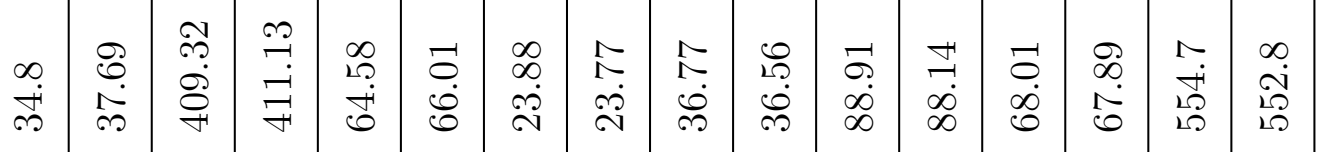

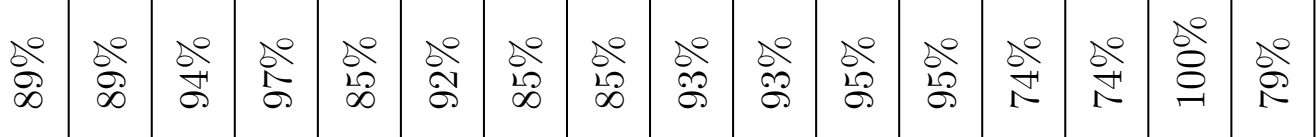

$$
\begin{aligned}
& \text { 急 }
\end{aligned}
$$

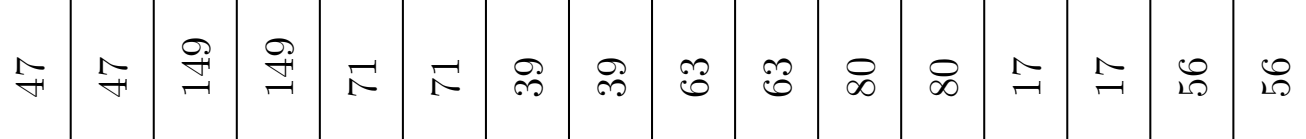

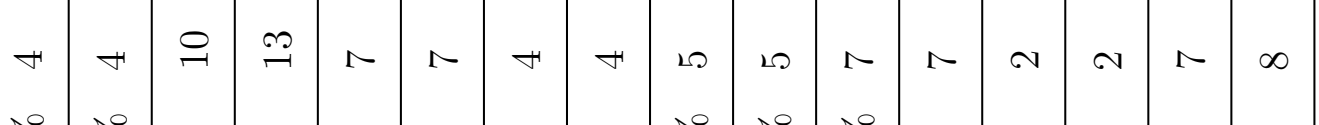

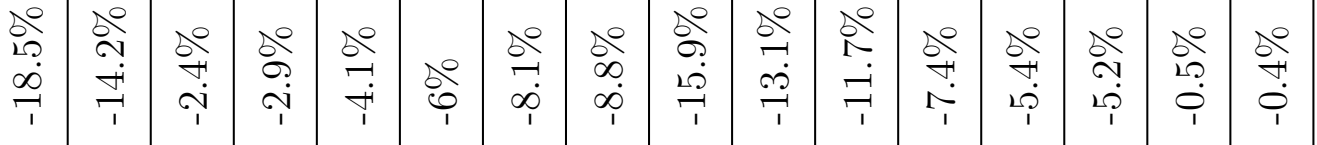

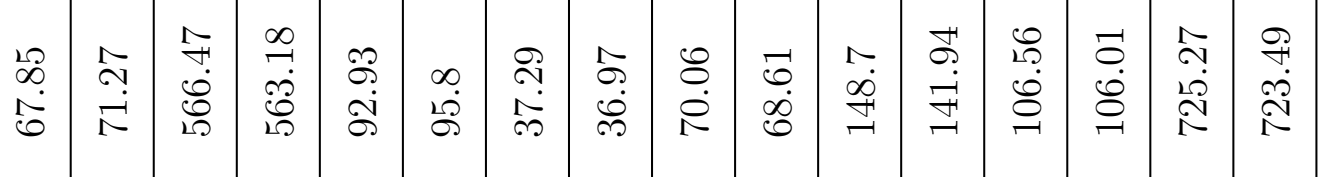

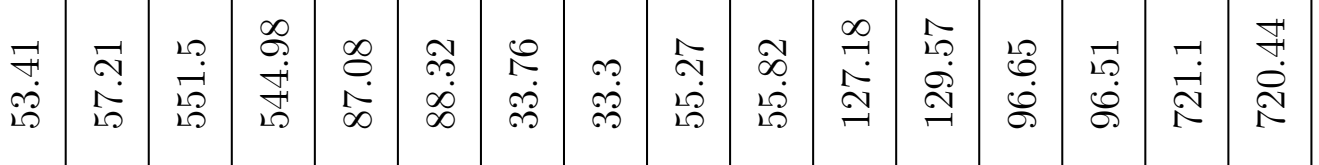

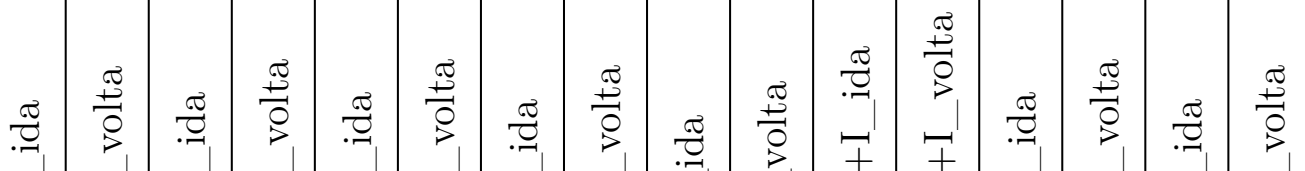

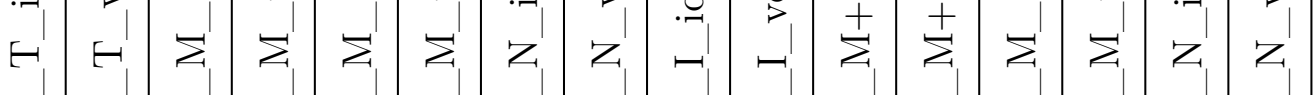

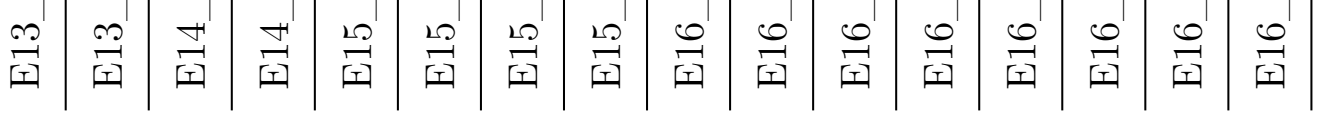




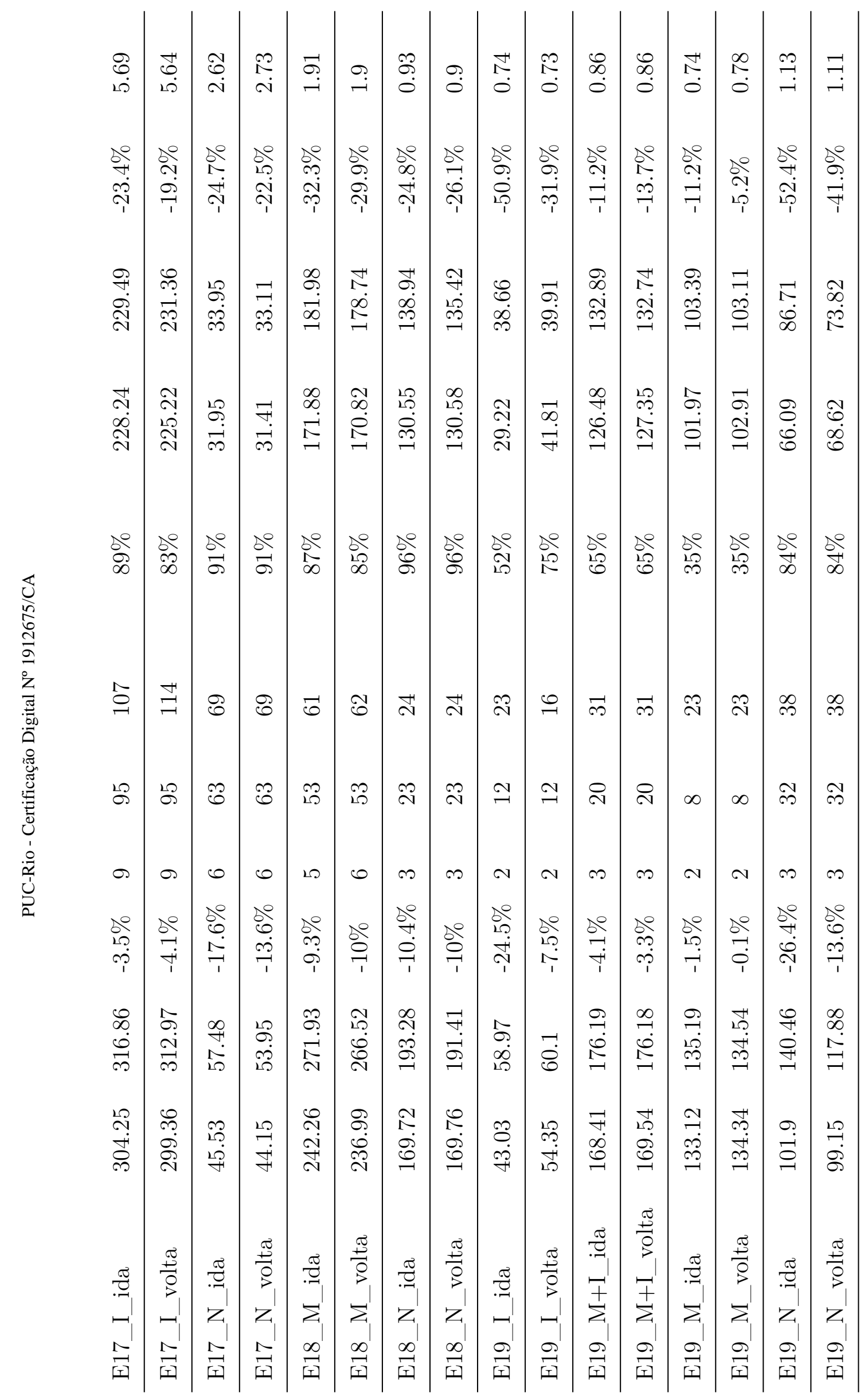




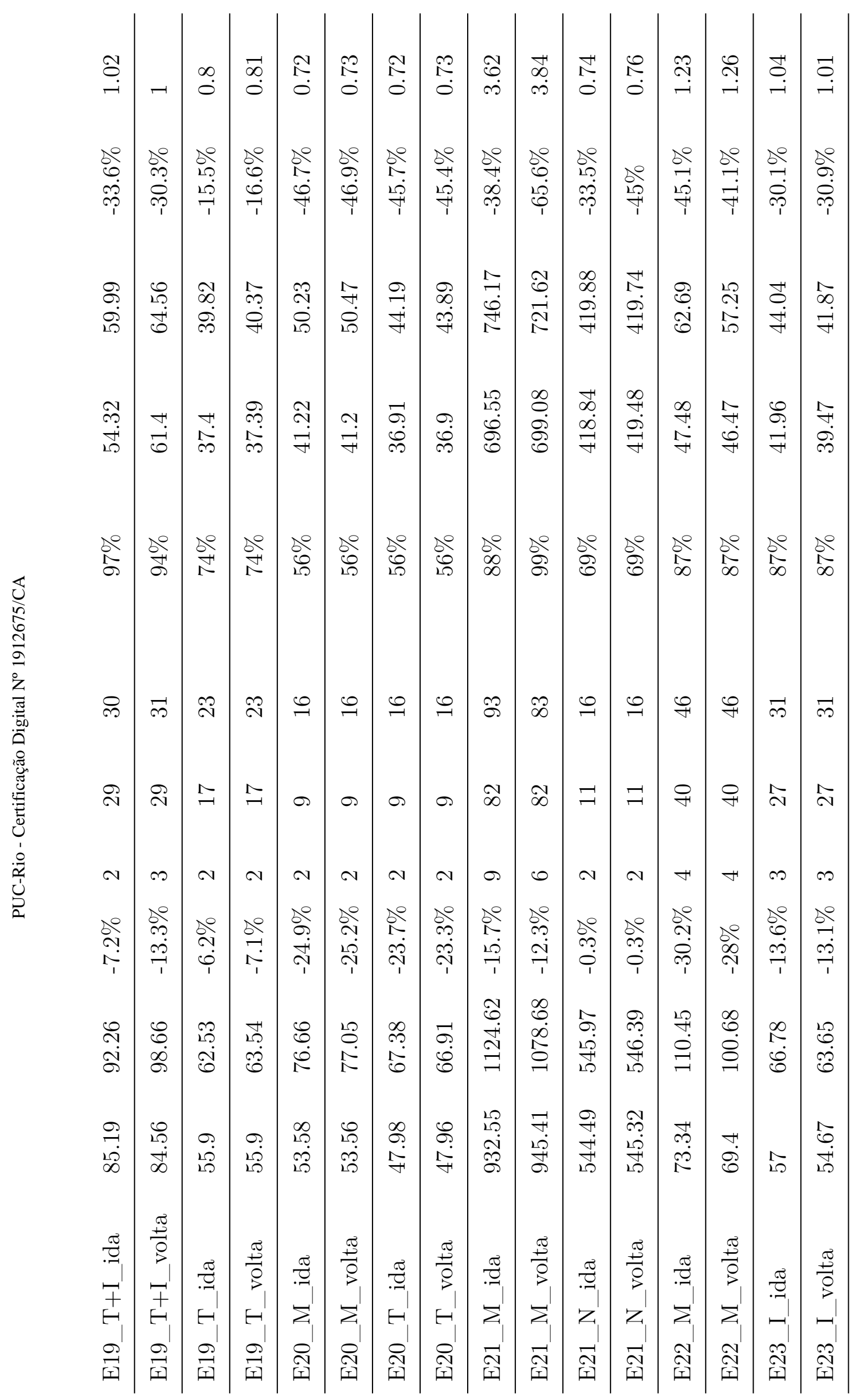




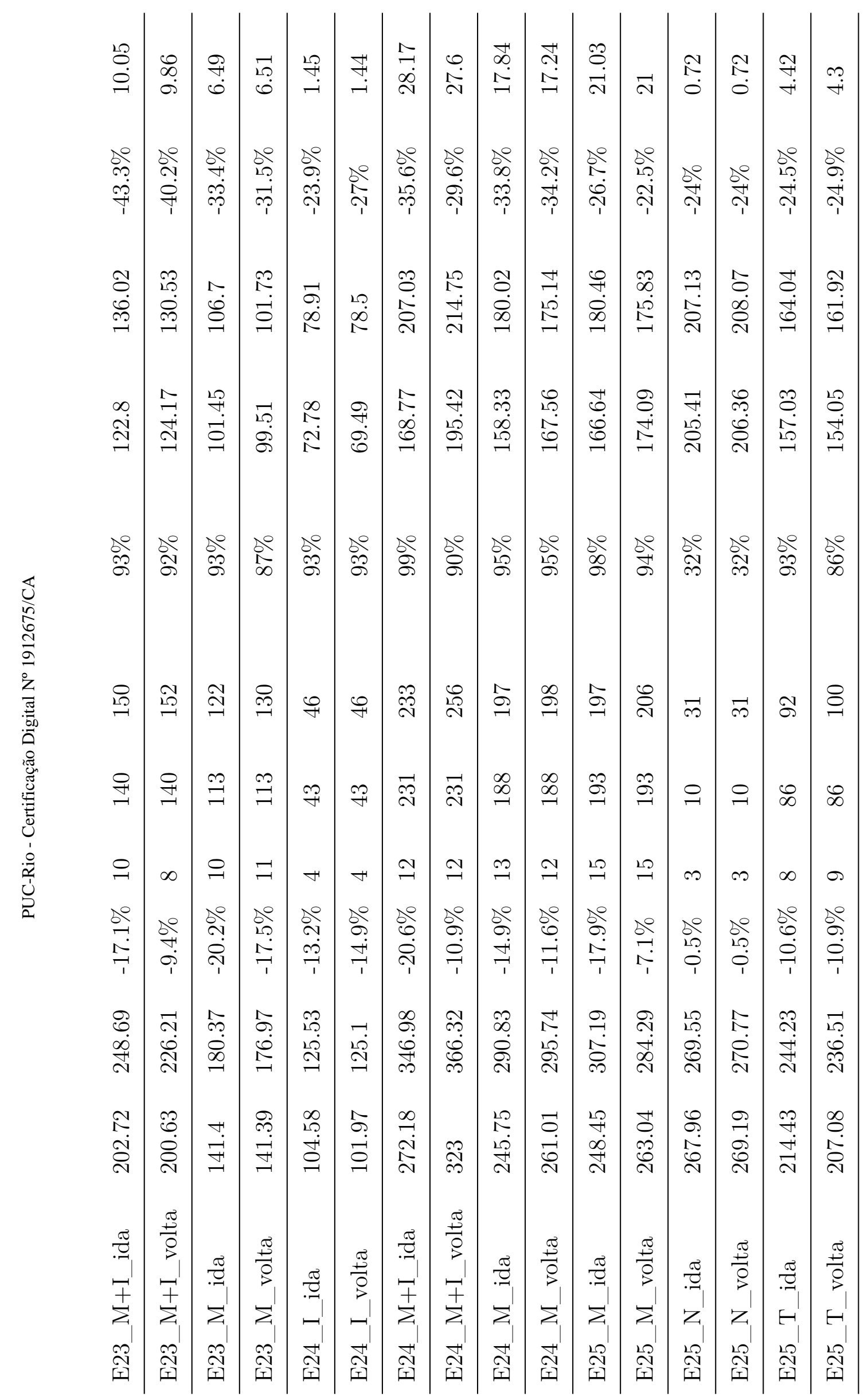




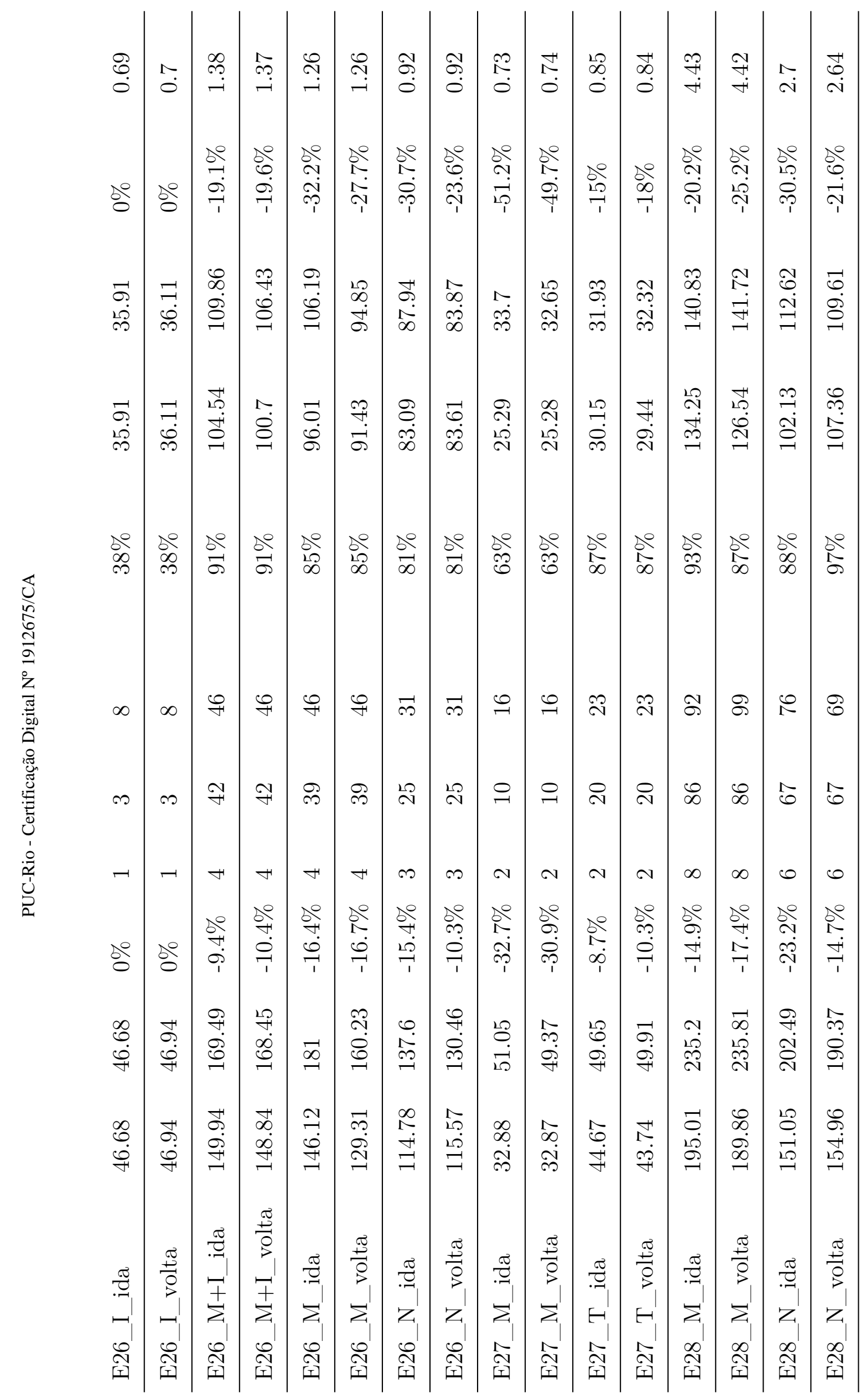




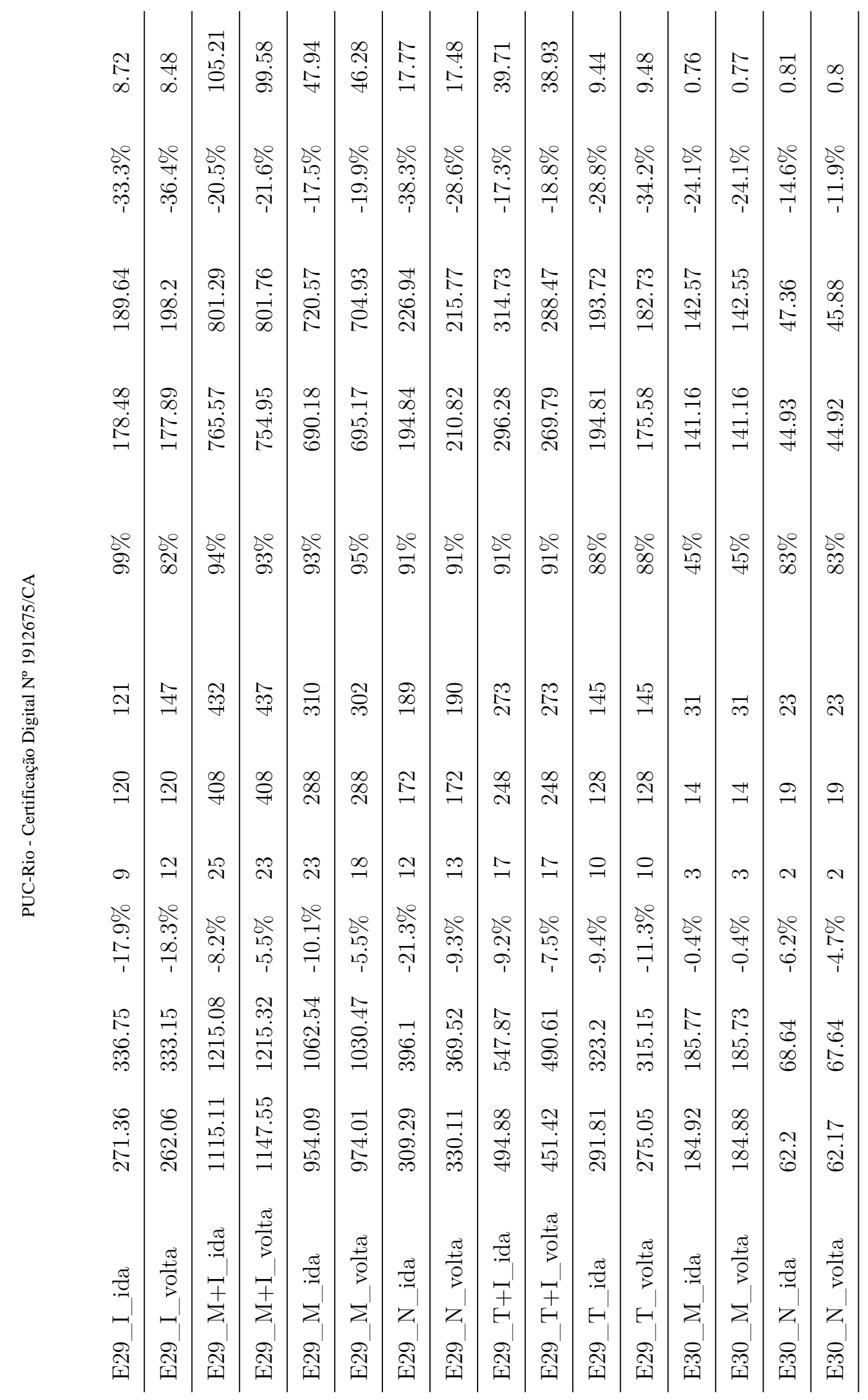




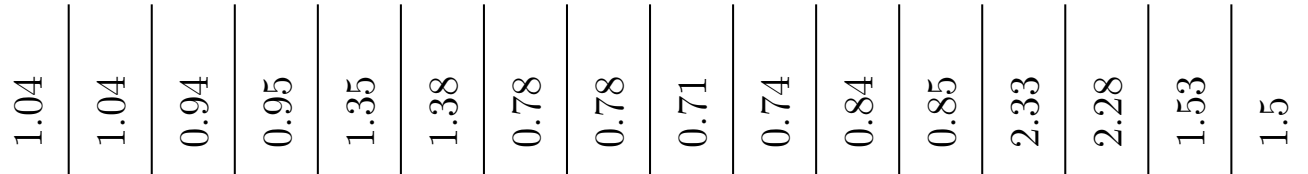

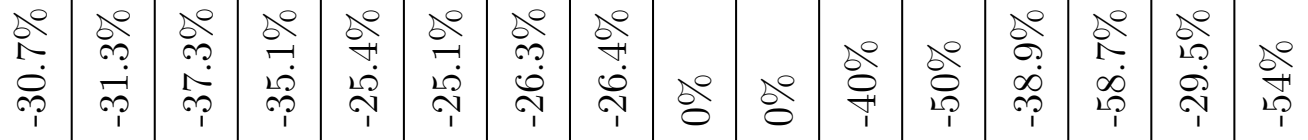

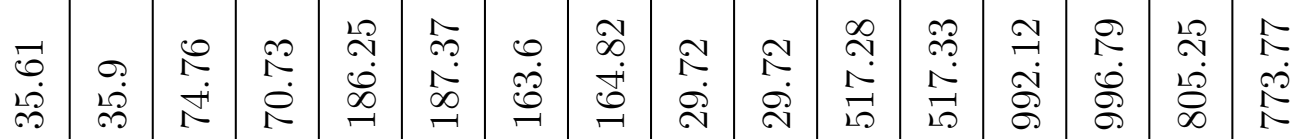

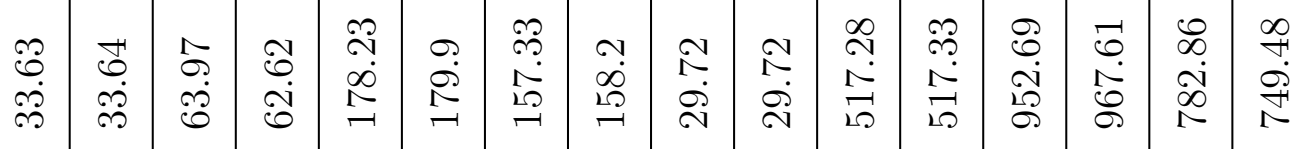

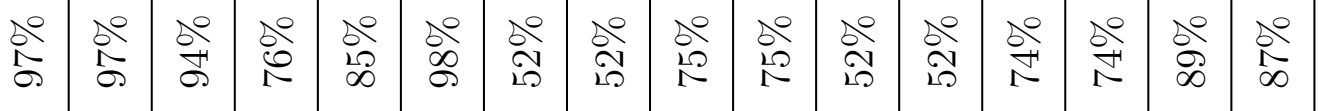

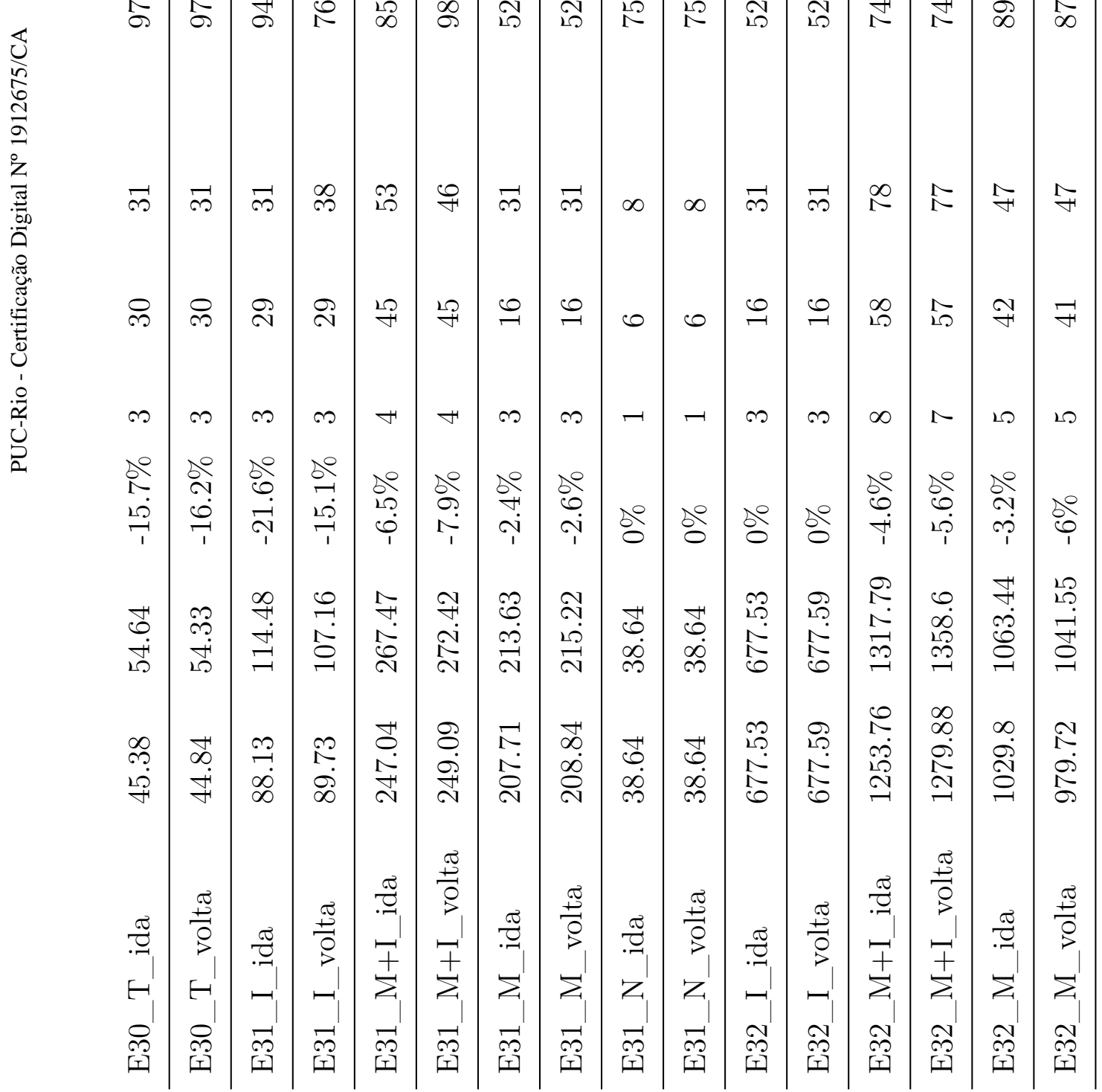




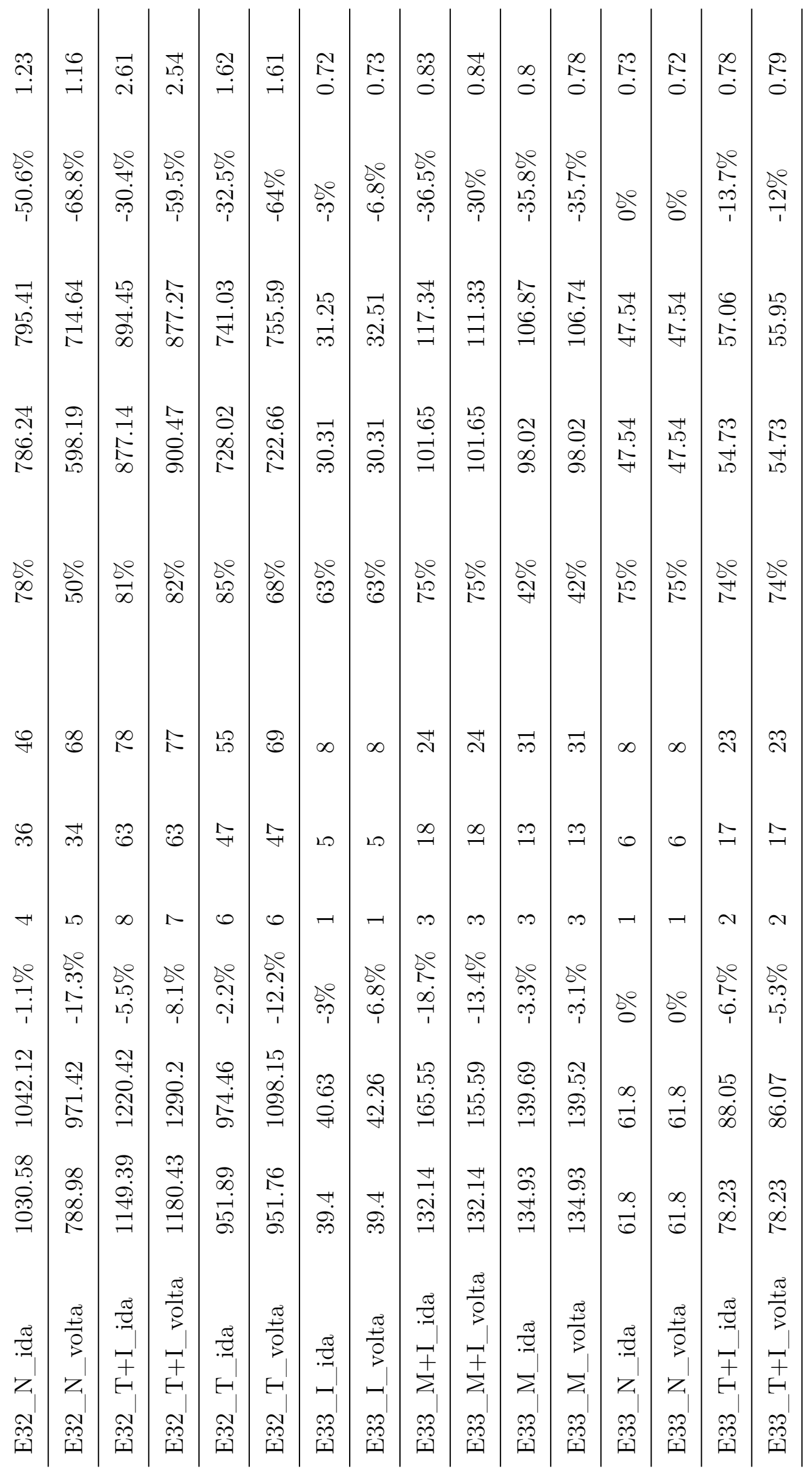




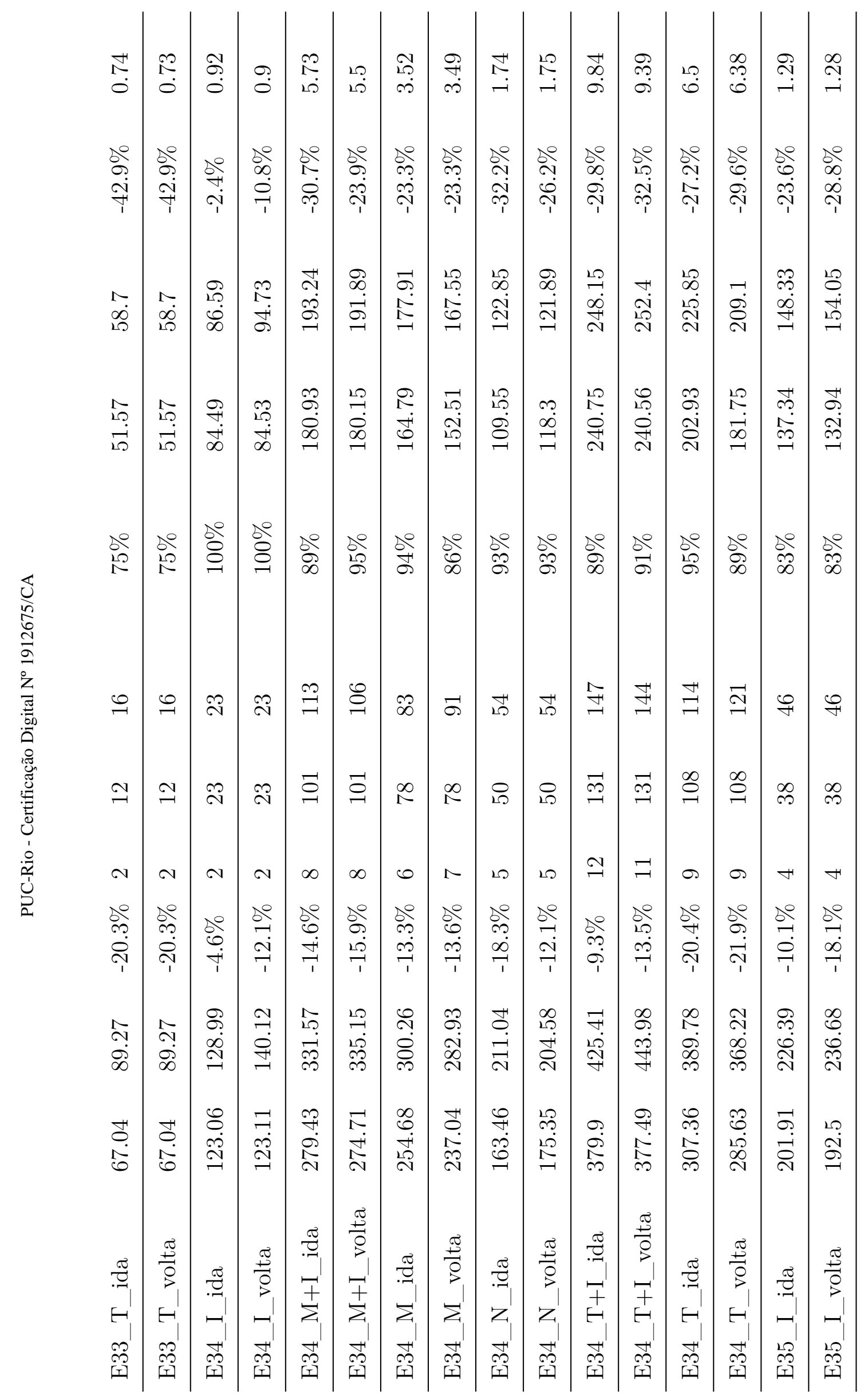




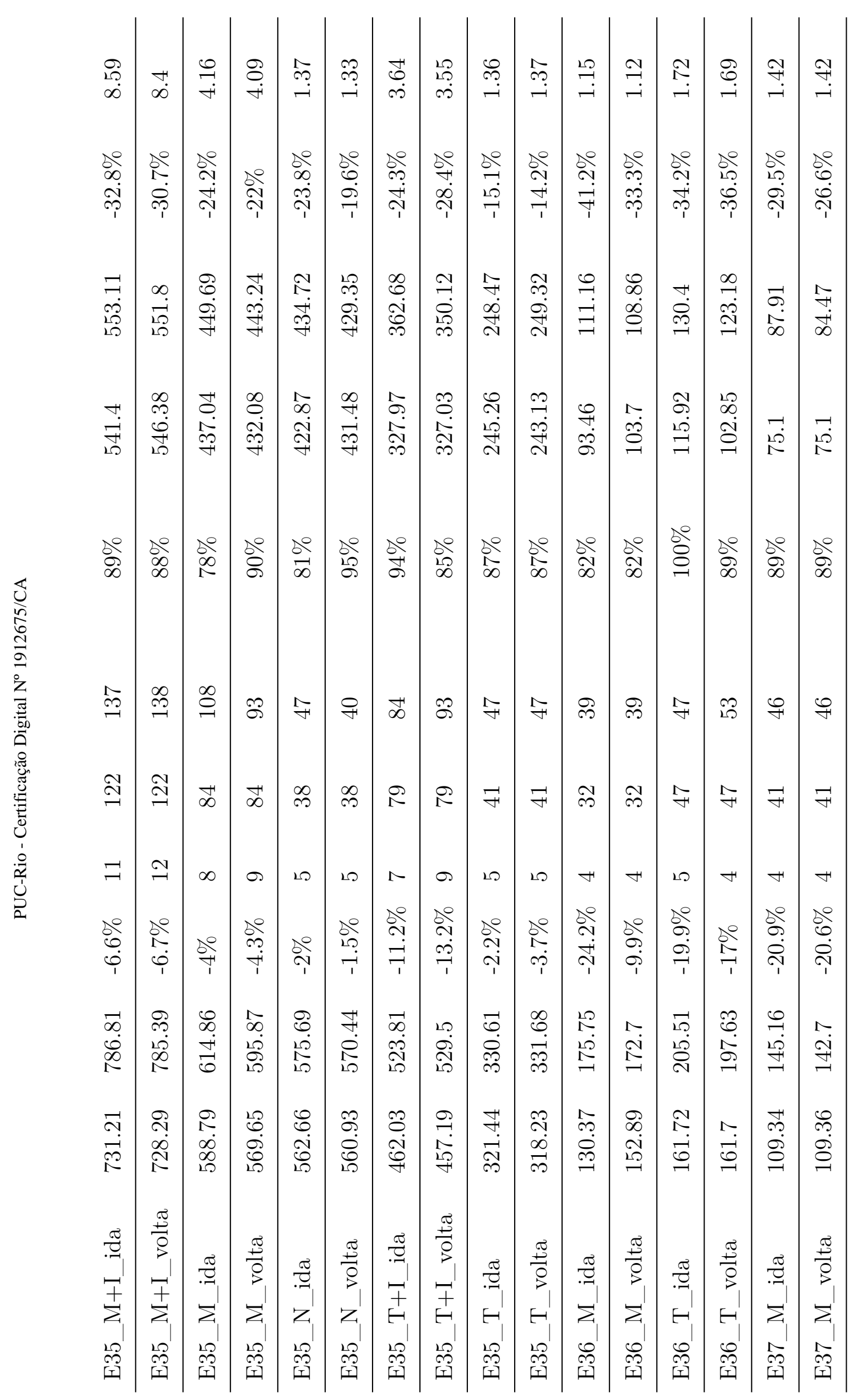




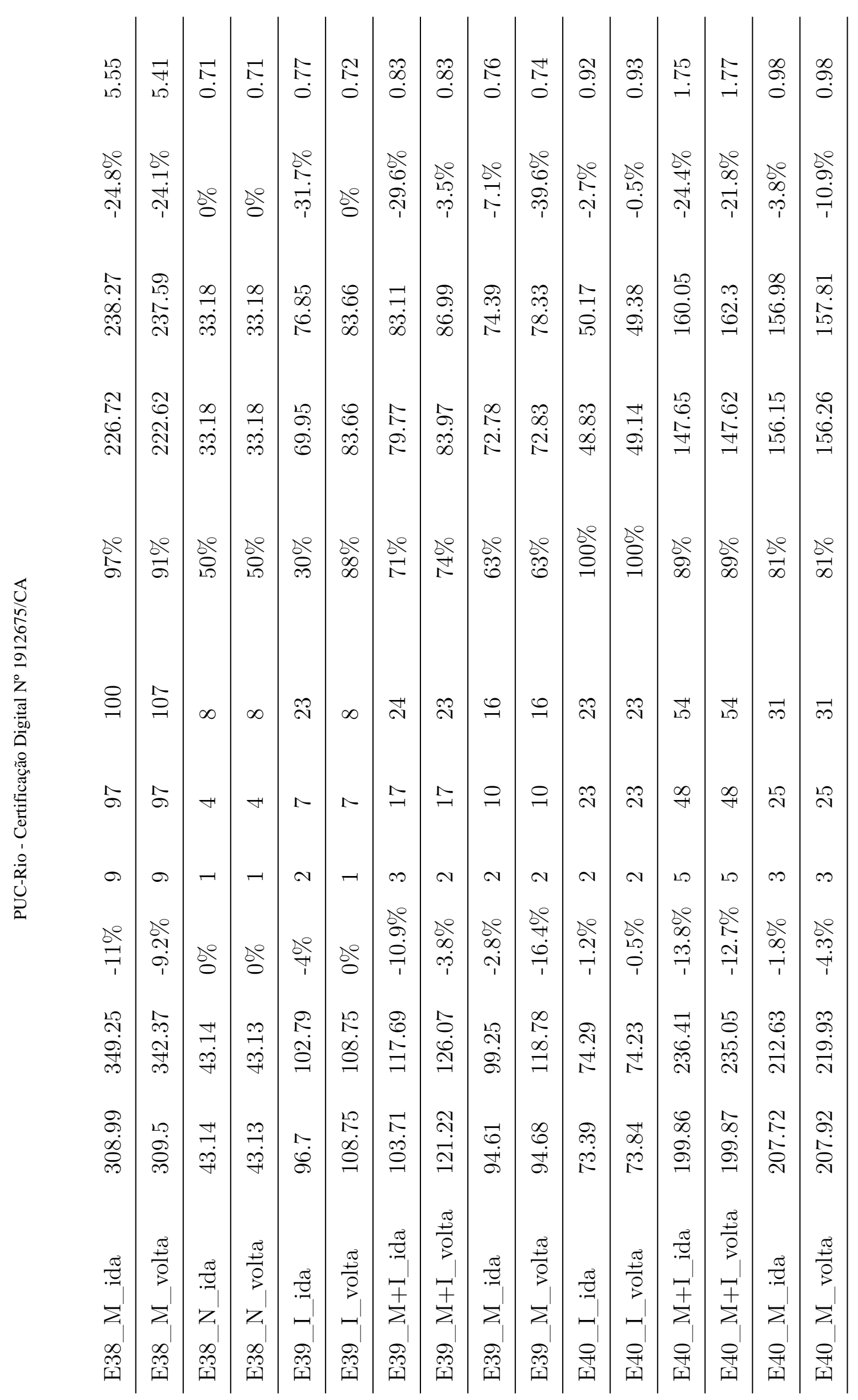




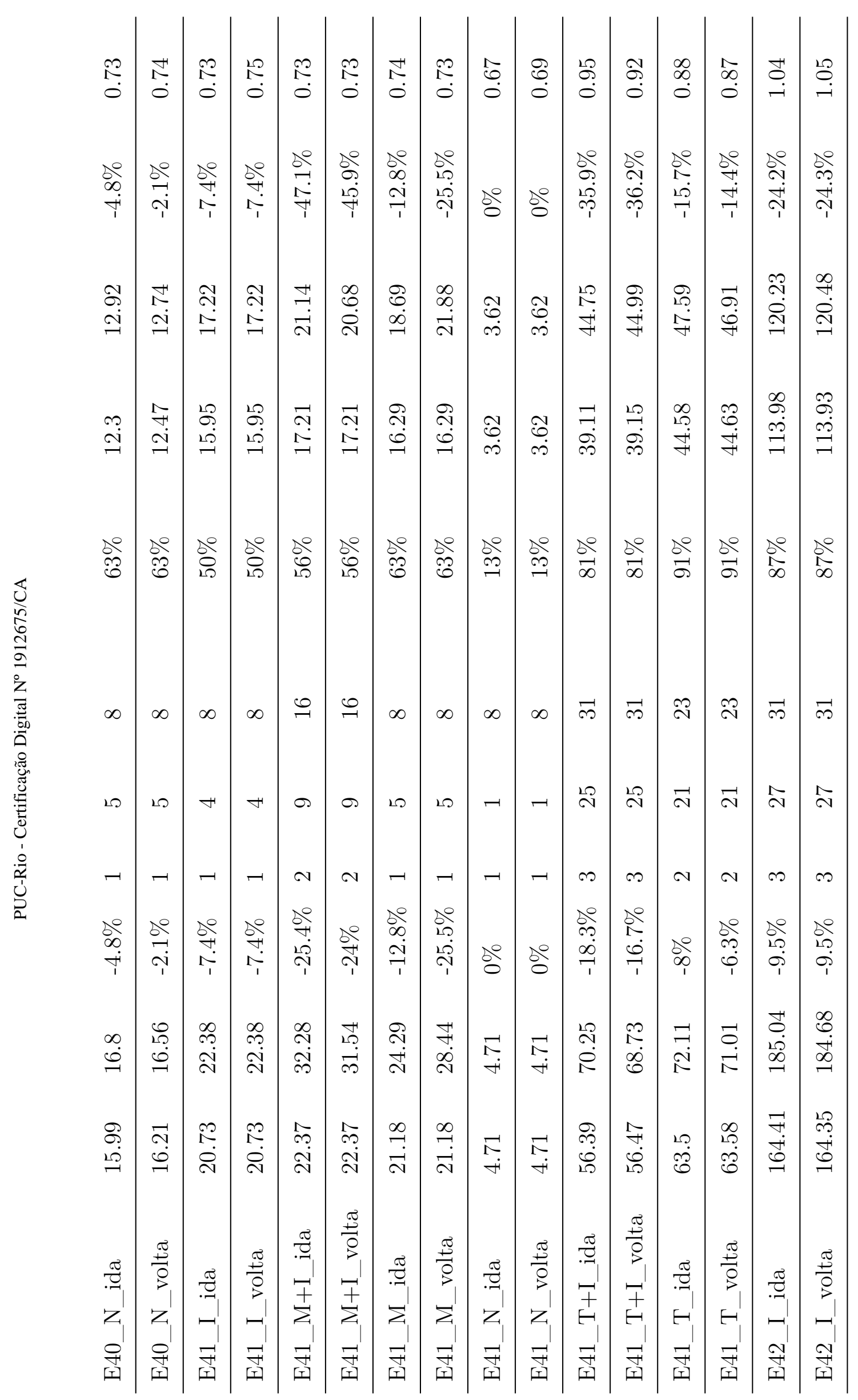




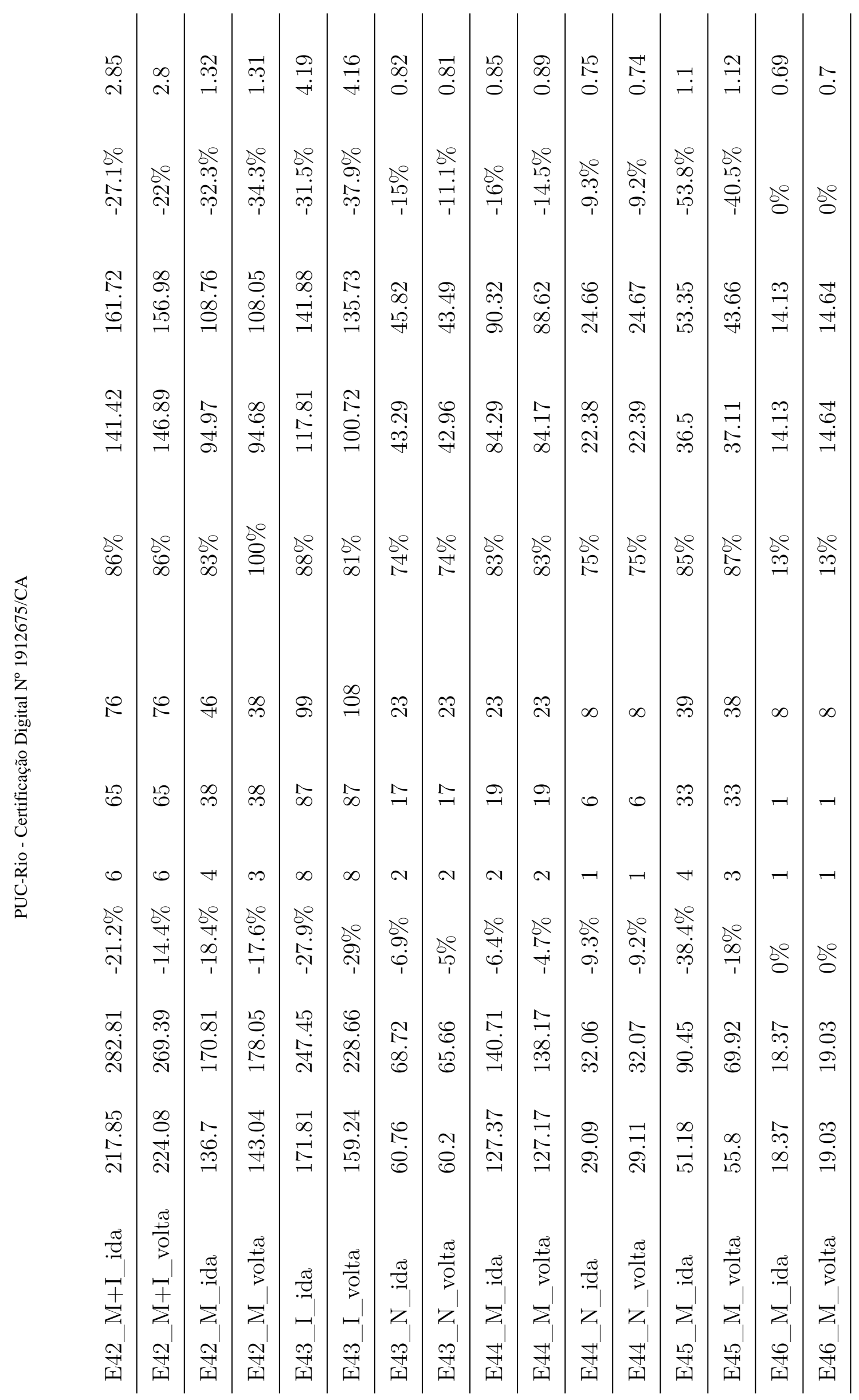




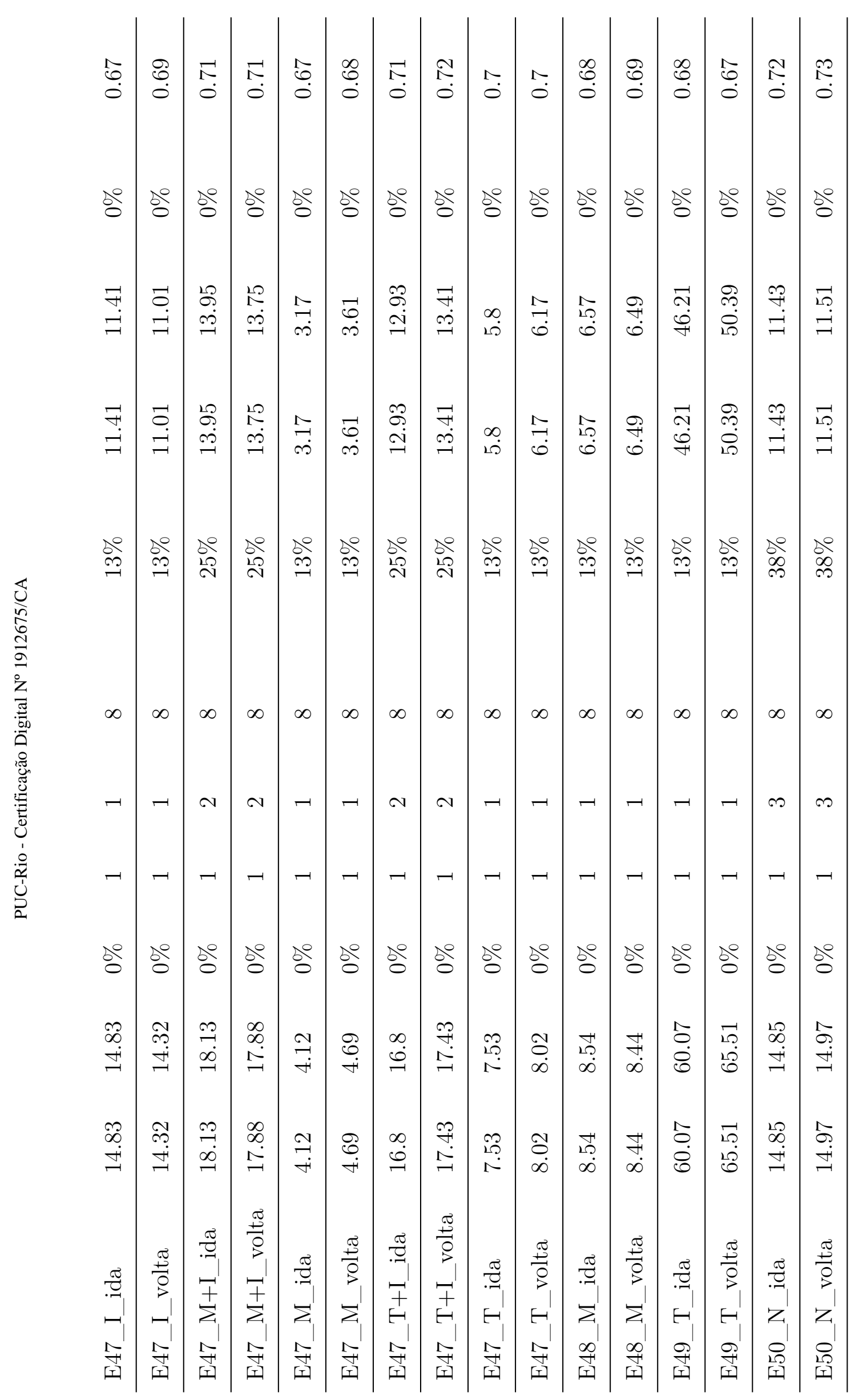




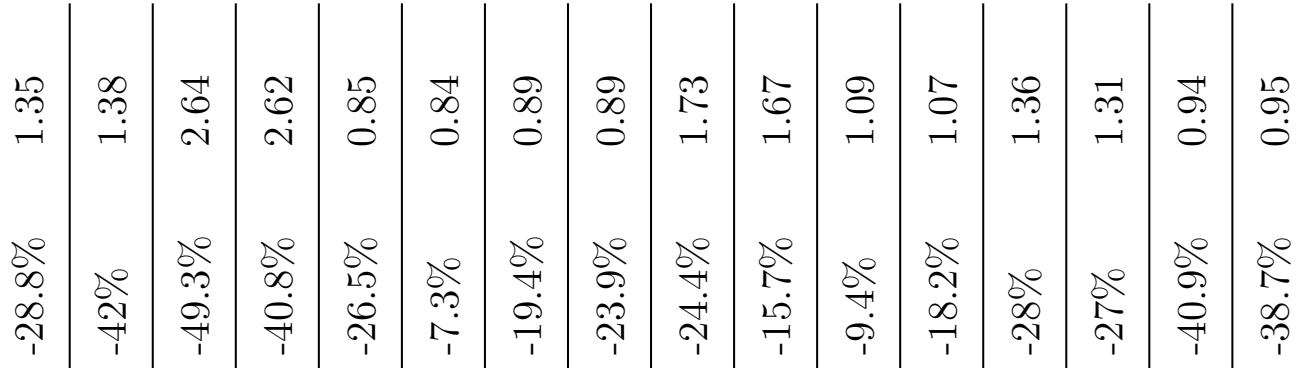

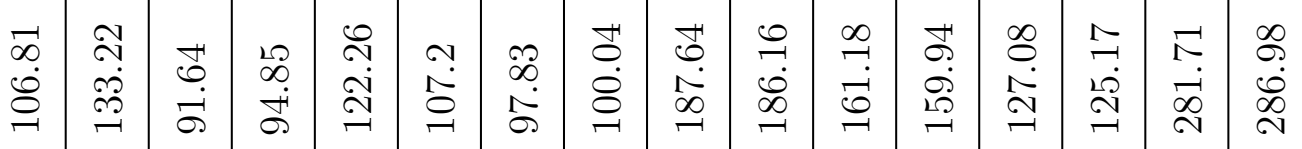

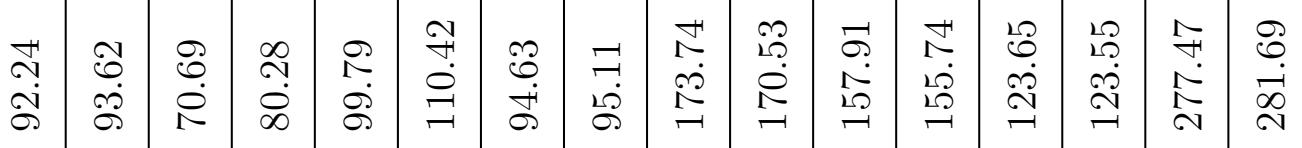

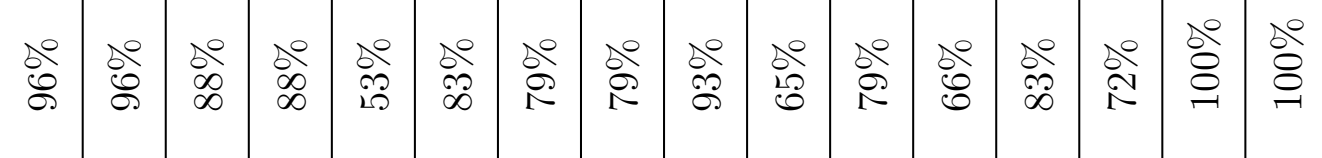

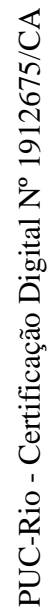

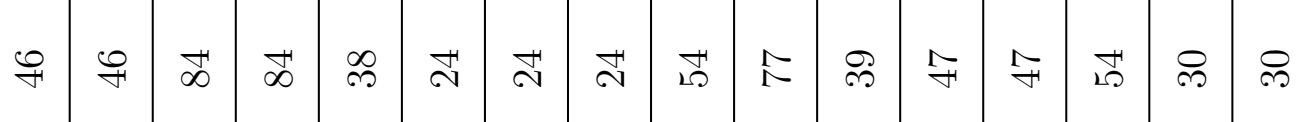

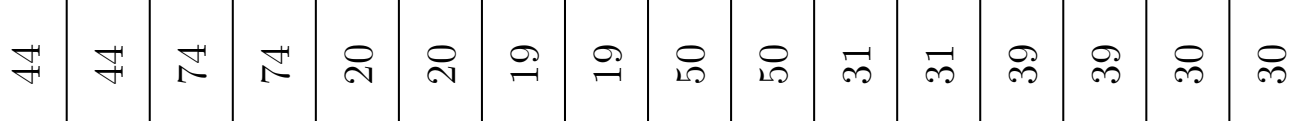

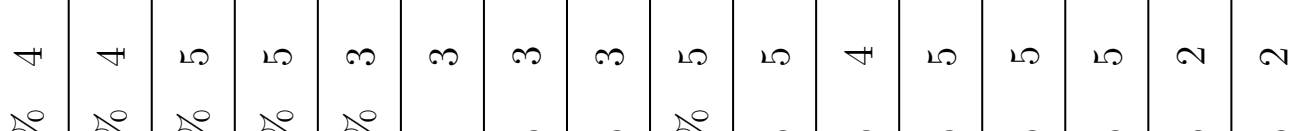

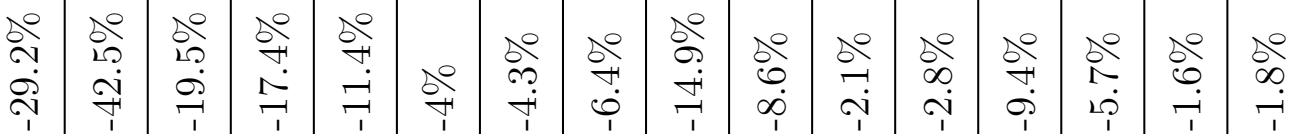

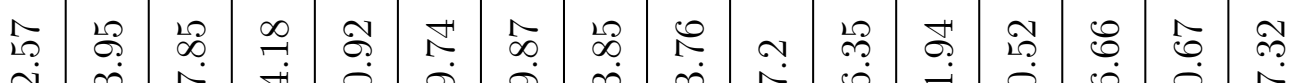

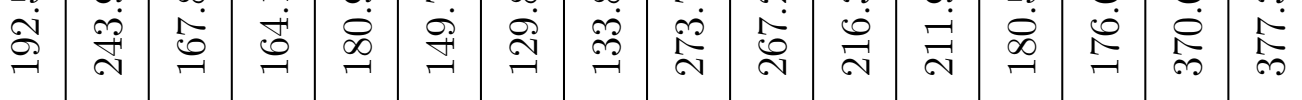

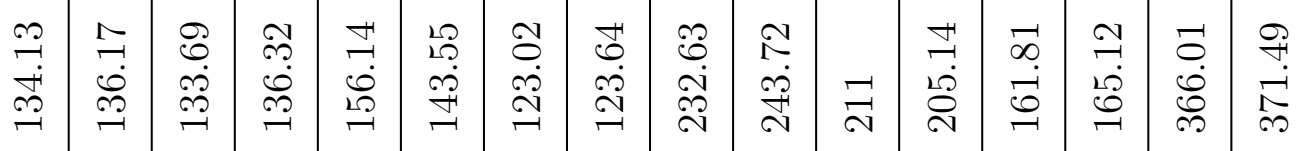

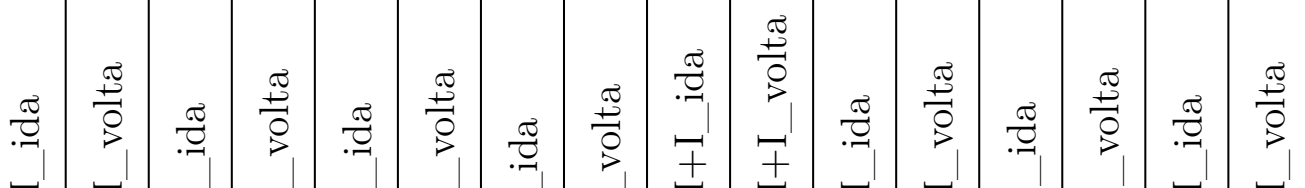

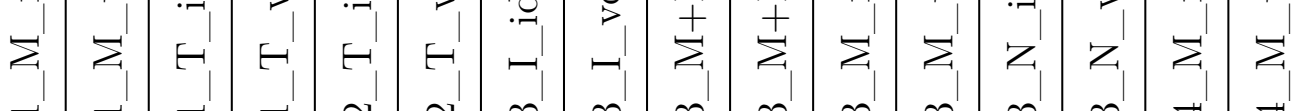

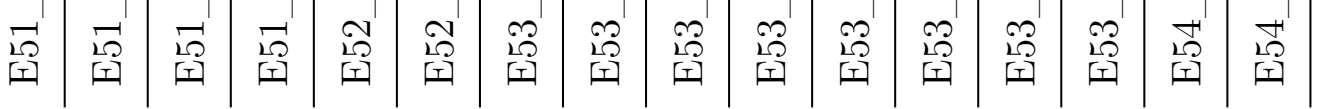




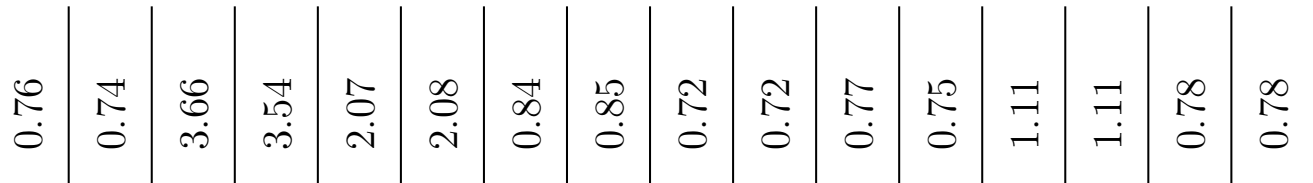

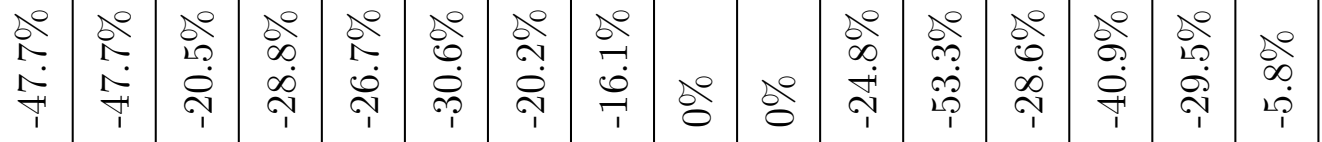

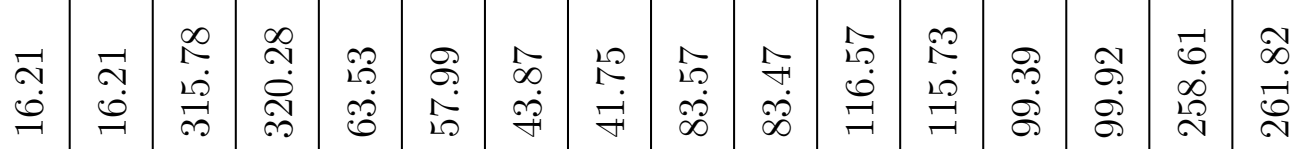

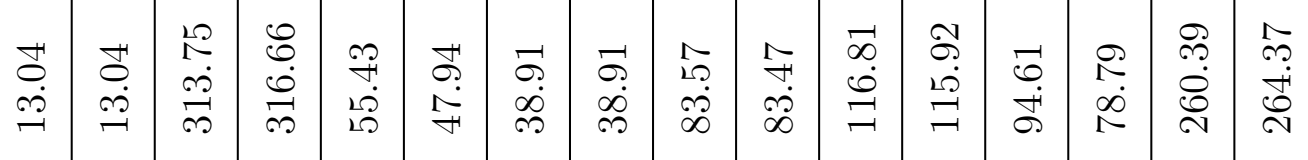

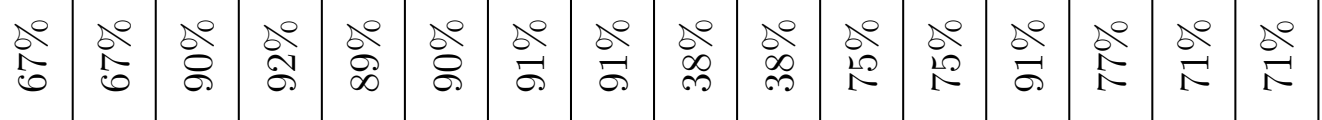

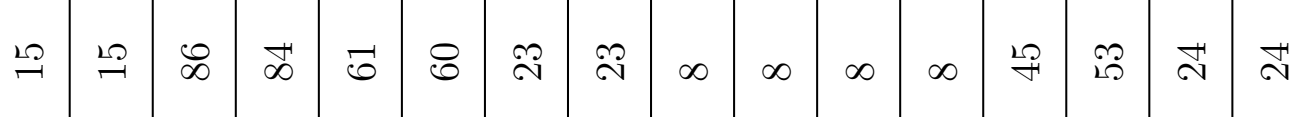

$$
\begin{aligned}
& \because
\end{aligned}
$$

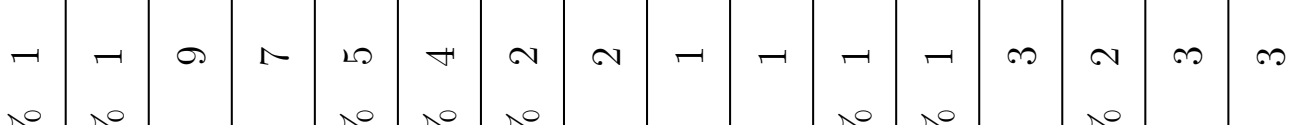

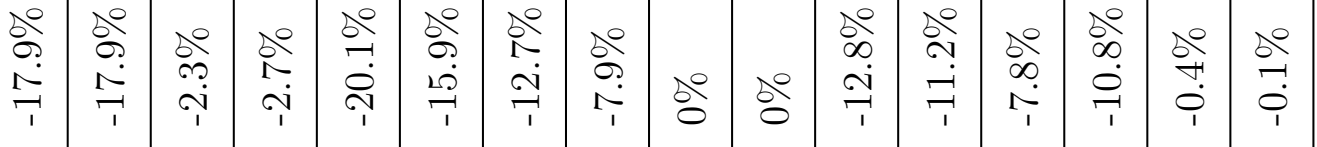

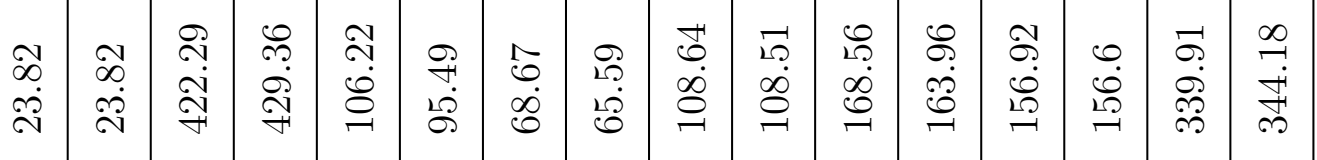

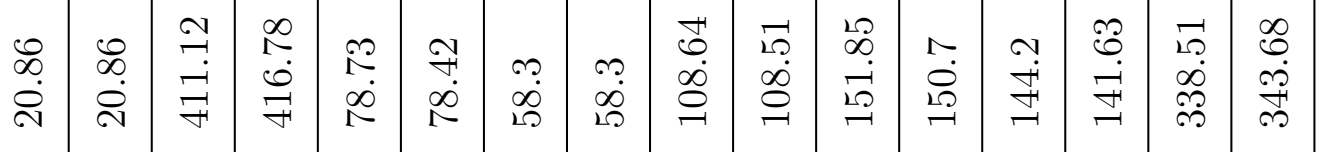

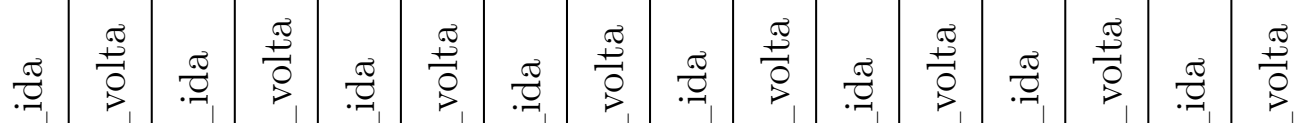

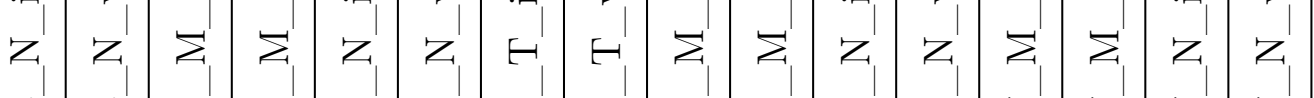

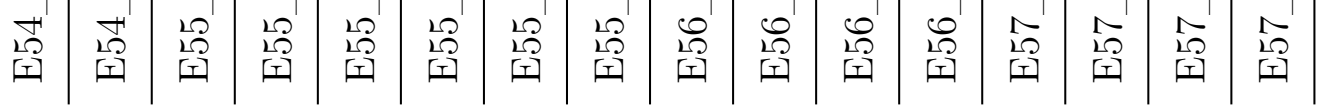

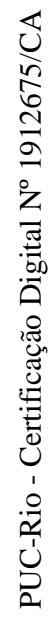




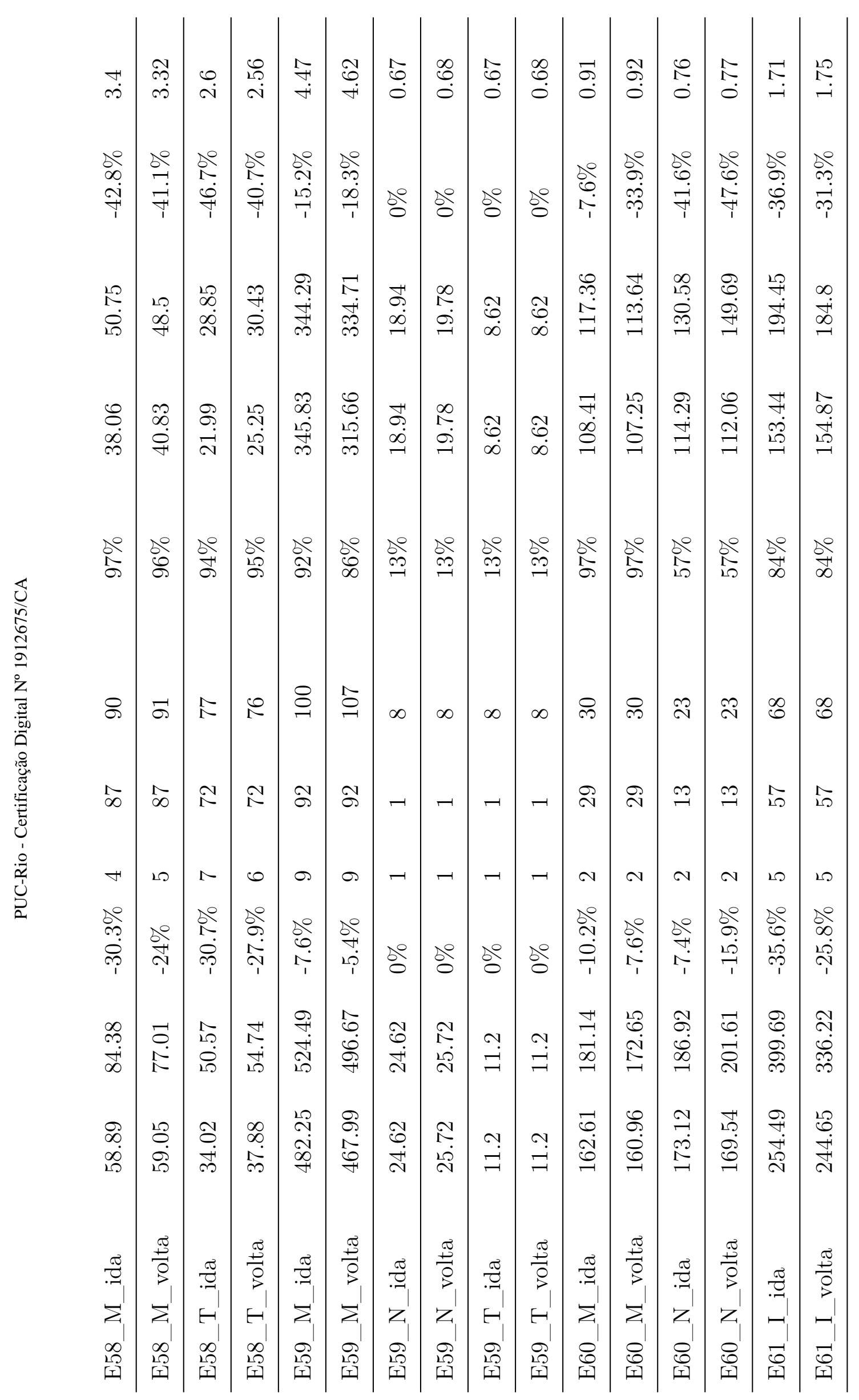




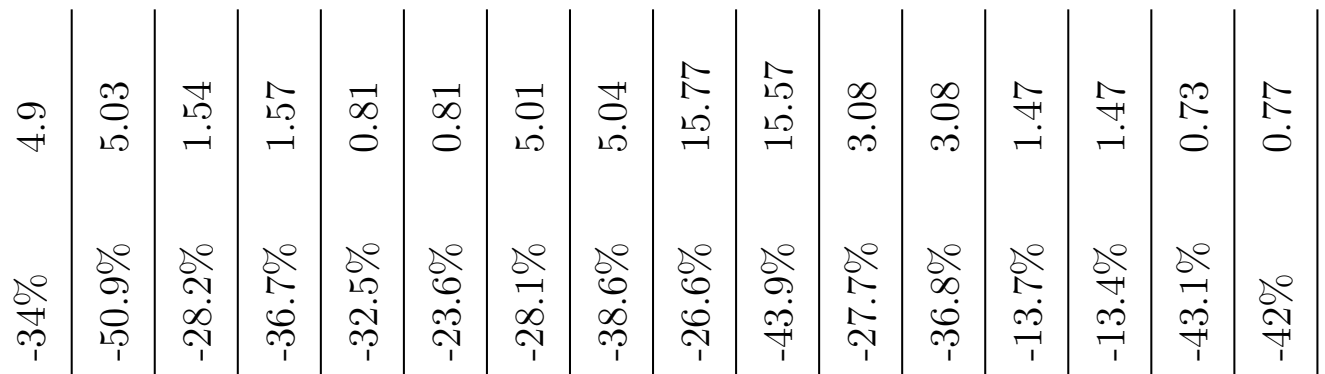

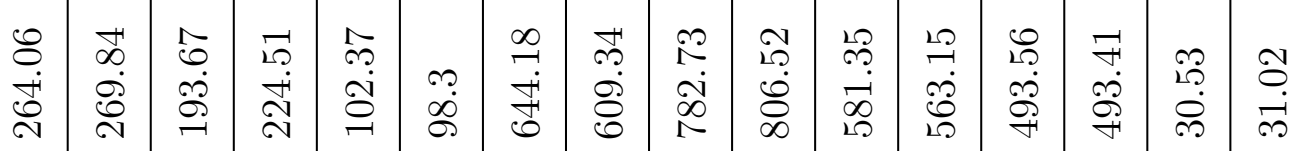

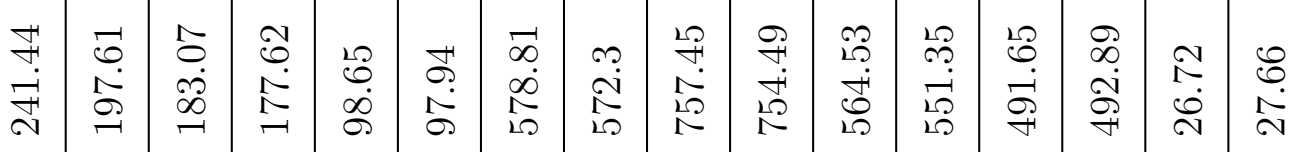

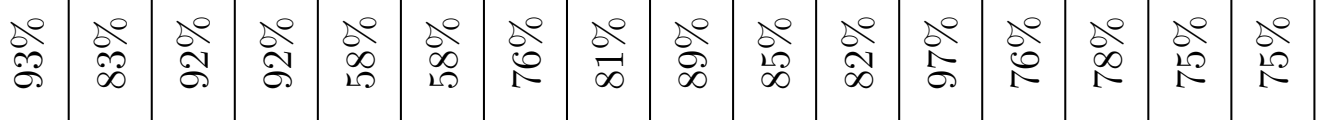

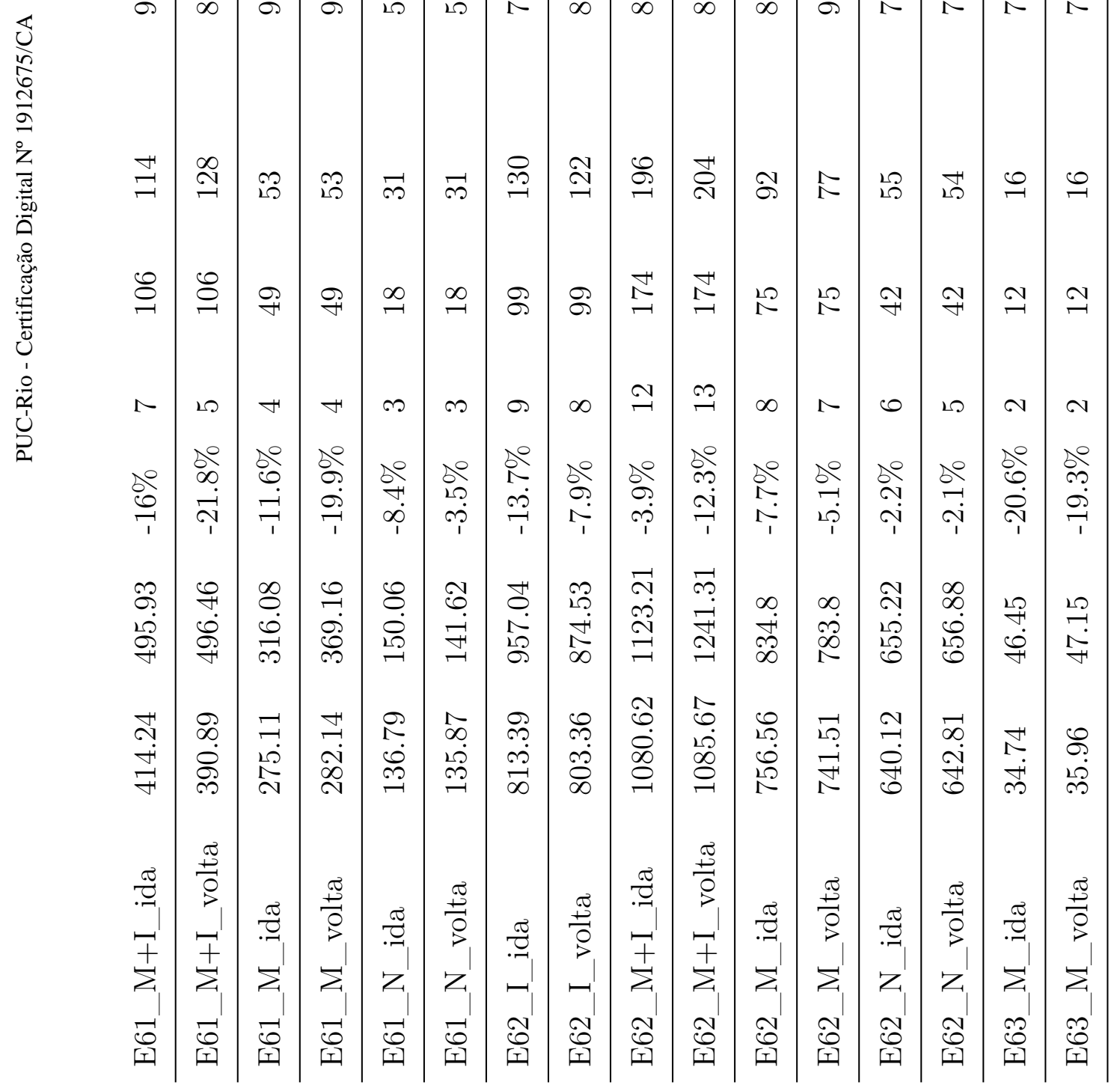




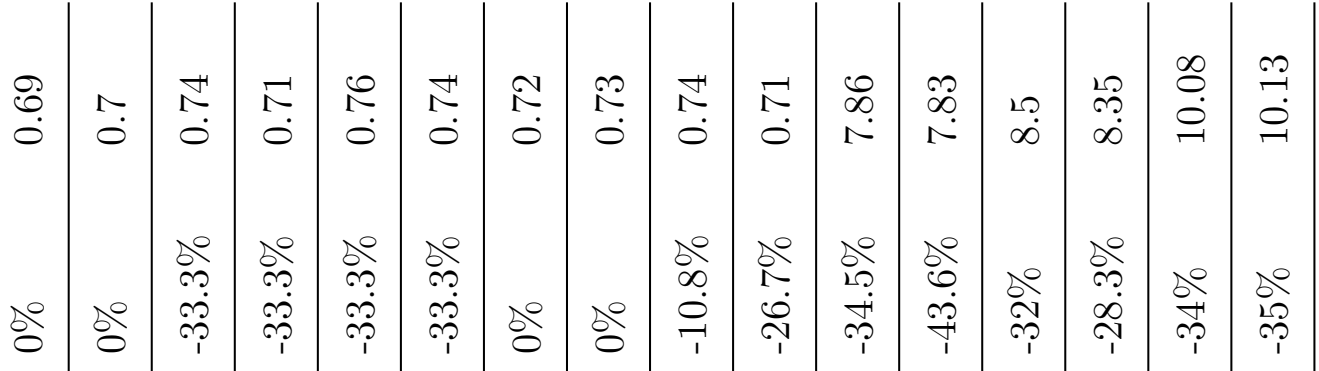

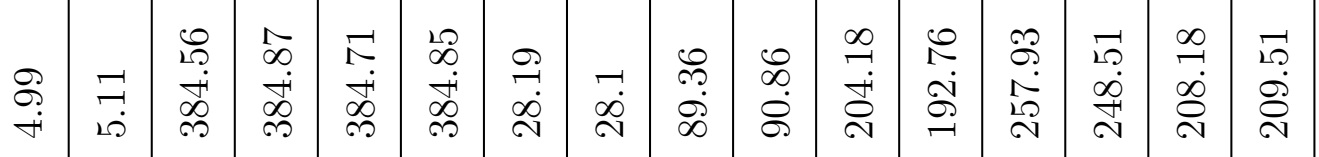

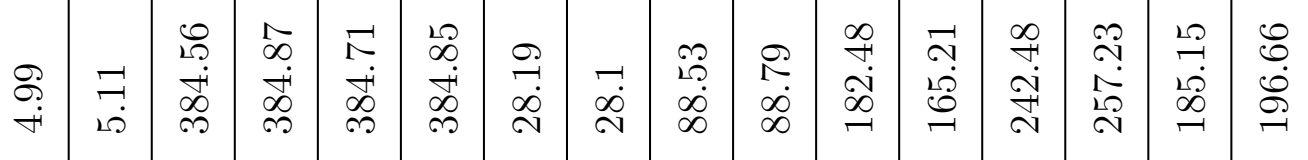

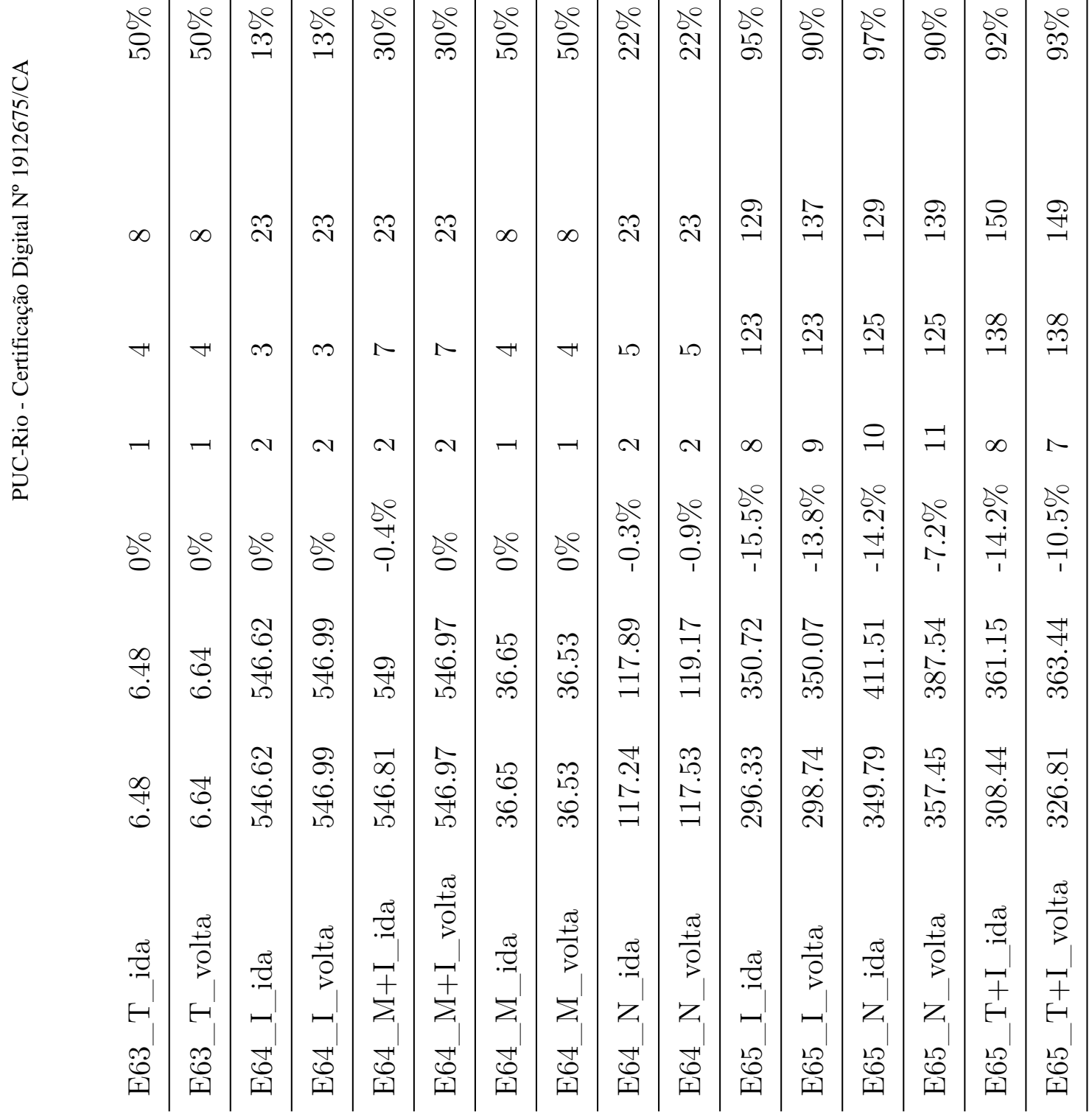




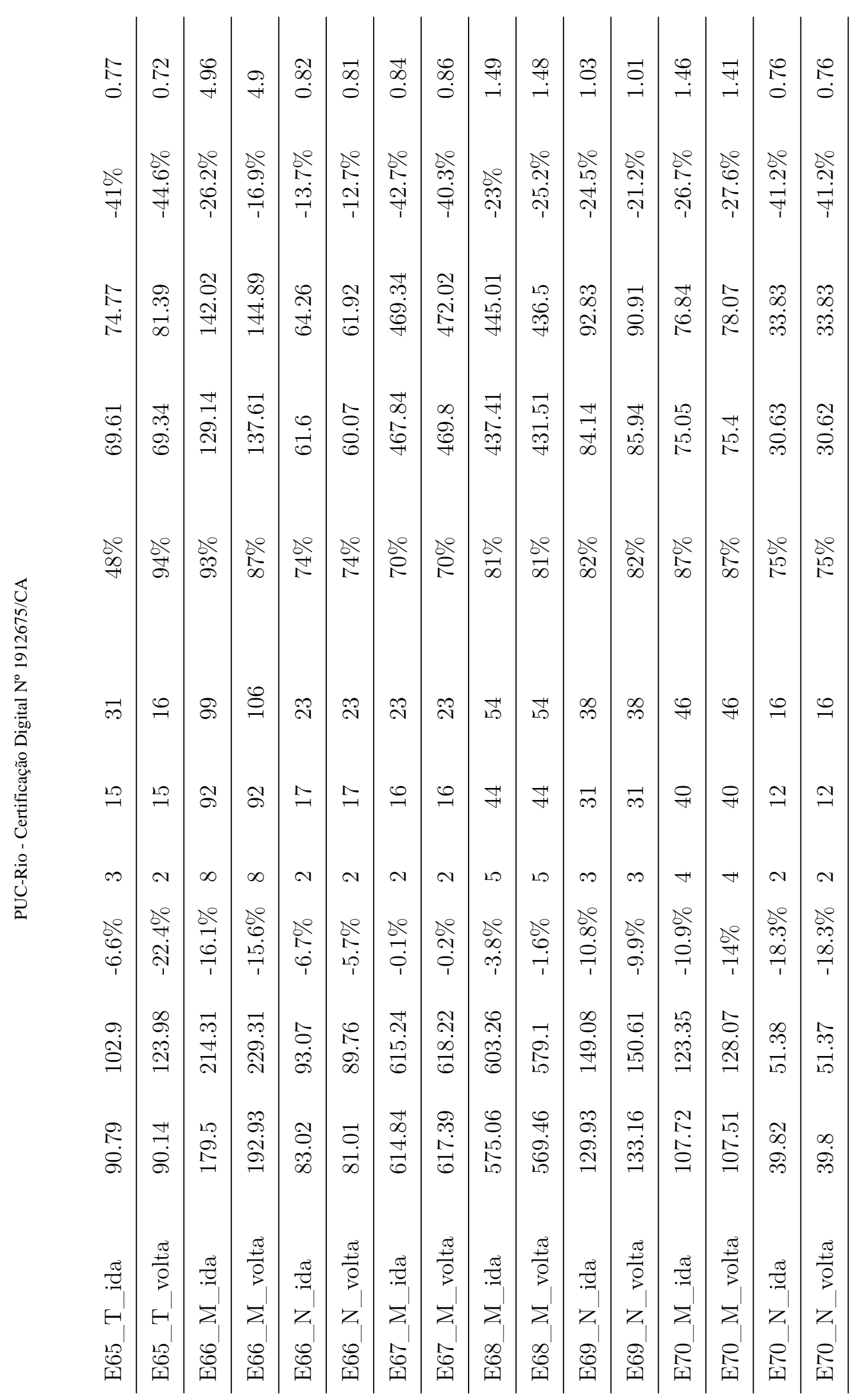




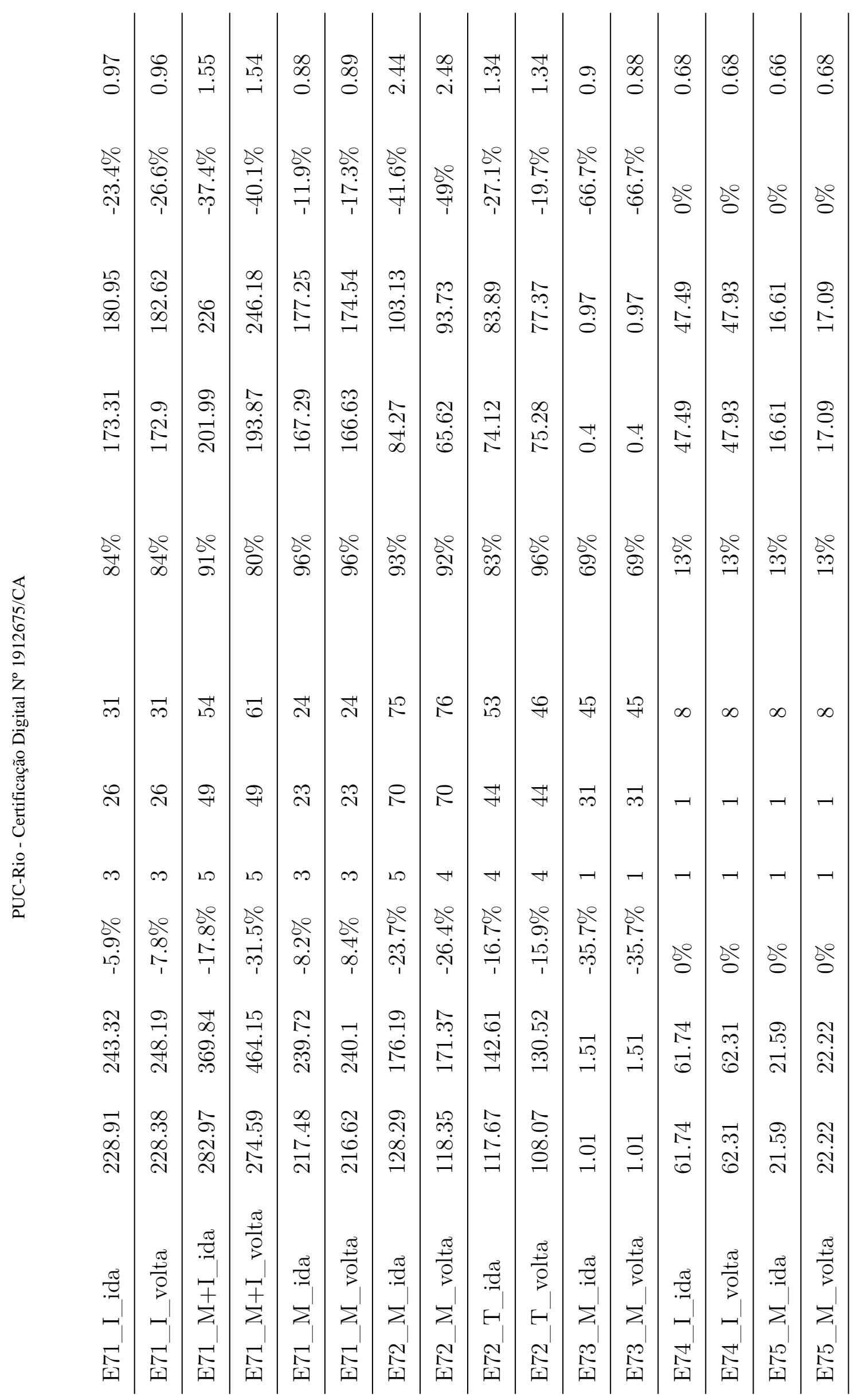




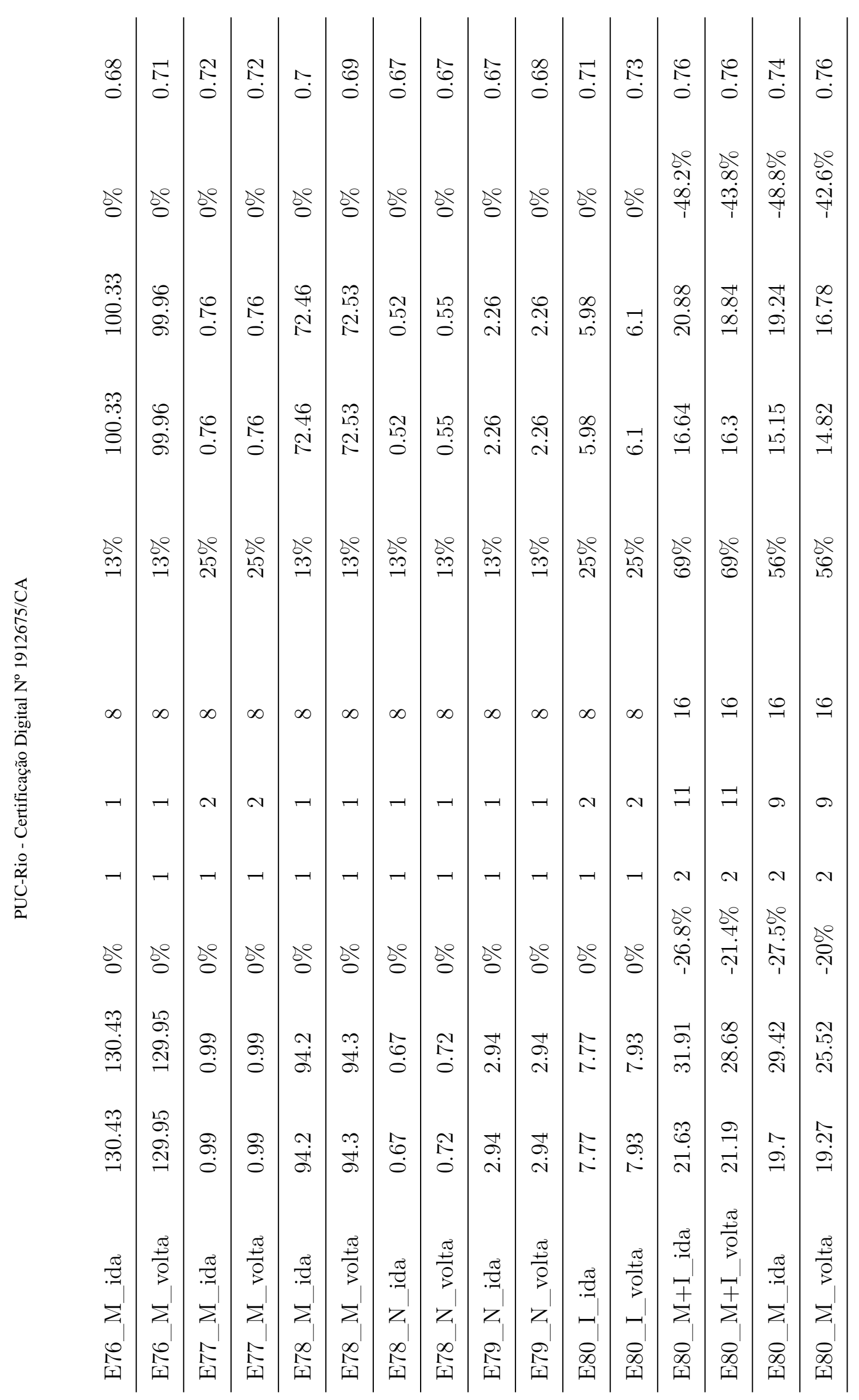




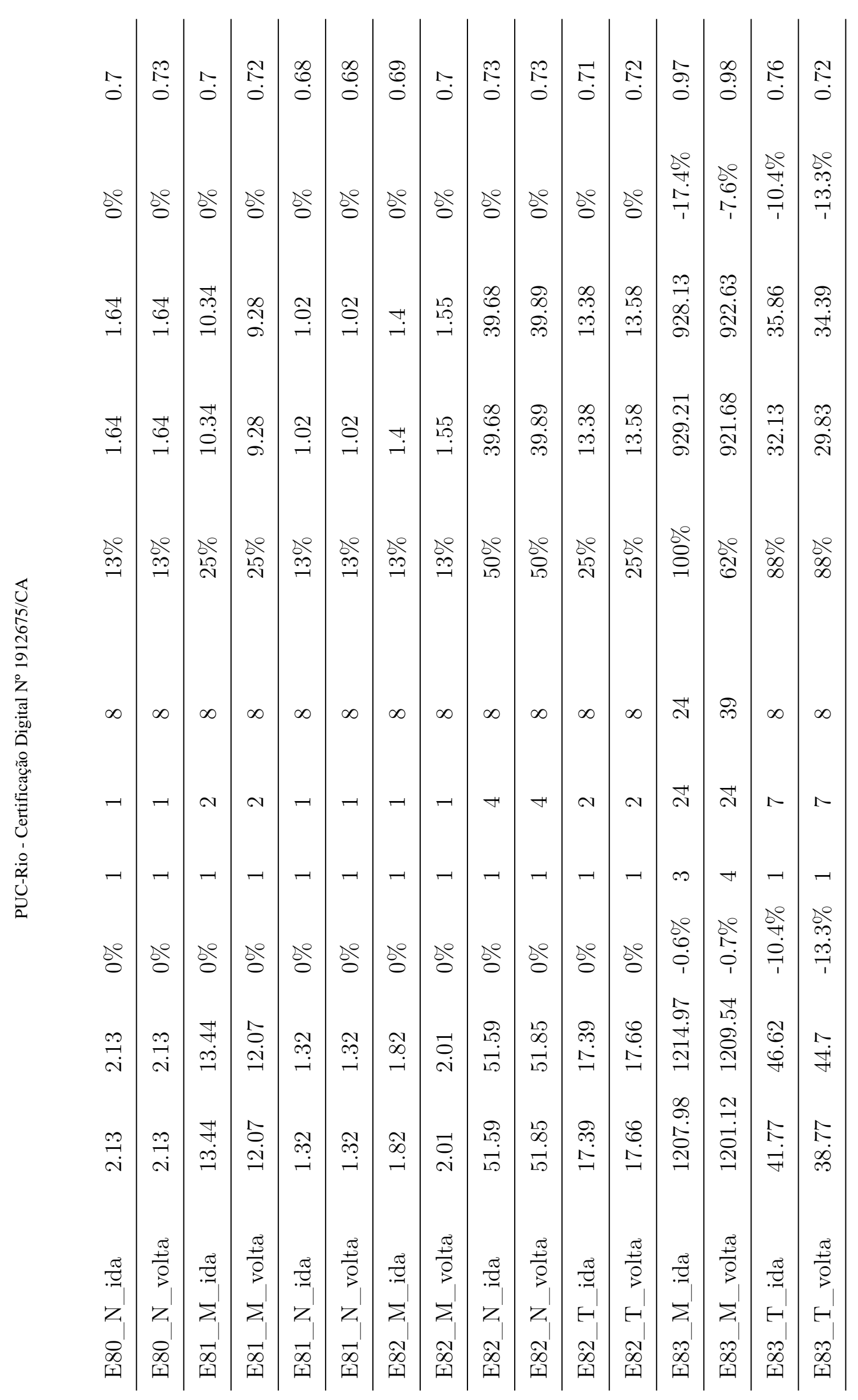




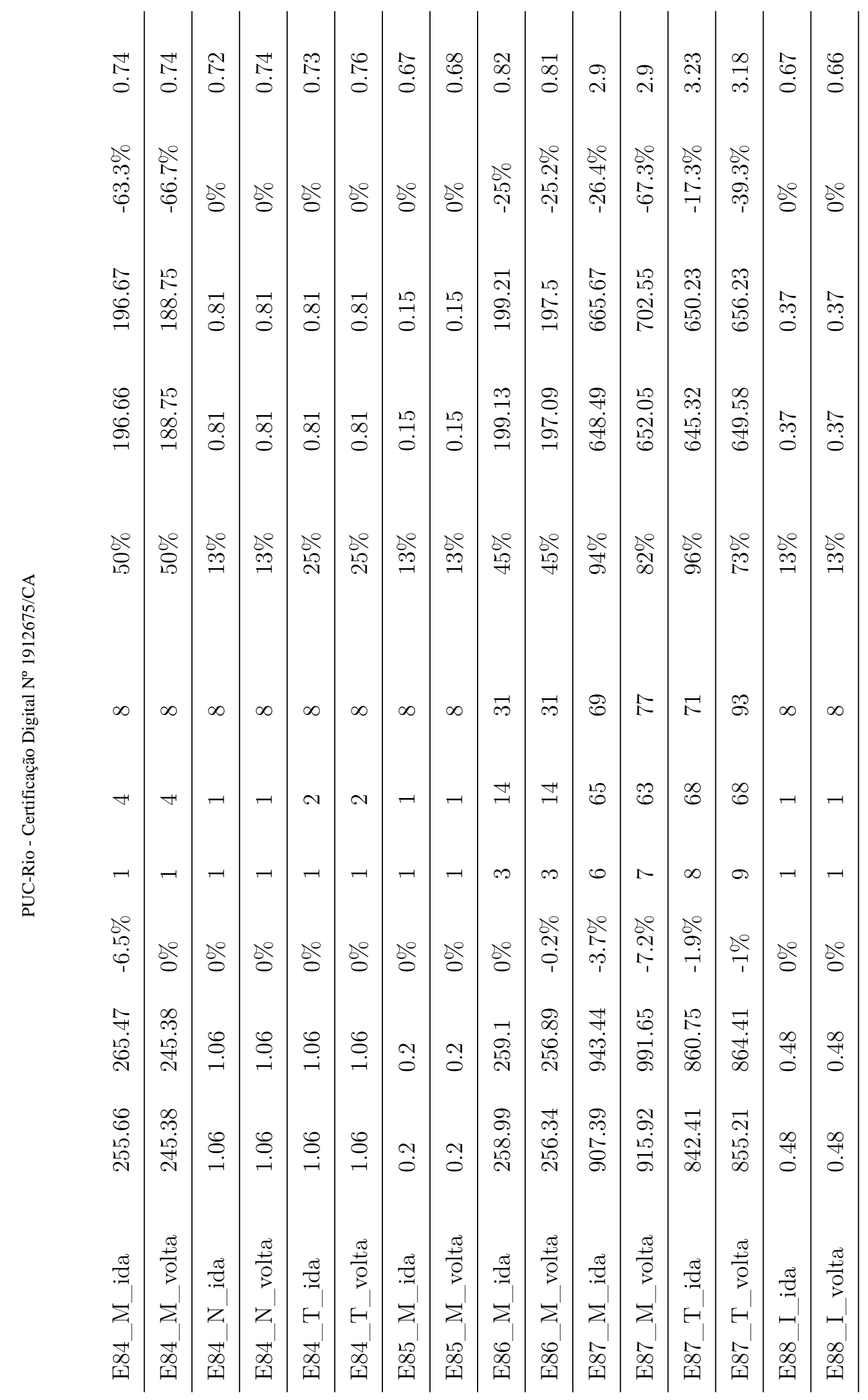




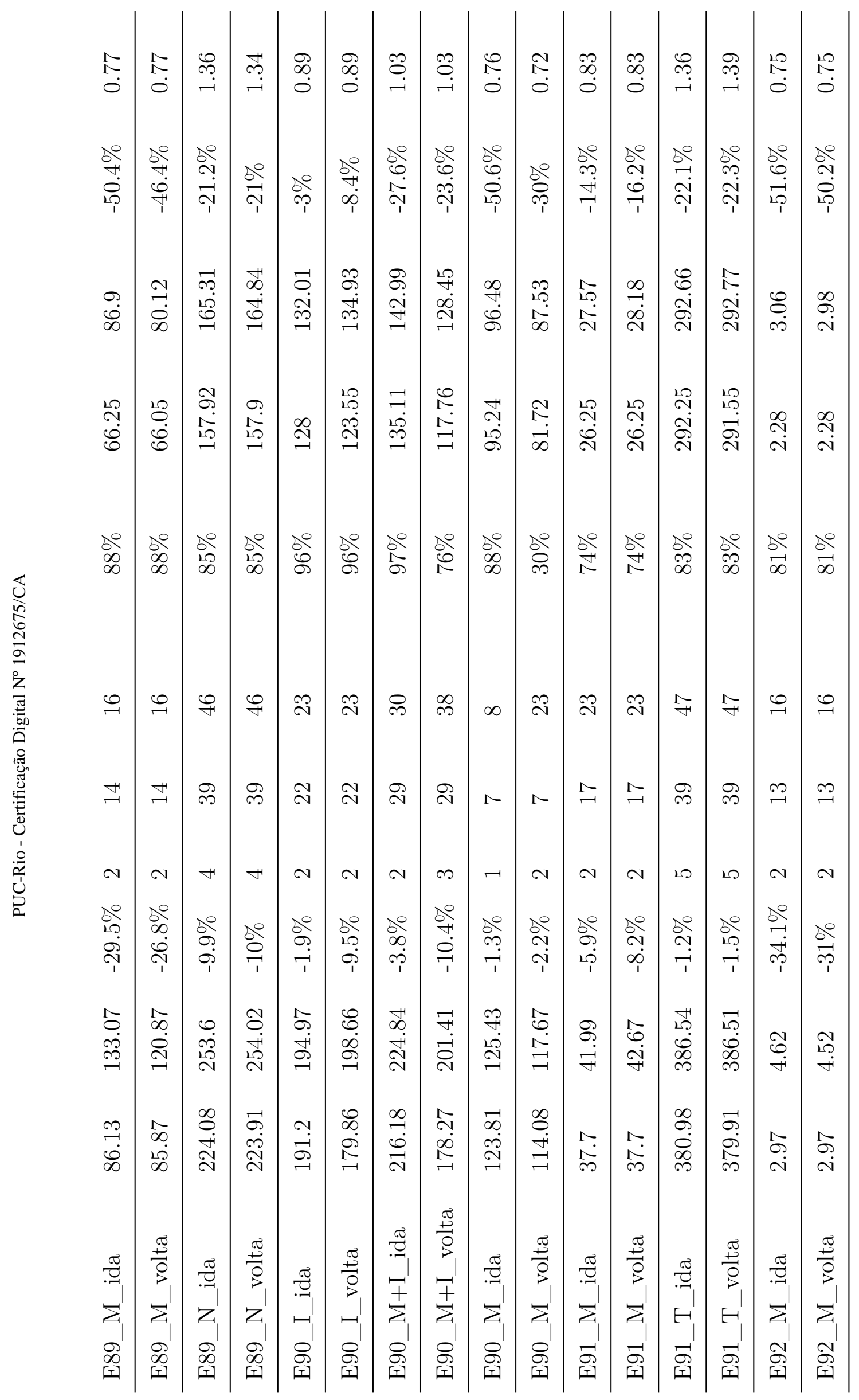




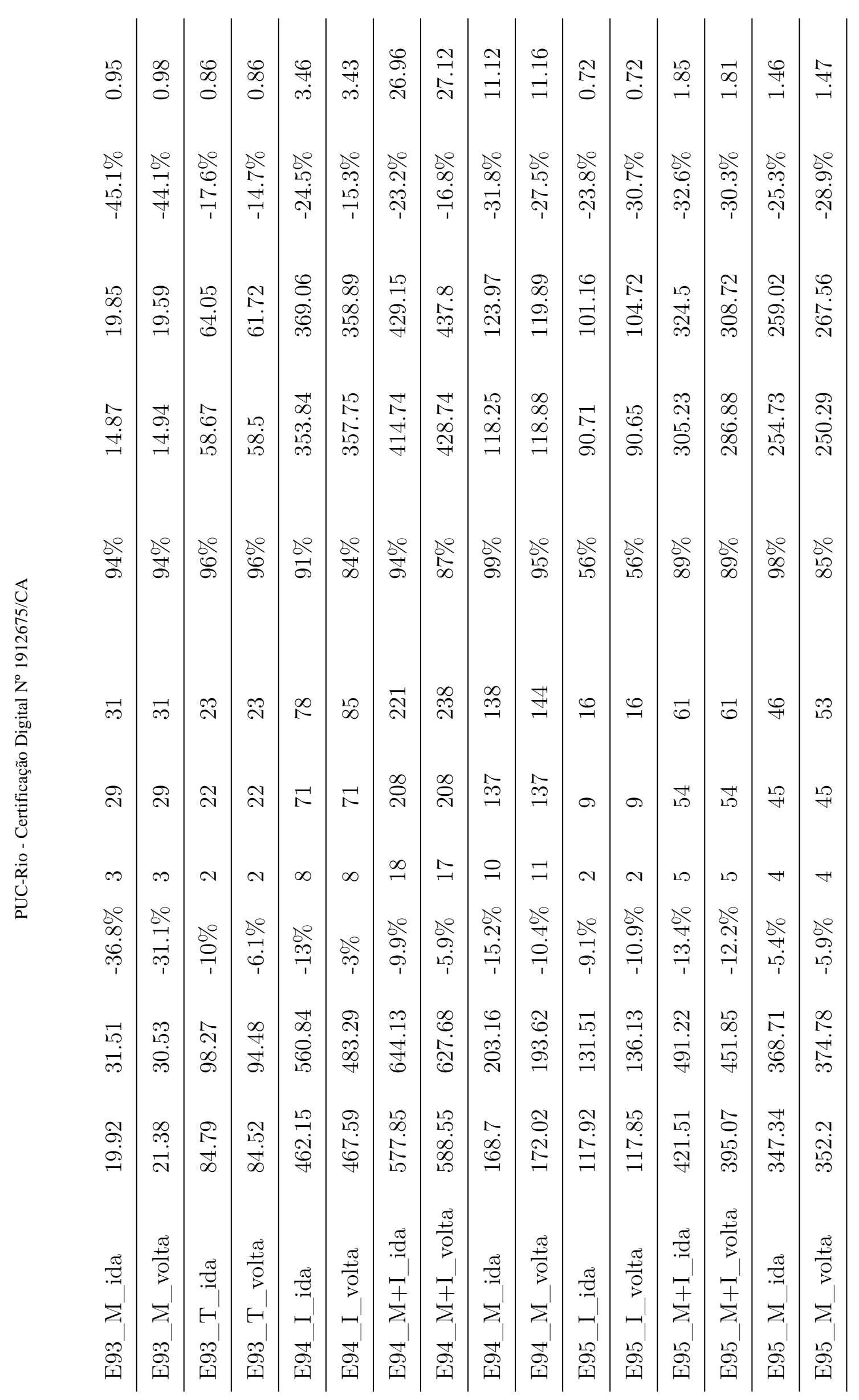




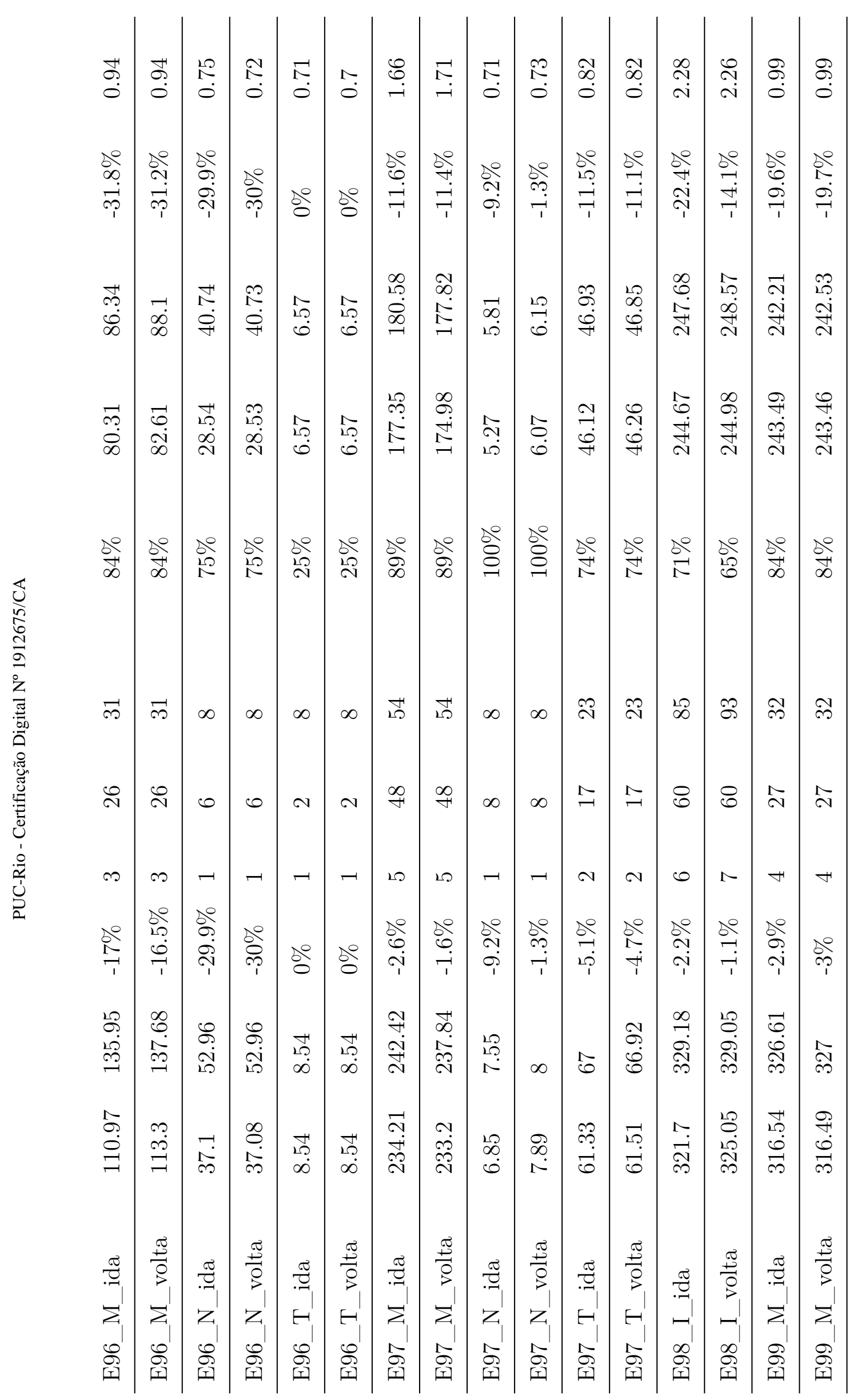




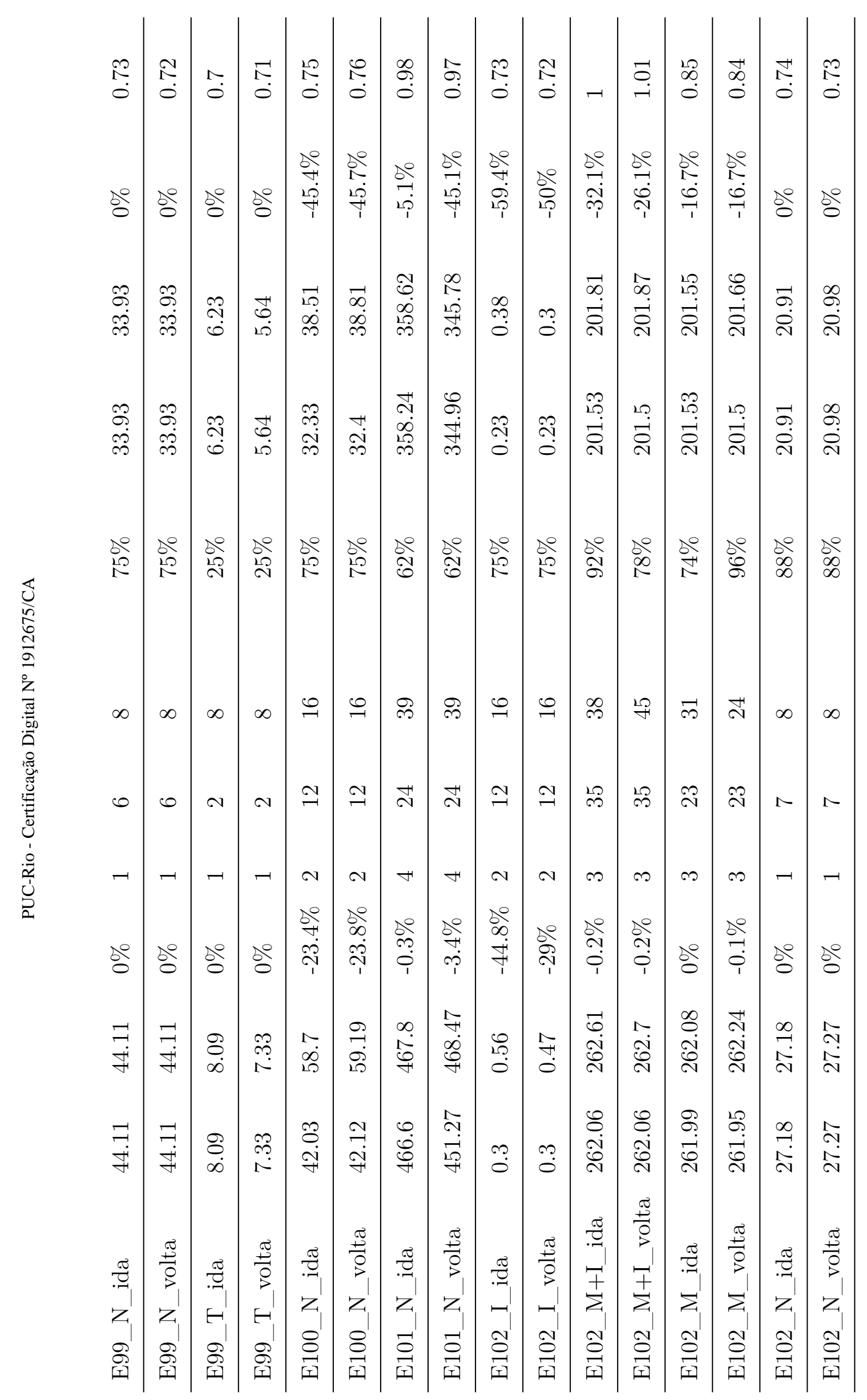




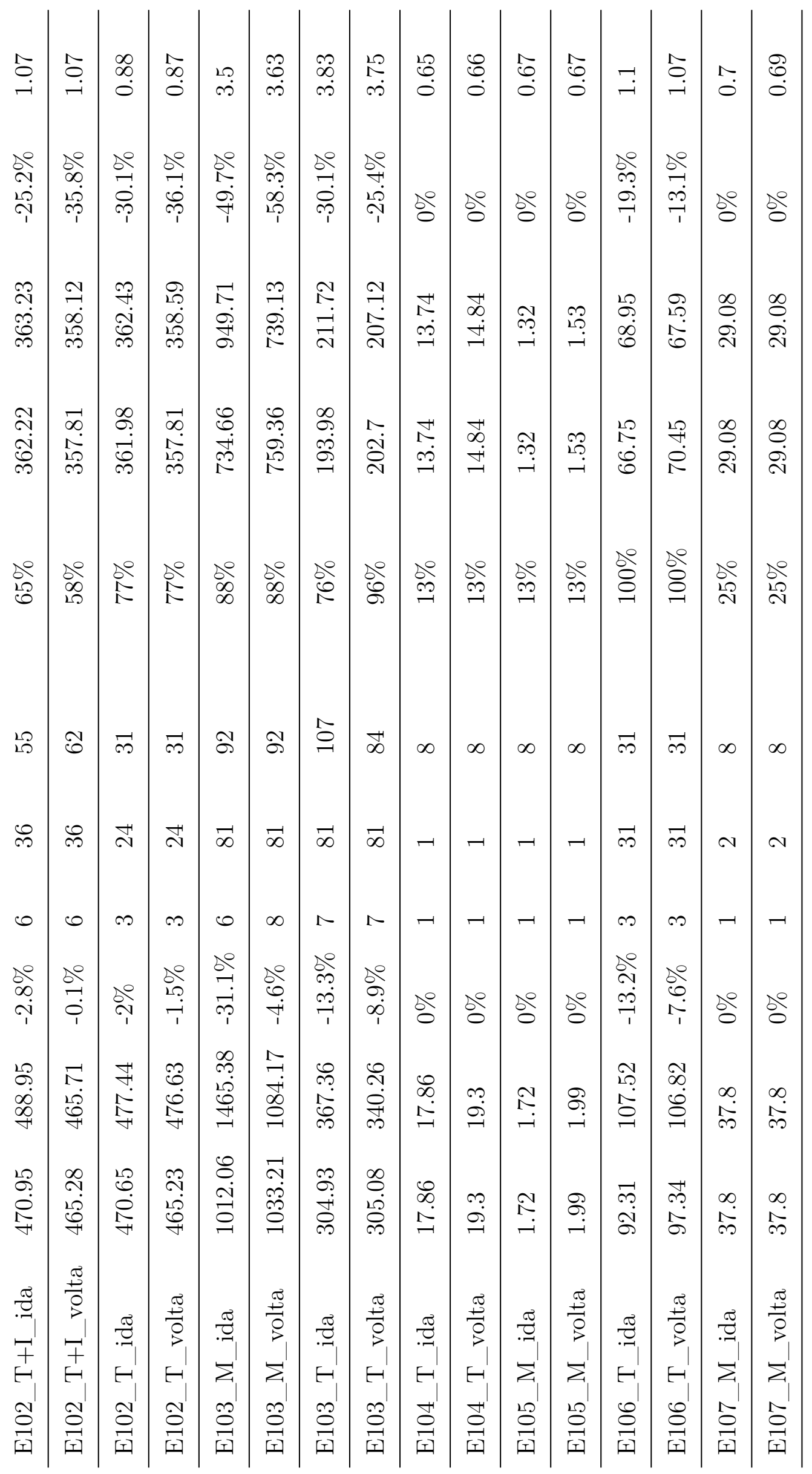




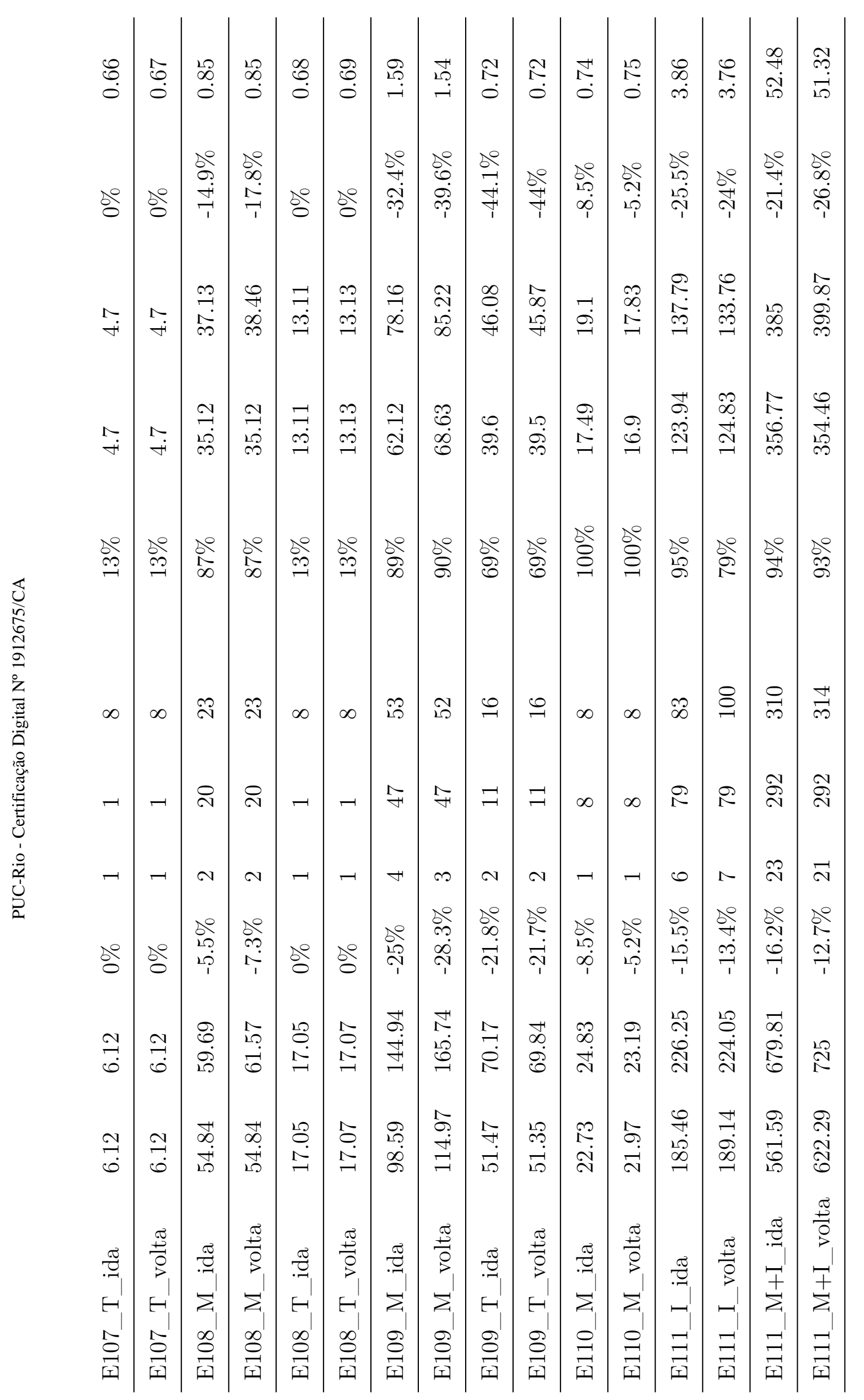




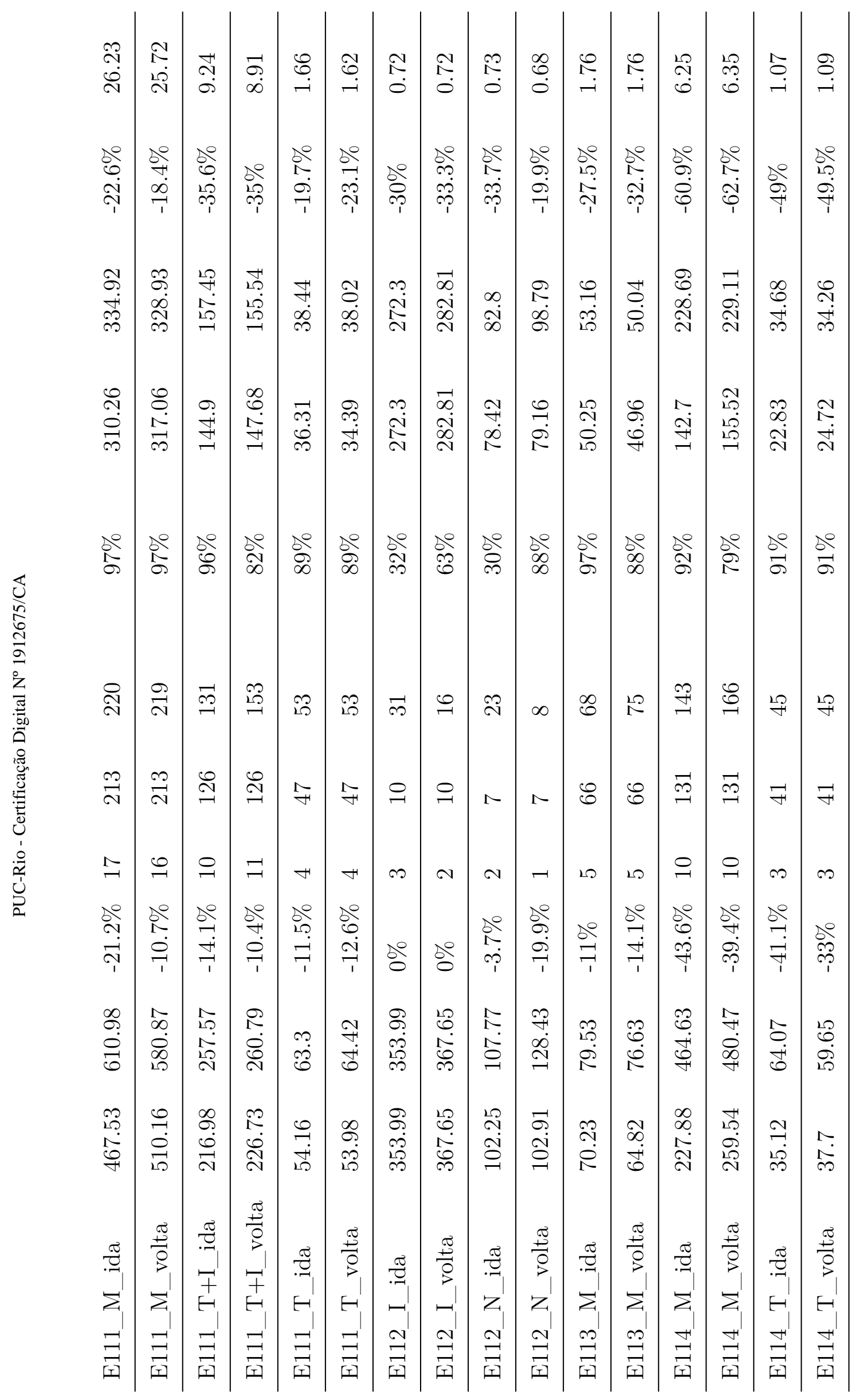




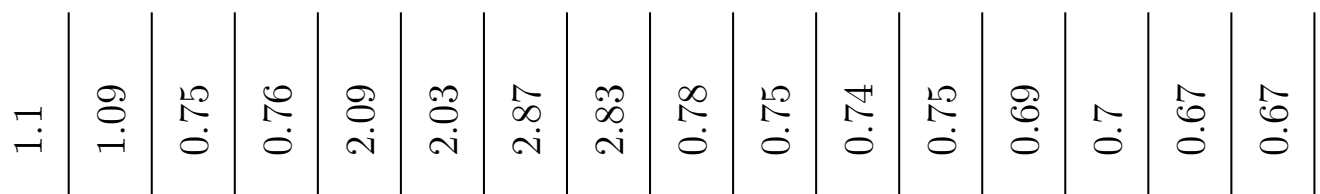

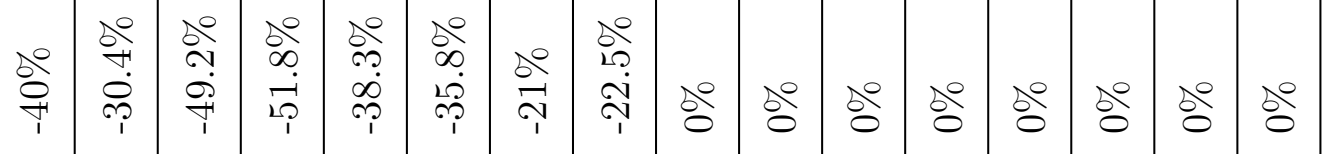

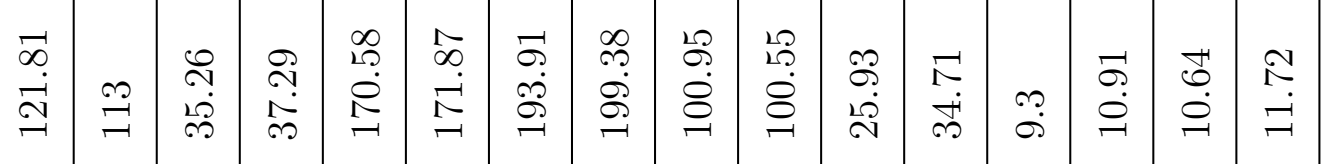

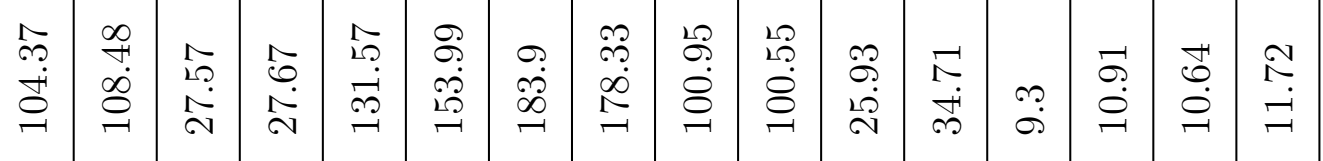

$$
\begin{aligned}
& \text { 咅 }
\end{aligned}
$$

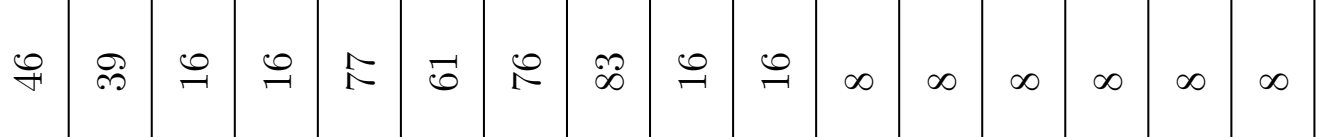

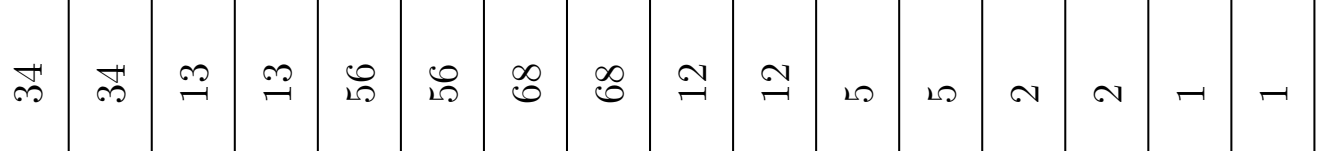

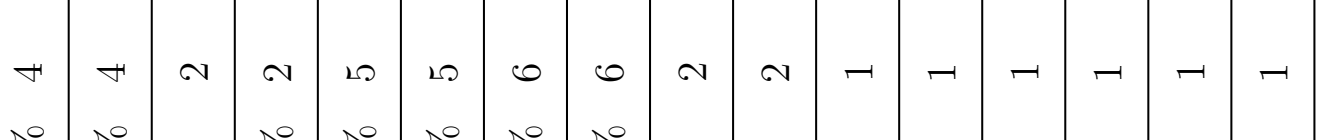

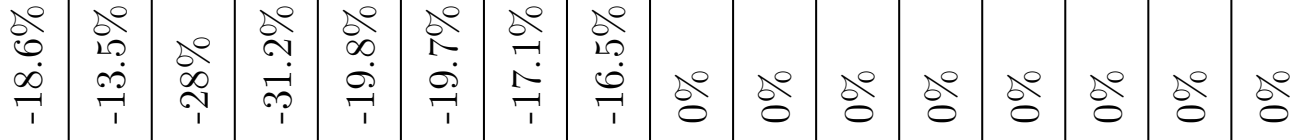

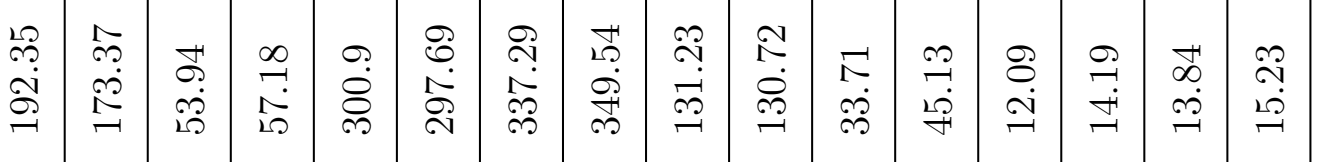

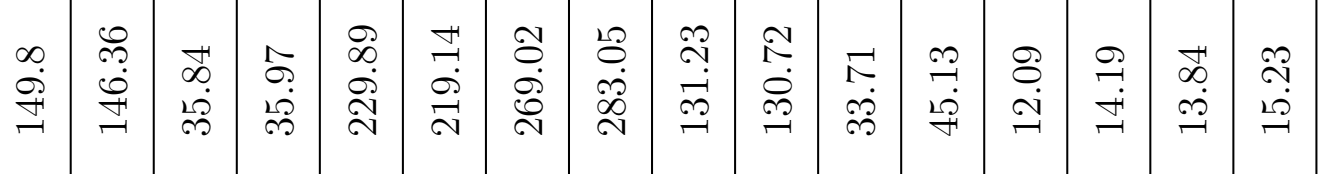

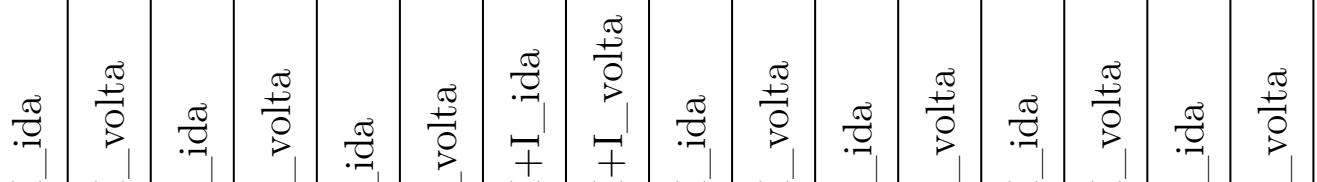

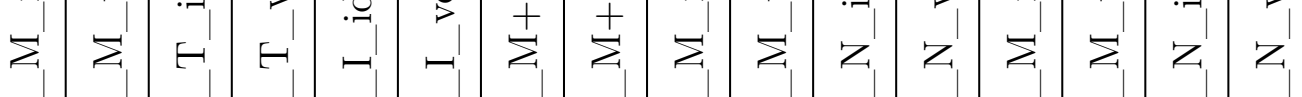

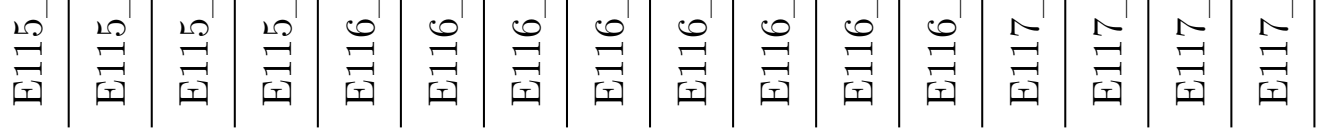




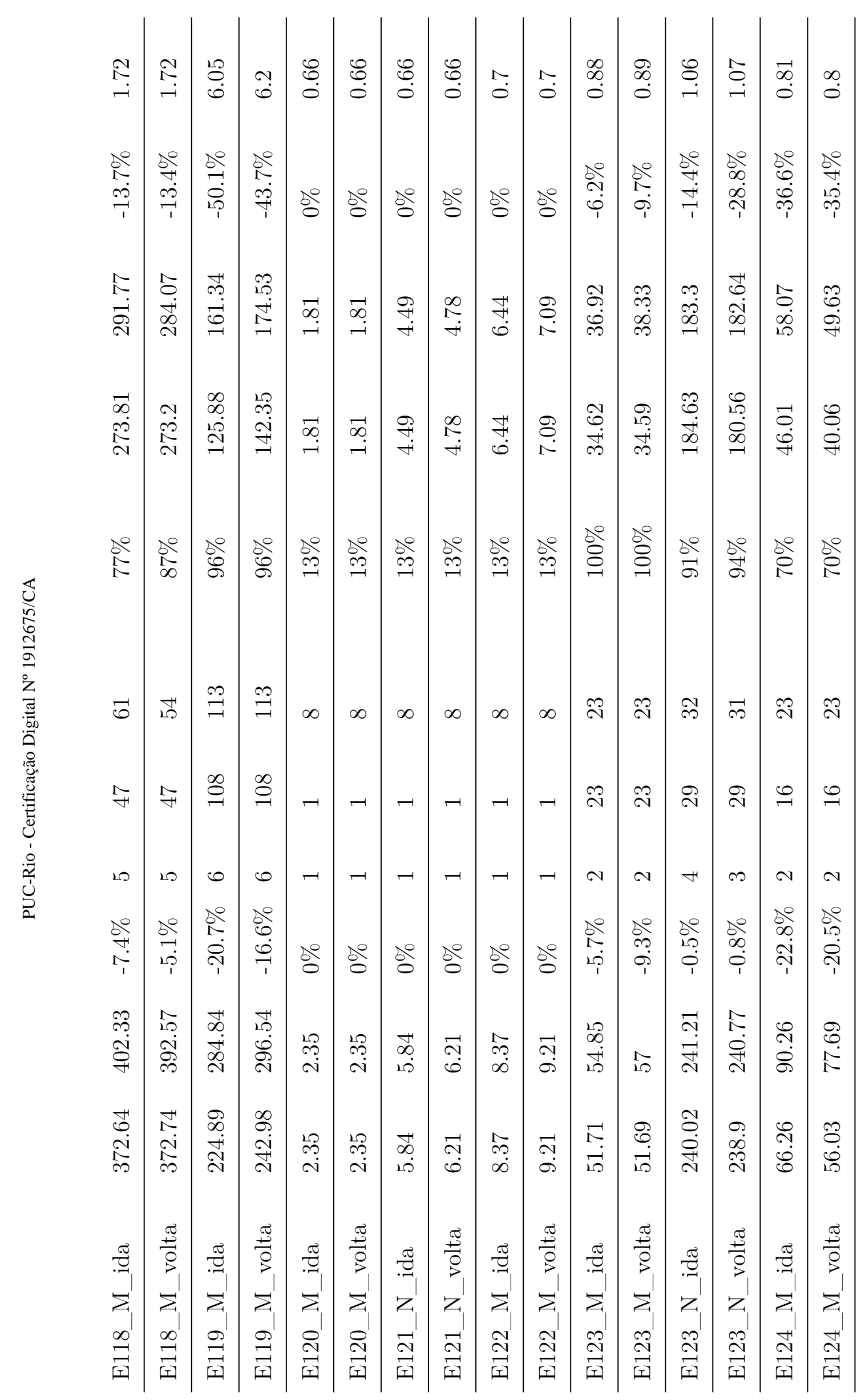




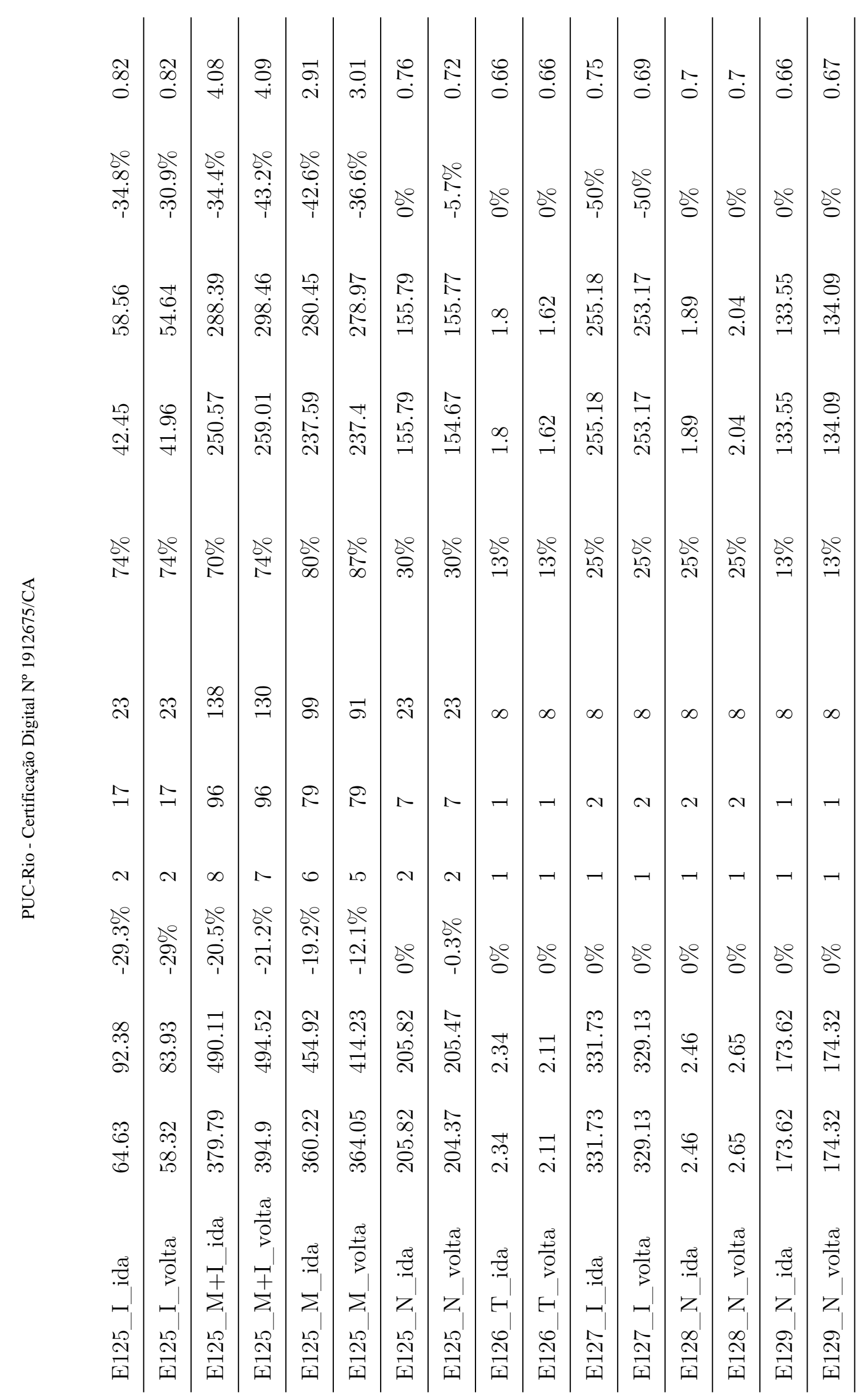




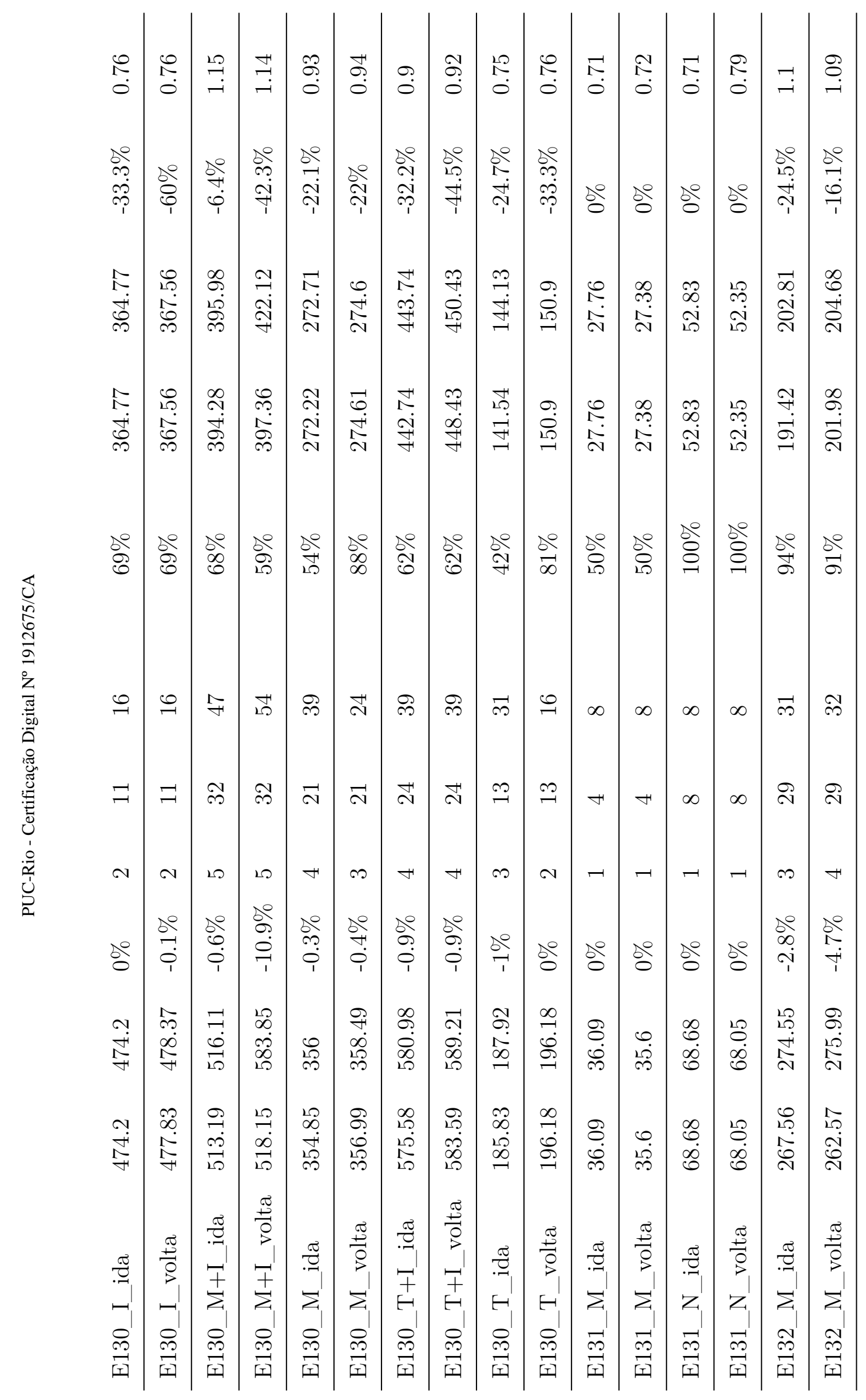




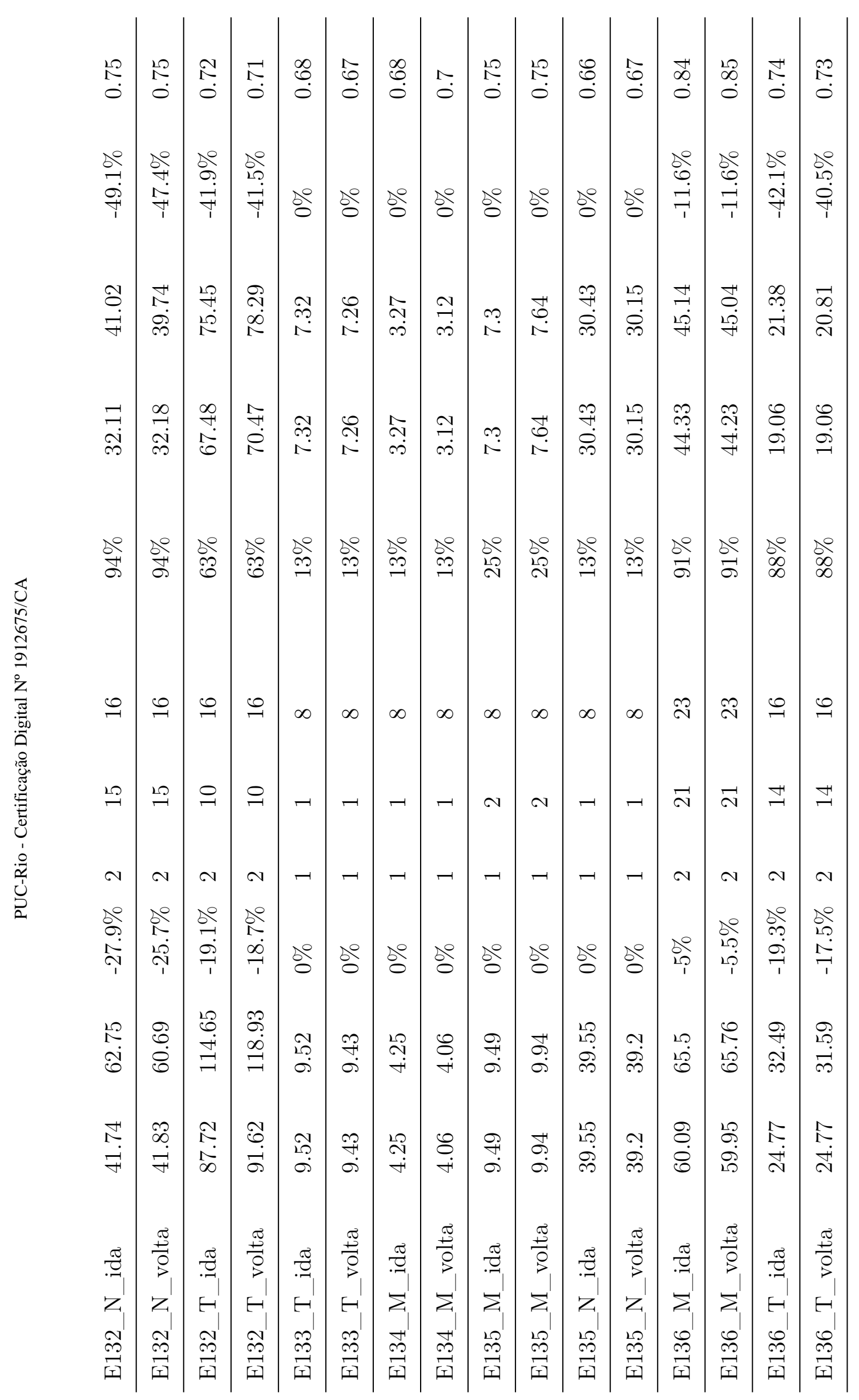




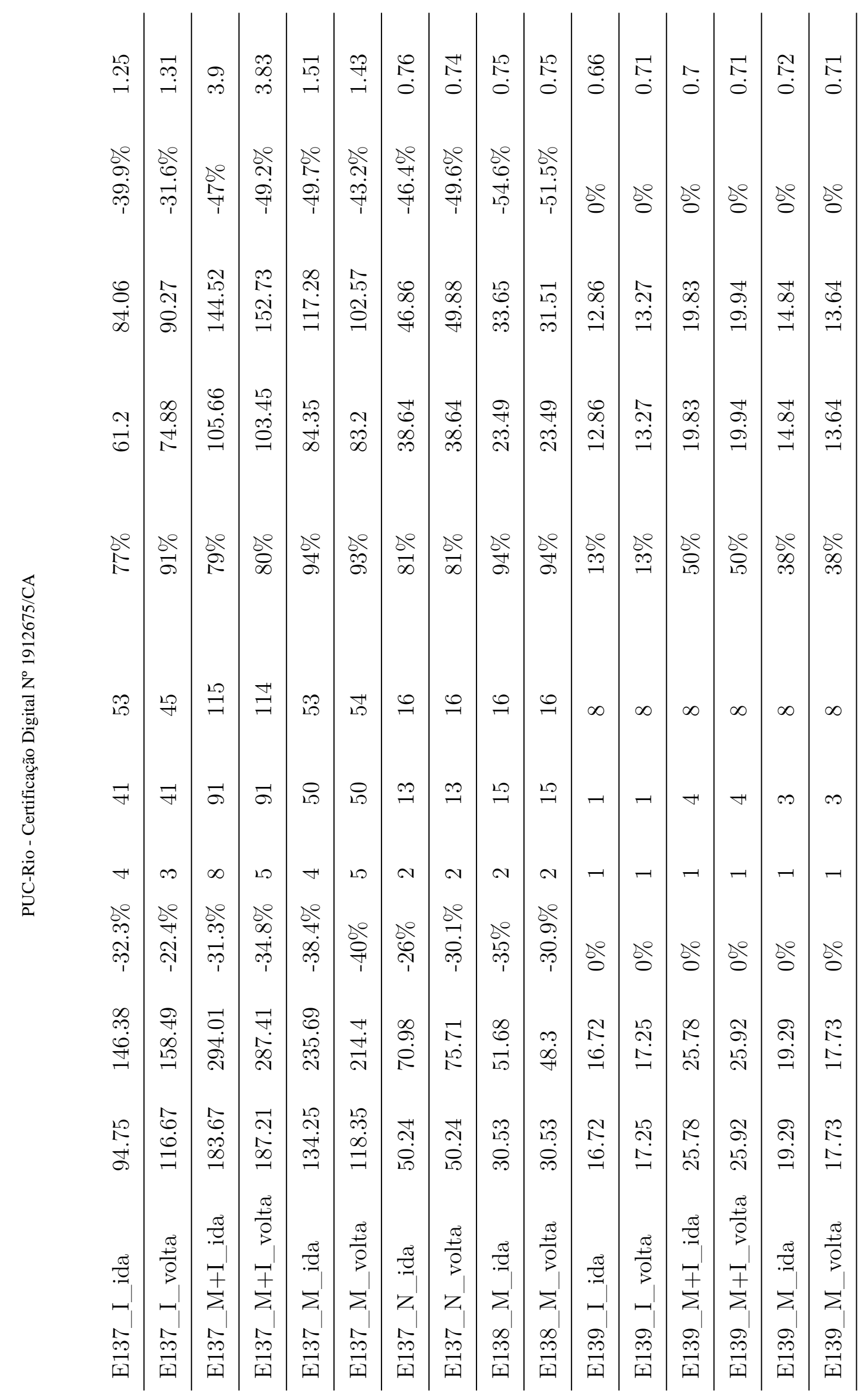




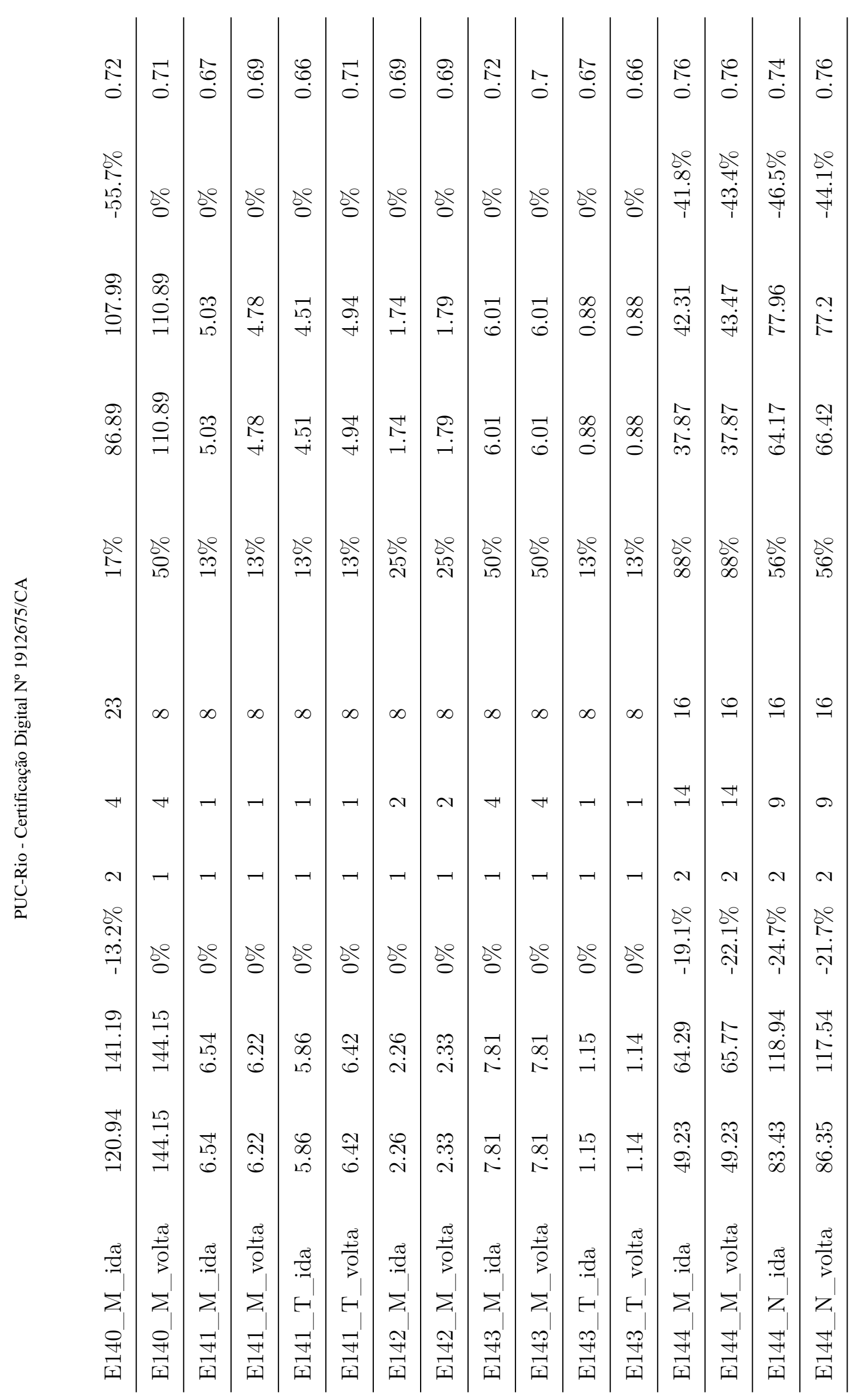




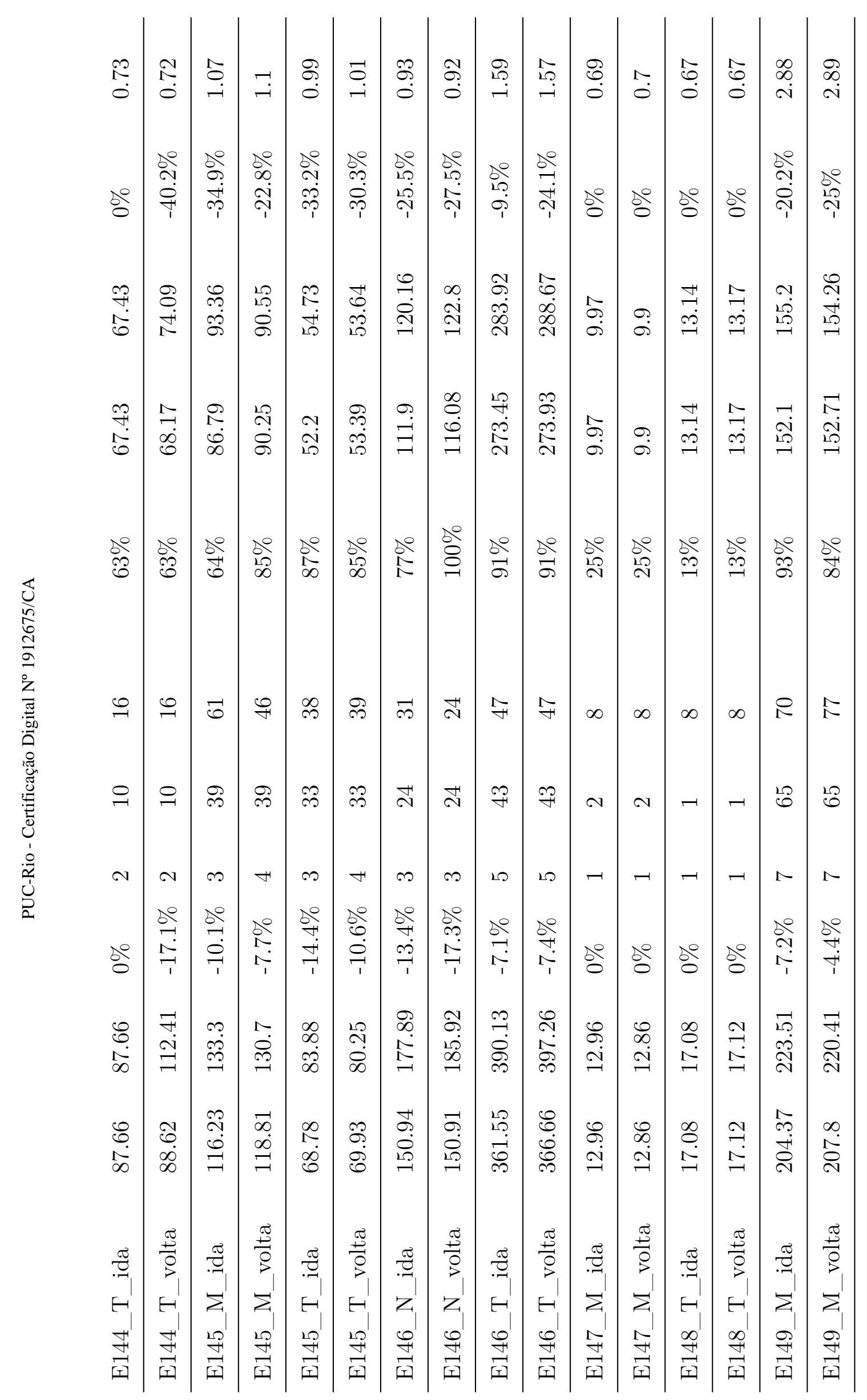




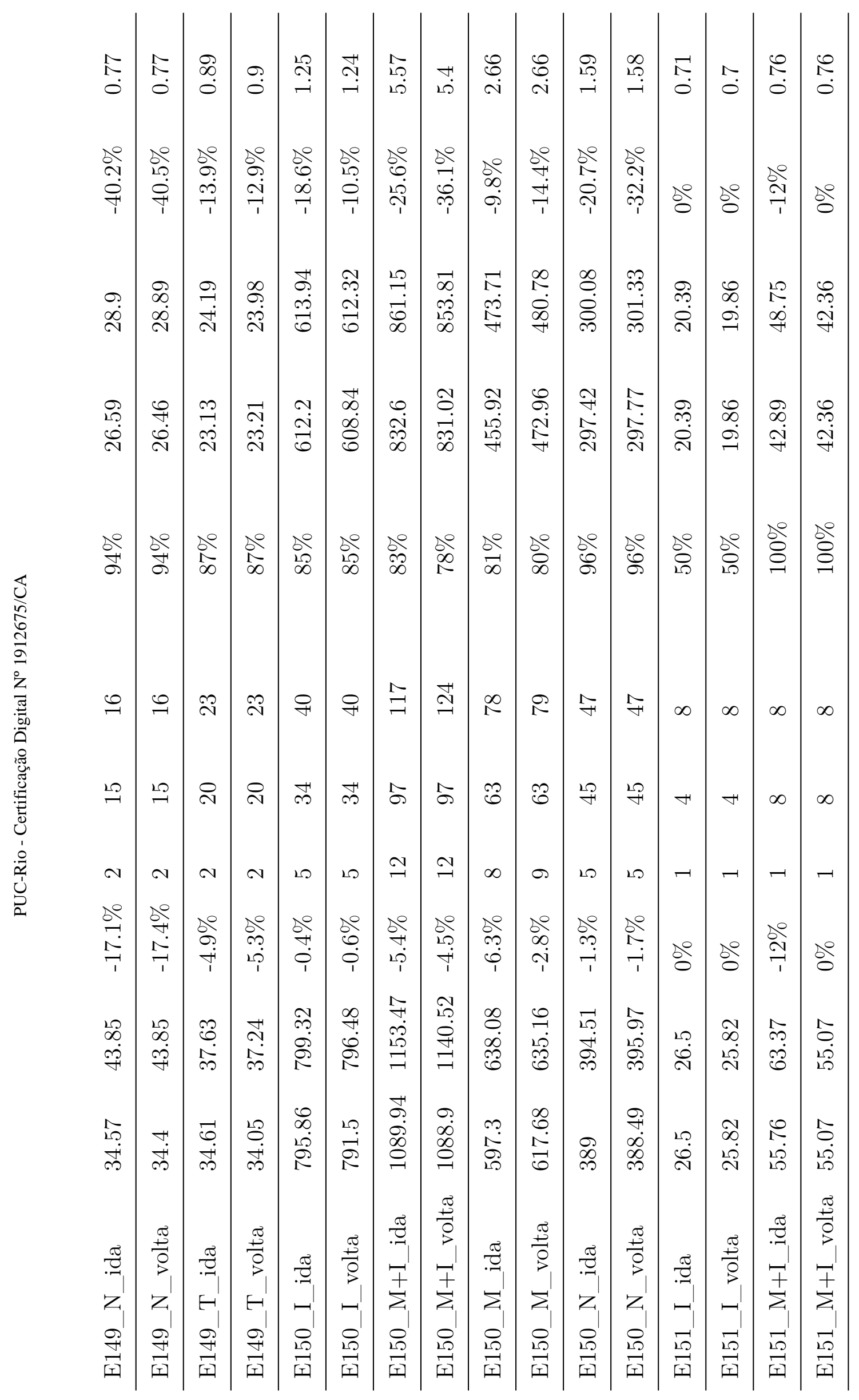




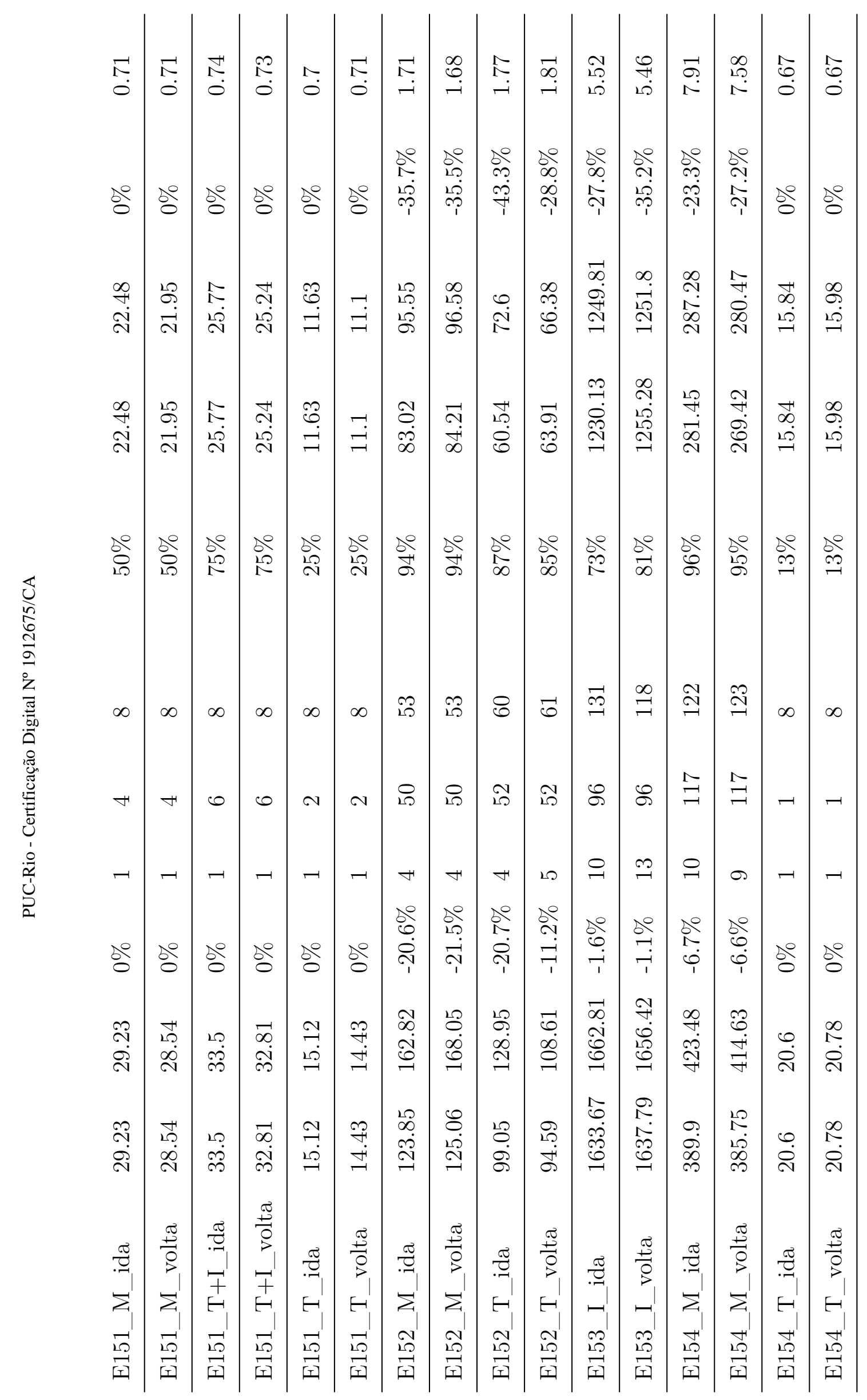




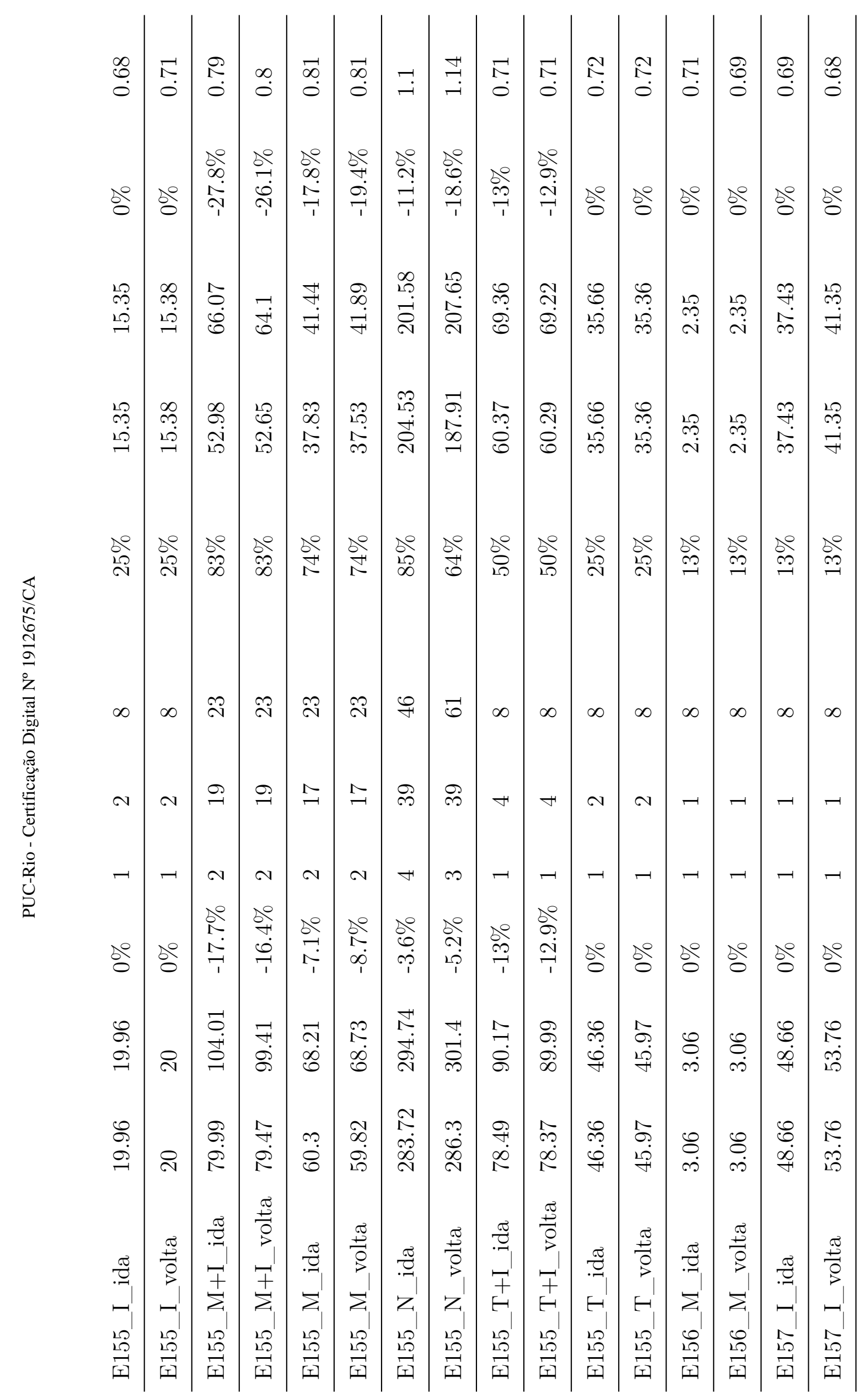




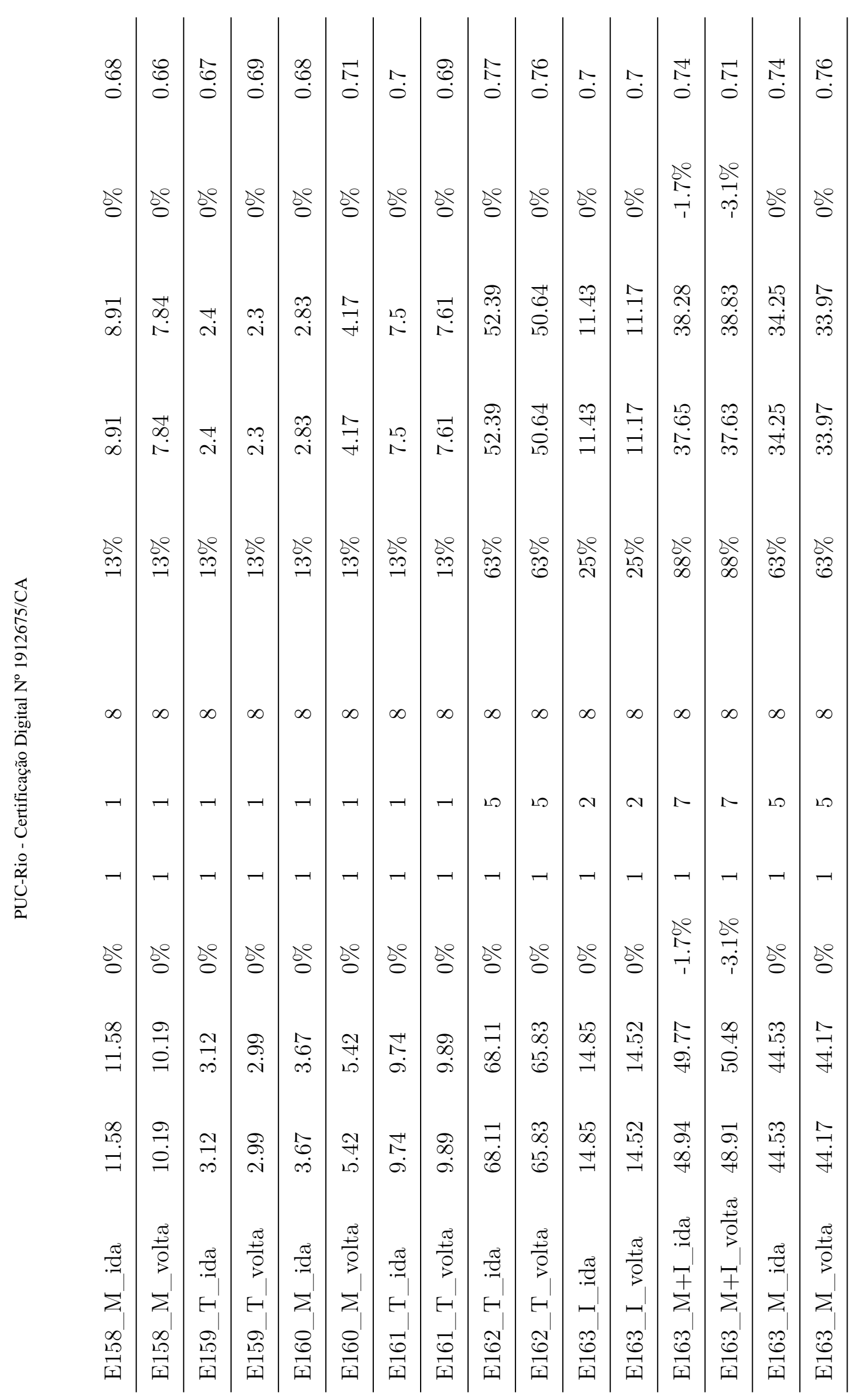




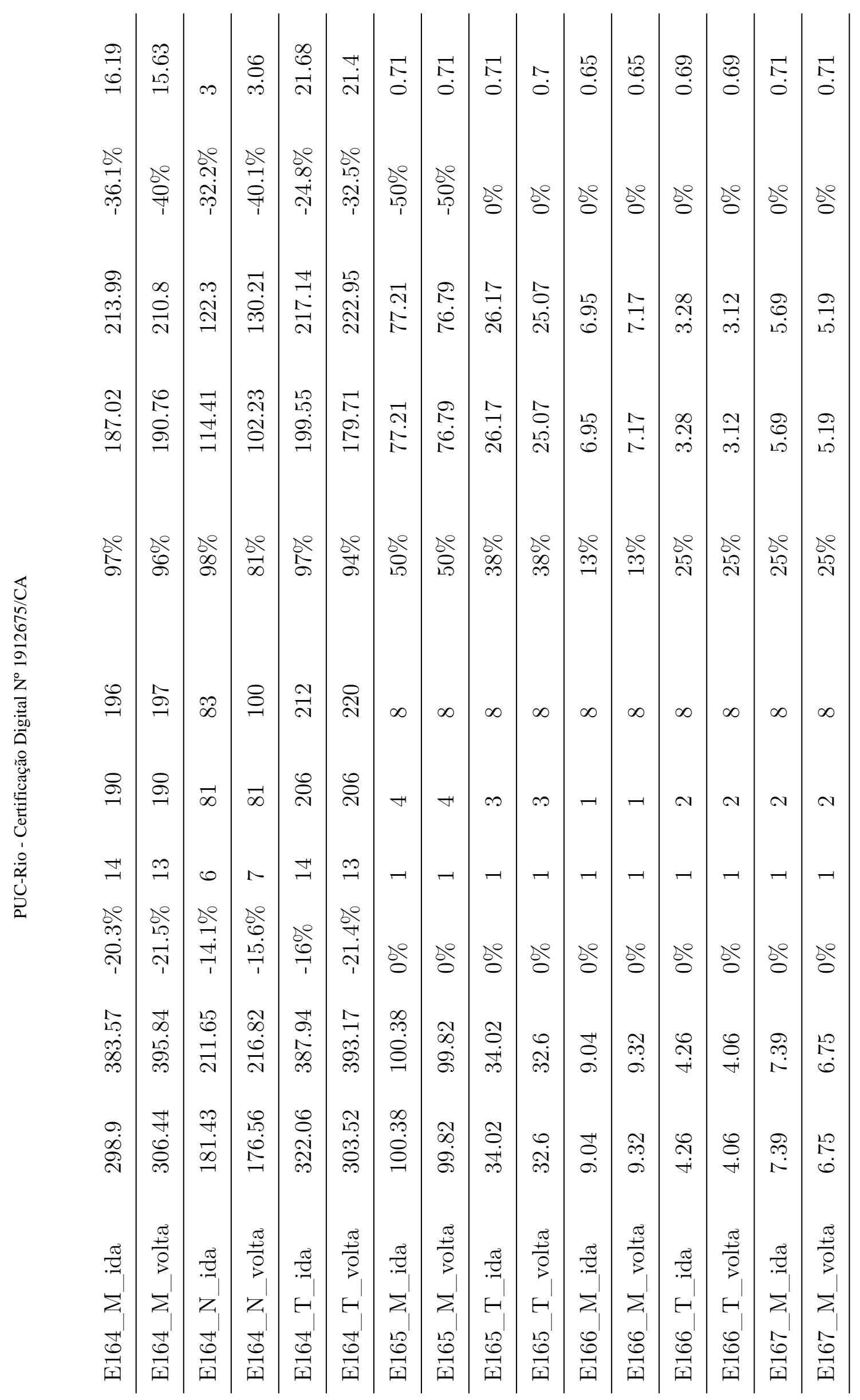




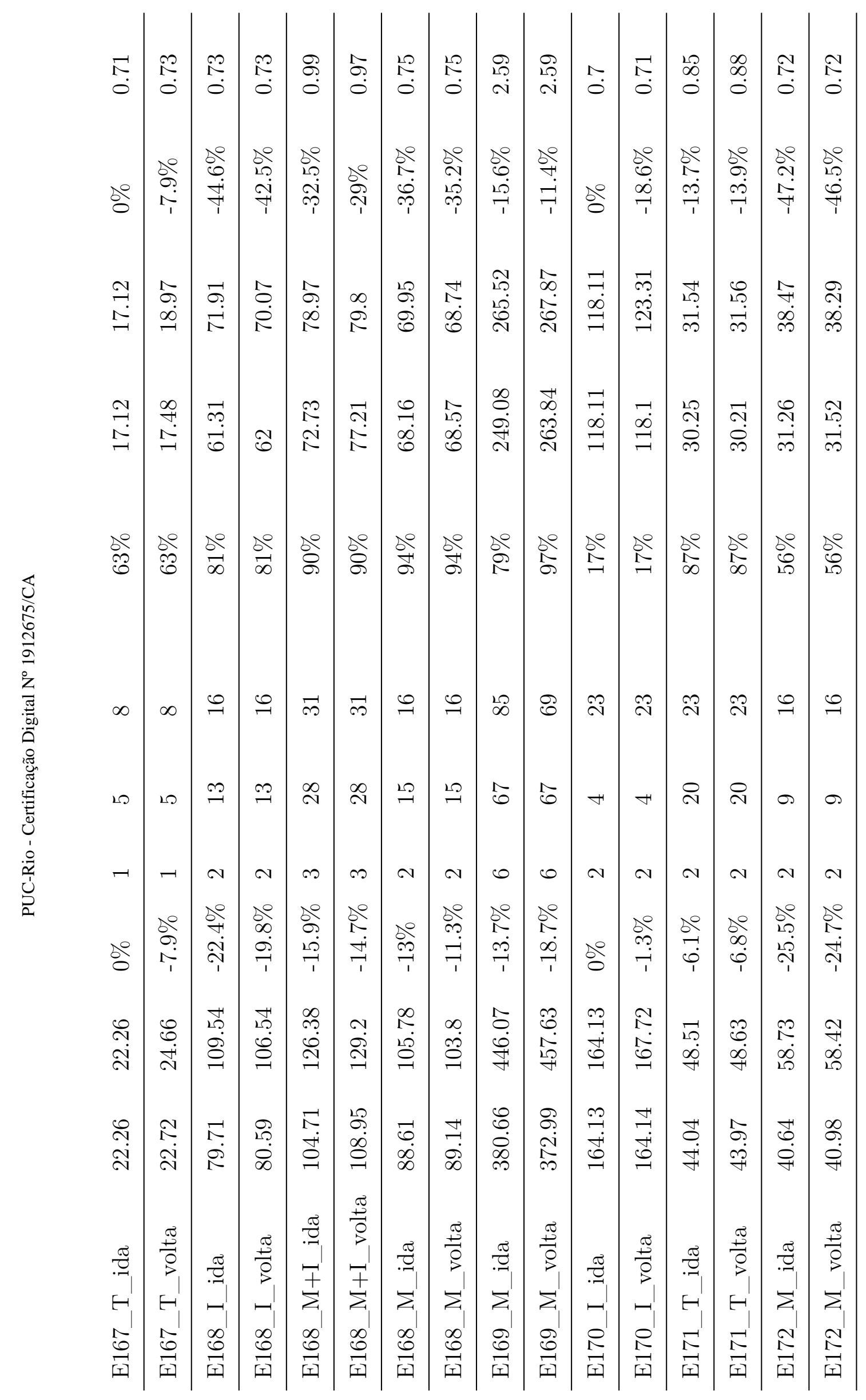




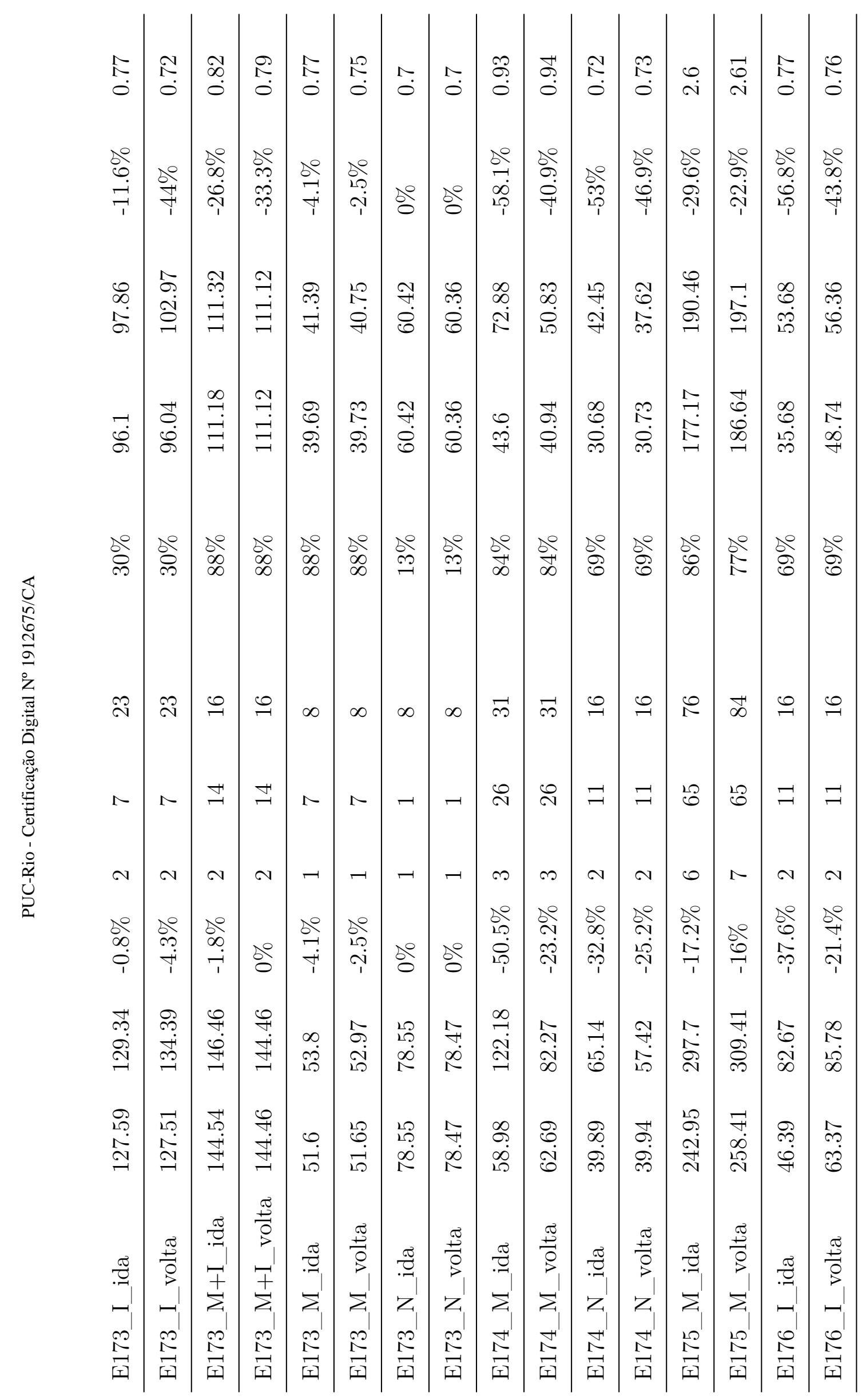




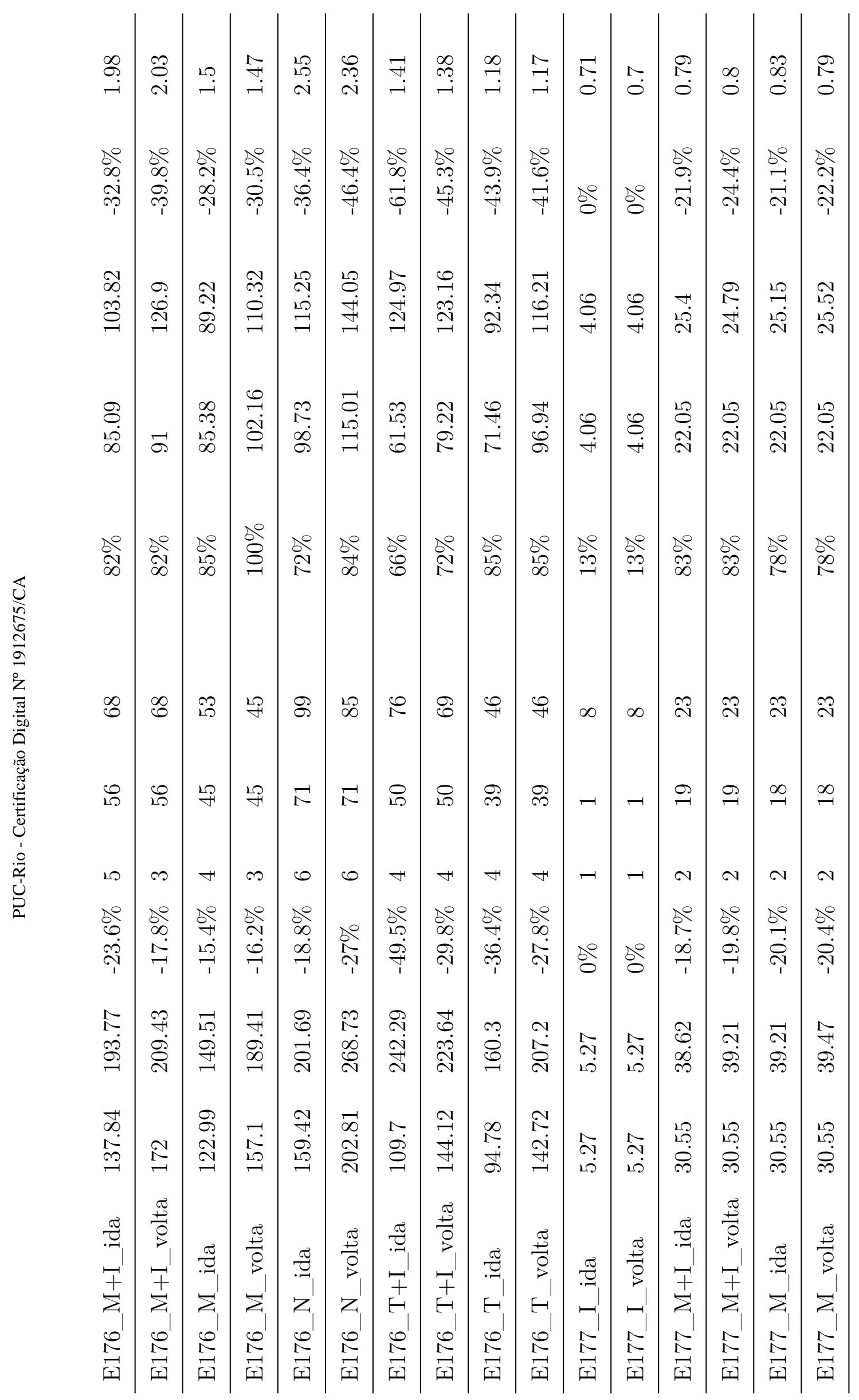




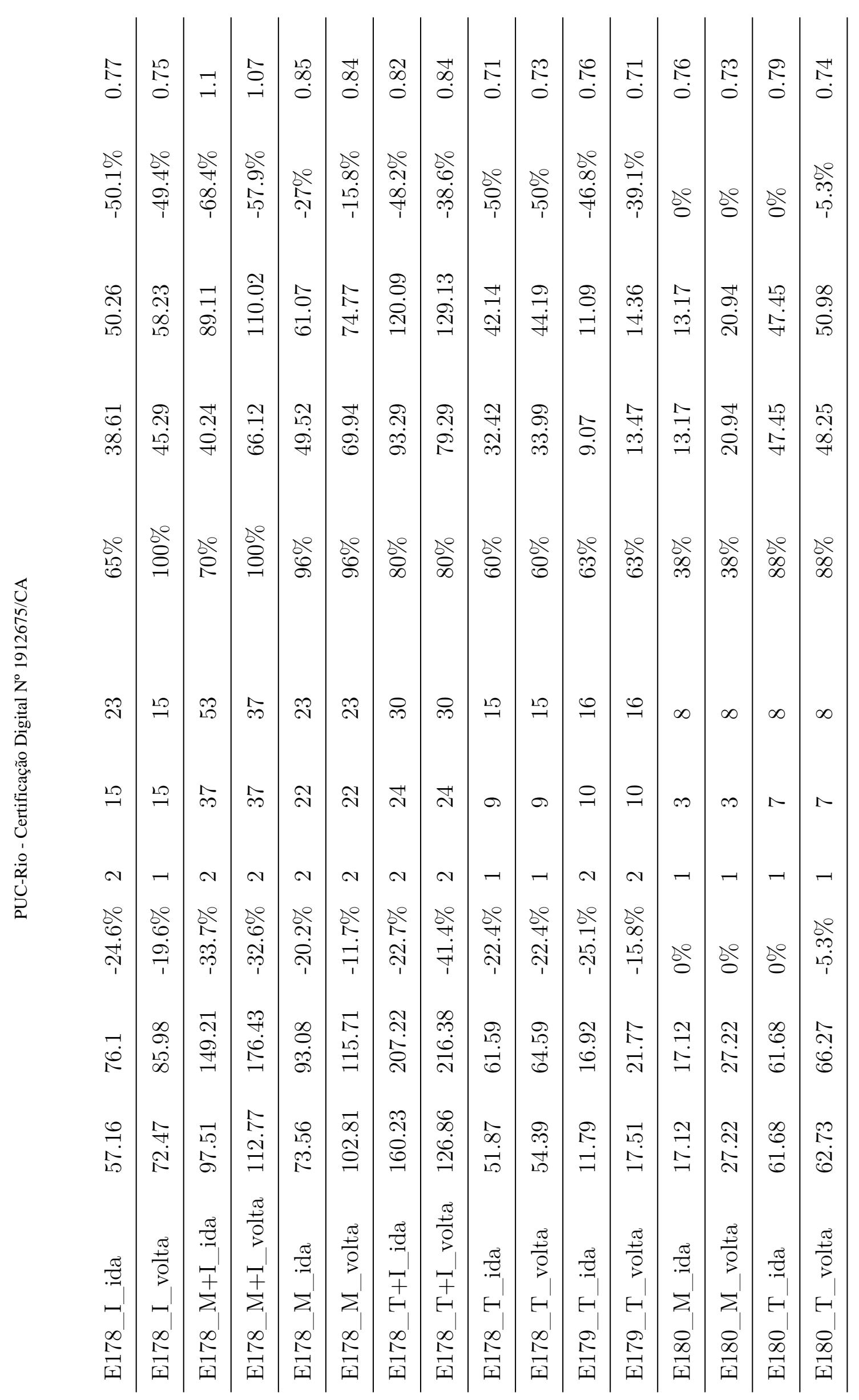




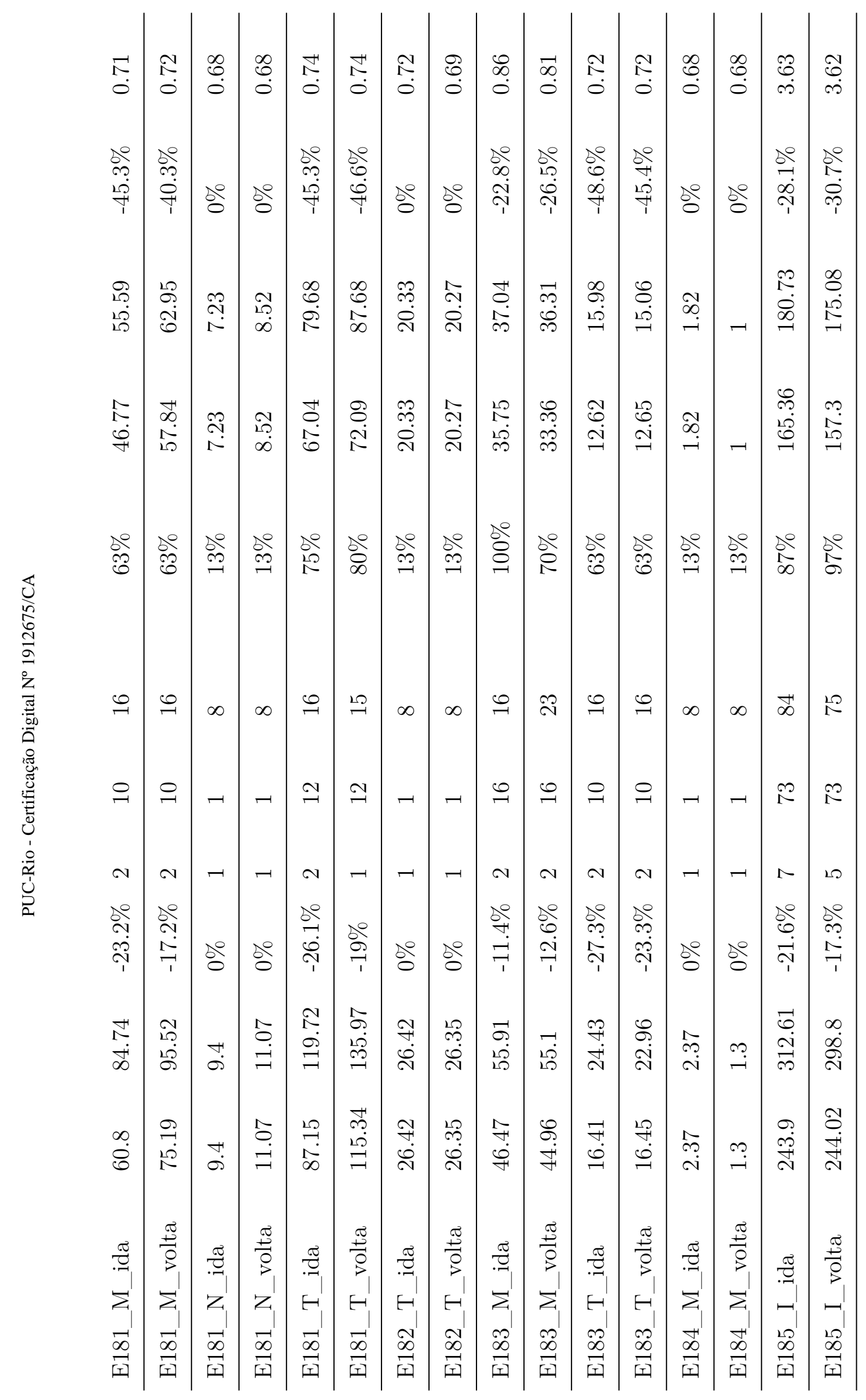




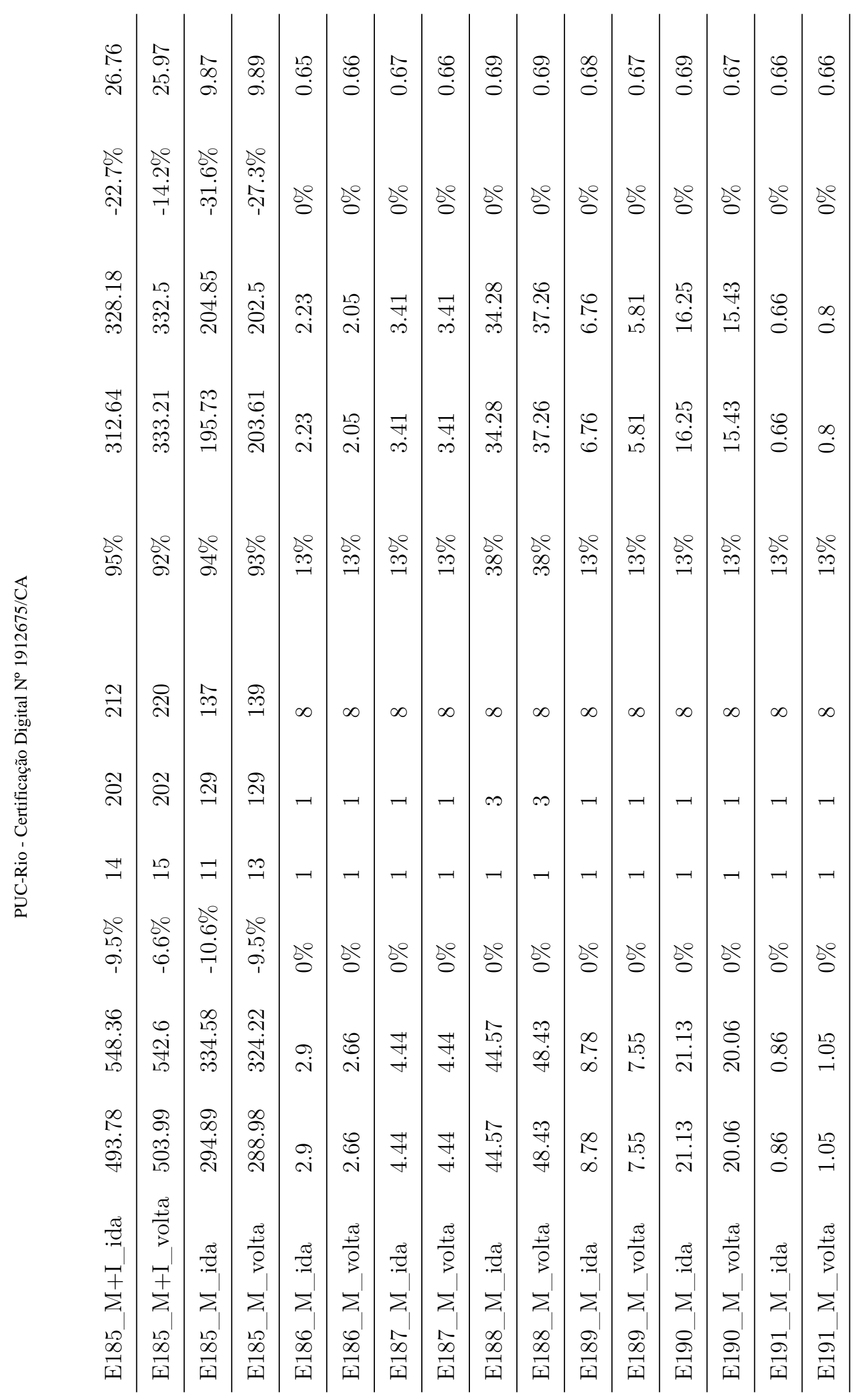




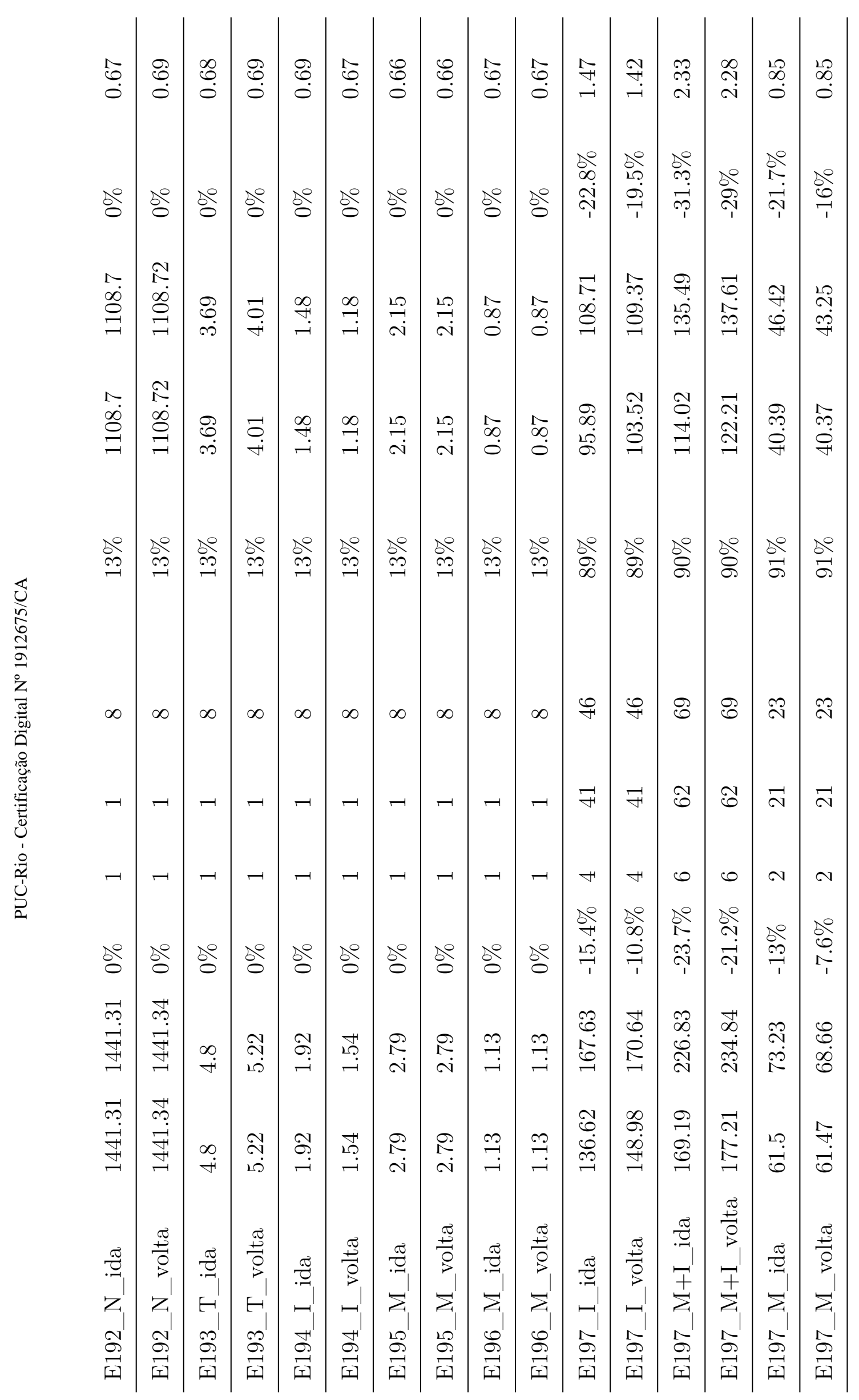




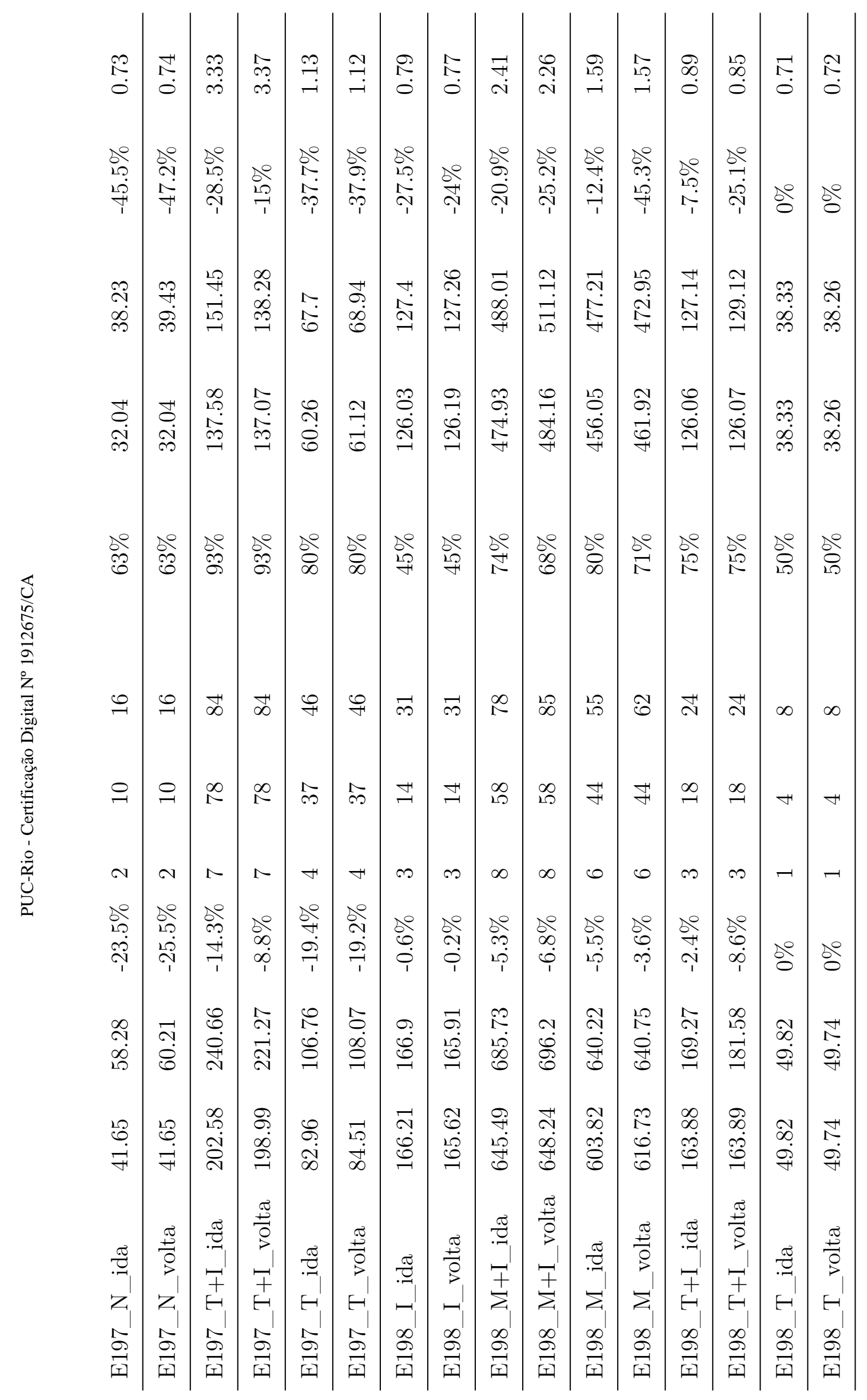




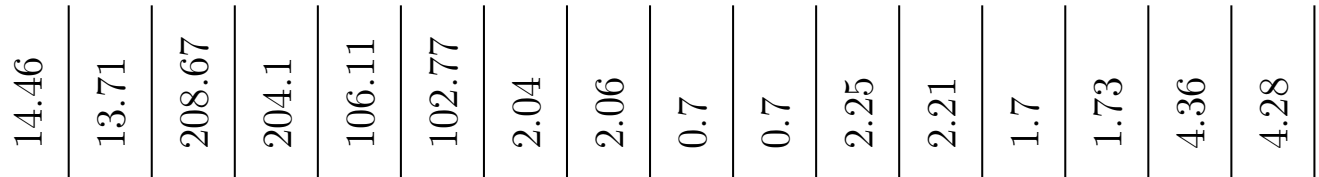

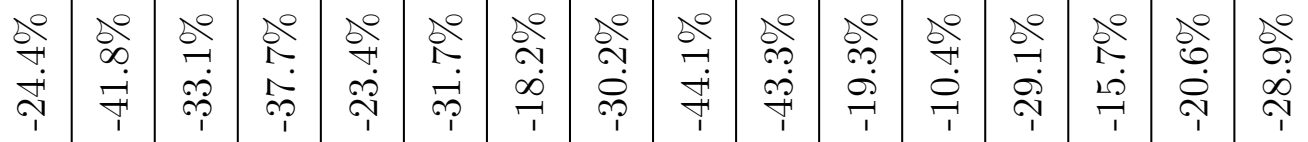

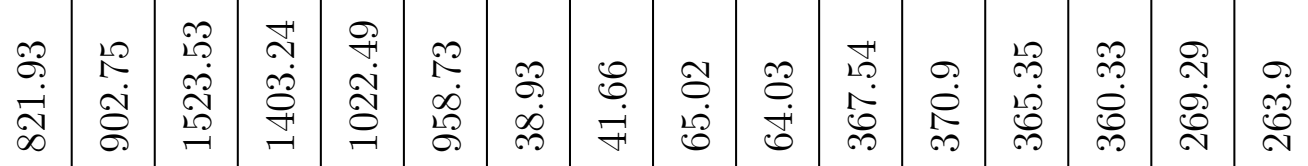

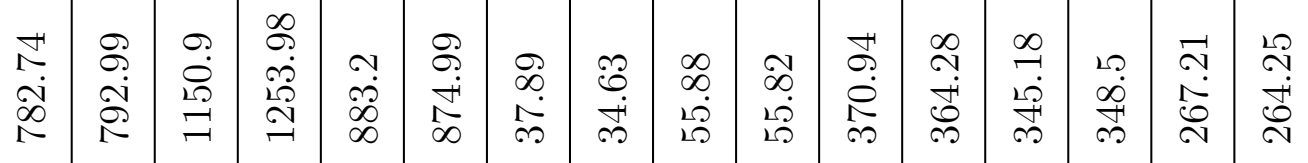

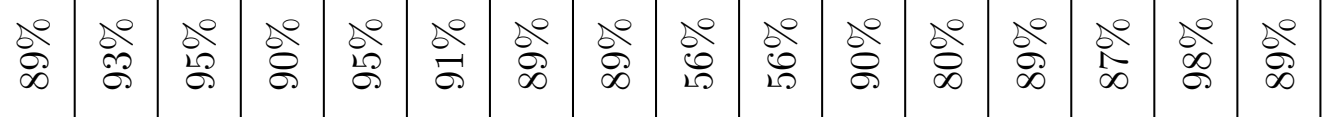

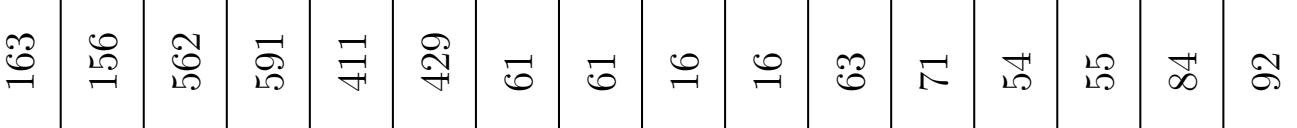

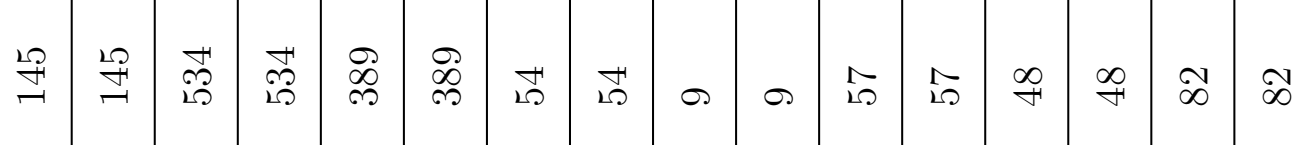

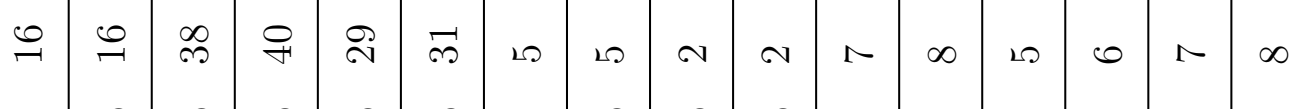

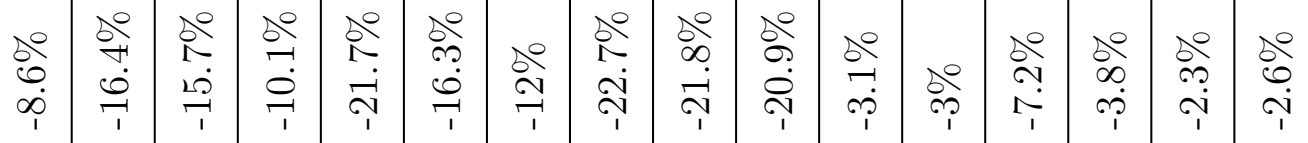

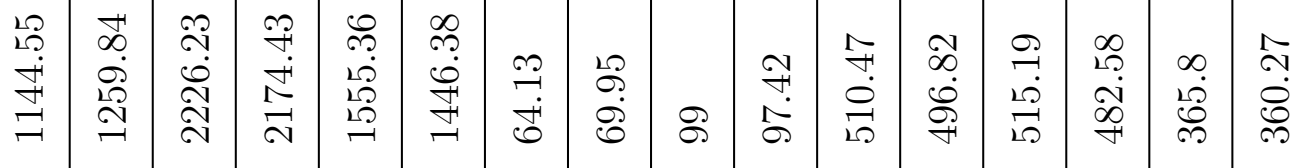

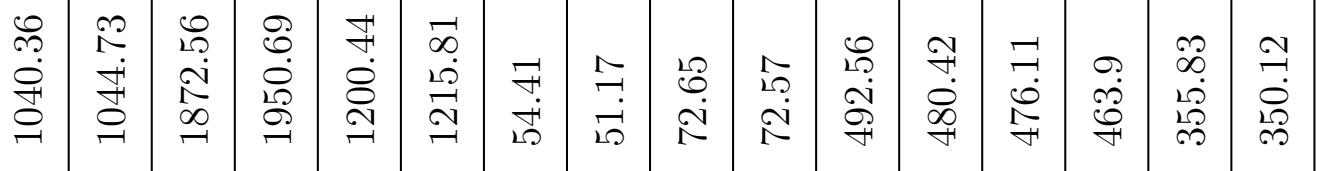

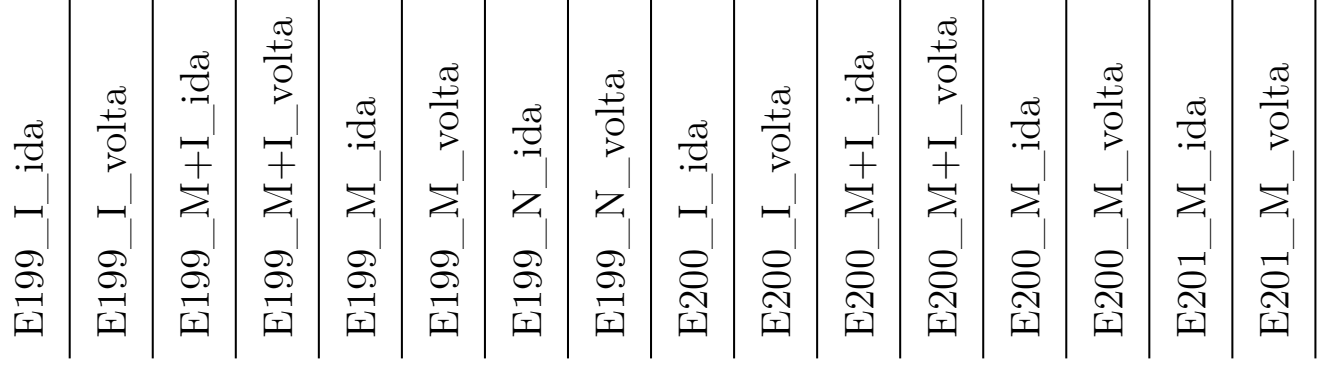

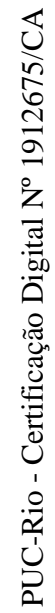




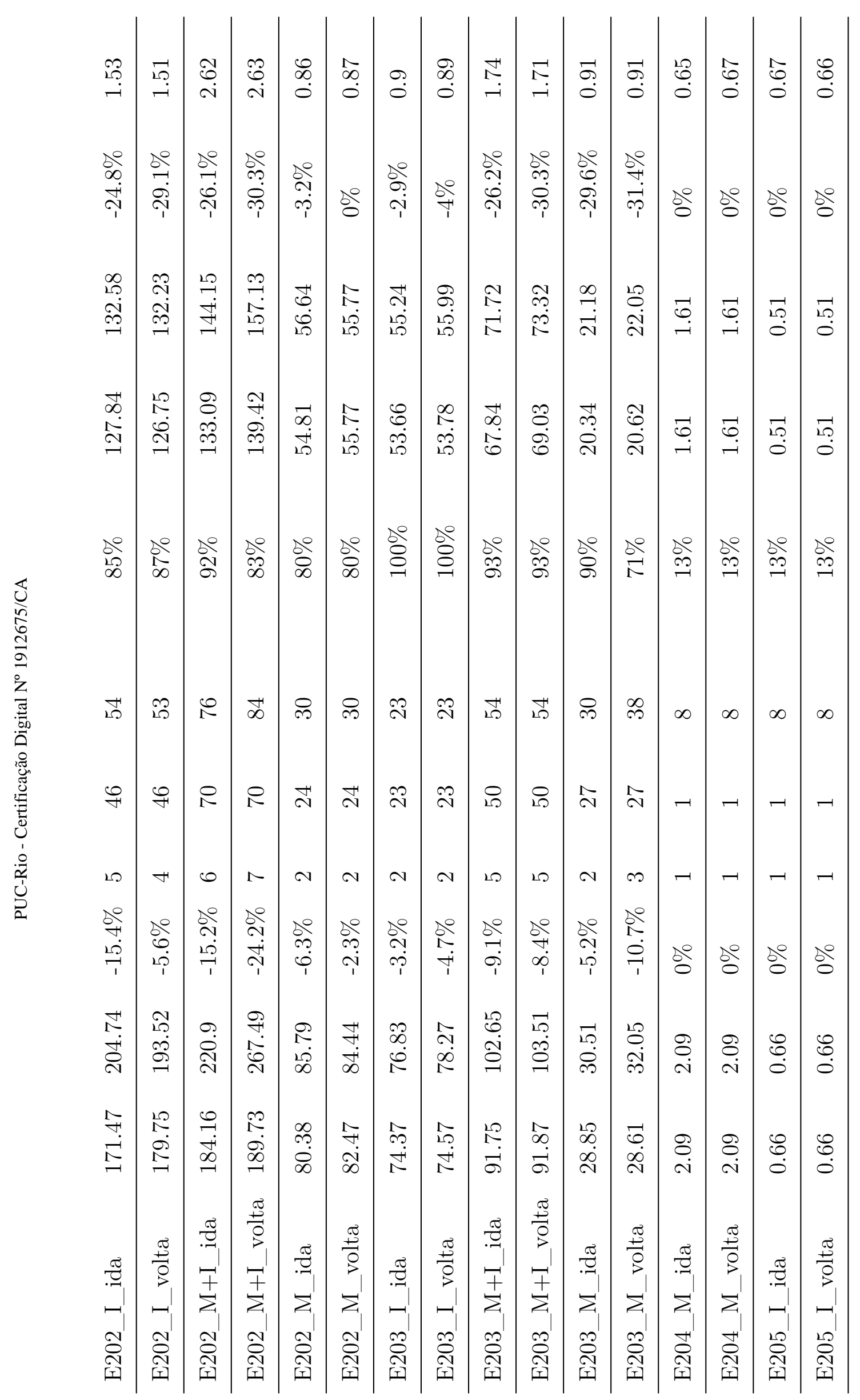




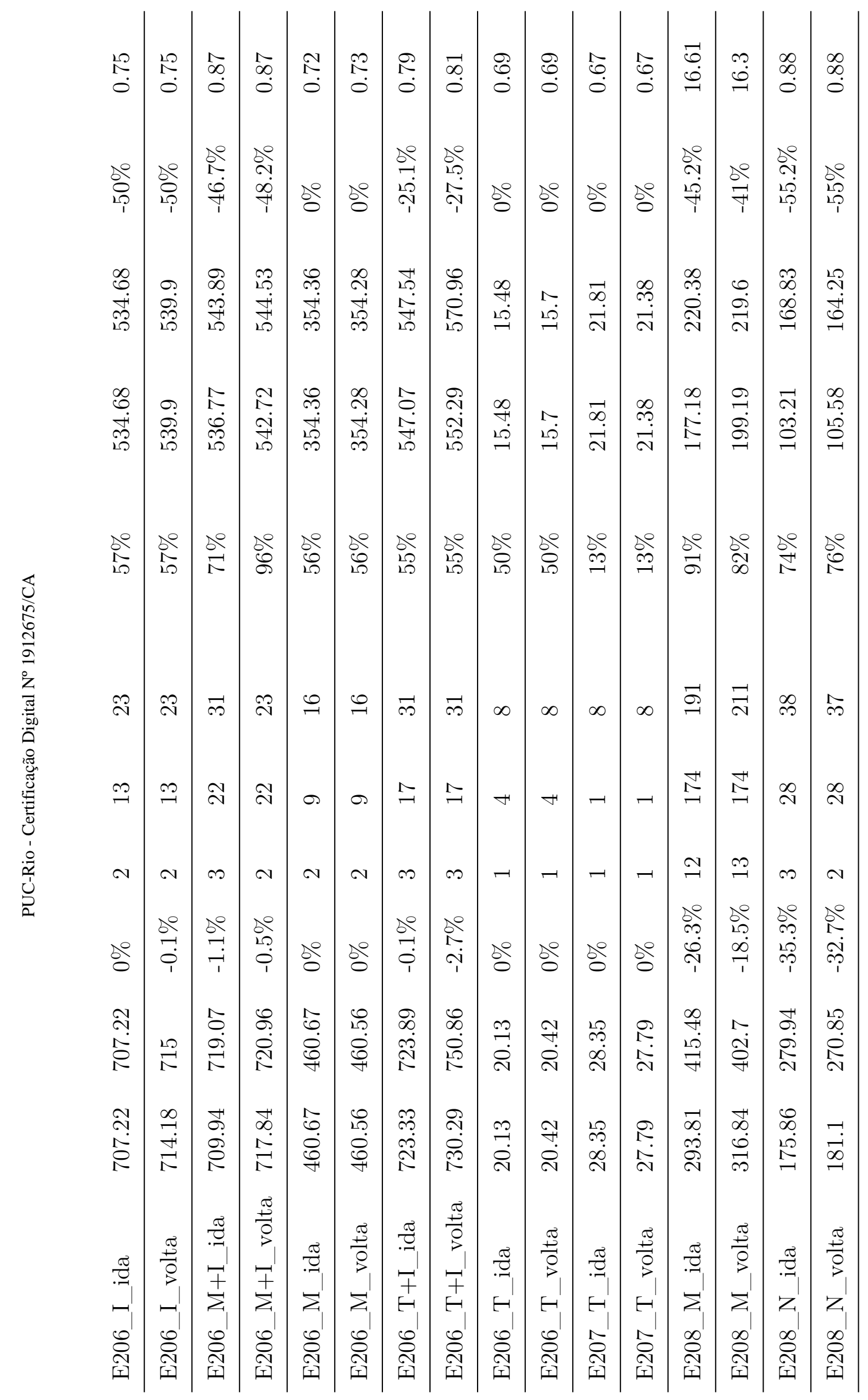




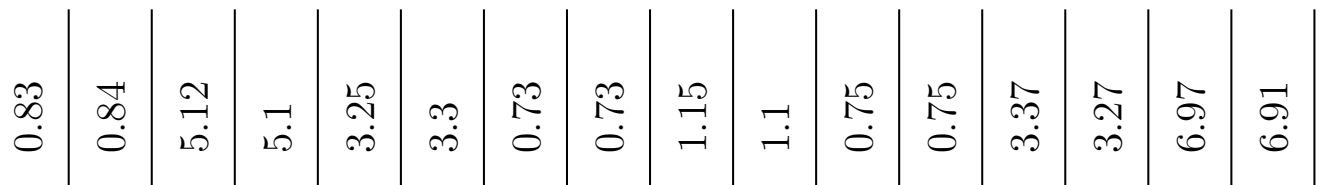

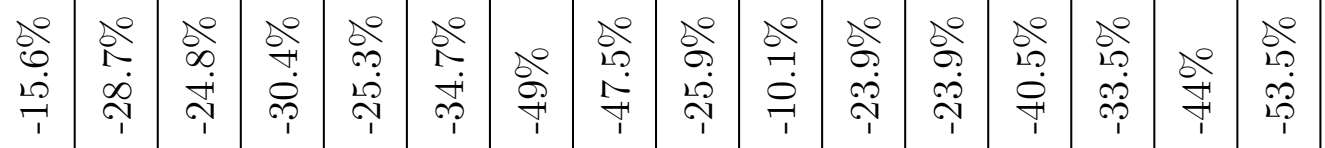

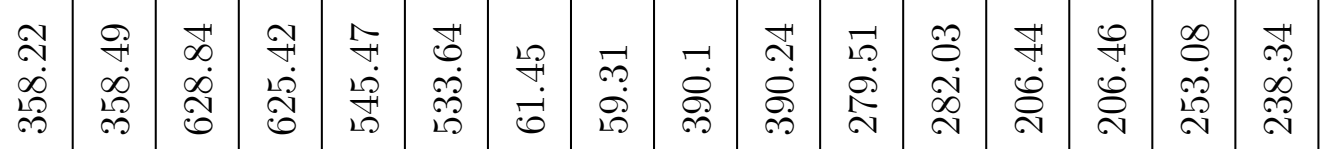

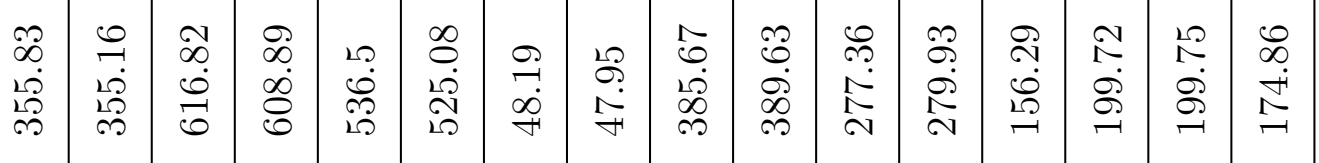

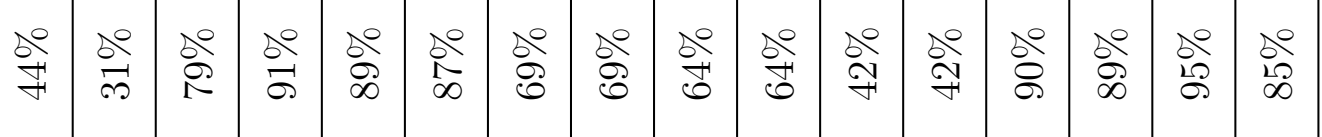

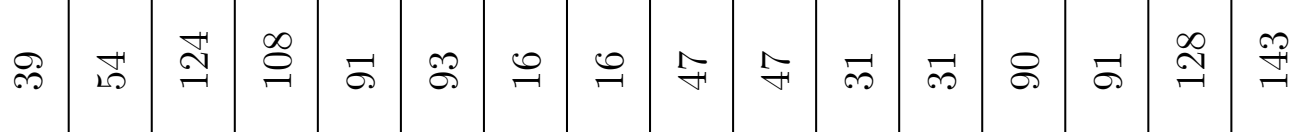

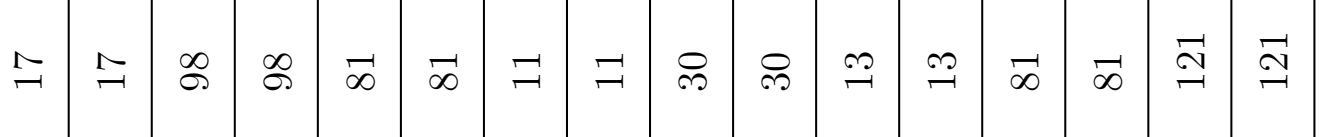

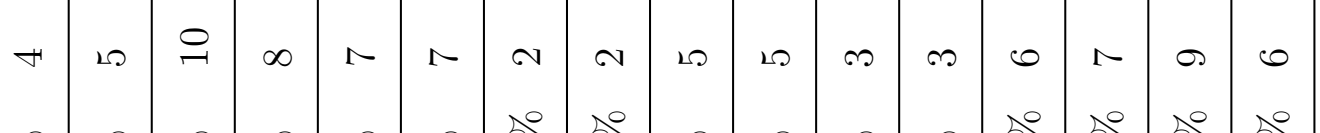

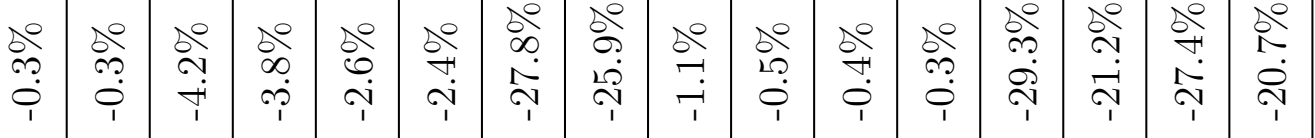

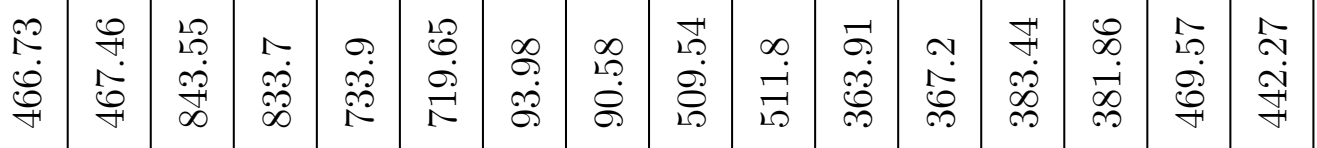

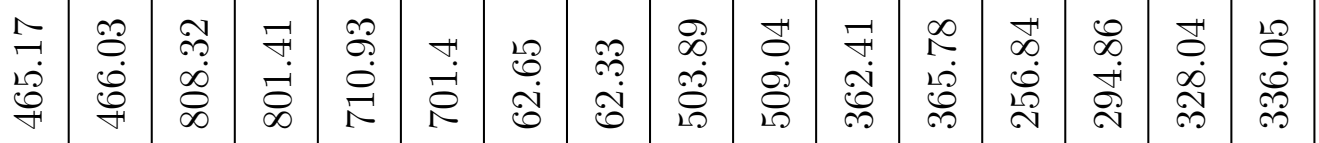

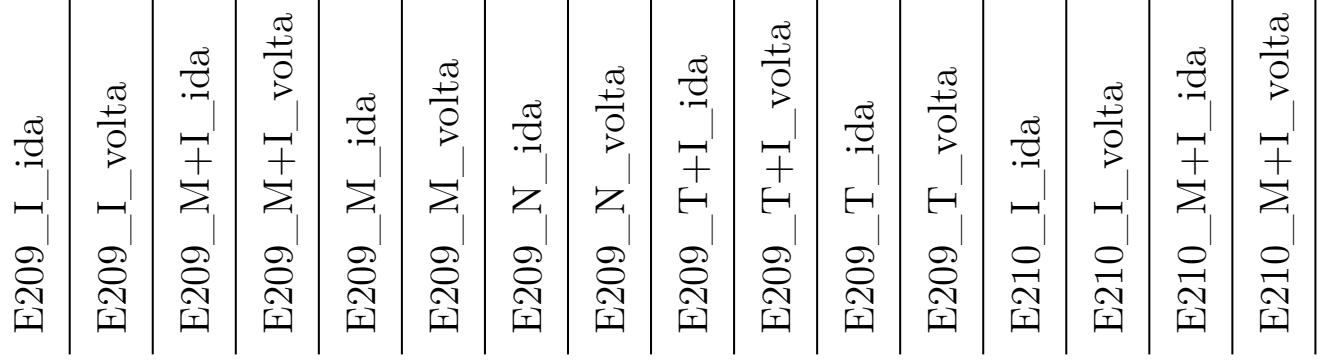




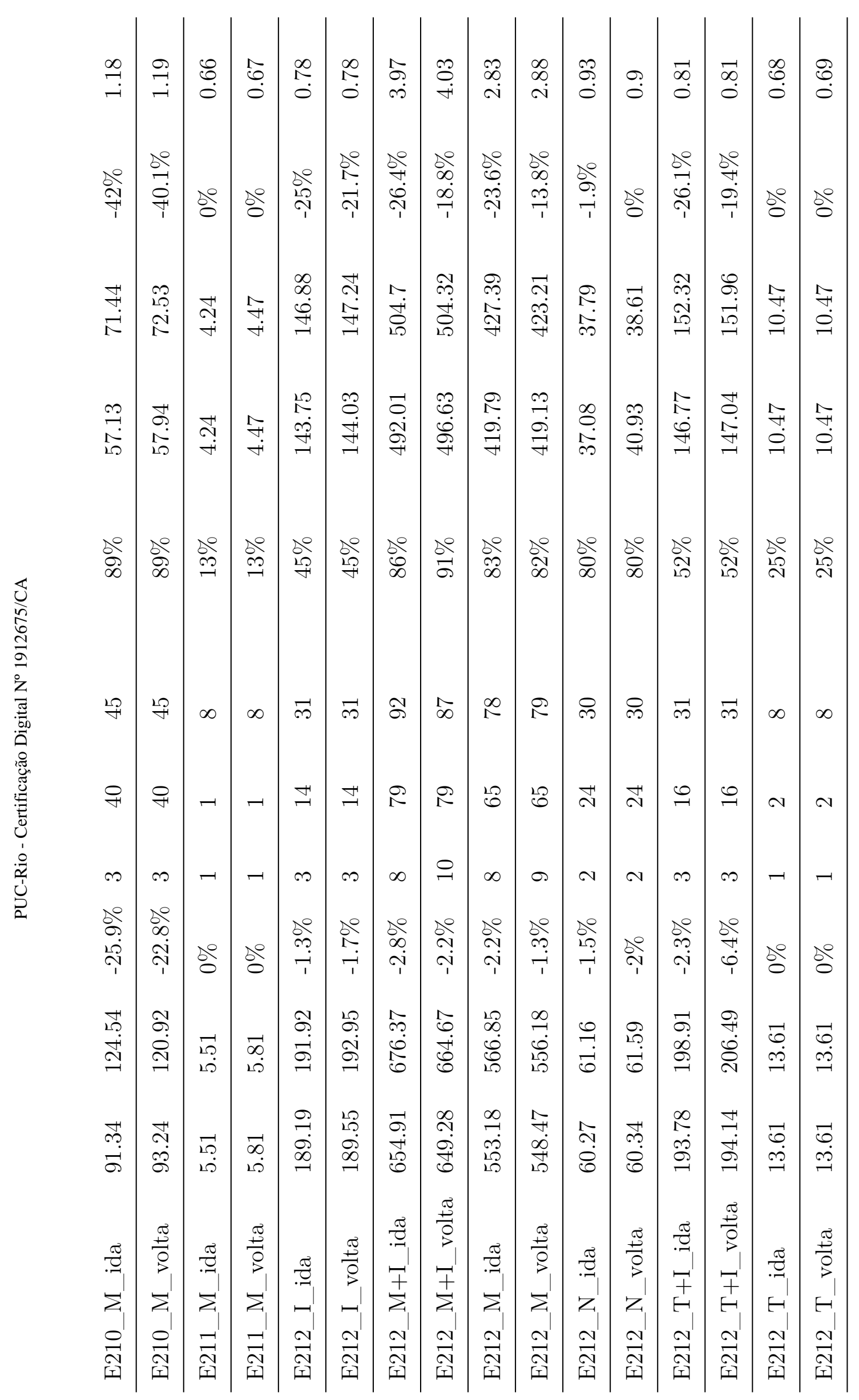




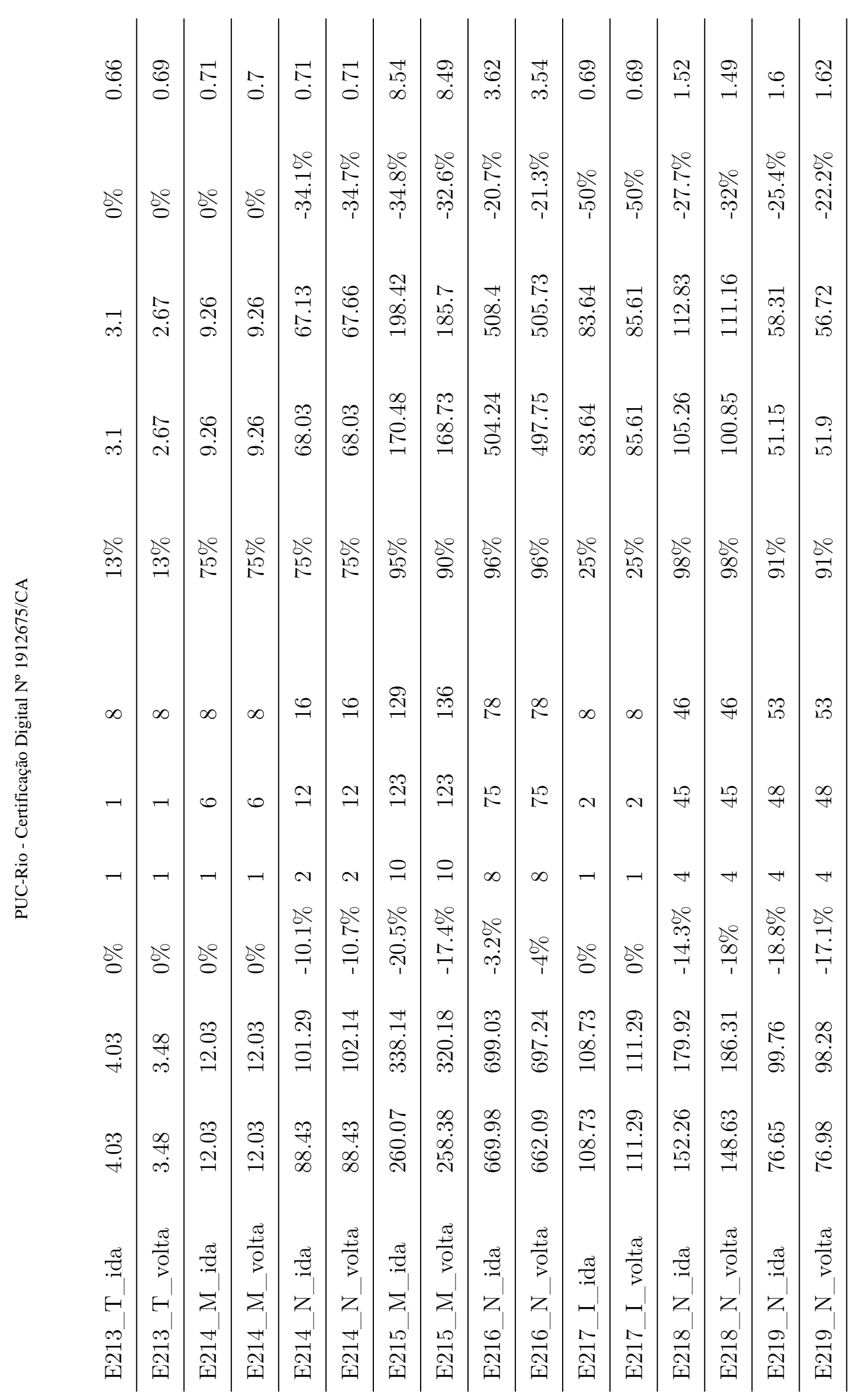




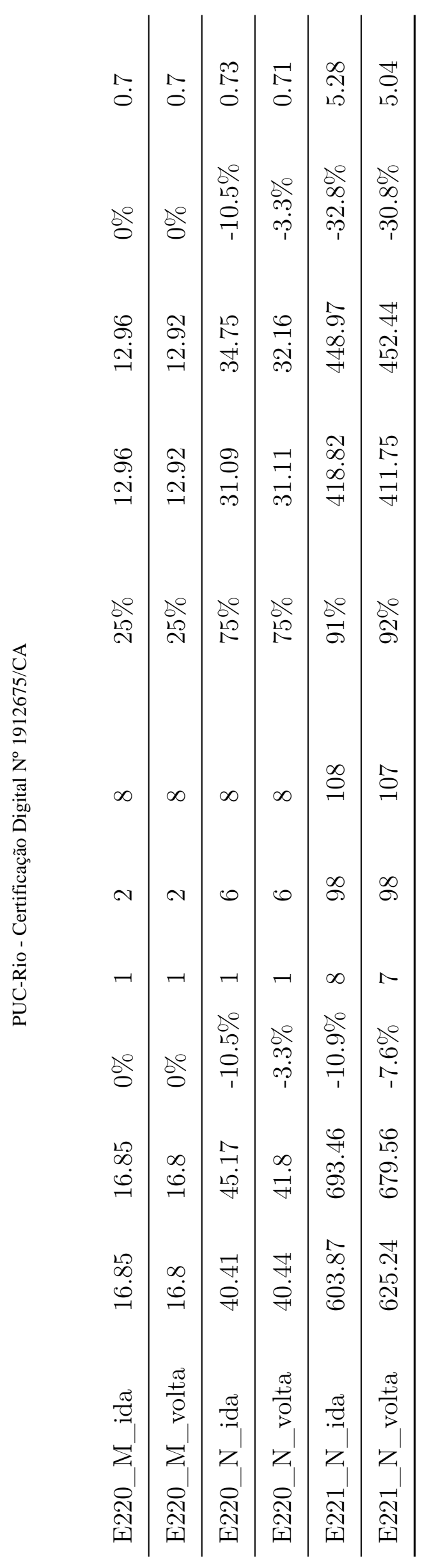

